- IfH

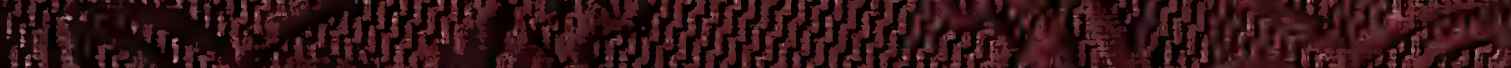

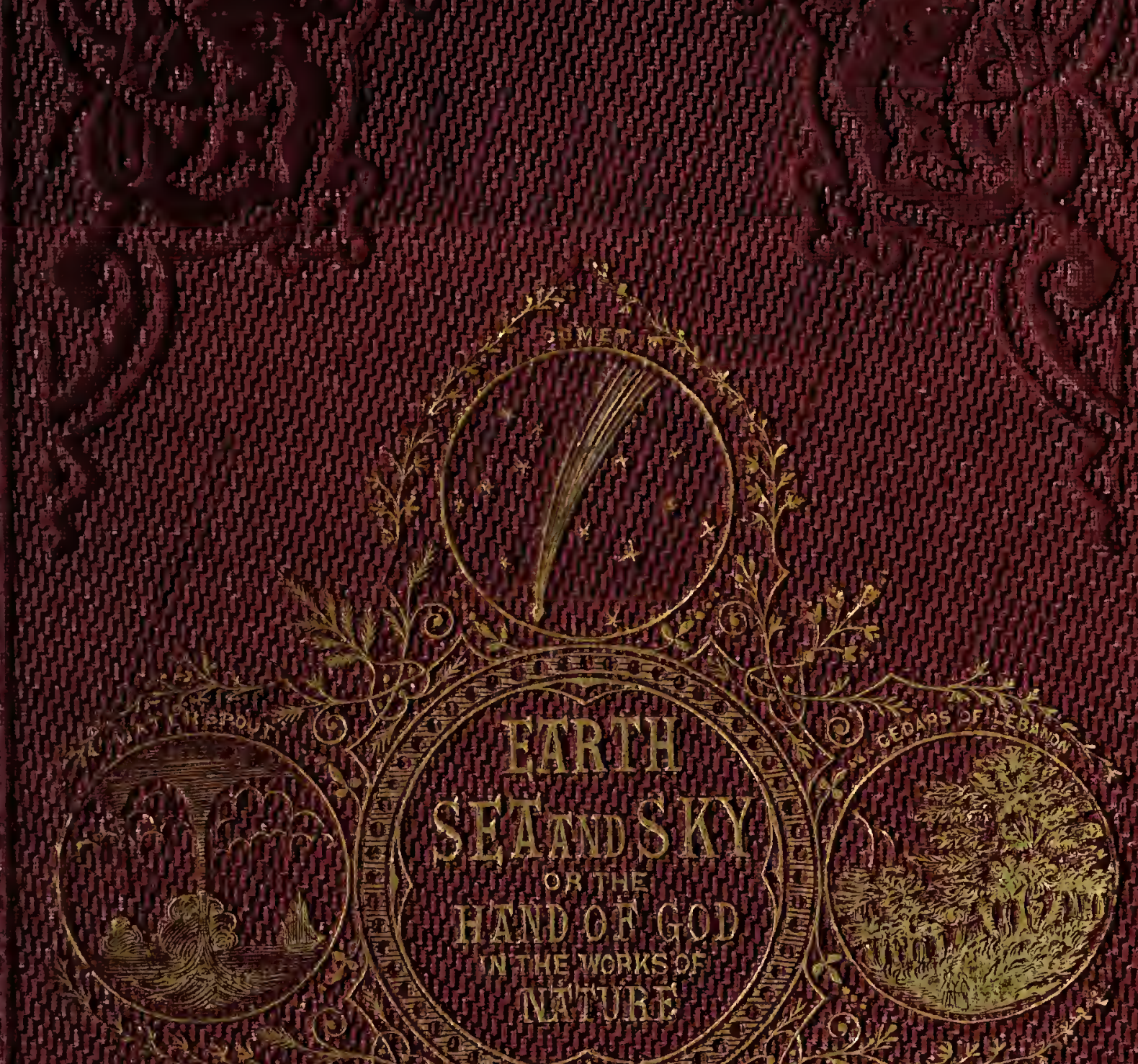

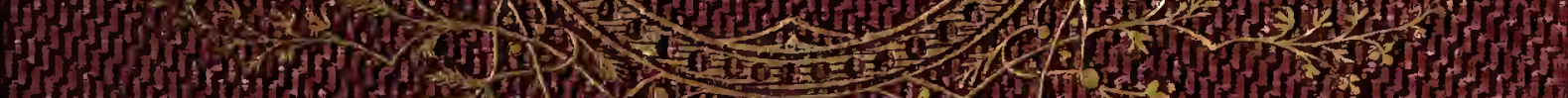

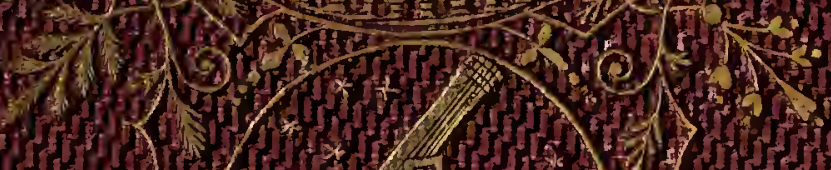

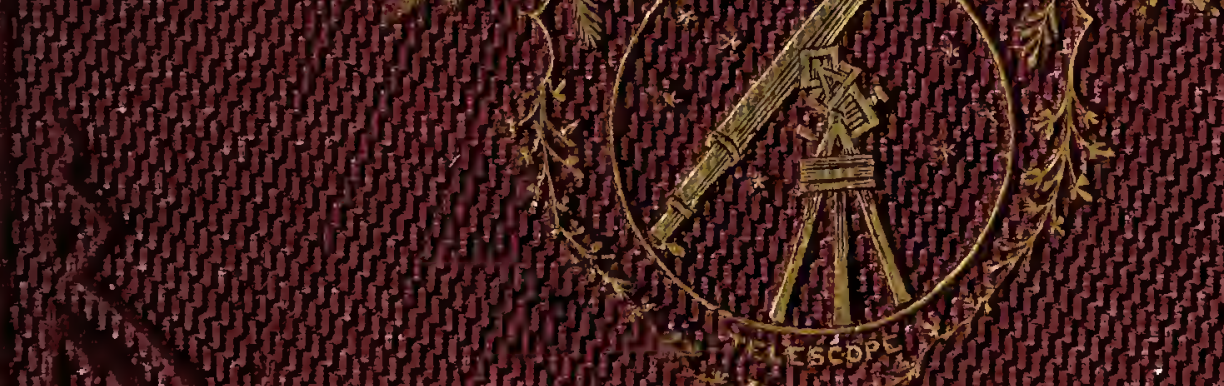

H. Whom

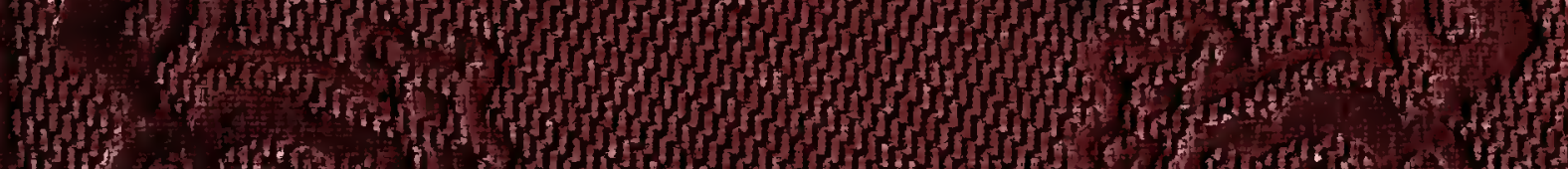

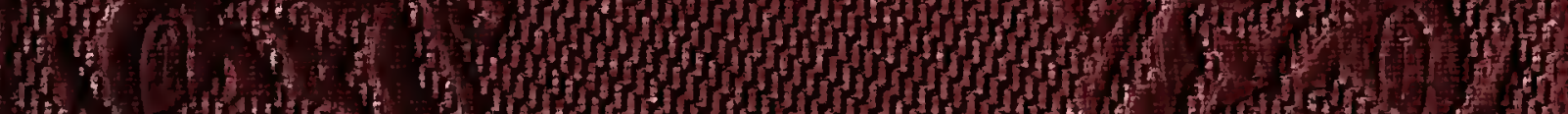

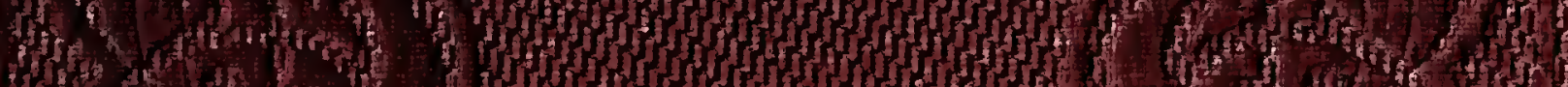

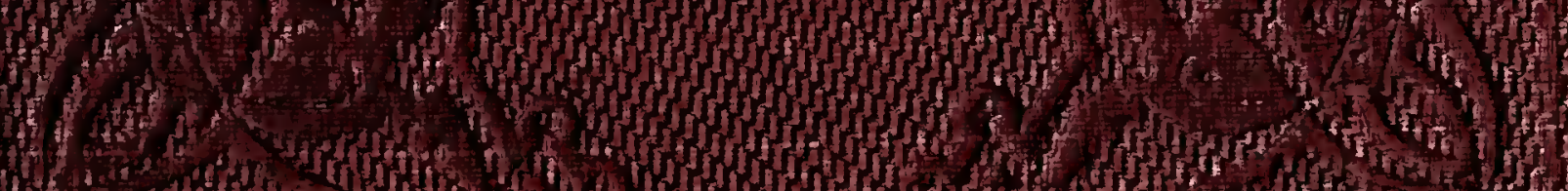

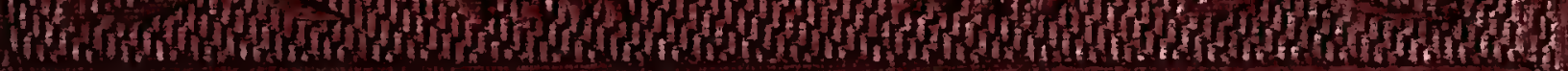


Thomas Fisher

Rare Book Library

UNIVERSITY OF TORONTO

Angelia M fameroustien

of How tern

1943 



$$
\begin{aligned}
& \text { Reuised edution } \\
& \text { [oog seond fody } \\
& 95-
\end{aligned}
$$

With 11 colourect platers ix nowkle-poge 


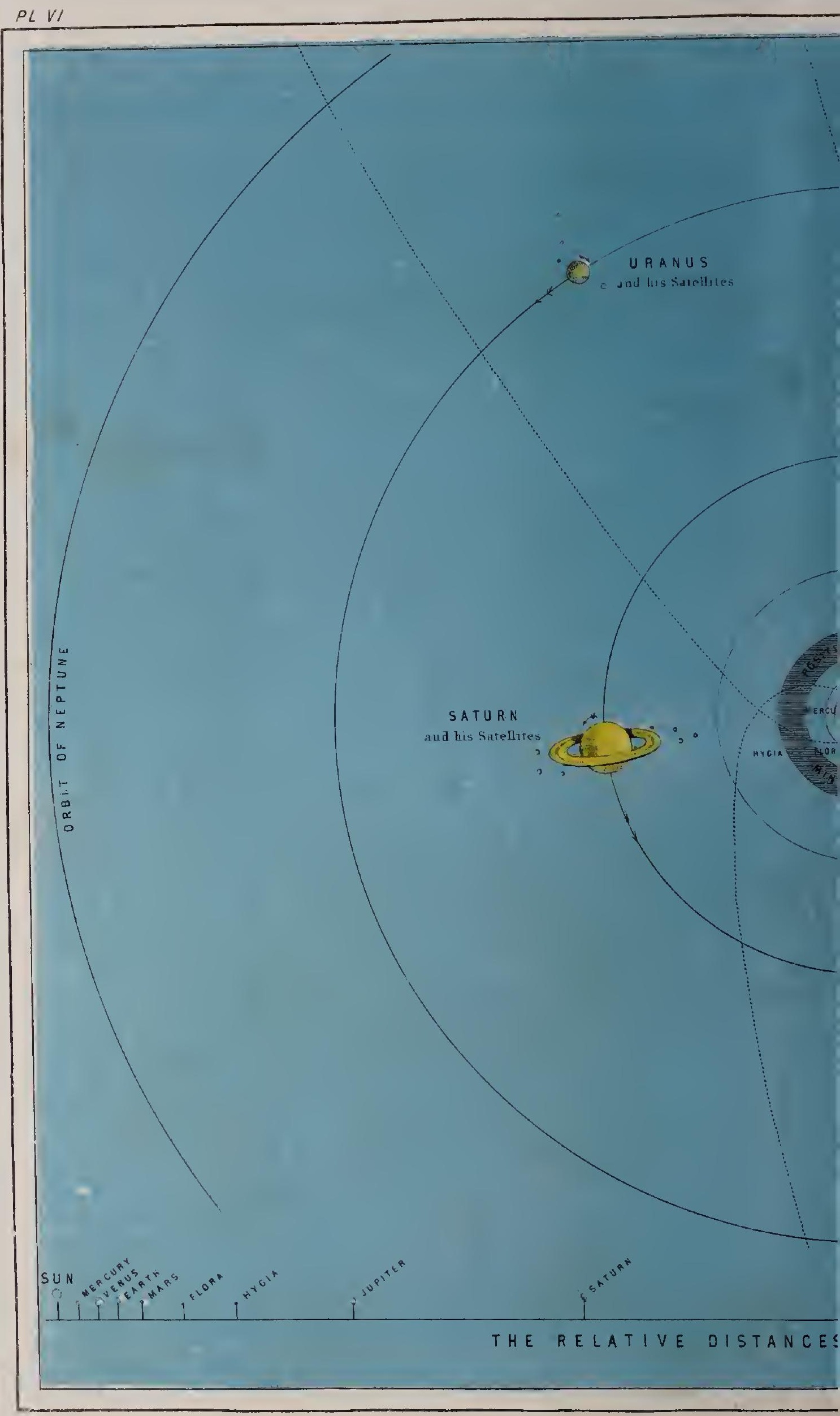

THE SO 


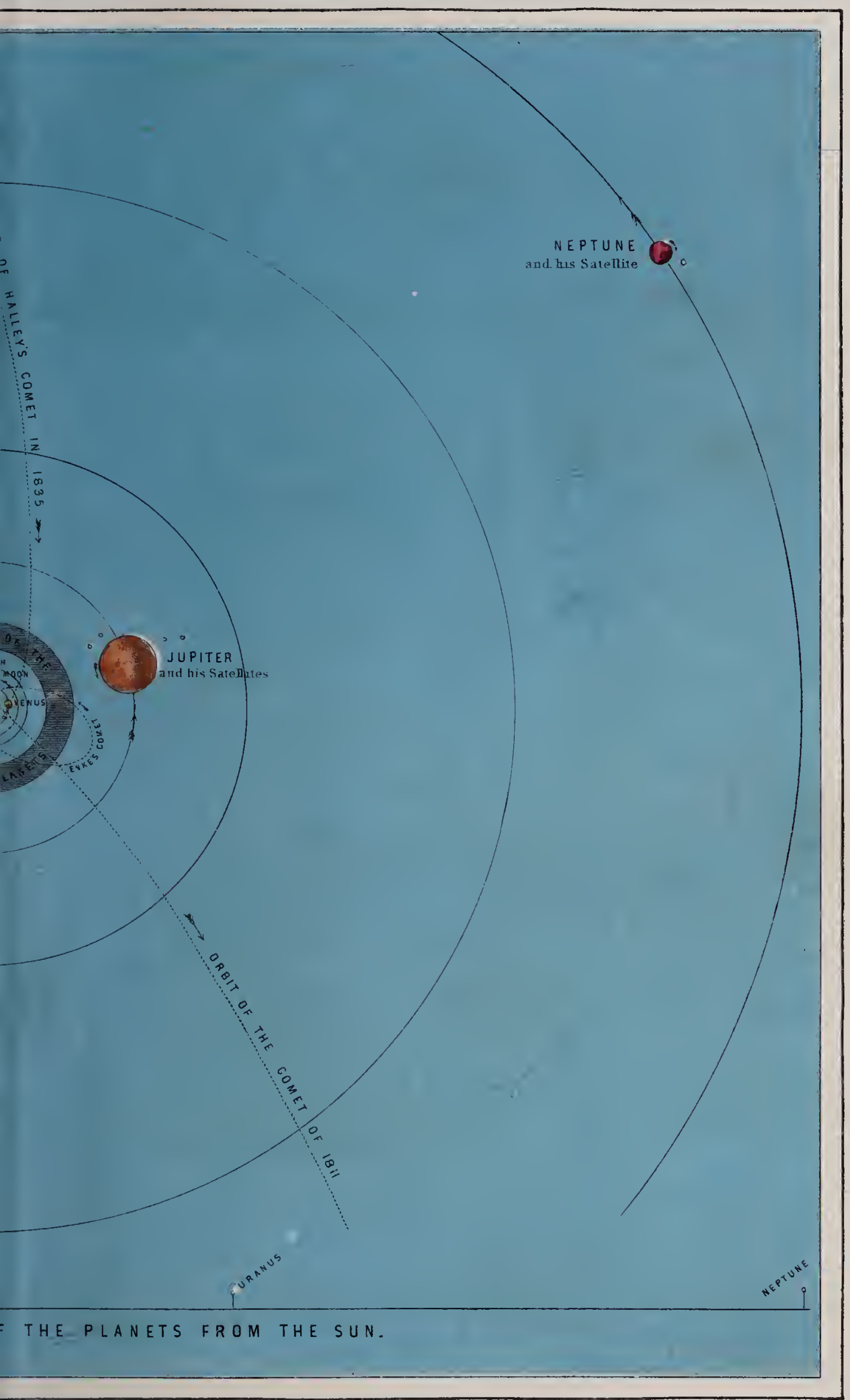

SYSTEM. 



\section{EARTH, SEA, AND SKY;}

OR,

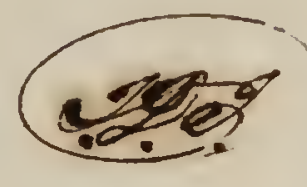

\section{THE HAND OF GOD IN THE WORKS OF NATURE.}

$\mathrm{BY}$

THE REV. JOHN M. WILSON.

"The works of the Lord are great, sought out of all them that have pleasure therein. He hath made his wonderful works to be remembered."-Psalm cxi., 2, 4.

\section{LONDON:}

M. NELSON AND SONS, PATERNOSTER ROW; EDINBURGH; AND NEW YORE. 



\section{PREFACE.}

FEw subjects are calculated to awaken in the mind of the Christian a juster source of pleasure, than the increasing relations between the disclosures of Nature and of Revelation. The time appears to have utterly passed away in which the derout believer could see, in the investigations of the laws of Nature, any ground for apprehension that the basis of faith in the economy of Providence might thereby be weakened. Natural philosophy, geology, chemistry, astronomy, and all the varied subdivisions of science, are found the ready handmaids of the great Book of Revelation, from whence we learn the purposes of God to man; and it is the glory of modern science that it restores the Book of Nature to the same Divine Author, and traces out his overruling presence alike in the works of creation and providence.

The following pages are designed to present, in a pleasing and attractive form, those most striking phenomena which, in erery department of creation, 
impress the thoughtful mind with a sense of the omnipotence of the great Architect of the universe, and of the divine wisdom and love which are manifest through all His-works. It embraces a popular view of many of the most interesting phases of Nature: the phenomena of the seasons-the laws and properties of light, heat, electricity, and other constant sources of change-and the economy of life in plants and animals. It is thus peculiarly adapted for leading the mind to reflection, and awakening in it a desire for further knowledge, and a sense of the delight which springs from the study of the Creator in his works. Readers of every age will, it is hoped, find in its pages views both of nature and providence calculated to enlighten the understanding and enlarge the heart.

EdNAdrahe, April 26, 1853.

[NoTE.-The work has now been revised, and some improvements have been made in it, and an INDEX added.]

Edinburghi, February 1, 1859. 


\section{CONTENTS.}

\section{CHAPTER I.}

THE SKY.

The Earth-The Moon-The Sun-Eclipses-The Planets-The Planetary System-The Fixed Stars-The Vastness of the Universe-The Connections of the Earth with the Central Heavens, ...................

\section{CHAPTER II.}

THE AIR.

The Constitution of the Atmosplere-The Height and Pressure of the Atmosphere-Evaporation-The Humidity of the Atmosphere-Dew -Hoar-Frost-Fogs-Clouds-Rain-Preternatural Showers-Snow -Hail-Air-Currents-Noxious Winds - Sand-Drifts-Whirlwinds and Watcrspouts-Tornadoes and Hurricanes-Fire-Balls and Aerolites-Meteoric Showers-Climate-The Seasons-General Vlew of

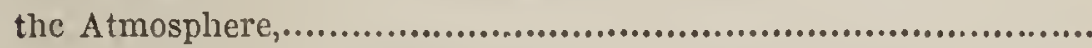

\section{CHAPTER III.}

\section{LIGHT.}

Nature and Laws of Light-The Spectrum-Rcfraction in the Atmospliere-The Tints of Sky and Landscape-Colours-The RainbowHalos-Mocksuns and Mockmoons-Spectral lllusions-Fata Morgana-Enclianted Coasts - The Mirage - Shadows on Mists and Clouds-Summary View of other Wonders of Light,.................

\section{CHAPTER IV.}

\section{ELECTRICITY.}

The origin and progress of Electrical Science-'The Electric Machine - The Nature and Varieties of Electricity-Lightning-ThunderBall Lightning-Extraordinary Lightning-Strokes-Sheet Lightning-Electric Meteors-Aurora Borealis-Summary View of many other Wonders of Electricity-The Galranising of a Corpse, .......... 


\section{CHAPTER V.}

CHEMICAI ACTION.

Definition of Chemical Action-Heat-Atmospheric TemperatureChemical Affnity-Divine Agency in Chemical Changes-Laws of Chemical Combination-Chemical Behaviour of Oxygen, of Nitrogen, of Hydrogen, of Chlorine, of Carbonic Acid, of Water, and of other Substances-Chemical Transmutations of Colour-Natural "Fields of Fire" and Burning Springs-Ignis Fatuus-Phospliorescence,..................................................................

\section{CHAPTER VI.}

SOUND,

The Nature and Laws of Sound-Two Sounds producing Silence-The Calls and Songs of Birds-The Music of Nature-The Roar of Storms -Diversities of Sound in Different Positions and Circumstances of Air and Land-Sonorous Currents through Gorges, Crevices, and Natural Apertures-Musical Rocks and Mountains-Echoes,...........

\section{CHAPTER VII.}

\section{FORCE AND MOTION.}

Force-Gravity-Attraction-Vis Inertia - Projection - Relations of the Earth's Attraction to the Mass and Power of Animals-Gravitation-The Motions of the Planets-The Tides-The Pressure of Still Water-The Pressure of the Atmosphere-Effects of Atmospheric Pressure on Minerals, Animals, and Machines-The Elasticity of the Air-The Interdiffusiveness of the Atmosplieric Gases,................

\section{CHAPTER VIII.}

\section{CONTINENTS AND ISLANDS.}

Land-Hemisphere and Water-Hcmisphere-Projections of Coast-line -The Old World and the New World-Characteristics of Africa, Asia, and Europe-The Great Mountain Chains-The Contour of Continents-The Features and Influences of Alpine Ranges-The Scenery of Mountains-The Antarctic Continent-Single Mountain Masses-Great Platcaus and Great Plains-The Pampas, Silvas, Llanos, and Prairies of America-Flat Landscapes-Valleys-Mountain Passes - Glens and Gorges - Earth-Chasms - Grottoes and Caverns-Basaltic Colonnades,......................................... 


\section{CHAPTER IX.}

\section{LAND AND SEA.}

Glaciers-Avalanclies-Land-Slips and Mountain-Falls-Earthquakes -Volcanoes - Causes and Uses of Volcanic Action-GeysersSprings-Rivers-Cataracts-Lakes-Torrents - Floods - Sea Erosion-Elevations and Subsidences of Dry Land and Sea-Bottom-.. The Ocean

\section{CHAPTER $\mathrm{X}$.}

\section{ROCKS AND FOSSILS.}

The Law of Development-The Great Age of the Earth-The Mosaic Account of the Creation-The Successions of Change in the Earth's Formation-Crystalline Rocks-Sedimentary Rocks-Effects of Disturbance in the Eartli's Crust-Fossiliferous Roclss-Characteristic Organic Rcmains of the Silurian, Old Red Sandstone, Coal. New Red Sandstone, Lias, Oolite, Wealden, Chalk, and Tertiary Formations -Series of Creations in the World's Progress, and their Prospective Adaptation to the Present Circumstances of Man,........................

\section{CHAPTER XI.}

\section{MINERALS.}

The Nature of Minerals-Their Origin-The Metals-Iron, its Oxides, its Ores, its Affinities, its Uses-Alumina-Aluminous Gems-Other Aluminous Minerals-Clay-Silicious Minerals-Calcareous Minerals -Reciprocation of Matter between Minerals and Living Beings-The Contrast between Inorganic and Organic Things in regard to Life,

\section{CHAPTER XIı.}

\section{PLANTS.}

Flowerless Plants - Sporules - Lichens-Funguses-Sea-Weeds and other Algæ-Ferns-Grisscs - Palms - Aloe-Plants - Tulipaceous Plants-Tulip-Flowers-Orchids-The Water-Soldier and Valisneria - Characteristics of Endogens and Exogens-Cone-Bearing TreesAuracaria and Norfolk Island Pine-The Nettle Family-The Nettle Sting-The Cow-Tree-The Banyan-Tree-The Pitcher-Plant-The Raffiesia-The Primrose Family-The Nightshadc Family-The Cacti-Mangroves-Tea-Plants-Camelias-Magnolia and Liriodendron-Silk-Cotton-Trees and Adansonia-Victoria Regia and other Water-Lilies-The Forms and Moral Influences of Flowers, ........... 


\section{CHAPTER XIII.}

THE ECONOMY OF PLANTS.

Contrasts between Plants and Animals-False and True Analogies between them-Elementary Cells of Plants and Animals-Aggrcgations of Vegetable Cells-The Structure and Functions of RootsThe Structure and Functions of Leaves-The Structure, Functions, and Uses of Seeds and Frnits-Summary View of other Wondcrs in

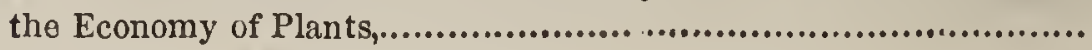

\section{CHAPTER XIV.}

ANIMALS.

Silicious-Coated Animalcules-Blood-like Spots on Human FoodOther Animalcules-Zoophytes-Sponges-Corallines and CoralRocks-Animal-Flowers-Sea-Nettlcs - Entozoons - Worms - Insects-The Transformations, Combinations, and Instinctive Skill of Insects-Ants-Aplides-Crustaceans-Molluscs - Mollusc-ShellsCuttles-Fishes-Flat-Fishes-Electric-Fishes-Reptiles-Transformation of Frogs-Shell of the Tortoise-Conformation, Beauty, and Classification of Birds-Specimen Instances of Birds-Characters and Classes of Mammals,

\section{CHAPTER XV.}

\section{THE ECONOMY OF ANIMALS.}

Specific Life-Aggregations of Cells-The Circulating System-Blood -Respiration-The Alimentary System-The Touth System-Summary View of other things in the Structure and Internal Economy of Animals - Domestication - Animal Prognostics of WeatherMoulting-Migrations-Hybernation-The Gregariousness of Birds and Beasts-The Social Principle in Man,............................... 


\title{
EARTH，SEA，AND SKY;
}

\author{
OR, \\ THE HAND OF GOD IN THE WORKS OF NATURE.
}

\section{CHAPTER I.}

\section{THE SKY.}

THE EARTH-THE MOON-THE SUN-ECLIPSES-THE PLANETS-THE

PLANETARY SYSTEM-THE FIXED STARS-THE VASTNESS OF THE UNIVERSE-THE CONNECTIONS OF THE EARTH WITH THE CENTRAL HEAVENS,

THE earth is one of many worlds which revolve round the sun as their common centre. It is rather larger than some, but exceedingly smaller than others. If we were situated on one of the nearer ones, we would see it as an ordinary star; but if we were situated on any of the more distant, we could not see it at all. Yet, even regarded as a star, a very little star, it possesses glorious magnificence, and is a world of wonders.

It has an almost globular form-exactly the shape best suited to bask it equably in the sun's rays. It turns continually round on its axis, so as to expose all its surface to the alternation of day and night. It maintains a mean distance of about ninety-five millions of miles from the sun, and enjoys there a happy mildness in the intensity of his light and heat. It travels 
at the average rate of sixty-eight thousand miles an hour, and is kept steadily in its path-as also every other planet is-by the perfect balance between the force of its motion tending to carry it away into space, and the force of gravitation tending to draw it on to the sun. It lies obliquely to the plane of its path, or with its axis not straight up, but aslant, and so enjoys the delightful changes, the beautiful phenomena, and the powerful influences of the seasons. It makes a very slow and perfectly steady oscillation, called the precession of the equinoxes, occasioning a small change in some of its relations throughout long intervals of time. It measures nearly eight thousand miles in diameter, or nearly twenty-five thousand in circumference. Its bulk and density, as also those of every other world, have an infinitesimal adaptation to the niceties of mutual attraction among the neighbouring orbs. Its surface is a picturesque arrangement of land and water, and of height and hollow. - It is curtained all over with an atmosphere of translucent gases, and of many-coloured clouds. And it is ever accompanied with the silvery moon, wheeling round and round it, as an eloquent writer has remarked, "like a playful lamb frisking round its mother."

All these astral wonders of the earth, and many more, are known to all persons of ordinary intelligence, or may readily be learned from elementary books on astronomy. But some others are either seldom adverted to, or very slightly understood. The earth occupies a place of perfect stability in the solar system, yet seems to have undergone great changes in size, density, and structure. It probably was created at the same time as the sun and the neighbouring worlds, 
but, nevertheless, does not appear to consist of quite the same materials. It seems in early times to have had different relations to them, than in modern epochs, in regard to light, and perhaps also in regard to other important things; and it possibly has passed through stages and cycles of existence peculiar to itself. The inclination of its axis to the plane of its path, may formerly have been much different from what it is at present; and, if so, its seasons and climates must have been correspondingly different. The structure or condition of its interior, from within a few miles of the surface, down to the very centre, is a matter which every inquisitive person would like exceedingly to know, but one on which we have no information, and scarcely one good conjecture. The constitution of the atmosphere has seemingly been unaltered from the creation of man, but probably underwent, in previous epochs, very great and wonderful changes. The eartli's surface, throughout all its earlier periods, appears to have been totally unfit for the residence of any such orders of organised creatures as now constitute its principal inhabitants, yet possibly-though we cannot say probably - was then peopled by a race or races of intelligent beings of too ethereal or soft-bodied a nature to have left any perceptible traces of their existence. The future condition of crust and climate, of land and atmosphere, in the same way, may possibly be shaped by the all-wise Creator into suitableness for the abode of new and higher races, after the cycle of human things shall be complete. And at any rate, throughout all the epoch of man's existence, the earth possesses a most exalted character, and exhibits most wondrous blendings of physical and moral things, and 
sustains most glorious relations to far distant regions of the universe. But some of these thoughts belong partly to other divisions of the wonders of nature, and may come in our way in subsequent chapters.

The orb nearest the earth is the moon. This is the most gorgeous object in the nocturnal heavens. It was set by the Creator to rule our world's night, as the sun was set to rule the day; it figures in ancient polytheistic idolatry as the "Queen of heaven;" and it has been sung in fervent strains and picturesque imagery by poets of all climes and ages. But it is important to the earth alone, and acquires all its importance from its comparative nearness and its relative position. Eyes like man's could not see it from any other planet. It is little more than one-fourth as thick as the earth, and only one forty-ninth as bulky; and it has an average distance from us of about 237,000 miles. It travels round the earth in the period between one new moon and another, and completes a turn on its own axis in exactly the same period. The dark or night part of it is all toward us at change of moon, and therefore is wholly invisible; the sunlit or day part of it is all toward us at full moon, and therefore has the appearance of an entire orb; and a constantly varying proportion of the two parts is toward us throughout the intermediate. periods, and therefore exhibits all the phenomena of waxing and waning.

The half which we see at any full moon, is the only half ever exposed to our view; and that half enjoys an earth-shine of far greater brilliance than the moonshine is to us. The faint light which we sometimes see revealing the whole disc at times between new moon and 
LUNAR CRATERS

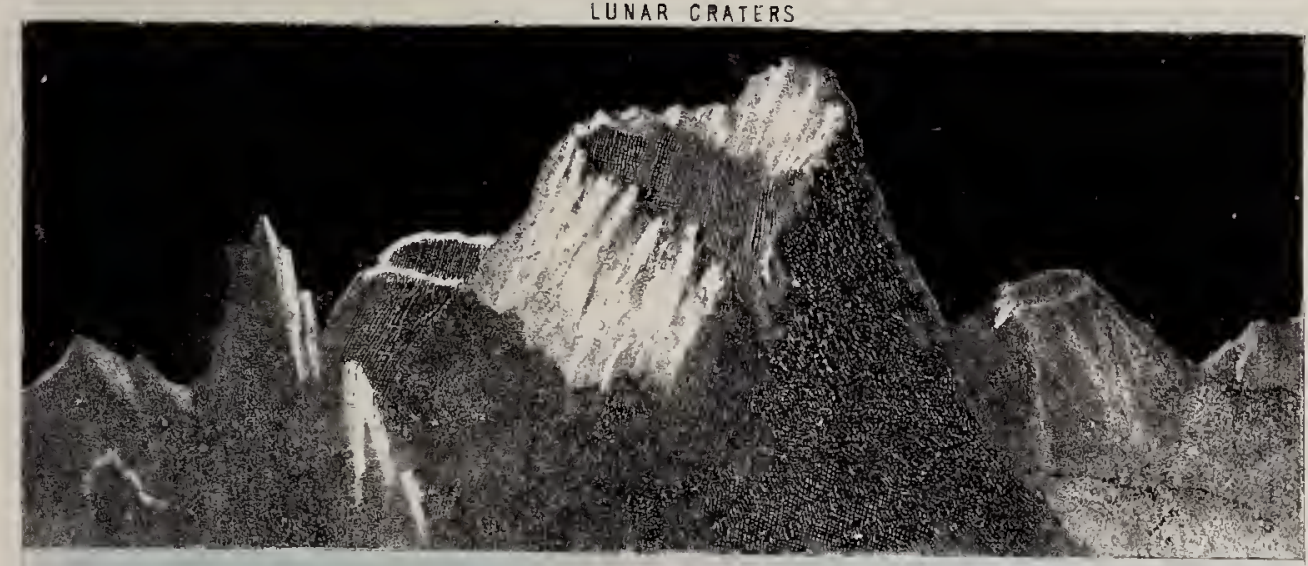

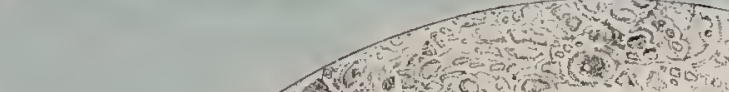

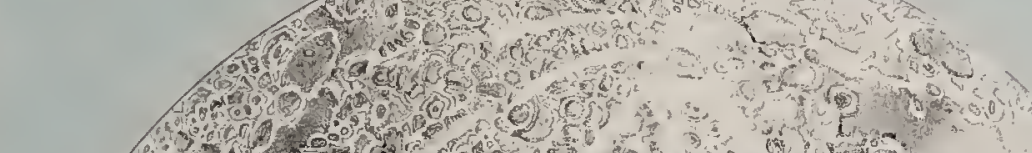

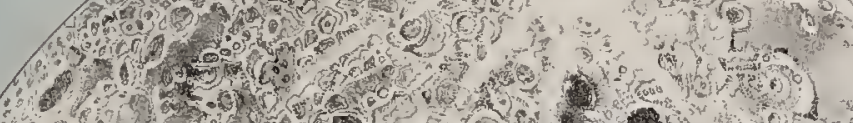

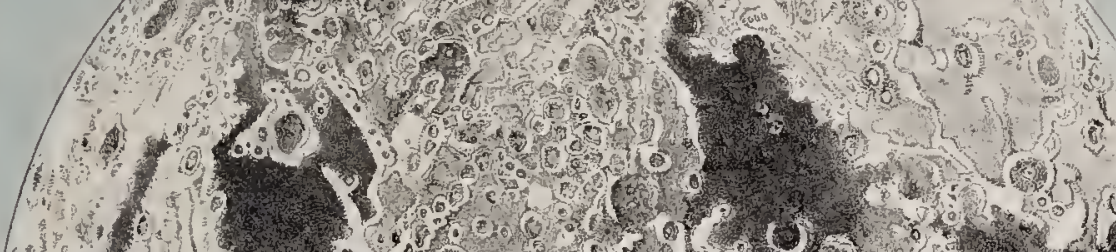

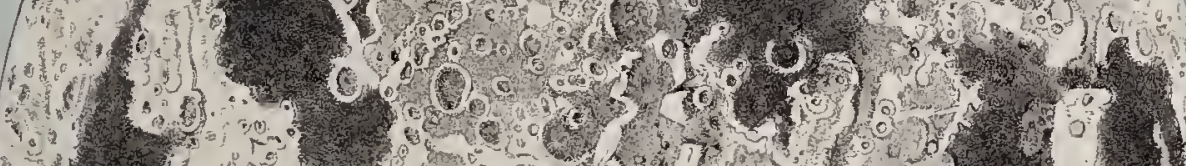

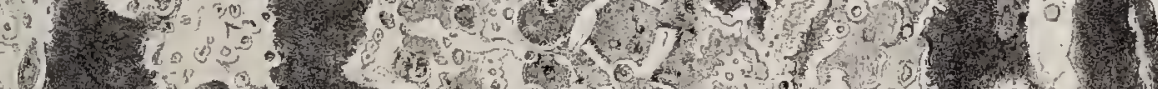

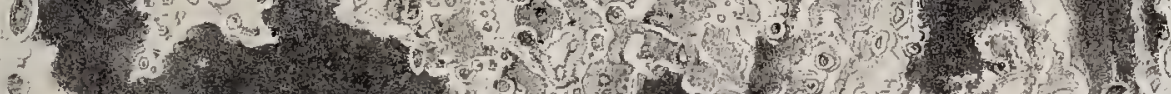

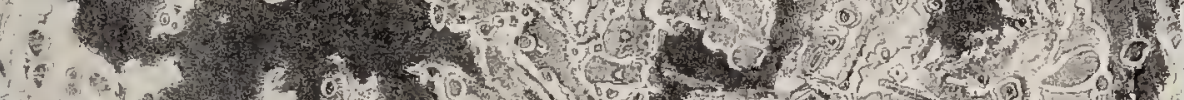

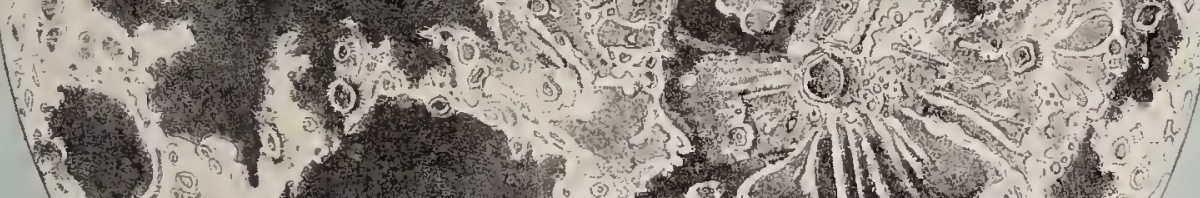
(3)

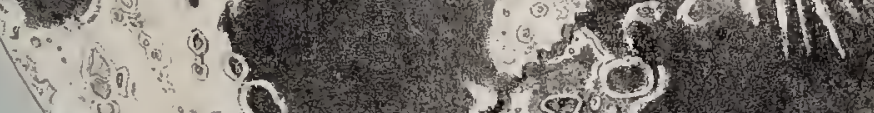

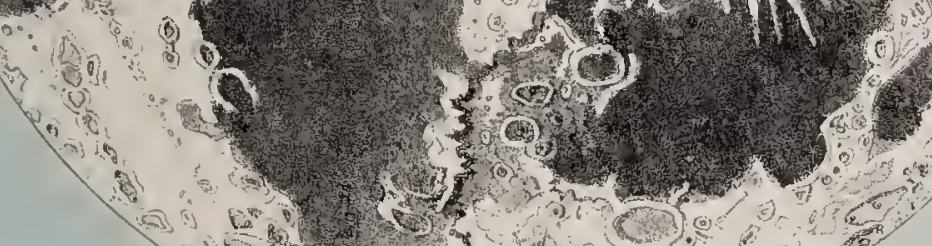
B.

TELESCOPIC APPEARANCE DF THE FULL MOON

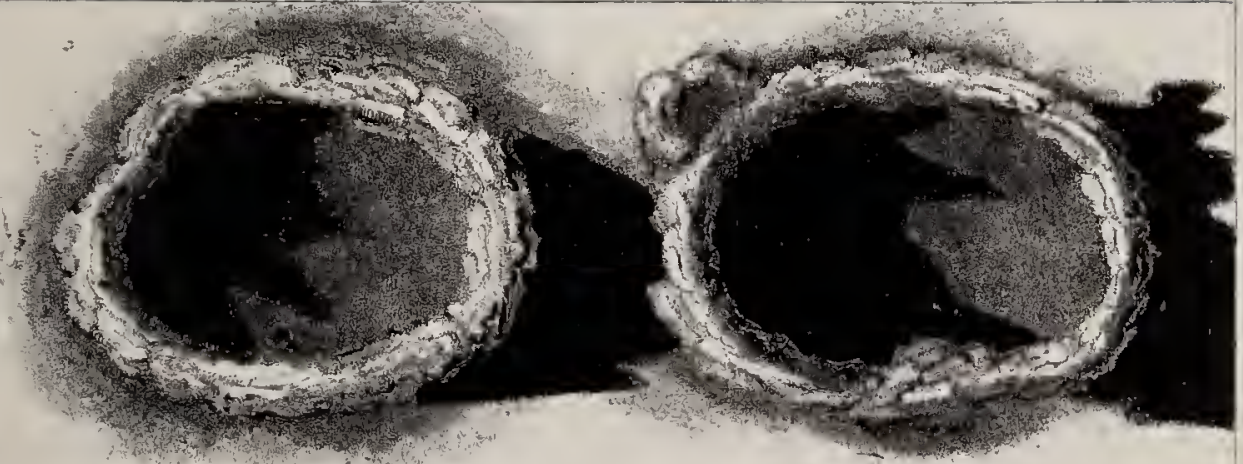


half moon, is earth-shine. The appearance of our world to observers in the moon, supposing them to have powers of vision similar to man's, must be exceedingly gorgeous. It presents to them a disc thirteen times larger than that of the moon appears to us; it displays from its clouds, and oceans, and continents, a grand and ever-shifting variety of light and shade; and it seems never to move from one spot of their sky, but may be left behind them by their travelling into their other hemisphere. How curious must it be for the inhabitants of that other hemisphere-assuming the existence of such - to come to the hither side, and see this magnificent world bursting into view!

Most of the earthward hemisphere of the moon has a very wonderful surface. The general appearance of it, as seen through a telescope, and also the appearance of conical elevations in it which some observers suppose to be craters, and that of great circular mountains in it, and their shadows, are shown in the accompanying plate. One feature consists of broad, pale, and very long streaks; another consists of narrow lines, supposed to be fissures; a third consists of solitary mountains, shaped like sugar-loaves; a fourth consists of mountain-ridges, some irregular, and others in lines; a fifth consists of enormous circular depressions, some of them five hundred or six hundred miles wide; and a sixth consists of huge hollow mountains, with summits like stupendous rings, and interiors like awful pits or caverns. Many of the mountains are much loftier than the highest peaks of our Alps, and some of the pits have a depth of more than twenty thousand feet.

The scenery must be sublime; but can it be "clothed 
with flocks?" Is the moon inhabited? There seems to be no water, little if any air, and probably no soil or vegetation, or any suitable conditions for the sustenance of either fish, or bird, or beast. Some philosophers have even leaped to the conclusion, that it is a volcanic chaos-a mere mineral world in an embryo stage of existence. Yet how beautiful does it look through a telescope, and how immensely more beautiful must it look to interior inspection! It hangs in the heavens, not at all "like a cinder," as some of the philosophers have rashly said, but rather like a lustrous crystal, or like an elaborately graven piece of art. It exhibits not the slightest sure evidence of even the smallest volcanic action, but seems to the full as stable, and also to the full as magnificent, as our regions of the Alps and the Himmalayas; and it may, with all safety, be assumed to possess races of inhabitants, and all requisite means of maintaining them, widely different, indeed, from those of the earth, but quite as glorious.

The very peculiarities of the moon, or of any other world, may, for ought we know, be indicative only of the ligh character or extraordinary diversity of its living wonders. The whole analogy of things on carth suggests the probability, we might almost say the certainty, that varieties and contrasts of constitution, in different worlds, are attended by corresponding varieties and contrasts in the forms of animated being. The viscera of our quadrupeds are totally unfit to be inhabited by any creatures which move in the open air, and yet are the proper home of intestinal worms. The waters of our lakes and seas are totally unfit to be inhabited by beasts or birds, and yet are the suit- 
able abode of all fishes, of countless kinds of softbodied animals, and even of some species of mammals. The cloudy regions of our atmosphere are totally unsuited for the ordinary uses of any wingless creatures, and yet are precisely adapted for the ordinary uses of birds. Even some conditions of things in our world, as in the case of many species of insects, are totally unfit to be inhabited by creatures in one stage of their organisation, and yet are precisely fit to be inhabited by them in another stage. And on the same principle, or on some similar one, the surface of the moon, while totally unfit to be inhabited by any such intelligent beings as men, may, nevertheless, be an eminently fit habitation for some other order of intelligent beings, with, perhaps, powers as great and frames as wonderful. The moon, and all other worlds, as well as the earth, are, doubtless, "full of God's glory."

The sun looks to be little different in size from the moon, yet is really sixty-three millions of times bulkier; and it owes its comparatively small appearance only to its enormous distance. Figures and comparisons can convey no notion of its magnitude; and the most vigorous fancy fails to imagine its sublimity. Yet it probably is all an inhabited and most beautiful world. Numerous dark spots which form upon its disc, and undergo continual change, have given astronomers some idea of its nature. It turns on its axis in a period corresponding to upwards of twenty-five of our days. A luminous atmosphere of great depth seems to form its outer envelope, and probably contains all the apparatus of light and heat. Another atmosphere of denser material seems to extend below, and probably lets only a very small proportion of the 
light and heat pass through The surface of the solid globe itself, therefore, may be neither brighter nor hotter than that of our own world.

The spots on the sun are believed to be breaks in the luminous atmosphere, disclosing the solid surface below. Some of them are amazingly large; and the smallest which can be distinctly seen have a breadth of nearly a thousand miles. An opposite kind of phenomena are enormous protuberances from the edge of the disc. Three of these were observed for the first time during the total eclipse of 1842, and were computed to be six times bulkier than our world. Both they and the spots are probably occasioned by tumbling commotion in the luminous atmosphere. But how any such commotion is maintained, or how the atmosphere is constituted, or how the continual evolution of light and heat is carried on, or how the sun altogether combines the character of a stupendous world of itself with the character of a life-centre to many other worlds, are wonders which no man can explain.

Eclipses are phenomena which always interest the curious, and generally astonish or terrify the ignorant, and sometimes attract the earnest attention of the most scientific; but they are easily understood. An eclipse of the sun is caused by the body of the moon passing direct between the earth and the sun; and an eclipse of the moon is caused by the shadow of the earth falling direct upon the moon, and they owe their varieties of form and duration to the relative places and distances of the earth and the moon in their respective paths. The minute accuracy with which astronomers predict them, is an incidental evidence of the infinitely nice adjustment, and infinitely regular 
movements, of "the mechanism of the heavens." Any total eclipse of the sun can occur over only a very limited portion of the earth; and the effect of one is always striking. An observer, speaking of that which happened in 1842 over southern France and northern Italy, says - "Yet a moment, and on a sudden an effect took place unexpected and sublime. The whole aspect of heaven and earth underwent a change with regard to light, shade, colouring, and everything; and the instant that preceded the total eclipse resembled in nothing, and gave no idea of, that which followed it." Many stars became visible; horses in the field were terror-struck; herds of oxen formed into circles, head to head, as if to repel an enemy; flocks of sheep lay down as if for the night; and bats and owls came forth from their retreats.

All the known planets which revolve round the sun, are illuminated by his rays, and otherwise powerfully affected by his influence. The nearest to him is Mercury-a small, rapid-going orb, so bathed in his effulgence, as to be very rarely discernible by either eye or telescope. The next is Venus, nearly as large as our world, and the brightest star in our sky-alternately the "morning star" and the "evening star." The third is the Earth, with its attendant moon. The fourth is Mars-a fiery-looking orb, about one-half the size of the earth, and supposed to be very similar to it in constitution. Beyond this, is a remarkable group of very small worlds, at least fifty-five in number, all revolving in one another's close vicinity, and some of them crossing one another's paths. The next planet is the superb and magnificent Jupiter, upwards of twelve thousand times larger than the earth, and attended by 
four beautiful moons. It is situated fully four times farther from us than we are from the sun, yet it shines almost as lustrously in our sky as the planet Venus; and, when looked at through a good telescope, it appears a surpassingly glorious object, the most picturesque in our heavens. Next to it, and not very much smaller, is Saturn. This is exceedingly dimmer to us, in consequence of its far greater distance, but, in itself, is exceedingly more wonderful. It has eight moons, and two vast flat concentric rings; and, to eyes like ours, if any such eyes be upon it, it must be hung all round by most gorgeous minglings and masses of glory. Next is Uranus, about eighty times the size of the earth, and attended by several moons, probably by six. And last is Neptune, discovered in 1846 in a manner most curious, and supposed to have at least one moon, a self-luminous atmosphere, and a ring of similar character to the rings of Saturn. Comets also move round the sun, but are exceedingly numerous and various; and most of them, on the one hand, go very near the sun, and on the other, pass far beyond Neptune into the depths of space. The relative paths of the planets, and the paths of two famous comets, are shown in the accompanying diagram.

The sun and all the planets turn on their axes from west to east. All the planets and most of the moons move along their paths also from west to east. All the planets and all the moons, in different degrees, but most of them in not much different degree, have a course rather elliptical than circular. All the planets, except the group of very small ones, and all the moons, except those of Uranus, move on nearly one plane. And most of the planets, as well as the sun and the 
earth, appear to have densely solid bodies and vapoury atmospheric coverings. These are wonderful unities; and, either when viewed by themselves, or especially when viewed in connection with the one force of gravitation and motion which maintains all the orbs in their respective spheres, they distinctly indicate the will and working of the one infinite, almighty Mind, not alone in the origination of the orbs, but throughout all the periods and incidents of their existence.

But the varieties among the worlds are quite as striking as the unities, and constitute, though in another way, quite as impressive indications of the allpervading divine agency. The magnitudes and distances of the planets are wonderfully diverse. Their densities, too, are so different, that some, in comparison to others, are almost as cork compared to clay. Their atmospheres, also, have very different depths and very different properties, and, possibly, still more different constitutions. The group of small planets-or asteroids, as they are often called-travel considerably above and below the average plane of the rest of the system. The moons of Uranus move almost transversely to that plane, and, at the same time, in a direction from west to east. The comets move in all directions, and appear all to consist of attenuated, vapoury, luminous matter. Some bodies within the planetary system, though we know not which or what, have sent to the earth starstones and other meteors of a composition widely different from anything in our soils or rocks. And the two worlds with which we are best acquainted-the only two, indeed, which human observers can closely compare-the earth itself and its moon-have constitutions not only different, but almost contrary. 
May we not, then, presume that the Most High gave to all the worlds, as he afterwards gave to the seeds of plants on earth, "bodies as it pleased him, and to every world its own body?" They have a common character in form, and may not impossibly have a general character in ultimate elements, but they seem nevertheless to have distinct, separate, individual characters in the proportions, arrangements, and adaptations of their ingredients. They no more grew erratively out of one slowly consolidating " fire-mist," than all kinds of seeds, or any kinds, grew accidentally out of one slowly evaporating mud-hole. All sprang direct from the divine command, or were moulded direct by the divine will, in perfect fitness for their several destinations; and all might be expected, even though positive evidence on the subject were awanting, to exhibit the "diversity in unity" which more or less characterises all the known subordinate departments of the divine works. The earth, too, has a most. intricate adjustment of all its ingredients-and specially. of what are presumed to be its veculiar ingredients-on the one side, to the action upon them of things and influences from the worlds without, and, on the other side, to the wants and reactions of the million kinds of beings on its own surface. And so, no doubt, has every other world; so that each in its own way-each, perhaps, in millions of diversities from the rest-each to an amount which a Newton might require ages to study-is a museum of wonders, a platform of "the manifold wisdom of God."

Yet our sun and all its worlds constitute only a single star system. Analogies and facts, which he 
cannot take time to state, make it highly probable that all the fixed stars are suns; that each, like our own sun, is attended by a retinue of planetary orbs; that many, or perhaps all, as suns and as centres of systems, possess both most glorious unities and most wondrous diversities; and that myriads, inclusive of our sun, are arranged in stupendous compound relations, with revolutions of inconceivable magnitude around common centres.

But the numbers, and distances, and immensities of these systems of stars prodigiously exceed all mortal man's possible powers of comprehension. To say that many millions of fixed stars are perceptible through the largest telescopes-that stupendous groups exist at such distances as to seem through these telescopes only little clouds of luminous dust-and that the light from many, though travelling at the rate of two hundred thousand miles per second, takes thousands of years to arrive at the earth-to say these things, and such as these, conveys no positive idea to the mind, but only bewilders or confounds it. Any attempt to express, in a sentence or two, a notion of the universe, would be quite as vain as an attempt to express the notion of immensity or of infinitude. We can do no more than glance at some salient points of the idea, and at the mighty lessons which they suggest; and this we cannot do better than in the brilliant words of Professor Mitchell:-

"If there be anything which can lead the mind upward to the Omnipotent Ruler of the universe, and give to it an approximate knowledge of his incomprehensible attributes, it is to be found in the grandeur and beauty of his works. If you would know his glory, 
examine the interminable range of suns and systems which crowd the Milky-way. Multiply the hundred millions of stars which belong to our own 'island universe,' by the thousands of those astral systems that exist in space within the range of human vision, and then you may form some idea of the infinitude of his kingdom; for, lo! these are but a part of his ways. Examine the scale on which the universe is built. Comprehend, if you can, the vast dimensions of our sun. Stretch outward through his system, from planet to planet, and circumscribe the whole within the immense circumference of Neptune's orbit. This is but a single unit out of the myriads of similar systems. Take the wings of light, and flash with impetuous speed, day and night, and month and year, till youth shall wear away, and middle age is gone, and the extremest limit of human life has been attained-count every pulse, and at each speed on your way a hundred thousand miles, and, when a hundred years have rolled by, look out, and, behold! the thronging millions of blazing suns are still around you, each separated from the other by such a distance that, in this journey of a century, you have only left half a score behind you.

"Would you gather some idea of the eternity past of God's existence, go to the astronomer, and bid him lead you with him in one of his walks through space; and, as he sweeps outward from object to object, from universe to universe, remember that the light from those filmy stains on the deep pure blue of heaven, now falling on your eye, has been travelling space for a million of years.

"Would you gather some knowledge of the omnipotence of God, weigh the earth on which we dwell, then 
count the millions of its inhabitants that have come and gone for the last six thousand years. Unite their strength into one arm, and test its power to move this earth. It could not stir it a single foot in a thousand years; and yet, under the omnipotent hand of God, not a minute passes that it does not fly far more than a thousand miles. But this is a mere atom-the most insignificant point among his innumerable worlds. At his bidding, every planet, and satellite, and comet, and the sun himself, fly onward in their appointed courses. His single arm guides the millions of sweeping suns; and around his throne circles the great constellation of unnumbered universes.

"Would you comprehend the idea of the omniscience. of God, remember that the highest pinnacle of knowledge reached by the whole human race, by the combined efforts of its brightest intellects, has enabled the astronomer to compute approximately the perturbations of the planetary worlds. He has predicted, roughly, the return of half a score of comets. But God has computed the mutual perturbations of millions of suns, and planets, and comets, and worlds without number, through the ages that are passed, and throughout the ages which are yet to come, not approximately, but with perfect and absolute precision. The universe is in motion-system rising above system, cluster above cluster, nebula above nebula_all majestically sweeping around under the providence of God, who alone knows the end from the beginning, and before whose glory and power all intelligent beings, whether in heaven or on earth, should bow with humility and awe.

"Would you gain some idea of the wisdom of God, 
look to the admirable adjustments of the magnificent retinue of planets and satellites which sweep around the sun. Every globe has been weighed and poised, every orbit has been measured and bent to its beautiful form. All is changing; but the laws fixed by the wisdom of God, though they permit the rocking to and fro of the system, never introduce disorder, or lead to destruction. All is perfect and harmonious, and the music of the spheres that burn and roll around our sun is echoed by that of ten millions of moving worlds, that sing and shine around the bright suns that reign above."

But have men no other interest in the starry heavens than merely to contemplate them? Do the orbs of the solar system, and the millions of millions of suns in the nearer parts of the universe, glitter but as bright points in the azure concave merely to suggest to us remote though sublime lessons respecting the attributes of the Infinite Creator? Or have we not relations to them which affect our lives, and come home to our hearts, and involve the manifestations to us, now and for ever, of the Infinite One's infinite love and moral glory? Has not our world, though almost a microscopic point in comparison to the maze of systems and universes within view of the telescope, and though but a dark spherical speck, shining solely in the light of a single one of the fixed stars-has it not connections, intimate and special, with the central orb of our system, and with the central regions of the heaven of heavens, sustaining a character as lofty, and making displays as wonderful, as probably the most magnificent in all the star-powdered empire of "the King eternal and invisible?" This is the thought 
about physical things which, immensely more than any other, concerns both the curiosity and the wellbeing of men; and no glance at the wonders of nature can be just or clear which does not say something to illustrate it. Yet, because it leads direct to sermonising, we shall dispose of it in two brief paragraphs.

The economy of living creatures on the earth, is one of reproduction, decay, and death; and, in consequence of changes made upon his bodily nature by sin, it affects man in the same way as the lower animals. A main agency in working it is the rays of the sun co-operating with our atmosphere; and other agencies, subordinate yet essential, are the mutual attractions between the earth and all neighbouring orbs. The influences of mortality spring up no more certainly from arrangements within our world, than from the general arrangements of the planetary system. Man's frame, though originally formed to resist them, was thrown open by sin fully and throughout all time to their power. But another economy has been established over him, to make him live again, and to transfer him in a glorified existence to other and far distant spheres. The eternal God, the second person of Deity, became incarnated on earth, took human substance into personal union with his divine nature, and thus linked our world to the central glories of the universe. He achieved here the work of human redemption; he evolved here the divine contrivance for transmuting the mortal bodies of men into immortality; he set agoing here that series of special divine works by which " the manifold wisdom of God is made known to the principalities and powers in the heavenly places." One result will be, that the immor- 
talised bodies of his redeemed will carry away to the celestial glory as much of the earth's substance as will serve to maintain their identity with the mortal bodies which were laid in the grave: and another will be, that their entire persons, body and soul, will exhibit to the view of exalted, intelligent, ever-sinless creaturcs, throughout the grandest regions of existence, the effects of God's love to men on earth, in the development and completion of the scheme of redemption. All the human inhabitants of the heaven of heavens will for cver speak of the earth, and for ever carry about with them the memorials of what they have experienced and witnessed herc of God's displays of his glory.

A physical system of decay and death upon our world, in its place among the planets, is thus intimatcly associated with a moral system of deliverance and immortalisation in its relations to cternity. Mcn die under the rays of the material sun, but they live again under the rays of the "Sun of Righteousness;" they all perish from the earth, but all pass away into other worlds; they spend only a brief period in making acquaintance with the things of this life, but learn lessons from them, and make uses of them, which, for good or for evil, will elicit everlasting results in far distant regions of existence. Every man, therefore, or, at least, evcry reflecting one, fcels within him an instinct of intimatc connection with remote worlds. As surely as he expects death, and thinks of rotting away to dust, so surcly does he expect a futurc life, and think of soaring among the stars to some centre of effulgence which no mortal cye has ever descried. The starry heavens seem to him for eternity what the 
shores of an adopted land are to an emigrant for timethe region in which he will ever rove, whose beauties will ever charm him, and on whose scenes he will imprint all the recollections of his former life. Hence many an ardent mind, even entirely apart from the proper feelings of religion, regards the earth as her prison, and the stars as her home,--anticipates often and eagerly the time of her release,- - and, as the poet Akenside beautifully expresses it,-

Disdains to rest her lieaven-aspiring wing Beneath its native quarry. Tired of earth And this diurnal scene, she springs aloft Through fields of air, pursues the flying storm, Rides on the volleyed lightning through the heavens, Or, yoked with whirlwinds and the northern blast, Sweeps the long tract of day. Then high she soars The blue profound, and, hovering round the sun, Beholds him pouring the redundant stream Of light; beholds his unrelenting sway Bend the reluctant planets to absolve The fated rounds of Time. Thence far effused, She darts her swiftness up the long career Of devious comets; through its burning signs Exulting measures the perennial wheel Of Nature, and looks back on all the stars, Whose blended light, as with a milly zone, Invests the orient. Now amazed she views The empyreal waste, where happy spirits hold, Beyond this concave heaven, their calm abode, And fields of radiance, whose unfading light Has travelled the profound six thousand years, Nor yet arrives in sight of mortal things." 


\section{CHAPTER II.}

\section{THE AIR.}

THE CONSTITUTION OF THE ATMOSPIIERE-THE HEIGHT AND PHESSURE OF THE ATMOSPHERE-EVAPORATION-THE HUMIDITY OF THE ATMOSPHERE - DEW-HOAR-FROST - FOGS-CLOUDS-RAIN-PRETERNATURAL SHOWERS-SNOW-HAIL-AIR-CURRENTS-NOXIOUS WINDS-SAND-DRIFTS-WHIRLWINDS AND WATERSPOUTS-TORNADOES AND HURRICANES-FIRE-BALLS AND AEROLITES-METEORIC SHOWERS-CLIMATE-THE SEASONS-GENERAL VIEW OF THE $\triangle \mathrm{T}$ MOSPHERE.

THE air, or atmosphére, is a light elastic fluid. Birds, and beasts, and men, live and move in it as truly as fishes live and move in water. It has real substance and actual weight, just as certainly as the heaviest liquid. It differs from water chiefly in being a mixture of things, in never having the running or the solid form, in always diffusing its contents equably through one other, and in being exceedingly light, and very easily expansible. Its principal ingredients are oxygen gas, which supports life and flame, and nitrogen gas, which cannot in any degree supporti. life or flame, and serves to dilute the oxygen, or to keep it from acting too strongly on plants and animals. Another ingredient, but a remarkably small one, is carbonic acid gas - a chemical compound of oxygen and charcoal. These three ingredients always maintain the same, or very nearly the same, proportions to one 
another, and may be regarded as constituting the proper atmosphere in its relations to life. The vapour of water is a fourth ingredient, and often a considerable one; but it is very variable, and is subject to laws of its own, and may be considered as a kind of atmosphere by itself-an atmosphere within the atmosphere.

Other things in the air are very numerous and very interesting. Some rather dart through it than exist in it, and have no appreciable weight-such as light, heat, the electric fluid, and perhaps the principle of sound. Some are gases, all different from one another, and from the oxygen, and the nitrogen, and the carbonic acid, and all possessed of curious properties. Some are rarified or vapourised essential oils-the substances which constitute odours. Some are invisible and inconceivably minute reproductive organs of the smallest plants, and of microscopic animals. Some are particles of inorganic matter, either so minutely divided as to be imperceptible by the naked eye, or occasionally so coarse and plentiful as to appear like smoke and dust. And some are unknown substances of great power and mystery, associated, no man can tell how, with the invigoration of plants and animals, and with sudden and temporary outbursts upon them of fatal diseases. But all these matters are mere admix tures in the atmosphere; and all, except the imponderable ones, occur in exceedingly minute quantities, and are exceedingly fitful and fluctuating.

The atmosphere envclopes the solid earth like a spherical stratum or all-encompassing sea. It holds on quite firmly, and partakes steadily of the earth's 
revolutions; and, though subjeet to many powerful currents and commotions within itself, it is but very slightly affeeted, in the way the ocean is, by tidal forces. Its total height is believed to be about fortyfive miles. But its density at the bottom is sixty-four times greater than at or near the top, and decreases one half at every distance of about two and three quarter miles. Its total weight is eomputed to be upwards of five thousand billions of tons, or equal to that of a globe of lead sixty miles in diameter. Its pressure at the surfaee of the sea and of the lowest valleys averages about fifteen pounds on every square ineh, but constantly varies, at any one place, from elianges in the amount of its vapour, from expansions and condensations of its gases, from the effects of its currents and commotions, and from the action of heat, electricity, and other agents. The variations of pressure or of local weight are readily measured by the rise and fall of the mereury in the barometer, and furnish man with his best artifieial means of anticipating changes of weather. The average pressure upon a human body of nearly fifteen square feet of surfaee, is about fourteen and a half tons; and this is essential to man's breathing and moving with health and comfort. The effects of the diminished pressure, and of the attenuated density at mountain elevations, are always painful; and at heights of from ten to fifteen thousand feet above sea-level, they commonly inelude exeessive weakness, great difficulty of breathing, and sometimes aeute agony, and a sense of suffocation. The pressure at ordinary levels is also a great force, and works wonders by its aetion, and is capable of being turned to mighty praetieal account in human meehanies. 
But this will be better explained in a subsequent chapter.

Evaporation is continually going on from seas, lakes, rivers, moist soils, and all sorts of moist surfaces. Water passes into vapour at all ordinary temperatures, simply by absorbing heat; and the vapour formed at all ordinary temperatures is commonly invisible at the time of its furmation, and becomes instantly diffused through the air. If no atmosphere existed, evaporation would still take place, and would maintain around the earth a constant yet very variable envelope of vapour. The rapidity of it, in particular conditions of the air, is often astonishingly great, and may sometimes be remarked in the quick drying of clothes, and in sudden dryings of the ground after summer showers; but, if it were not repressed and regulated by the weight and counteraction of the atmosphere, it would frequently be tremendous, and might, in one day, render fields, and fens, and shallow pools as dry as parched deserts. It is very various at different times, and very various in different countries, and it makes surprising differences on clouds and landscapes, and on crops and animals, by its varieties; yet, in general, it is greater in summer than in winter, greater in the day time than in the night, greater in a dry state of the air than in a moist state of it, greater even in a dry cold day of winter than in a moist warm day of spring, greater in warm and low countries than in cold and mountainous ones, greater in districts adjacent to seas and lakes and large rivers than in districts distant from any expanse of water, and greater in a wind than in a calm, in a brisk breeze than in sluggish puffs of air. All these differences work in the same general way as 
the variations of temperature and the succession of the seasons, and play a powerful part in the glorious vicissitudes of clime and weather.

The quantity of water evaporated into the air throughout the year, is estimated at a depth over all the globe of about thirty-three inches, or at an aggregate bulk of about an hundred thousand cubic miles. Yet never does the vapour of more than a small portion of that prodigious quantity exist in the atmosphere at one time; and never or seldom does this constitute more than nearly a twentieth part, or less than about a two-hundredth part of the atmosphere's contents. It does not diminish rapidly in density upward, as the atmospheric gases do, but is quite as dense, or nearly so, at a considerable height, as at the surface or the ground. It is also a good deal lighter than the atmospheric gases; so that the atmosphere, when very humid, has a good deal less pressure than when very dry. How curious that, in rainy weather, when sensitive persons feel languid, and "as if a load were on them," they really sustain very many pounds less pressure than in fair weather, when they feel light and spirited! This may afford every one an idea of the happy effects of great pressure in low situations, and of the disastrousness of small pressure at lofty mountain elevations.

In some states of the atmosphere, invisible vapour forms into fogs and clouds, and, in other states, it passes at once into dew and rain. But what those states precisely are, or what are other states in which dews, and fogs, and clouds, and invisible vapour resolve back into one another, or congeal into hoar-frost, and snow, and hail, philosophers do not well know. 
Electricity, and winds, and changes of temperature have mainly to do with them; but in what proportions, or under what precise laws, we cannot tell.

Dew is a deposition of vapour upon objects which are freely exposed to the atmosphere. It resembles the moisture which is formed on the walls of a room when they have a lower temperature than the humid air within, or that which is formed on the inside of windows when a fall of rain or hail suddenly diminishes the temperature of the air without. It commonly begins to form about sunset; and it abounds more in spring and summer than in the other seasons, more in valleys and in the vicinity of waters than in uplands and dry regions, and a very great deal more in hot tropical countries, which have few or no rains, than in the cold countries of the temperate zones which have a dripping climate. It always refreshes vegetation, and, in some burning districts near the equator, it supplies many plants with all the moisture they need, even in defiance of a scorching sun, and a perfectly arid soil. It forms also on stones, and even on metals, and no doubt gave rise to certain remarkable appearances which occasioned ancient poets and historians to speak of sweating statues and weeping images. The deposition of it is the gentlest of all atmospheric phenomena; and hence the beauty of the allusion of Moses, when he said that, in discoursing to the Israelites about the character of the Most High, his "speech should distil as the dew."

Hoar-frost, or rime, is simply frozen dew, or frozen fog. It abounds most on the low slopes of hill-screened valleys, and occurs oftener in autumn and winter than in spring. It commonly forms only when the atmos- 
phere is almost or altogether cloudless; and, when formed in the early part of the night, it may melt away under a gathering close cloud before the morning. It often presents most beautiful assemblages of specular crystals on the ground, and sometimes makes superb deposits on the sidcs of trees and walls against which it is drifted; and, though usually disliked by farmers and gardeners for the injury it inflicts on ripening crops and on opening blossoms, it constitutes; on the whole, a beneficent provision for protecting plants from the scverity of keen frosts.

A haze in the air is vapour obscurely visible, and may frequently be observed brooding over the face of watcrs, or over the face of moist lands, at times when a hot sunshine from an unclouded sky is producing rapid evaporation. A fog or mist, in all ordinary instances, is merely vapour completely visible, or a cloud resting at the bottom of the atmosphere. But a thick driving fog is generally very electric; and a stagnant fog in a great city has sometimes a dense intermixture of smoke, and is sometimes a curious compound of vapour, hoar-frost, smoke, and dust. London fogs are notoriously dense and dismal; and one which lasted six days in the winter of 1814, not only, like many others, occasioned a necessity for artificial lights through all the day-time, but congealed itself on walls and railings, and made a frozen deposit beneath the trees of St James' Park to the depth of an inch. So awful is the gloom of the worst fogs in London, Glasgow, Amsterdam, and some other populous cities, - so oppressive to the feelings of the sensitive, and so obstructive to the business of the active- that the words might almost be applied to them which Byron penned 
in description of an imaginary darkening of the universe-

"The bright sun was extinguish'd, and the stars

Did wander, darkling in the eternal space,

Rayless and pathless; and the icy earth

Swung blind and blackening in the moonless air.

Morn came, and went, and came, and brought no day.

And men forgot their passions in the dread

Of this their desolation; and all hearts

Were chill'd into a selfish prayer for light."

What is called a dry fog, however, is greatly worse than the fogs of cities, and probably arises from a dirersity of causes, and has a corresponding diversity of nature. It does not always make the air murky, but oftener gives it a muddy hue, and causes the sun and moon to look like blood; nor does it always maintain a still and suffocating character, but frequently has all the accompaniments of both electric outburst and volcanic convulsion; and it commonly extends over great tracts, and has been known to affect so much as one-fourth of the world. Tn the summer of 1783 , a dry fog prevailed during four weeks over all Europe, and passed on to the centre of Asia, and struck such terror into millions, that they abandoned their occupations, and imagined the end of all things to be at hand. The air was thick, and of the colour of rust; the electric fluid produced intense sultriness, and played away in frequent and destructive thunderstorms; hail-showers, hurricanes, and floods strewed some districts with desolation; and earthquakes and volcanic eruptions shook large portions of both the north and the south of Europe. Some fogs also have a luminous appearance, and are supposed to be mag- 
netic; and a peculiar fog broods over the Polar Seas on the approach of winter, and bears the expressive name of frost-smoke.

Clouds are not so diversified in nature as fogs, but possess wondrous diversity of size, form, colour, and evolution. They look like the drapery of the sky, and exhibit the most glorious beauty. The aerial scenery which they form, conjointly with the azure above them, and the lights and shades below them, has often incomparably more power and gorgeousness than the most brilliant landscapes of sea, and dale, and mountain; and, by being ever shifting, ever various, and ever new, it combines the witchery of a camera-obscura with the graces of a fixed picture. The clouds are also an awning to the earth, and a pavilion to the sunshine; and they possess the most sublime associations with the poetry of all time, and with the imagery of the sacred oracles. The Saviour of men was received into heaven in a cloud, and will come again in the clouds of heaven.

The densest clouds sometimes float so low as to touch the tops of trees and steeples; and the thinnest and lightest often rise so high as from three to five miles. Some are the smallest perceptible masses of visible vapour; and others have a thickness of many hundred feet, and a superficies of from twelve to twenty square miles. But most in our latitudes have both a medium height and a medium size. The curl-clouds, or those which look like locks of hair, are the highest. The stacken-cloud, or cumulus, of dense structure and either convex or conical form, floats near the ground, yet often rises with the advance of day, and sinks with its decline, and sometimes swells outward and upward 
in bulk, till it resembles a stupendous mountain, or range of mountains, clad in snow. The fall-cloud, or stratus, is a level sheet-like expanse, increasing from beneath; and it commonly forms in the calm of the evening from an evolution of vapour immediately over lake or valley, and glides slowly up the neighbouring ascents, to brood over the tops of the hills. The fleecycloud is an aggregation of small roundish masses, fleeting in winter, playful in summer, floating at great varieties of height, and often adorned with the gayest gems of colour. The wane-cloud is a medium thing between the curl-cloud and the fall-clond, but frequently changes its form, and at one time bursts into rain, at another soars away to a high altitude. Other clouds-and there are many others-are variations or combinations of these; and all the clouds, except the black ones, which are just discharging themselves in rain, and the piled and fiery ones, which are full of electricity, pass by many degrees of transmutation into one another, and effect their grandest feats of scenery by the number, and novelty, and variety of their neverccasing mutual changes.

Rains have every variety of cliaracter, from the slightest perceptible drizzle to the most deluging thunder-plumps, from the smallest visible globules to drops of nearly half an inch in diameter, and from a mere momentary sprinkling to continuous wide-spread falls for months. The annual quantity is greatest in the regions of greatest evaporation, and therefore greater in the tropics than in the temperate zones, and greater in the temperate zones than toward the poles. But comparatively great quantities are often precipitated in comparatively small periods. The rains of the tropics 
are about six times heavier than those of central Europe, and sometimes fall like water-spouts, or like lakes from the sky; and they also occur mainly, or almost solely, at one season of the year, and are then so constant or prolonged, as to constitute the characteristic feature of the tropical winter. Even the rains of some places in Britain yield much larger aggregate quantities than those of others, and yet fall in far fewer days. Most of the rains of cooi countries are fitful and local, and many are either much modified or wholly determined by the relative positions of land and sea, and of mountains and plains; but some are of such enormous extent as to fall simultaneously over many hundreds of miles. The drops of most showers vary in diameter from the twenty-fifth of an inch to a quarter of an inch, but are commonly large or small, according to the height from which they come; and the monster ones which commence some thunder-plumps, and form marks as large as shillings, all descend from very lofty elevations.

Rains do not consist simply of water, but contain various though minute proportions of other substances, particularly gases and organic products and volatile matters, which serve as nourishment to plants. Indeed, they are the scavengers of the atmosphere, and sweep out of it all undue accumulations of its foreign admixtures; and, in this capacity, they sometimes have extraordinary and very curious work to do. Substances of striking colour and singular appearance are occasionally sent bigh into the air by conflagrations, tempests, whirlwinds, and volcanic eruptions, and when brought back to the ground, either by rain or in company with it, make awful and liorrifie showers. Even 
inscets, worms, frogs, fish, garbage, and gelatinous matters, occasionally figure in this way; and though these, or any such things, are never so plentiful as to darken the air, and would always fall by their own gravity without any assistance from rain, yet when they happen to come down amidst a splash of waters, they never fail to shock and terrify the vulgar. But the pollen of forests, the smolze of vast fires, the ashes of volcanoes, the fine sand of deserts, and the sporules of cryptogamic plants, of greyish, brownish, and blackish colours, when projected in such quantities as to form obscuring clouds, and continued so long as to stain and thicken a succession of rains, have occasionally alarmed the wisest of men, and given occasion among poets and historians to preternatural stories about portents, judgments, and showers of blood.

Holinshed relates, that, at an early period of British history, there fell in England "blood by the space of three daies together," and that, afterwards, there "ensued such an exceeding number and multitude of flies, so noisome and contagious, that much people died by reason thereof." The classic writers of Greece and Rome, and the ancient writers of other lands, record similar things respecting most parts of the known world. And the better informed historians of modern times record numberless instances of yellow, red, brown, and inky rains, some of which made quite enormous deposits of dust or of minute organic substances, while others were also accompanied with dreadful commotions of both air and land. One of the lattera very remarkable black rain which fell at Montreal, in the winter of 1819_may be quoted as a specimen. It was preceded, over all Canada and the United 
States, by gloomy, dark weather, with occasionally a sublime and terrific aspect of the sky. "In Montreal, the darkness was very great, particulariy on a Sunday morning. The whole atmosphere appeared as if covered with a thick haze of a dingy orange colour, during which rain fell of a thick and dark inky appearance, and apparently impregnated with some black substance resembling soot. At this period many conjectures were afloat, among which, that a volcano had broken out in some distant quarter. The weather after this became pleasant, until the Tuesday following, when, at twelve o'clock, a heavy damp vapour enveloped the whole sky, when it became necessary to light candles in all the houses; the stalls of the butchers were also lighted. The appearance was awful and grand in the extreme. A little before three o'clock, a slight shock of an earthquake was felt, accompanied with a noise resembling the distant discharge of artillery. It was now that the increasing gloom engrossed universal attention. At twenty minutes past three, when the darkness seemed to have reached its greatest depth, the whole city was instantaneously illuminated by the most vivid flash of lightning ever witnessed in Montreal, immediately followed by a peal of thunder, so loud and near as to shake the strongest buildings to their foundation, which was followed by other peals, and accompanied by a heavy shower of rain, of the colour above described. After four P.Mr. the heavens began to assume a brighter appearance, and fear gradually subsided."

Snow has the same relation to rain which hoar-frost has to dew, or which ice has to water. It is supposed to be formed at no great height in the atmosphere, 
and while the vapour is collapsing into drops. The powdery varieties, in particular, are believed to be formed near the suriace of the earth; and they have a greater density than the flaky varieties, and fall more rapidly, and enclose a much smaller volume of gases within their cells and interstices. The flaky and needly kinds are very numerous, and, in most instances, have very beautiful crystalline forms. The six-sided kinds like prisms, are hard, and firm, and small, and appear to be formed at much higher elevations than the other kinds; they constitute the chief bulk of the snow of very lofty alpine regions, and are therelifted and whirled and tossed by the winds in a similar manner to the light sands of an arid descrt; and they are commonly accompanied, in Britain, with some of the platelike varieties, which are believed to intercept them and mix with them in the lower part of their descent. The wheeled, and star-like, and jagged, and compoundly six-sided varieties, constitute the largest flakes and the softest snowy masses, and fall, in calm weather, in low districts, and with a slow and sluggish motion. Flakes which are nine times less dense, or nine times more expanded than water, fall, on the avcrage, three times less slowly; and the largest flakes are commonly formed in a frost so mild as to make the crystals soft and humid, and to allow them to cohere somewhat in the same manner as the rays of fcathcrs. All flaky snow, as soon as it has fallen, begins to consolidate into increasingly denser conditions; and it owes both this power of self-condensation and the capacity of great cohesion under mechanical pressure to the ncedly tcxture of its crystals, and to the presence of a ccrtcin degrec of enclosed and ccherent moisture which 
afterwards freezes. Sheets of snow on the ground are well known to reflect beautiful pink and blue tints under certain angles of sunshine, and to fling hack so much light as to be painful to the eyes by day and to guide the traveller in the absence of moonshine at night. The whiteness of snow arises from the extreme minuteness of its particles, and is precisely similar to the whiteness of very finely pulverised ice.

Snow occasionally, though not often, and only in a few countries, falls of a red colour; and it then owes its redness to the same or similar causes as red rain. Snow is not unfrequently accompanied by electric outbursts, and has even been observed of a luminous appearnnce. A boating party on Loch Awe, in the spring of 1813 , were suddenly overtaken by a dense murky fall of snow; and while they moved on, with the lake as smooth as glass, they saw for about fifteen minutes all the snow around them, and all their boat and their clothes and the exposed parts of their bodies, sheeted over with a luminosity like fiery flame. Snow may form in a room which is filled with humid air not far above the freezing point, and into which is suddenly admitted a sufficient stream of very cold air from without, to effect an instantaneous fall of temperature. An instance of this occurred in a crowded assembly-room near St Petersburgh, in consequence of the accidental breaking of a window; and instances are not uncommon in the dwelling-houses of Siberia and other frozen regions.

Snow is an exceedingly reluctant conductor of heat, and acts, in all frozen climes, as a remarkable equaliser and ameliorator of temperature. It firmly refuses to become colder than the freezing-point, and there- 
fore softens the rigours of the winter. So long as it is falling, and for some time before it begins to fall, the air continues at the temperature of about $32 \mathrm{deg}$; and a layer of it upon the soil, two or three inches thick, or even less, prevents the internal heat of the earth from radiating into the atmosphere, and preserves the surface of the land from congelation by subsequent frost; and it therefore ameliorates the soil in winter, protects the life of the natural grasses and herbage plants during the long and rigorous frosts of high latitudes, shelters the cereal grasses and other fieldplants of Britain so as to keep them safe in winter and make them rise vigorously in spring, and occasions a continual flow of water in the form of perennial springs, from beneath the perpetual frozen summits and shoulders of alpine mountains.

Hail may be called frozen rain. It results from sudden intense cold in a rain-cloud. Its drops are variously globular, pyramidal, stellated, angular, and irregular. Some look like congealed rain-drops, some like compressed snow-flakes, and some like little pieces of ice. Some have a soft exterior and a hard centre, and some a hard exterior and a soft centre; and many, when cut across, present beautiful radiations or very elegant concentric plates. They commonly are of a size between that of a mustard-seed, and that of a small marble; but those of extraordinury storms are as large as pigeons' eggs; and a few have been found each as big as a man's fist, and from twelve to sixteen ounces in weight. An instance occurred in Gloucestershire, not many years ago, of a downfall of frozen atmospheric water which had the appearance far more of a discharge of fragments of ice than of even an extraordinary hail 
shower. The pieces were flat, rugged, and of all sorts of outline, some of them three inches broad, and very many as likc as possible to bits of broken ice-plate from the surface of a lake.

Hail showers are commonly formed in vcry disturbed states of the atmosphere, or at the crises of great and violent changes in its electric conditions. Most are confined within very small limits; and those which traverse any considerable distance have a surprisingly narrow breadth. They are most frequent and devastating in the south of Europe; but they sometimes fall with disastrous effects both in the colder temperate regions and within the tropics. Many beat down crops, strip trees, and desolate gardens; and some strew a land with havoc, and kill birds and beasts and men. A recent hail storm in India fell almost like a discharge of musketry; and many hail-storms figure in both ancient and modern records in as terrible power and with as dismal effects as famine and pestilence. Very many hail storms, or all, might serve to inflict divine chastisement on nations just as readily now as in the times of the ancient Egyptians and of the Canaanites; and since the vast majority fall lightly and do no harm, but on the contrary serve well to purify the atmosphere and to fertilise the soil, they ought to be regarded as sublime evidences of the long-suffering and mercy of the All-Benevolent Deity.

Winds may seem to careless observers very uninteresting or even unmeaning and annoying things, yct they really rank high amoug the wonders of the world. If the atmosphere had been incapable of them-if it stood stagnant in perpetual calm-all its many mighty 
properties would be useless to both plants and animals. Winds maintain an equable diffusion of the atmosphere's foreign admixtures. They promptly restore disturbed balances among its proper ingredients. They disperse into speedy dilution the noxious exhalations from swamps and towns. They carry clouds and vapours from the regions of the ocean and of wet lands to the dry and parched countries which lie sick and faint for want of moisture. They invigorate splashy regions by assisting to dry them, and refresh hot and arid ones by fanning and cooling them. They agitate seas and lakes, and prevent their waters from becoming putrid. They scatter seeds and give exercise to plants. They ventilate the dens of wild beasts, and the habitations of the domesticated animals and of man. They drive machinery and impel ships. They give circulation and activity to all moveable immaterial things, and impel the energies and promote the health of all air-absorbing and air-breathing creatures. Without them, the whole atmosphere would speedily become a stagnant pool, and the whole surface of land and sea an expanse of vilcness. Even a brief cessation of them on the ocean, a very few days' continuance of a calm at sea, where their action is incomparably less necded for any uses of organic existence than on land, is one of the most dismal themes of human thought. Whoever has witnessed one in the tropics will give a ready response to the well-known lines of Coleridge,-

"All in a hot anci copper sliy, The bloody sun at noon, Right up above the mast did stand] No bigger than the moon. 
Day after day, day after day,

We stuck, nor breath nor motion,

As idle as a painted ship

Upon a painted ocean.

Water, water everywhere,

And all the boards did shrink;

Water, water everywhere,

Nor any drop to drink.

The very deep did rot;--how strange, That ever this should be!

Yea, slimy things did crawl with legs

Upon the slimy sea."

Winds are produced by the beautifully simple means of the action of heat upon the elasticity of the air. Whenever heat, either direct from the sun's rays, or reflected from the surface of land or sea, or put into play in any other manner, is greater than the surrounding or adjacent temperature, it expands the air, drives it upward or outward, and occasions an influx of denser and cooler air to supply its place. A disturbance by expansion over but a small extent, through but a brief period, occasions a long and farspread wind. When the water of a pond is suddenly lowered at only one small point by the opening of a sluice, it becomes affected far and wide by a current; and, on a similar principle, when the air of but a small region of the atmosphere is suddenly expanded and pushed aloft by a rise of temperature, it draws on a rush or commotion from a great distance. Where the play of superior heat is constant, as happens along the equatorial zone, it produces the constant currents called the trade-winds. When it is seasonal, or acts during one season of months and does not act during 
another, as happens over all the Indian Ocean, it produces the seasonal currents called monsoons. Where it is diurnally alternating, or acts at one time of the day along one course of surface and at another time of the day along another, as happens along multitudes of the sea coasts of the world, and very specially along those of the torrid zone, it produces the alternating currents of day and night, which are called land and sea breezes. And wherever it acts fitfully, whether from the peculiar relations of a country to the earth's rotation, or from the peculiar configurution of its surface, or from the disturbing influence of its sands or marshes or forests, or from changes in the state of the evaporation and the clouds, or from evolutions and outbursts of the electric fluid, or from any other of the causes or combinations of causēs which control the temperature and variegate the seasons, it produces some one or other of the many kinds of currents which are called variable winds. All these are interesting; but only two classes, the noxious and the tempestuous, require any remark.

Noxious winds are an exception to the beneficial effects of currents in the air, yet perhaps more an apparent than a real one; for as they derive their noxiousness from the exhalations or influences of the regions whence they blow, they probably prevent awful catastrophes by sweeping away accumulations of aeriform poison. The worst arise only in the deserts and arid plains of Africa and South-western Asia, and bear the names of harmattan, sirocco, simoom, and samiel.

The harmattan blows periodically from Central Africa to the Atlantic. It is accompanied by thick dry fogs, and by quantities of very fine sand. It contains not 
a trace of humidity, and does not permit the deposit of a drop of dew. And it dries furniture to splinters, withers growing grass into hay, and produces painfully parching effects on flocks and men.

The sirocco blows from the Sahara across the Mediterranean to Italy and Greece and the Levant. It seldom lasts longer than about a day and a half, yet commonly works much disaster. It operates in the manner of intolerable heat and of a deficiency of oxygen. It has a medium temperature of about $112 \mathrm{deg}$., and produces the same kind of sensation on the face as scalding steam from an oven. Fires burn languishingly in it, and animals have difficulty of breatling. It kills plants, produces extreme langour in brutes, sinks strong native men into profound depression, and is dangerous or deadly both to sick natives and to healthy foreigners. Persons who are best acquainted with it, and have the best known appliances for resisting it, simply shut themselves up in their houses, cut off every possible communication with the open air, and keep down the temperature by sprinklings of water.

The simoom occurs in the deserts of Egypt, Syria, and Arabia, and in the adjacent countries. It may at first be only light and rapid, but it soon becomes burning and portentous. It careers on with a heat of at lcast $128 \mathrm{deg}$., and with obscuring loads of minute dust. The sun becomes lurid or blood-like; the air exhibits various tints of yellow and blue and red, and seems all on fire; and living creatures are hurled into a struggle with suffocation or death. The wind happily moves a little above the ground, and is of brief continuance, else it might destroy the life of all breath- 
ing things. Travellers fall prostrate on the ground, and lie there till it passes, or till they die; and the people of inhabited places shut themselves fast in houses, or tumble into subterranean retreats. Yet all terrible though the simoom be, it rarely visits the haunts of men, or even the haunts of useful vegetation, but commonly expends its force in the wilderness; so that the poet is correct when he speaks of

\footnotetext{
"The red-hot breath of the most Ione simoon, Which dwells but in the desert, and sweeps o'er The barren sands which bear no shrubs to blast, And revels o'er their wild and arid waves, And seeketh not, so that it is not sought, But being met is deadly."
}

The samiel haunts the deserts adjacent to the Euphrates and the Persian Gulf. It is akin to the simoom, and sometimes bears its name, but has a more terrible character. Many learned persons believe it to have been the pestilence of the ancients; and the Mahommedans of Arabia and Persia suppose it to be under the management of a minister of vengeance. It suddenly kills many a wanderer in the deserts, and rushes violently to the very gates of Badgad, yet never injures any person in the city. The kind of death which it inflicts is reputed to be death and putrefaction in one, and has occasioned it to be called the mortifying wind. Fraser, speaking of it in connection with some of the worst tracts of Persia, says, "These deserts, at all times perilous, are in the hotter months frequently visited by blasts of the simoom, which crack and shrivel up the skin and flesh, occasioning all the agony of scorching; while, from the gaping rents, the dark and distempered 
blood pours in quantities that soon occasion death. In some cases, life seems at once dried up, while the corpse, changed to a putrid mass, separates limb from limb on being touched." The death, however, seems really not at all so horrific as this statement would suggest; for the most probable proximate cause of it, as argued from the sciences known to medical men, is simply congestion of the lungs.

Sand-drifts and sand-whirls have a medium character between noxious winds and tempestuous winds. The former blow in squalls, the latter move in vast whirling pillars, and both are suffocating and violent. They have overwhelmed thousands of travellers, and buried many villages and towns. An army of fifty thousand, which Cambyses, in ancient times, led into the Lybian desert, was so utterly destroyed by them that not a man survived to tell the incidents of the catastrophe; and an army which Alexander the Great led from Memphis to the temple of Jupiter Ammon narrowly escaped a similar fate. The sand-drifts have desolated palm-groves and oases, and are now bringing invasions of sand-hills upon the fertile land of Egypt. The sand-whirls sometimes rise with startling suddenness, and sweep round and onward with confounding fury. Numbers are occasionally seen, in the far distance, moving in company, some with majestic sluwness, and others with impetuous speed. Caillie, describing a large and rapid one which crossed his company's camp, says, "It overset all the seats, and, whirling us about like straws, threw one of us on the other in the utmost confusion. We knew not where we were, and could not distinguish anything at the distance of a foot. The sand wrapped us in darkness like a fog, and the sky 
and the earth seemed confounded and blended in one. Whilst this frightful tempest lasted, we remained stretched on the ground, motionless, dying of thirst, burned by the heat of the sand, and buffeted by the wind."

Whirlwinds are the same as sand-whirls, but with. out their sand, and often far larger and far more violent. They occur in all parts of the world, but are most frequent and perilous within the tropics. Some precede volcanic eruptions; some are accompanied or followed by thunder-bursts; and many of the ordinary kinds, which consist merely of air-whirls, suck up the contents of yards and fields, and sometimes even objects several hundredweights heavy, and transport them to surprising distances. Small whirlwinds may do no more than sweep the ground; but very great ones overthrow buildings and uproot strong trees, or even smash and overwhelm a forest.

Waterspouts are akin to whirlwinds, but make a discharge of water, and commonly occur on rivers, lakes, or seas. They ought rather to be called airspouts or water-whirls, for they whirl air rather than water, and consist properly of condensed vapour, and do not spout water in greater copiousness than the sand-whirls spout sand. They often have a deep indigo blue colour, of similar tint to the cloud above them; and they gyrate sometimes perpendicularly, sometimes slantingly, and, in rare instances when there are two of them, with a horizontal column extending between their summits. A moderate kind of one, seen by Captain Napier, commencing in a whirlwind and estimated at one-third of a mile in height, may be quoted as a specimen. "The whirlwind formed 
about three cables' length from the starboard-bow of the ship. It carricd the water up along with it in a cylindrical form, in diameter, to appearance, like that of a water-butt, gradually rising in height, incrcasing in bulk, advancing in a southerly direction; and, when at the distance of a mile from the ship, it continued stationary for several minutes, boiling and foaming at the base, discharging an immense column of water, with a rushing or hissing noise, into the overhanging clouds, turning itself with a quick spiral motion, constantly bending and straightening, according as it was affected by the variable winds, which now prevailed alternately from all points of the compass."

Tempests of all sorts may be loosely regarded as vast outspread whirlwinds. They were believed, till a few years ago, to be straight-onward currents, dcriving all their peculiarity of character from sheer vclocity; but they are now known to be atmospheric vorticcs-great whirls, moving round and onward like eddies in water, or blowing in spiral curves along an axis. The typhoon is a common one in the Chinese seas, with breadth of curves varying from a hundred to two hundred miles, and with a violence of action most terrific to everything within its sweep. Ordinary sea storms are tempests in any ocean, with all varieties of both curve and fury; and tornadoes are sudden and severe ones on land, moving in the manner of stupendous whirlwinds. But the true tornado is a peculiar tempest of Africa, which seems to leap down from the clouds, and has a sublime retinue of thunders and onfalls. The horizon is clcar and blueish; a dark cloud forms above it, at first little bigger than a speck, but rapidly enlarging and blackening; luridness kindles 
aloft, and lightnings begin to play; the higher air tumbles and rolls in tumultuous agitation, but as yet the lower air is sullenly calm, and as silent as the grave. A gentle breeze now steals forth below; and, in a mo. ment, gusts, thunders, and torrents follow.

$$
\text { "Then down at once, }
$$

Precipitant, descends a mingled mass

of roaring winds, and flame, and rushing floods."

The hurricane is an enlargement of the tornado, as the tornado is of the whirlwind. It comes on some. times as an increase of an ordinary storm, but more commonly in the sudden manner of the tornado, and with similar portents. It occurs in all regions of the world, but is most frequent and fearful in the torrid zone. Its velocity is not seldom less than about one hundred miles an hour; and its force sometimes falls on forests like the sickle on corn, and on walls and buildings like the kick of a man's foot on a pasteboard toy. One of the most awful on record is a hurricane which swept across Britain in the winter of 1703, and which seems to have gone round the world. It roared like thunder, and appalled every heart. It swept away light buildings like chaffi, and laid multitudes of heavy buildings in ruins. Nearly one thousand British boats, about three hundred British ships, and twelve men-of-war of the British navy, were blown away, and many of them were never again heard of. Twenty thousand sheep were destroyed in the county of Kent, and fifteen thousand on the banks of the Severn. The Eddystone lighthouse, believed to be one of the strongest structures ever erected by man, was precipitated into the sea. Many persons were killed by the falling of houses, and eiglit thousand perished $\mathrm{i}$ is 
the Thames and the Severn, and in the cast-away British ships. The damage done to property in the city of London alone, was computed at upwards of two millions of pounds sterling. Yet, though the eftects of a hurricane often fall like a judgment, the scenery and power of it are usually a glory, and make a profound impression on devout and poetic minds. How admirably is this exemplified in the following graphic lines of Bryant! -

* And lo! on the wings of tho lieavy ga!es, Through the boundless arch of heaven he sails: Silent, and slow, and terribly strong The mighty shadow is borne along, Like the dark eternity to come;

While the world below, dismay'd and dumb Through the calm of the thick, hot atmosphere, Looks up at its gloomy folds with feur.

They darken fast, and the golden blaze Of the sun is quench'd in the lurid haze; And he sends through the shade a funeral rayA glare that is neither night nor dayA beam that touches, with hues of death, The clouds above and the earth beneatl.

He is come! he is come! Do ye not behold His ample robes on the wind unroli'd?

Giant of air, we bid thee hail !

How his grey skirts toss in the whirling gale! How his huge and writhing arms are bent, To clasp the zone of the firmament, And fold, at length, in their dark embrace, From mountain to mountain the visible space!

Darker, still darker, the whirlwinds bear The dust of the plains to the middle air; And liark to the crashing, long and loud, Of the chariot of God in the thunder-cloud: You may trace its path by the flaslies that start From the rapid wheels where'er they dart, 
As the fire bolts leap to the world below, And flood the sky with a lurid glow.

What roar is that? 'Tis the rain that brealis

In torrents away from the airy lakes, Heavily pour'd on the shuddering ground, And shedding a nameless horror round.

Ah! well known woods, aud mountains, and skies, With the very clouds, ye are lost to my eyes.

I seek ye vainly, and see in your place The shadowy tempest that sweeps through space-

A whirling ocean that fills the wall Of the crystal heaven, and buries all; And I, cut from off the world, remain Alone with the terrible hurricane."

A very brilliant class of occasional objects in the air are fire-balls or fiery meteors. They have a varied appearance, and perhaps also a very varied nature and origin; and most or all, though visible chiefly in the atmosphere, seem rather to fall into it and expire in it than properly to belong to it. The grandest single one on record blazed over Europe from Ireland to Rome in the autumn of 1783 . It at first had a greenish colour and a long tail, but afterwards unrolled itself into a series of spheres and streams of different hues. It was supposed to be seen far above the atmosphere, and to move with the velocity of not less than one thousand miles a minute, and to have a diameter of two thousand eight hundred yards. And ten minutes after it exploded, a detonation was heard like a peal of thunder. All ordinary fire-balls are seen only within the atmosphere, though at very different altitudes. Some answer well in appearance to their popular name of "shooting stars;" and others throw off brilliant sparks, and leave behind them a luminous 
trail. Most seem to be entirely gaseous; but some, of rare occurrence, and with rushing sound, attend the fall of aerolites or star-stones. Aerolites are of various sizes, and fall sometimes singly, and scmetimes in mimic showers. One which fell in Brazil weighs about fourteen thousand pounds; but few weigh more than three or four pounds, and most are no larger than a pin's head or a pea. All closely resemble one another in both texture and composition, and bear every evidence of an origin foreign to our world.

Meteoric showers are incomparably grander than any single fire-balls, and have been more than once so profuse and blazing as to make vulgar observers imagine that "the world was on fire." The most superb one ever described fell over a large portion of North America throughout most of the night of the 12 th and 13th November, 1833. Professor Olmsted of New Haven, who saw it, and who is known to fame as an eminent astronomer and astronomical author, says respecting it_-"Let the reader imagine a constant succession of fire-balls resembling sky-rockets, radiating in all directions from a point in the heavens, a few degrees south-east of the zenith, and following the arch of the sky towards the horizon. They commenced thcir progress at diffcrent distances from the radiating point; but their directions were uniformly such, that the lines they described, if produced upwards, would all have met in the same part of the heavens. Around this point, or imaginary radiant, was a circular space of sevcral degrees, within which no meteors were observed. The balls, as they travelled down the vault, usually left after them a vivid streak of light, and, just before they disappeared, exploded, or suddenly resolved 


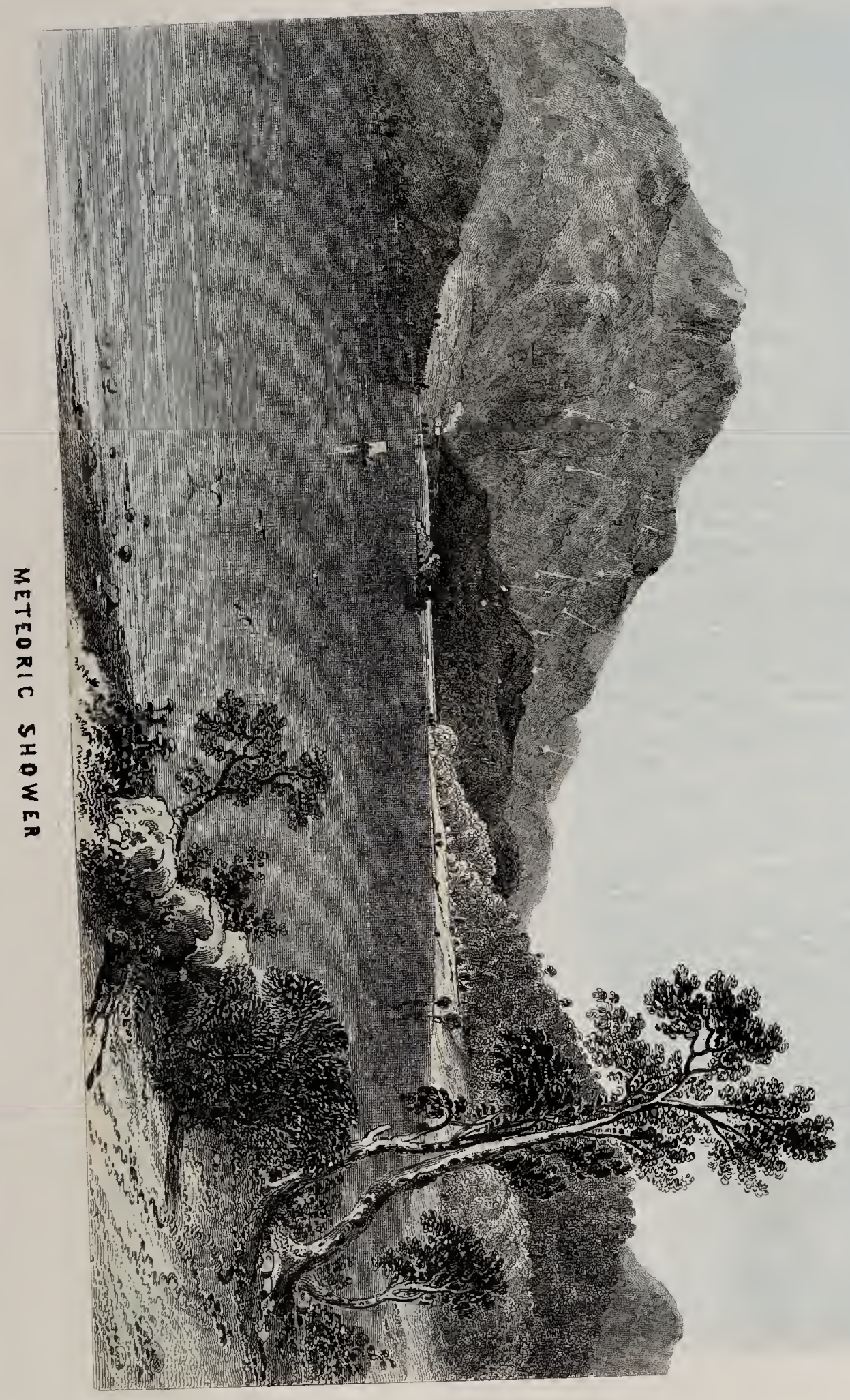



themselves into smoke. No report of any kind was observed, although we listened attentively.

"Beside the foregoing distinct concretions, or individual bodies, the atmosphere exhibited phosphoric lines, following in the train of minute points, that shot off in the greatest abundance in a north-westerly direction. These did not so fully copy the figure of the sky, but moved in paths more nearly rectilinear, and appeared to be much nearer the spectator than the fire-balls. The light of their trains was also of a paler hue, not unlike that produced by writing with a stick of phosphorus on the walls of a dark room. The number of these, luminous trains increased and diminished alternately, now and then crossing the field of view, like snow drifted before the wind, although, in fact, their course was towards the wind.

"From these two varieties, we were presented with meteors of various sizes and degrees of splendour; some were mere points, while others were larger and brighter than Jupiter or Venus; and one, seen by a credible witness at an earlier hour, was judged to be nearly as large as the moon. The flashes of light, although less intense than lightning, were so bright as to awaken people in their beds. One ball that shot off in the north-west direction, and exploded a little northward of the star Capella, left just behind the place of explosion a phosphorescent train of peculiar beauty. This train was at first nearly straight, but it shortly began to contract in length, to dilate in breadth, and to assume the figure of a serpent drawing itself up, until it appeared like a small luminous cloud of vapour. This cloud was borne eastward (by the wind, as was supposed, and which was blowing gently in that direc- 
tion), opposite to the dircction in which the meteor itself had moved, remaining in sight several minutes. The point from which the meteors seemed to radiate kcpt a fixed position among the stars, being constantly near a star in Leo, called Gamma Leonis."

Sever'al theories have been started respecting the source or nature of these wondrous bodies; and the one most generally received supposes them to be portions of some gaseous group or mass revolving round the sun, and coming at certain periods within the reach of the earth's attraction. But even if this theory were proved, "perhaps," to quote Professor Olmsted once more, "ages may roll away before the world will be again surprised and delighted with a display of cclestial fire-works equal to that of the morning of November 13, 1833."

The conditions of local atmosphere which constitute what is called climate, rank high among the wonders of nature, but are too many and intricate to be unravelled within our narrow limits. They comprise position with regard to the equator and the poles, altitude of the ground above sea-level, exposure and configuration of surfice, relation to neighbouring seas or lands, character of prevailing winds, nature of the soil, presence or absence of forests or morasses, and all things else which affect temperature, humidity, and foreign admixture with the air; and these make such a compound of influences, or rather of co-operations and antagonisms, as cannot possibly be described in a few sentences. There is one thought about them, however, whieh deserves to be dragged into prominencethat, in their grand result, in the character which they 
give to local climate, particularly in regard to its salubriousness, they are, in a large portion of the world, powerfully controlled, for good or for evil, by the care or the carelessness of the cultivators of land.

When excessive quantities of vapour arise from the marshiness or moistness of a district, they rarefy the superincumbent air, decrease its capacity for heat, and, in consequence, render the local climate humid, cold, and chilly. But, by a beautiful law of the all-beneficent God, these can be promptly and permanently diminished throughout even so small a tract as a single farm, by means of the simple, and otherwise eminently profitable, operation of draining. That not much cold air and clamp air shall accumulate in any one place, is provicled for by a decrease in the atmosphere's capacity for watery vapour, proportionately to the fall of its temperature; and that chilliness and dampness shall be driven from the climate of a district by thorough cultivation, is provided for by the disappearance of the stagnant waters and the bibulous and spongy surfaces whence the local aumosphere was formerly charged with vapour. When all the land of a district has been thoroughly drained, and all its ascending and accumulating waters either drawn off to a river-course, or gathered into such small deep pools as present comparatively trivial scope for evaporation, the local atmosphere receives less vapour, acquires increase of capacity for direct solar heat, and obtains a larger amount of radiated heat from the ground: so that, though the same quantity of rain fell annually as before, the stratum of air immediately over the soil, or the actual climate of the district, will possess a far higher degree of both dryness and heat. Hence the 
foulness of our pastures, the poverty and lateness of our crops, the stiffness of our carses, the miriness of our loams, the wetness of our vegetable moulds, the spoutiness and rankness of our meadows, the blights upon our crops, the occasional pestilences upon our Hocks, and the frequent coughs, and fevers, and consumptions of our families, ought, in multitudes of instances, to be ascribed not to the raininess of our climate, the fickleness of our seasons, or the chilly dampness of our atmosphere, but either mainly or solely to the had agricultural condition of the soil.

Let even a very small tract of land be effectually drained, and the heat of the air over it will be at once and always warmed; and rains, while continuing still to give it all the refreshment it requires, will no longer lie upon its surface or stagnate within its bosom, to poison the suffused atmosphere with fogs and miasmata. An increase of atmospheric heat without a corresponding drainage of terrestrial surface, would not only be useless, but most malignant. The coughs, asthmas, consumptions, and intermittent fevers which arise from the cold, damp air of a churlish and niggard country, are mild in their character, and gentle in their operation, compared to the fierce fevers, the murderous diarrhœas, and the fell and furious inflammations, which scourge the population of a warm damp air in regions of moist, rank, luxuriant vegetation. The agues of our own fenny districts are playthings in comparison to the red-hot pests and plagues which desolate the low wet regions of the Levant and the tropics. About a century ago, a wind which sweeps across the vast swamps and oozy mangrove thickets of the low sultry delta of the Niger, and carries loads of putrid vege- 
table exhalations over all the adjacent coasts, made such wholesale havoc upon the population, that the survivors were not numerous enough to bury the dead.

The glories of the seasons, notwithstanding that every man has been familiar with them from his infancy, are deserved objects of admiration, and deep sources of enjoyment, through all the years of our earthly existence. The cause of them, indeed, as we hinted in the former chapter, is astronomical; yet the seasons themselves are mainly wonders in the air, or at least wonders which, while developed over all land and sea, and among all the living things within them, begin and go on by means of the light, and heat, and other agencies in the air. And how rich are these wonders-how varied, and endless, and unceasinghow replete with blessing to creatures-and how pervaded by the benignity of the Creator!

The summer of the arctic regions is a continual sunlight of many weeks in duration. The sun, through all that time, never goes down, but only approaches the horizon, and curves aloft again to the upper sky. The landscape is a blaze of brilliance, and the clouds, and seas, and mountains often display a drapery of hues almost as gorgeous as the rainbow, but with breadths and blendings of massive magnificence. The arctic winter is a correspondingly long period of continual night. But what a night! The land and the ocean a tumulated expanse of glittering crystals; the sky a clear blue dome, hung over with thousands of lamps, all like globules of the purest silvery-burning gas; the moon a great reflecting mirror, flinging floods of light upon the world; and the aurora borealis occa- 
sionally streaming down from the apex of heaven like a visitation of cherubim!

The whole year within the tropics is a stranger to frost, and snow, and the aurora-and maintains an almost equal diurnal distribution of day and night-and luxuriates incessantly in stove warmth, lustre light, the vegetation of a garden, and the teeming life of a menagerie. Yet it has grand vicissitudes; and at least two great seasons. Its courses of weather pass on from the rotting calm to the convulsing hurricane; and its courses of reproduction and growth alternately sink to exhaustion, and go round the circle of a paradise. In its summer of drought and cloudlessness, the earth suns herself into sickly sloth, till she seems almost ready to die; and, in its winter of deluging rains and crashing thunder-storms, she reeks in the bath, and becomes strong again for her gymnastics.

What a happy medium between the extremes of the arctic and the equatorial regions are the seasons of the middle parts of the temperate zones! Our summer is all splendid with its blazing days, and its burnished nights, its sudden rains and its flashing thunder-bursts, and yet all beautiful and mild, with its vigorous verdure and its laughing landscapes, its sky-awnings and its varied winds. Our autumn is soft and mellowing, -all a season of waving grain and ripening fruit, of gentle breezes and balmy odours, of sumptuous scenery and bounding health, of songs of gladness and of "joys of harvest." Our winter is an alternation of storms and calms, of fogs and frosts, of funereal skies and the most starry nights, - a season of repose to plants, of invigoration to soils, of relaxation to useful animals, of torpidity to useless ones, of sloth to sluggards, of 
laziness to laggards, and of the most active labours, the liveliest emotions, and the strongest mind-stirrings of wise and intelligent men. Our spring is the commencement of another cycle of existence,- the season of revival to dormant plants and torpid animals, of grermination to seeds and arousal to roots and stems, of upstarting to herbs and exfoliation to trees, of begun glee and singing to the songsters of the grove, of renewed activity to herds and flocks, of call and promise to the cultivators of the land, and of struggling warmth for all, and mingled smiles and tears to all, from the sympathising hearens. Could these things be concealed from any man till he has a well-developed mind, and then allowed to burst upon him in the progress of a single year, they might overwhelm him with astonishment, or put him frantic with delight; and they are none the less glorious for being let out upon all men, little by little, from their earliest years onwards, in such blendings and increase as to offer gentle, steady, radiant happiness to the whole course of their sublunarg life.

Great as are the wonders in the air at which we have glanced, there are many others at least equally great. The atmosphere, as we hope partly to show in some subsequent chapters, is adapted not more to the evolutions of vapours and winds, of meteors and seasons, than to the action of light, the outshining of the starry heavens, the play of the electric fluid, the vibrations of sound, the chemistry of land and sea, the vitalities of plants and animals, and the countless nutual dependencies of all earthly things; and it is as perfectly suited to each as if it were suited to none 
other, and never undergoes an atom of impairment of its suitableness to one by thoroughly, or as it might secm laboriously, performing its offices for the rest. It has an equipoise of forces which keeps it permanently steady in spite of the most violent convulsions, and an equipoise of properties which keeps it permanently uniform in spite of the most copious admixtures or abstractions. What Christian man can reflect on its constitution and its glories, and not devoutly exclaim with the poet Peabody,-

"God of the light and viewless air!

Where summer breezes sweetly flow,

$\mathrm{Or}$, gathering in their angry might,

The fierce and wintry tempests blow;

All from the evening's plaintive sigh,

That h rdly lifts the drooping flower,

To the wild whirlwind's midnight cry-

Breathe forth the language of thy power.

God of the fair and open sky!

How gloriously above us springs

The tented dome of heavenly blue,

Suspended on the rainbow's rings!

Each brilliant star that sparkles through, -

Each gilded cloud that wanders free

In evening's purple radiance, gives

The beauty of its praise to Thee.

God of the rolling orbs above!

Thy name is written clearly bright,

In the warm day's unvarying blaze,

Or evening's golden shower of light,

For every fire that fronts the sun,

And every spark that walks alone

Around the utmost verge of heaven,

Were kindled at thy burning throne." 


\section{CHAPTER III.}

\section{LIGHT.}

NATURF IND LAWS OF LYGHT-THE SPECTRUM-REFRACTION IN THE ATMOSPHERE-THE TINTS OF SKY AND LANDSCAPE-COLOURS-THE RAINBOW-HALOS-MOCKSUNS AND MOCKMOONS-SPECTRAL ILLUSIONS-FATA MORGANA-ENCHANTED COASTS- - THE MIRAGE-SHADOW'S ON MISTS AND CLOUDS-SUMMARY VIEW OF OTHER WONDERS OF LIGHT.

LIGHT is the emanation from luminous or illuminated bodies which makes them visible to the eye. Some philosophers suppose it to be a subtle and extremely attenuated fluid - $\mathrm{a}$ real substance, yet so fine as to have no appreciable weight; and others suppose it to be merely the undulation or vibration of an ethereal medium, which is luminous when in motion, and dark when in repose. Light may be flung from one illuminated body to another, and from a second to a third; but, in every case, it must come, in the first instance, from a self-luminous body. Its grand source throughout the solar system is the sun; a minor source of it, in this part of the universe, is the fixed stars; and the local sources of it in our world are principally the flashes of the electric fluid, the glow of phosphorescence, and the flame and red-heat of combustion. It is always of the same colour as the body from which it comes; it always moves in straight lines, and consists of rays, related to one another in some such way as 
the straws of a sheaf of corn; and it. streams from every visible point of the body which emits it, and in every direction whence that point can be seen. It passes through transparent substances, whether gaseous, liquid, or solid, but is variously bent by them, or turned from the line of its previous course, according to their density and other circumstances; and it is partly alssorbed and partly flung back by non-transparent bodies, in a diversity of ways, and with most gorgeous appearances, but under uniform and well-known laws. The light of the sun has been ascertained to take only seven minutes and a half to travel to the earth, or to move through a space equal to the circumference of our globe in the eighth part of a second; and all other light is presumed to travel at the same rate.

When a small sunbeam is admitted to a dark room through a little hole of a window-shutter, and projected on a white screen or on a sheet of paper, the insertion in it of a triangular piece of glass, technically called a prism, separates it into a series of splendid colours exactly similar to those of the most perfect and brilliant rainbow. This is termed the spectrum, and comprises always the same colours in the same order. The red is at the end which is least refracted, and the violet at the other end; and, if the whole be artificially divided into three liundred and sixty parts, the red will be found to occupy forty-five of these parts, the orange twenty-seven, the yellow furty-eight, the green sixty, the blue sixty, the indigo forty, and the violet eighty. When all the series, or the entire spectrum, is caught upon a lens of such form as to concentrate it to one spot, it reproduces the white sun- 
beam or original colourless light. The different colours possess different powers, and are technically regarded as different rays. The lightest green and deepest yellow are the most illuminating; and either the violet or a dark space immediately beyond it, is the most heating; and the spectrum as a whole affords ample scope for wondering inquiry and keen investigation as to its action on living organisms, on photographic preparations, and on select objects in the chemist's laboratory. The light of the moon, and various lights of combustion too, differ in their properties or actions from one another, and from the light of the sun. In all cases, however, the degree of brightness depends on the extent of the undulations, and the predominance of any ray or colour depends on their number.

The varied refraction of light in our atmosphere is the cause of twilight, and of all the tints and magnificence of landscape, cloud, and sky. Were the atmosphere awanting, or did it not possess the power of deflecting and diffusing light at a great variety of angles, and with a great variety of effects, the sun would rush up from night in a moment in the morning, and pass over the hemisphere in a uniform garish blaze through the day, and plunge back to night in a moment at sunset. His rising would resemble the sudden kindling of a bonfire by a great charge of gunpowder; his walk over the sky would resemble the steady flame of that fire without flicker or diversity; and his setting would resemble the instantaneous extinction of it by the fall of a waterspout. He would glare in the face of observers who looked at him, but would give them no light when they turned their backs 
to him, and would never, in any circumstances, throw illumination, or colour, or the charms of perspective, on either the outspread earth or the overarching sky. Sunshine would scarcely do more for the world, or do it much differently, than a flambeau does at midnight for a mountain glen. "The number of objects in the heavens would, indeed, be augmented, for the stars would shine through a canopy as black as ebony, even when the sun was above the horizon; but all the gay colouring of the terrestrial landscape, which now de. lights the eye and the imagination, would be for ever veiled from the inhabitants of the world. In such a state of things, it would be always night; and the difference between such a night and that which we now enjoy would be, that the celestial orbs, instead of being grounded on a beautiful azure sky, would appear on a black canopy, like so many white points on a dismal mourning carpet."

Sunbeams entering the atmosphere in any other direction than the perpendicular one, but especially sunbeams entering it in a very slanting manner, as all do when the sun is far down the vault and near the horizon, undergo a long series of flexure through the various densities of gas and vapour before they reach the ground. They sustain little, indeed, in the higher regions of the air, where its density is very attenuated, and where no vapours ever exist in sufficient quantity to form a cloud; but, in struggling through the increasingly thick masses of the last two or three miles, they undergo so much as to be eventually bent almost like the segment of a hoop. Hence, as the lower end of a stick inserted in clear water appears to the eye several degrees away from what is known to be its true 
position, an object in the sky exactly on a line with the horizon appears to the eye to be a considerable distance above the horizon. The sun and the moon, therefore, are always visible at their rising some little time before they actually rise, and continue visible at setting some time after they actually set. And when an eclipse of the moon happens, as on rare occasions it does, exactly at the time of sunset and of moonrise, the curious spectacle is beheld of the sun in full orb on the one rim of the sky, and the moon in full orb, darkened by the earth's shadow, on the other. The earth is then in the exact line between them; yet, in consequence of the refraction of the light through her atmosphere, she appears to the eye to be considerably helow both.

The sunbeams are so very diversifiediy rcfracted by the many different kinds of surfaces and substances on the ground, and by the many different conditions of air and vapour immediately above them, as to produce, in the very act of their falling, all the endless, sumptuous, brilliant varieties of tint and shade which adorn our landscapes. Colours, whether fixed or fleeting, are nothing more than the refractions of the precise rays or mixtures of rays which correspond to them, $o r$, in other words, are not at all properties in objects, but simply portions of the spectrum. The very play of light is essentially a play of all the gorgeous hues of the rainbow, now flowing forth in the silver whiteness of the undivided beam,-now bursting into all the divisions, as when the beam passes through the prism,and now dispersing and regathering and wheeling fitfully out its diversities of ray, as when the beam is thrown over a cabinet of gems, or whirled into a re- 
volving kaleidoscope. Objects of fixed reirracting properties exhibit fixed colours, and objects of changeful refracting properties exhibit changing colours; the former class of objects abound most on the ground, and the latter class abound most in the air; and hence all the well-known beauteous characteristics of the tinting of land and cloud and sky.

But there is one prevalent arrangement in the general results of refraction which singularly combines magnificence with usefulness, and both with benignity. The violet ray of the sunbeams which break in their progress through the atmosphere,-that ray which develops the greatest quantity of heat, and which, if it came floodingly down, might fall on all breathing creatures with the suffocating warmth of a simoom, -is so easily and eminently refrangible, thatitgreatly deflects in the very highest regions of the air, and at length goes so far aside as very rarely to reach the ground, or become apparent to the eye. The indigo and the blue rays, which are next in refrangibility, go off at just so much less a slant, and at just so much lower an altitude, as to be commonly the highest rays visible, and therefore to form the predominant colour of the sky. And how superb is their azure, how luscious to the eye, how grand and fit a setting to the star-gems of the heavens! The green ray, situated in the middle of the spectrum, and the yellow ray; situated next to it, are the rays most abundantly reflected by the herbage of the ground and by the leaves of trees; and therefore they form the predominant dyes of the land's carpet,-- the verdure of luxuriant pastures and waving forests, and the creamy and golden hues of ripening corn,-_colours which at once contain the 
greatest amount of luminousness, and convey it with the greatest softness to the eye. The orange and the red rays, which are the least refrangible, can struggle through the air when all the other rays are flung oft or tilted up, and are able even to make a horizontal passage, in all their brilliance, from the face of the setting sun, among the dense atmospheric strata immediately incumbent on sea and land. Hence the gorgeous glories of a calm and clear sunset,- the magnificence of the evening " clouds which cradle near the sun,"-the masses of visible burnished vapour which refract the beams that fall on them, and float the while in the flood of the unbroken beams, like islands of gold in a sea of molten silver. Then

"Is the last sweet smile of the evening sun;

How bright, how sublime its beaming!

What golden tides of splendour steep

The rosy clouds as they softly sleep

Beneath its holy gleaming!"

The rainbow, "the airy child of vapour and the sun," consists of many millions of minute spectrums arranged in the circumference of a circle. It is formed only on a falling shower, when the sun is more than half-way down the sky, and is seen only by spectators situated between it and the sun. The rain-drops act as prisms, each one dispersing a pencil of sunlight into a spectrum; the background of dark cloud acts as a screen to receive the spectrums, and to reflect them back on spectators; and every eye which beholds the bow is in a direct line between the sun and the summit of the arch, so that each spectator secs a different set of spectrums from another, and sees them so 
aggregated on the curve of the sphere, as to form part. of a circle.

"Where rests that arch? How stands its form so true

Upon the darkening, gleaming, changing sky?

It rests upon thine own enchanted view,

Its central point thine own admiring eye.

The falling crystals in the showery air

Transmit the colours of the riven rays,

And build ten thousand separate arches there,

Around the charm'd ten thousand eyes that gaze."

When only bits of shower are before the spectator, only bits of bow are beheld; and when an entire shower of sufficient breadth and height is seen from a very elevated position, almost an entire circle of bow is beheld. A secondary bow somctimes forms exteriorly to the primary one, larger, fainter, and spanning the same centre, but always exhibiting the colours in the reverse order.

The rainbow charms all eyes, and adorns all landscapes, yet is supereminently beautiful, and surpassingly glorious, in a region of abruptly and stupendously tumulated surface. Any devout person who sees it over a snow-peak of the Alps, can scarcely fail to think of " the last rainbow o'er the skies-the emerald rainbow round the throne of God;" and perhaps all Christian voyagers who have beheld it amid the soaring volcanic isles of the Pacific Ocean, or on the mural mountains of the Norwegian sea-fiords, or at any similar blendings of the sublimities of cliff and ocean, may say, with Messrs Tyerman and Bennet_." The ground being heaved into enormous mountains, with steep and narrow dells between, the sun is continually faced by superb eminences on which 'the weary clouds oft 
labouring rest;' and showers fall many times in a day, accompanied by brilliant segments of the glorious arch which, under certain happy circumstances, may be seen bestriding the island itself from sea to sea, or resting one foot upon the sea, and the other on the earth, like the angel in the Apocalypse, who was himself 'clothed with a cloud, and had a rainbow over his head."

The rainbow, of course, existed as well before the general flood as after. It had ever been observed as "the bow in the clouds," and could never have failed to enrapture the antediluvians as the most gorgeous appearance in the heavens, and was no doubt identified in the minds of Noah's family with the onfall of rain, and probably had been seen vividly and long on the water-bursts which first descended at the judicial opening of "the windows of heaven." It was, therefore, with pre-eminent fitness, and with utmost pathos of appeal, "set" or appointed as the token of God's covenant with them, that he would never again overwhelm them in a flood. It stood like a bridge of glory connecting the world which had been destroyed with the world which still existed; and the message of the divine mercy, when coming down to proclaim hope to all future ages, appropriately "lighted in mid ether on its brilliant arch." And now, in its moral meaning to all generations, as truly as in its physical cause, it is a mingling of "rays from heaven with tears from earth."

"Such is the rainbow with its thousand dyes, Emblazon'd like a triumph on the skiesMajestic token of its Maker's might,

Pure zone of grace, grand coronal of light,

God's own blest hand-mark, mystic, full, sublime,

Graven in glory to the end of time." 
Rainbows of faint colour and imperfect development, and rainbows with the green colour awanting, or with the yellow and the blue scarcely perceptible, occur under deficient conditions of light or of refraction. Arches of unrefracted light, or what might be called white rainbows, have been seen, but are very uncommon. Rainbows at night, formed by the light of the moon, are exactly similar to rainbows in the day, but whitish, and less bright. Mist-bows appear on fogs. Sea-bows are frequent on the spray of waves, and are distinct and vivid, and usually occur many together, but have their convexity downward, and their ends upward, and are very brief and vanishing. Grass-bows abound on the morning dew of pastures, and flit onwards before an advancing spectator, and present their convex part to the eye, and have different curves according to the height of the sun, but are necessarily all very tiny and toyish. Spray-bows, as brilliant as the bow in the heavens, and always popularly called rainbows, overarch the fall of many cascades and cataracts, and constitute a very striking feature of their scenic power. The bow of the Alpbach waterfall, near Meyringen, is one of peculiar beautytriple, and very bright; the innermost iris almost a complete circle, and the two others more or less full according to the volume of the waters.

The sun, and the moon, and sometimes also clouds and fogs, are liable to make very extraordinary appearances in unusual refractions or diffraction of light. When the air is charged with dry exhalations, the sun sometimes looks as red as blood. When it is loaded with vapour, in a state approaching that of thin fog, he appears shorn of his beams, but presents a white 
silver-like disc. When vapours are afloat in the form which is technically called vesicular, and under conditions which are not uncommon in Italy, Africa, and the West Indies, they make the sun look blue. In certain humid states of the atmosphere, with the vapour foggy, and the clouds light and fleecy, the sun and moon are often encircled with one, two, or three, or even more coloured, plate-like rings; and in similar states, with the temperature so low as to freeze the vapour, and to aggregate it into snowy flakes, they sometimes display retinues or counterparts of very extraordinary or complicated glories, consisting of concentric circles, pillars, and broad beams of light radiating off from their circumference, and resemblances of their discs, or mocksuns and mockmoons, at the parts where the circles intersect.

Halos of the sun are sometimes very large and very brilliant, exhibiting the colours of the rainbow, and occasionally double or treble, and blending with the clouds; but they are of rare occurrence, and seldom can be well seen, except when reflected in a pool, or in a darkened mirror. Halos of the moon, especially whitish ones, are very common, aud usually indicate a coming change of weather. Beautiful small halos sometimes appear on certain kinds of clouds, and round the planet Venus. Coloured circles and radiations of the kind technically called glories, are occasionally seen round reflections of the human head; and they probably suggested to the painters of Roman Catholic countries those preternatural decorations with which they set off their pictures of saints. A company of travellers on the Andes once saw their shadows, each with three concentric rainbow rings round its 
head, and a great white circle encompassing the whole; and persons on the bridge of Perth, during an intense frost in the winter of 1820 , saw their shadows on the vapour which arose from the frozen river, each shadow of gigantic size, and environed by a halo with rainbow radiations. Aeronauts, too, when at great heights in the air, have seen their balloon reflected on the upper surface of clouds with three or more environing rings.

Mocksuns have commonly a very glorious appearance; and, though seldom seen in Britain, or in the warm parts of the world, they burst frequently forth in the polar regions, and rival there the most brilliant displays of the aurora borealis. They do not consist simply of plain counterparts of the sun, but comprise halos, luminous arcs, and broad radiating beams, studded with imitation sun-discs, and either lustrous with golden light, or steeped in all the dyes of the rainbow. Multitudes have been described, all different in arrangement, and some with few parts, and others with very many, but every one a magnificence and a wonder. No fewer than seven or nine sunimages, together with numerous circles and segments, to say nothing of other features, have been seen at one display; yet the most common number of sun-images is only one, or two, or three. The accompanying picture, representing an appearance which was seen in England, shows a halo with three sun-images, surmounted by an arc of an inverted rainbow. Mockmoons are less frequent than mocksuns, and, of course, occur only at night, and during moonshine; and never more than five moon-images, we believe, are recorded to have been seen on any one occasion. 


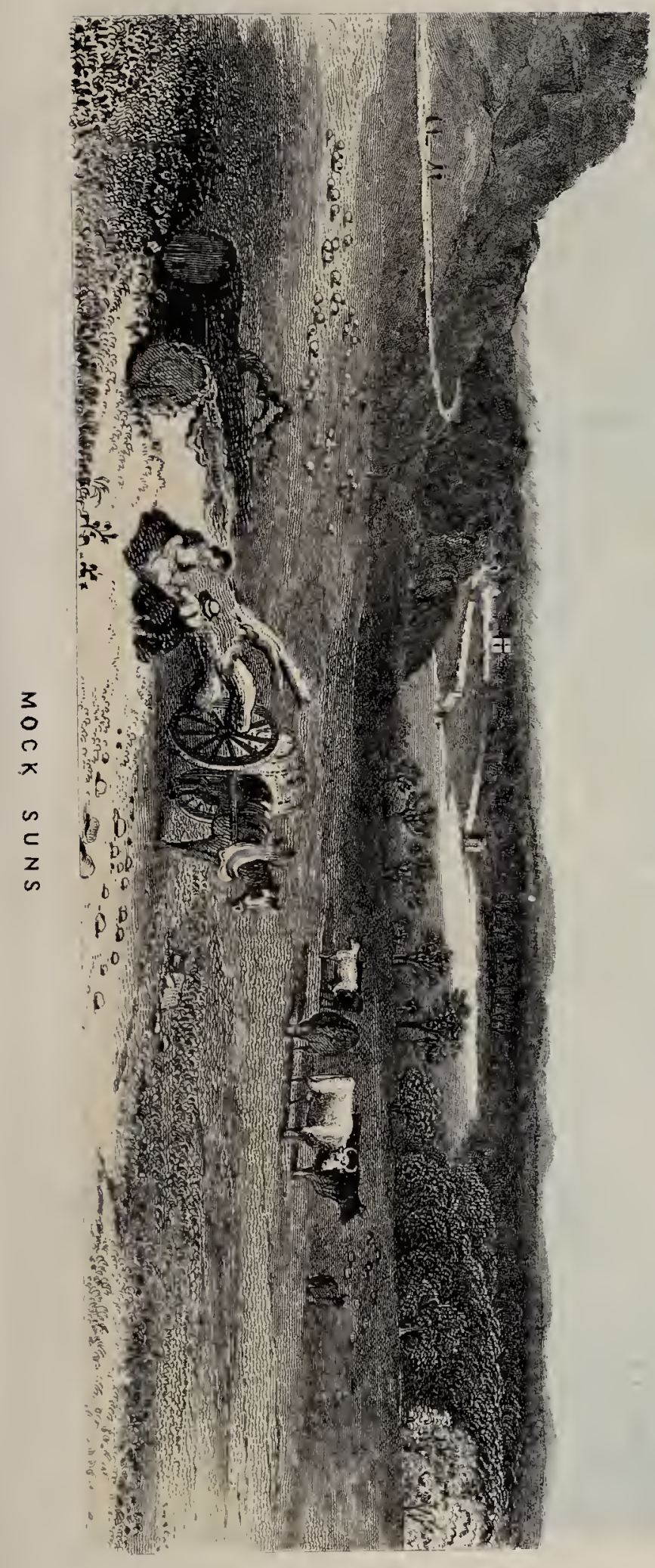



Terrestrial objects are sometimes imaged in the air or on the clouds in ways fully more remarkable than the celestial. Things at a distance suddenly look as if brought close to hand. Things on the ground look as if high in the air. Things small and low are magnified and exalted into things great and lofty. Beasts and men walking on a plain, are imaged into spectres careering on a mountain; or, moving on a mountain, are imaged into spectres gesticulating among the clouds. Ships appear double, with sometimes their image inverted. Mountain-tops seem to curve toward each other so as to form an arch. Expanses of arid desert look like ponds, or like an extensive lake. Icebergs and frozen coasts give off resemblances of cities and cultivated lands. And pieces of scenery, of ordinary character and limited extent, figure in aerial images as variedly and sumptuously as if they were a collection of models and master-specimens of the richest landscapes in the world.

Most or all of these appearances seem to ignorant persons entirely preternatural, and have given rise, in the regions where they occur, to many wild legends and superstitious fears. "In the names by which they are familiarly known," remarks Sir David Brewster, "we recognise the terror which they inspired; and even now, when science has reduced them to the level of natural phenomena, and developed the causes from which they arise, they still retain their primitive importance, and are watched by the philosopher with as intense an interest as when they were deemed the immediate effects of Divine power." Some are produced by very slight deviations from the ordinary reflections and refractions of light; some in ways exactly similar 
to the extraordinary appearances of the sun and the moon; and the rest by very unusual and irregular transmissions of light through atmospheric masses or strata of different density, or rather by very great, very unusual, and very irregular differences of density in the coadjacent portions of air through which the rays of light pass-differences occasioned either by local action from the ground below, or by extraordinary junctures in the many influences which form and rule the weather. Persons cannot perfectly understand these without getting some little linowledge of optics, and making some little study of diagrams; but let any man mark the transmutations and mockeries of his own facc, and of things around him, which are made by different kinds of mirrors, good and bad, and by different forms of bits of glass; and let him remember that what glass does to light, so also does air, and he will have small difficulty in imagining abundantly sufficient causes in nature for all the kinds of "spectral illusions" which have ever been seen.

During several hours on a summer's afternoon in 1798, the coast of France, from Calais to Dieppe, became distinctly and minutely visible at Hastings; and Dungeness, which was sixteen miles distant, seemed to be close at hand. In Sir James Ross's voyage in the Antarctic Ocean, he, by an extraordinary refraction, got a clear view of land which he had never really seen, and which was ascertained to be then about one hundred miles distant. On an autumn evening in 1806, Dover Castle, though situated far distant from Ramsgate, and nearly all hid by an adjacent hill, was seen from that place as fully and clearly as if it had been near, and as if no hill had intervened. 
Dr Vince, looking through a telescope at Ramsgate, observed the top-masts of a ship on the horizon, and at the same time two images of the complete ship straight above in the air, the lower image inverted, and the upper one erect. Captain Scoresby, when in the Greenland seas, once saw from the mast-head eighteen ships under curious refractions,-one vertically elongated, another vertically contracted, three with inverted images of themselves above them, and two of these three surmounted also with images of masses of ice. Messrs Jurine and Soret saw on the Lake of Geneva a little vessel sailing in one direction, and an image of it in the air gliding in another direction, and diminishing in apparent size as it receded. Many persons on the shore of the Sound near Copenhagen, during about an hour of a summer morning in 1846, saw the Swedish coast as if it were close under their eye, the island of Huen as if it were fleeing away and disappearing, and the ships at sea all inverted, with their keels in the air, and their mast-tops in the water.

Troops of soldiers and sections of armies, either marching or exercising, have been reflected on the clouds, or in mid-air, or on the precipices and peaks of mountains, not only at great distances from the ground on which they were moving, but sometimes on the further side of an intervening upland. In 1835, a bright vision, so distinct as to exhibit minute features of dress and trapping, figured on the Mendip Hills in Wiltshire, representing movements and evolutions of a large body of mounted soldiers with drawn swords, and was afterwards ascertained to be the reflection of a body of yeomanry exercising at a place about fifteen 
miles distant. In 1744 , a similar vision, remarkably distinct, and displaying minute and curious military marchings, was seen athwart the steep lofty acclivities of Souter-Fell; and, though never positively accounted for, it was, in all probability, the aerial image of parties of troops secretly practising in some recess among the neighbouring hills, preparatory to the insurrection of the following year. The instance mentioned by Josephus, that, one day before sunset, spectral chariots and armed men careered through the air over all Judea, and passed along the clouds round about Jerusalem, however truly it may be regarded as a fit and intended means in Divine Providence of awing the minds of the people, was no doubt a case of the same. kind, due entirely to unusual refraction of light. In other words, even when viewed as a special "sign" from heaven, the Divine Being seems to have caused it, not by creating the "spectres," or by throwing illusions on the eyes, but by putting portions of the air into a condition of unequal densities.

The fata morgana, seen in the Straits of Messina is a singularly romantic and very famous phenomenon. A spectator on an eminence behind the city of Reggio, with his back to the sun and his face to the sea, at a time when the sun is about half-way down the sky, and when the sea is smooth and in full tide, sees gleaming and flitting rapidly and distinctly on the water colonnades, arches, castles, towers, palaces, rows of balconied houses, groups of buildings, villages, groves, pastures, herds and flocks, crowds of pedestrians, men on horseback, and other features and blendings of grand, gorgeous, urban and rural landscape. In certain states of the atmosphere, these objects appear 
tinted and fringed with the colours of the rainbow; and, in other states, they appear dimly, and in mid air.

Visions similar to the fata morgana occasionally appear on the north-west coast of Ireland, among the islands of the Baltic, and in other parts of the world. But one of the most unique on record, if, indeed, it may not be assigned to a different class of refractions, was an image of Edinburgh seen, on an autumn day of 1846 , in the air over the town of Liverpool. The image continued nearly an hour, and had its figures erect, and was so distinct and true, that those of the spectators who had been in Edinburgh instantly and unmistakeably recognised the localities. It was the magnified reflection of a large, well-executed panoramic painting which was then being exhibited in the open air at the side of a pond in Liverpool Zoological Gardens.

A very beautiful appearance, called the enchanted coast, is sometimes seen in the polar regions, caused by a series of irregular compound refractions of a line of sea board, with its tumulated surface, its coating of snow, and its flanking of icebergs. Dr Scoresby thus describes an instance of it:- "The general telescopic appearance of the coast was that of an extensive ancient city, abounding with the ruins of castles, obelisks, churches, and monuments, with other large and conspicuous buildings. Some of the hills seemed to be surmounted with turrets, battlements, spires, and pinnacles; while others, subjected to one or two reflections, exhibited large masses of rock, apparently suspended in the air, at a considerable elevation above the actual termination of the mountains to which they referred. 
The whole exhibition was a grand phantasmagoria. Scarcely was any particular portion sketched before it totally disappeared. It was, perhaps, alternately a castle, a cathedral, or an obelisk; then, expanding horizontally, and coalescing with the adjoining hills, united the intermediate valleys, though some miles in width, by a bridge of a single arch of the most magnificent appearance and extent. Notwithstanding these repeated changes, the various figures represented had all the distinctness of reality; and not only the diffcrent strata, but also the veins of the rocks, with the wreaths of snow occupying ravines and fissures, formed sharp and distinct lines, and exhibited every appearance of the most perfect solidity."

The mirage of the desert is a refraction in calm heated air, presenting the appearance of water. It often occurs in the hot arid wastes of northern Africa and south-western Asia. It sometimes looks whitish, and somewhat like a morning mist, and can be readily understood by a practised observer; but at other times it has a tint of the purest azure, and clearly reflects the images of neighbouring heights, and cannot at all be discriminated, except by knowledge of the locality, from real water. It commonly appears at a distance of half a mile or upwards, but occasionally maintains all its illusiveness so near as two hundred paces. It looks sometimes like an inundation, sometimes like a chain of lakes, and sometimes like a fancy piece of water in an ornamented landscape; and, in certain states of the atmosphere and the temperature, it slowly rises into the air, and continues for a while in its ascent to carry distinctly on its mirror-bosom the inverted images of all things which overhang or overtop it. 
Parched and wearied travellers feel fearfully tantalised by it,-or sometimes are awestruck at the seeming arrest which it puts on their progress; and the French army, when in Egypt, though often and often witnessing it, never got accustomed to it, but continued from day to day to be misled by its illusions.

Shadows on mists and clouds are sometimes so enormously magnified, or so otherwise extraordinary, as to possess uncommon interest; but, of course, they can occur only when the sun is almost close to the horizon. Shadows of islands or of the tops of mountains have occasionally been seen so high as to look like terrestrial isolations far aloft in the air. Gigantic shadows of men and of moving things at great elevations have been taken by the superstitious as sanction for their notions about "wraiths," demons in the air, and all sorts of hobgoblinry. Some localities are remarkable for both the magnitude of such shadows and the wildness of the connected legends; and none more so than the Brocken, the highest of the Hartz Mountains, elevated about 3540 feet above sea-level. When, soon after sunrise, a cloud hangs in a clear sky about two miles to the west, a small inn on the top of the Brocken is shadowed on the cloud as a stupendous castle, and a spectator beside it as a colossus of five or six hundred feet in height. M. Haüy, who witnessed the phenomenon in 1797, and wrote it into great literary notoriety, says, "I observed at a great distance, towards a mountain, a human figure of a monstrous size. A violent gust of wind having almost carried away my hat, I clapped my hand to it, and the colossal figure did the same. I immediately made another movement by bending my body, and the co- 
lossal figure repeated it. I was desirous of doing the same thing once more, but my colossus had vanished. I remained in the same position, waiting to see whether it would return, and in a few minutes it again made its appearance. I paid my respects to it a second time, and it did the same to me. I then called the landlord of the Brocken, and we had not stood long when two such colossal figures were formed over the same mountain, which repeated our compliments by bending their bodies as we did; after which they vanished. We retained our position, kept our eyes fixed on the same spot, and in a short time the two figures again stood before us, and were joined by a third. Every movement that we made by bending our bodies, these figures imitated, but with this difference, that the phenomenon was sometimes weak and faint, sometimes strong and well-defined." The figures were evidently ordinary shadows, caused by the spectators standing direct between the sun and the cloud; and the third seems to have been a duplication of one of the others, caused by unequal refraction. Precisely similar things have been seen on Skiddaw, on Benlomond, and on other elevated spots in Britain.

We might now proceed to speak of the passage of light througb the humours of the eye,-of visuary illusions, - of accidental colours, - of the absorption of light,_- of the polarisation of light, —of the chemical action of light, - of its connection with heat and electricity,_-of photography, ${ }^{*}$ _- of optical instruments,_-and

* The photographic power is really as distinct from luminosity as heat is, and has received the name of actinism; yet will always be popularly regarded as identical with light, on account of its residing in the sunbeam. 
of the action of light on the life and growth and colours of plants and animals; and we should observe in each of these departments fresh occasions to admire devoutly and fervently the glory of the Infinite One who said, "Let there be light, and there was light." But though we have glanced at only reflections and refractions in the air, and have done no more than glanced at them, we have done enough to show that light has many wonders. Nor could we well rise higher on this subject without feeling induced to soar to its centre; and then everything around us would be "dark with excessive brightness." - Light, far more than anything else in nature, is sublime in moral analogies, and manifold and mighty in theological suggestions. Not only does it shed its effulgence on the general imagery of the Bible, and fling its rainbow arch on many a shower of inspired poetry, but it concentrates its rays on the Bible's lessons concerning the gospel and Christ and God. Hence do we read that "God is the Lord who hath showed us light," - - that Christ is " the true light which lighteth every man that cometh into the world," - that "God who commanded the light to shine out of darkness hath shined in his people's hearts, to give the light of the knowledge of the glory of Grod in the face of Jesus Christ," - that God "covereth himself with light as with a garment," - that he "dwelleth in light which no man can approach unto,"-that "God is light, and in him is no darkness at all." Yet, even apart from the immensities of its most sacred and divine associations, and regarded simply in its own proper nature, light is too wondrous a subject to be penetrated beyond the vestibule. For, after all that philosophers have learned about it, they are profoundly 
at variance as to what it is,-whether it be itsell something or only a property of something; and not a few of them can sympathise strongly with the spirit of Milton's address to it, even when entirely differing from him in sentiment:-

"Hail, holy Light, offspring of Heav'n first-born, Or of the eternal co-eternal beam; May I express thee unblamed? since God is Light, And never but in unapproached light Dwelt from eternity, dwelt then in thee, Bright effluence of bright essence increate. Or hear'st thou rather pure ethereal stream, Whose fountain who shall tell? Before the Sun, Before the Heav'ns thou wert, and at the voice Of God, as with a mantle, didst invest The rising world dark and deep, Won from the void and formless infinite." 


\section{CHAPTER IV.}

\section{ELECTRICITY.}

THE ORIGIN AND PROGRESS OF ELECTRICAL SCIENCE-THE ELECTRIC MACHINE-THE NATURE AND VARIETIES OF ELECTRICITY - LIGHTNING-THUNDER-BALL LIGHTNING-EXTRAORDINARY LIGHTNINGSTROKES-SHEET LIGHTNING-ELECTRIC METEORS-AURORA BOREALIS-SUMMARY VIEWS OF MANY OTHER WONDERS OF ELECTRICITY -THE GaLtanising OF a CORPSE.

WHAT electricity or the electric fluid is, no man knows. The earliest notion of it was obtained through amber, called by the Greeks electron, and by the Romans electrum. This substance was observed by the ancients to possess so curious a capacity that, by being rubbed, it became able to draw to itself, and to hold for a short while in suspension, any light loose substances, such as small pieces of feather, which happened to be in its vicinity. Many other substances, such as resins, gums, glass, sulphur, and silk, were in the course of time observed to possess the same capacity, and, in allusion to amber, were designated electrics. Their peculiar power-the power put into them by friction-was very long regarded as a mystery, an amusement, or a thing meresy to be wondered at; but eventually, it was accumulated in large quantity, and found to emit crackling sounds and sparkling light, and to give off smart instantaneous energetic shocks; and then it was 
assumed to be a distinct though obscure element, and called electricity.

The first thought of any consequence which occurred in connection with it was to use it for the cure of diseases. A particular kind of friction machine was constructed for obtaining quantities of it at will, and for pouring them upon invalids at a touch; and this acquired rapid, general overtowering fame as one of the grandest inventions ever known in the healing art,but was so abused by quacks, and so enormously overestimated by physicians, that it soon became little more than a means of philosophic experiment. In this character, however, it led the way to amazing discoveries. The power obtained by it was easily proved to be got out of the ground; for, when the machine stood on any substance which could not become electrically affected by friction, it was useless; and ever while standing on the ground, it retained all its susceptibility. Either the crust of the earth, or perhaps the solid globe, was hence inferred to be one vast reservoir of electricity. A suspicion by and by arose that the air is full of it too, or at least that the lightning of thunderstorms and the crackling, sparkling, energetic power of the electric machine, were the same thing; and this suspicion was traced on to truth, in a series of masterly experiments, by several distinguished philosophers of Europe, and most of all by the celebrated Franklin of America. Electricity henceforth was recognised as a grand agent in weather,and particularly as the presiding power in thunderstorms, sultriness, and outbursts of typhoon and hurricane; and, in the course of later, manifold, and highly curious investigations, it came to be identified also- 
at least as to its cssential characteristics, though under great differences of intensity and of some other characters, with several sorts of luminous appearances in the air, with the furmation of hail-showers, with the occasional luminosity of fogs and snow, with the peculiar power of magnets, with the peculiar power of the galvanic pile or voltaic battery, with certain energies of steam and gun-cotton and other remarkable things or conditions of things, and with the subtle agencies over animal physiology and animal life which have obtained the designations of mesmerism, electro-biology, animal magnetism, and odyle.

Still no man can tell what electricity is. It may be a material fluid of the closest possible similarity which a material thing can possess to an immaterial,and therefore prodigiously versatile, prodigiously subtle, and without any appreciable weight; or it may be two such fluids, most curiously related to each other, yet mutually repulsive, and rushing off to opposite poles. It may be a substance or substances strictly peculiar; or it may be a primal element identical in some way with the matter of light and heat, and possibly als with the matter of some of those seemingly undecomposable things which chemists call elements. Or it may be not a fluid or substance or primal element at all, but only a condition of sometling else so subtle and recondite as hitherto to have escaped all detection or recognition by man. Yet here is a wonder that, nevertheless, it displays itself to all eyes, and works magnificently and mightily as one of the sublimest powers of nature, and behaves according to laws of the most perfect precision and not difficult to be ascertained, and is altogether as well known by its 
properties and effects as many of the grossest substances which lie thoroughly open to man's investigation. And another wonder is that, in spite of all diversities of character, it is essentially and absolutely the same in the crashing thunderbolt, the beauteous aurora, and the tiny machine-spark, - the same in the tornado, the magnet, and the dewdrop,- the same in shivering the lightning-rod, in playing on the mariner's compass, and in gliding along the telegraphic wire,- the same in creating a hail-storm, in producing an electrotype, in mesmerising a man, and in convulsing a corpse.

Lightning leaps either from cloud to cloud, from clouds to the ground, or from the ground into the air. It sometimes flashes without showing any precise form; sometimes forks or runs zigzag, with sharply defined outline; sometimes leaps crookedly and obliquely, and goes to pieces like a broken chain; and sometimes rolls along the ground in a series of balls, or with a continuous glow. The flashes occur most commonly in leaps from cloud to cloud; the forkings, in leaps from clouds to the ground; and the obliquities and chain-like appearances, in leaps from the ground into the air. The ball lightning is the only kind which does not evanish at a glance; and probably owes its more than instantary duration to a continuous series of discliarges from a moving cloud.

All lightnings-as also other evolutions of electricity which are not visible to observers-make sudden and overwhelming upsets among the clouds, and all therefore affect the world of plants and animals through the medium of onfalls, winds, and other changes of weather. But only lightning which leaps to the ground is dangerous, or answers to the popular idea 
of a thunderbolt; and this is truly terrible. Nothing can withstand its power. It splits rocks, shivers strong masonry, fuses metals, and rends and scatter's the strongest timber. Some rare curious tubes occur in sandy districts, resembling perpendicular pipes of a glassy texture, an inch or more in diameter, and traceable, in at least one recorded instance, to a depth of more than thirty feet; and all such tubes are believed to be instantaneously formed by the dive of thunderbolts penetrating the earth, and vitrifying the flinty sand through which they pass. Yet how comparatively few disasters occur from lightning-strokes, and how easily might most be averted by the use of obvious and well-known precautions!

Thunder accompanies lightning on the same principle that booming and reverberation accompany the firing of a gun among mountains. A loud sound arises from the sudden violent compression of the air; and is variously echoed by the opposed surfaces of land and clouds. The inconceivable velocity of the lightning occasions the flash to be instantaneously seen, no matter how far off; and the slow velocity of sound prevents the first pulse of the resulting thunder from being heard sooner than at the rate of a second for every intervening distance of three hundred and eighty yards. The longest observed interval between the flash and the peal is seventy-two seconds,equal to a distance of about fifteen miles. The loudness of a peal depends not on nearness only, but on the strength of the discharge, and on the extent and form of the echoing surfaces, and the character of the reverberation, whether long or short, and whether cadence or crash or roll, depends on the direction in 
which the lightning runs. When the flash moves in a straight line away from the observer, the peal is a dying cadence; when the flash moves in a straight line toward him, whether directly or obliquely, the peal is an increasing cadence; when the flash moves in a circular curve around him, the peal is a crash; when the flash moves zigzagly, either away from him or toward him, the peal is a rolling or perhaps leaping series; and when the flash moves very irregularly in forkings and deflections, the peal is a combination of two or more of these characters.

Allusions to thunder embellish every language, and every style of speech; but all are excelled by one brief utterance of the Bible, "The God of glory thundereth." Descriptions of thunder-storms, also, have taxed the highest powers of almost every great poet; but what are they all, in either moral power or poetical sublimity, compared to the few words, "The voice of the Lord divideth the flames of fire, the voice of the Lord shaketh the wilderness; the Lord shaketh the wilderness of Kadesh ?"

Ball lightning makes many kinds of appearances, and is sometimes accompanied with very singular evolutions of cloud and tempest. A common variety occurs in some ordinary thunder-storms, running with great velocity along the ground, and is always very dangerous, setting on fire corn-ricks or other combustible matters in its way, and instantly killing sheep or cattle or men whom it may strike. But the most curious and most destructive varieties are very rare.

In an autumnal night of 1772 , an extraordinary cloud enveloped a mountain in the island of Java, emitted booming thunders similar to the reports of 
artillery, rolled down the declivities to a thicklypeopled region below, evolved balls of lightning so many and vivid as to illumine all the local sky, formed a thick fog around the people like foldings of gauze or muslin, carried them up and down and hither and thither in the manner of the tumblings of a troughy sea, and inflicted desolation on fields and houses, and death on flocks and men, over a tract of about twenty miles. Plantations were uprooted, buildings of every kind overthrown, multitudes of cattle and horses and goats and other animals destroyed, and upwards of two thousand human beings killed.

In a December afternoon of 1846 , at about a mile from the shore, near the southern extremity of Cornwall, while four waterspout-whirlwinds near the place were just about expending their force, a pillar of 'ightning, exceedingly vivid, and apparently about the girth of a man's arm, sprang suddenly from the sea, dispread itself at the top in brilliant corruscations, and sent off a peal of thunder so loud and awful as to seem to all who heard it for several miles distant like the sound of "the last trump." The shock of the ground for some way on the coast made many persons reel, and threw some off their balance; and the peal seemed to miners at the depth of forty-four fathoms below the surface precisely similar to the terrible rumble which accompanies an earthqualie.

In an October night of 1767, a great black cloud approached the city of Melita or Malta, in the island of the same name in the Mediterranean,-gradually changed its appearance, till it became like a mass of bright flame mingled with murky smoke,-emitted thundrous sounds, which waxed louder and louder, ar.d 
aroused all the sleeping inhabitants, and struck terror into all who were awake,-passed over a part of the city and over the harbour, overwhelming all edifices - in its path, shattering and sinking boats and ships, and killing nearly two hundrec. human beings,-and then mounted aloft with a tremendous peal, and thoated over to Sicily, and there renewed on a small scale its devastating fury.

A peculiar flash, accompanied by a peculiar peal, sometimes springs from the hither end of a common thunder-cloud which has just made its main discharge from the further end. This seems to be in some sense a rebound, and is technically called the backstroke; and it may occur at the distance of several miles from the main discharge, and is usually more dan srous, and much more startling, than the direct thunderbolt. In some of the finest climates, where sound travels far and under choice conditions, thunder is occasionally heard when no lightning is seen, no clouds are visible, and no indication of electric disturbance whatever, except the thunder itself, can be discerned; and then it rolls sweetly and softly, far aloft, in the calm blue sky, sounding like the bass of the unheard "music of the spheres." And in our climate, whenever a flash is so large and high as to be seen a very long way off, and the resultant peal so intercepted by humidity or heights or distance as not to be able to travel equally far, we have the opposite phenomenon of lightning without thunder. And akin to this is the sudden silvery outsplash, resembling a momentary concentration of many moonbeams, and popularly called sheet lightning,which, in some cases, may be the sideward reflection of a thunder-storm in the distance, and in other cases 


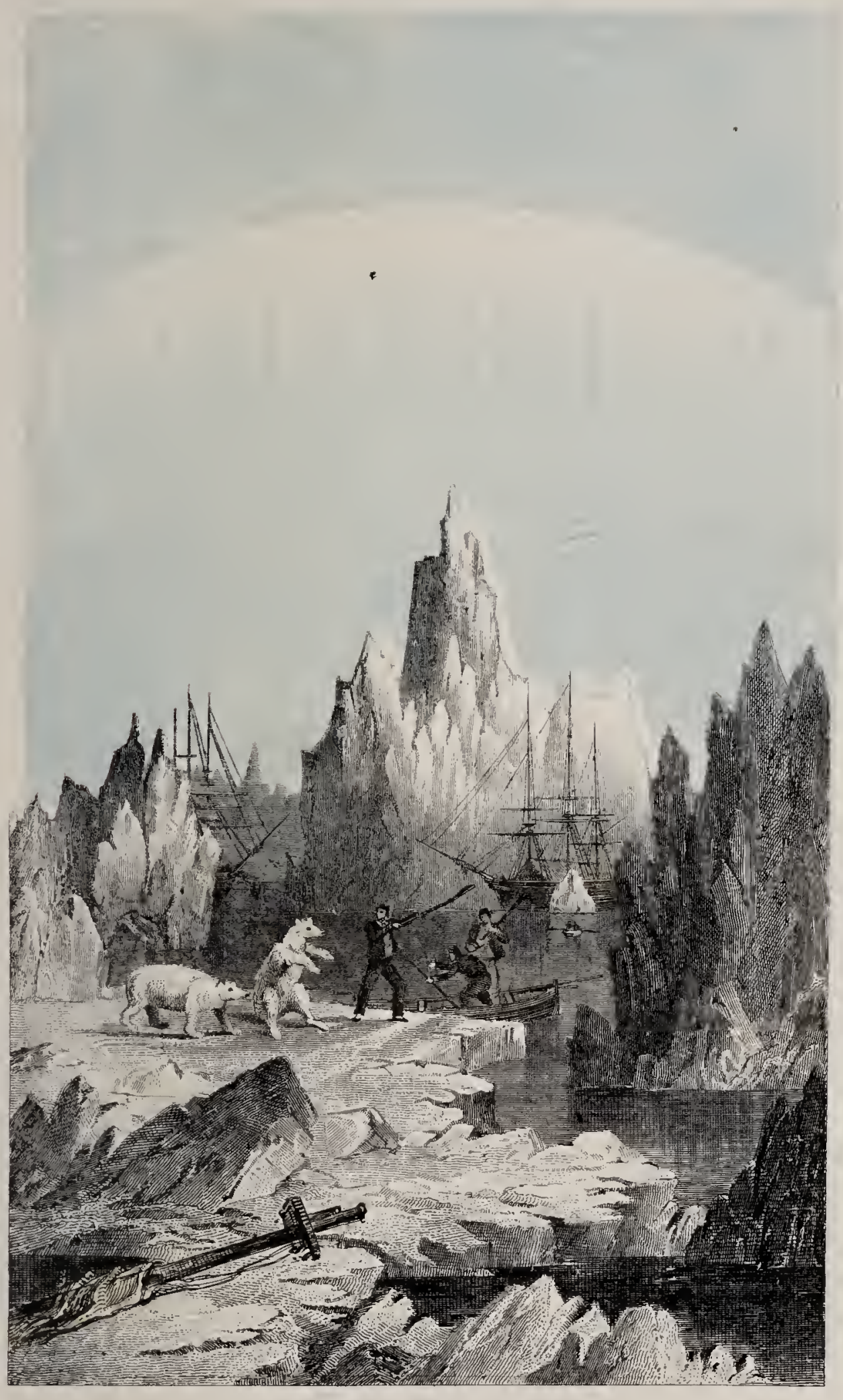

AURORA BOREALIS 

may be the downward reflection of a flash darting aloft from the upper surface of a large cloud, and in all cases is a simple smile on the cheek of heaven, unattended by anything to frighten or chastise.

Brilliant and beautiful electric meteors often occur, and comprise many varieties. One which plays as a brilliant light, or sometimes as a pale phosphorescent flame, on the tops of the masts of ships at sea, has been famous ever since the ancient classic times, and is now commonly called St Elmo's Fire. And many curious kinds, somewhat similar to this in certain states of the atmosphere and the clouds, are seen on the tops of spires, on the tips of whips and of bayonets, on the ears of horses, and on the fingers, whiskers, and hair of men.

But by far the most gorgeous electric meteor is the aurora borealis. This is frequent in the arctic regions, and enlivens there the long absence of the sun; but occasionally occurs also, in all its glory, in lower latitudes. It flits and flickers, shoots and streams, shakes and corruscates, moves now slowly and now briskly, at one time majestically and at another fantastically; and it is never in complete repose, and always delights the eye as much by the variety of its motions as by the brilliance of its lights. It has likewise great diversity of colour and form. It varies from a silvery whiteness to a smoky black, from a deep yellow to a steel grey, from orange to violet, and from russet brown to fiery red; and in its grandest occurrences, it combines or alternates these and many intermediate tints in one long variegated ever-changing display. It sometimes looks like little else than the sweep of a comet's tail near the horizon; sometimes appears only as nebulnus masses, or curdled light patches, or broad 
luminous bands, a short way up the sky; sometimes comprises streaks and beams and streamers, springing from transparent fogs or curious sky-banks, and mounting over a fourth or a third or a half of the heavens; sometimes almost an entire truncated cone of glory, filling most of the hemisphere from near the horizon to near the zenith,_but occasionally with a curious gloomy segment, affording a vista-view of the stars; and sometimes a perfect truncated cone, perfect at least in its middle and upper parts, terminating at the magnetic zenith either in a brilliant wreath like a crown, called the corona borealis, or in a dark oval opening, fringed all round with luminosity, and seeming to even the most unpoetic observer like the eye of Omniscience gazing on the world. It is commonly charming and inspiriting, but occasionally arousing and impressive, and in rare instances awfully solemnising. But always it gives light, and often is brightly illuminating; and never does it fail to strike both savan and savage as a brilliant wonder of nature. And many persons, when beholding it, are ready to exclaim with the Russian Lomonosov,-

"What fills with dazzling beams the illumined air ?

What wakes the flames that light the firmament The lightning's flash: there is no thunder there,

And heaven and earth with fiery sheets are blent;

The winter's night now gleams with brighter, lovelier ray, -Than ever yet adorn'd the golden summer's day.

Is there some vast, some hidden magazine,

Where the gross darkness flames of fire supplies? Some phosphorous fabric, which the mountains screen,

Whose clouds of light above those mountains rise? Where the winds rattle loud around the foaming sea, And lift the waves to hearen in thundering revelry ?" 
Many theories have been promulged respecting the aurora borealis. . Some of the most recent and bestargued ones ascribe it to magneto-electricity, or regard it as a magnetic storm; and a very recent and highly plausible one by M. de la Rive supposes it to be an effect of electric currents in particular conditions of the atmosphere. "When the sun," says M. de la Rive, "having passed into the southern hemisphere, no longer heats so much our hemisphere, the aqueous vapours which have accumulated during the summer in this part of the atmosphere begin to condense, the lind of humid cap enveloping the polar regions extends more and more, and facilitates the passage of the electricity accumulated in the upper portions of the air. But in thesc elevated regions, and especially at this period of the year, the aqueous vapours must most frequently pass into the state of minute particles of ice or snow floating in the air, similar to those which give rise to the halos; they form, as it were, a kind of semi-transparent mist. Now these half-frozen fogs conduct the electricity to the surface of the earth near the pole, and are at the same time illumined by these currents or electric discharges. In fact, all observers agree in asserting that the aurora borealis is constantly preceded by a mist which rises from the pole, and the margins of which less dense than the remainder are coloured the first; and indeed it is very frequent near the pole in the winter months, and especially in those where there is abundance of vapour in the air. For it to be visible at great distances from the pole, it is necessary that these clouds, composed of frozen particles, extend in an almost uninterrupted manner from the polar regions to somewhat southern latitudes, 
which must be of rare occurrence. These same clouds, when they are partial, which is frequently the case, produce the halos."

We might now go on to speak of the identities and differences of respectively free electricity, magnetic electricity, galvanic electricity, and steam electricity, --the action of free electricity on the gases and currents and meteors of the air,- the reciprocations of free electricity between the atmosphere and the ground, particularly through the tops of thorns, leaves, grasses, mosses, and all the other pointed forms of vegetation, - the lights and colours and odours and sounds which accompany different kinds of electrical discharge,the experiences and perils undergone from free electricity by experimenters and travellers,- - the character of the world as all one stupendous magnet,- the properties and actions of magnetic bars and magnetic needles,- the stroke of the torpedo, of the electric eel, and of other electrifying creatures,- the action of electricity, free, magnetic, and galvanic, on living plants and animals, - the structure and power of the galvanic battery,- the agency of electric sparks and currents in decomposing and recombining mineral, liquid, and gaseous substances, - - the application of electricity to such purposes as the electric telegraph, the electric clock, the electro-type, the lighting of rooms, and the propelling of machines,-and the electric influences of such things as voltaic ignition, the connection of magnetism and the will, the galvanizing of patients, the mesmeric sleep, and the producing of extraordinary effects on men's senses and consciousness by the power of magnets, and by inappreciable electric currents. All these matters, as well as many 
others of kindred nature, are full of wonders, and intensely interesting. But they would require more lengthened statements than our limits will permit; and some also are not entirely within our sphere-being so essentially connected with artificial apparatus and human effort, as to be but partly wonders of nature, and very largely wonders of art. Yet one instance, considerably different from all, and quite as curious as any: may be given by way of specimen. It is the power which galvanic electricity possesses to contract the muscles and convulse the body of dead animals. And this might be illustrated by multitudes of experimental instances-and, among others, bysome on frogs, which first brought this kind of electricity into notice -but will be seen with most startling interest in a brief detail of the far-famed case of Dr Ure's operations on the body of the executed murderer Clydesdalc.

The case occurred at Glasgow; and we shall detail it in the words of Dr Aitken, in his "Elements of Physiology:"- "Clydesdale was a powerfal, middlesized man, about thirty years of age. After being suspended from the gallows about an hour, having had no convulsive struggles when he dropped, he was carried to the anatomical theatre about ten minutes after he was cut down. His face had a perfectly natural appearance, without lividity or swelling; neither had the neck been dislocated. An incision was immediately made in the nape of the neck, in order to expose the spinal marrow. The principal nerve of the thigh was laid bare on the left hip, and a small cut was also made in the heel; from neither incision did any blood flow. A pointed rod, connected with one 
end of a powerful galvanic battery, was brought in contact with the spinal marrow; while a similar rod, connected with the other end of the battery, was applied to the nerve at the hip. Every muscle of the body was immediately agitated with convulsive movements, resembling a violent shuddering from cold, the left side being most powerfully affected. On removing the rod from the hip to the heel, the knee being previously bent, the leg was thrown out with such violence, as nearly to overturn one of the assistants, who in vain attempted to prevent its extension.

"In order to excite the movements of breathing, the nerve of the diaphragm (the principal muscle of respiration) was exposed in the neck, and one of the rods applied to it, while the other was brought in contact with the diaphragm through an incision made under the seventh rib. On the circuit being completed, the diaphragm instantly contracted, but with no great force. 'Satisfied,' says Dr Ure, 'from ample experience on the living body, that more powerful effects can be produced in galvanic excitation by leaving the extreme communicating rods in close contact with the parts to be operated on, while the electric chain or circuit is completed by running the ends of the wires along the top of the plates in the last trough of either pole, the other wire being steadily immersed in the last cell of the opposite pole, I had immediately recourse to this method. The success of it was truly wonderful. Fül, nay, laborious breathing instantly commenced. The chest heaved and fell, the belly was protruded, and again collapsed, with the relaxing and retiring diaphragm. The process was continued without interruption as long as I continued the electric 
discharges. In the judgment of many scientific gentlemen who witnessed the scene, this respiratory experiment was perhaps the most striking ever made with a philosophical apparatus. Let it also be remembered, that, for full half an hour before this period, the body had been well nigh drained of its blood, and the spinal marrow severely lacerated. No pulsation could be perceived meanwhile at the heart or wrist; but it may be supposed, that, but for the evacuation of the blood, the essential stimulus of that organ, this phenomenon might also have occurred.'

"In a third experiment, the nerve of the forehead was exposed, and one of the rods applied to it, the other to the heel. Dr Ure says:- ' Every muscle of the face was thrown into fearful agitation. Rage, horror, despair, anguish, and ghastly smiles, united their hideous expressions in the murderer's face, surpassing far the wildest representations of a Fuseli or a Kean. At this period, several of the spectators were forced to leave the room from terror or sickness, and one gentleman fainted.' The last experiment consisted in transmitting the electricity from the spinal marrow in the neck to one of the principal nerves of the arm at the elbow, when the fingers moved quickly like those of a violin-player; and an assistant who tried to close the fist, found that the hand was forcibly opened, in spite of every effort to prevent it. When the rod was applied to a slight cut on the tip of the fore-finger, the fist being closed, the finger was instantly extended, and, from the convulsive movements of the arm, he seemed to point to different spectators, some of whom thought he liad come to life." 


\section{CHAPTER V.}

\section{CHEMICAL ACTION.}

DEFINITION OF CHEMICAL ACTION-HEAT-ATMOSPHERIC TEMPERATURE-CHEMICAL AFFINITY-DIVINE AGENCY IN CHEMICAL CHANGES -LAWS OH CHEMICAL COMBINATION-CGHEMICAL BEHAVIOUR OF OXYGEN, OF NITROGEN, OF HYDROGEN, OF CHLORINE, OF CARBONIC $\Lambda C I D$, OF WATER, AND OF OTHER SUBSTANCES-CHEMICAL TRANSMUTATIONS OF COLOUR-NATURAL "FIELDS OF FIRE" AND BURNING SPRINGS-IGNIS FATUUS-PHOSPHORESCENCE.

Whatever turus two or more substances into one of a different nature, or so alters one substance as to give it a new set of properties, is called chemical action. Two things which have a good deal to do with it are light and electricity; and a third is heat. These three things, indeed, as we have already hinted, are very intimately connected with one another, and possibly may be found, in the future progress of discovery, to be only different conditions or different emanations of some extremely subtle primal power which effects and controls all sorts of changes among the particles of matter.

Heat is evolved in a primary or originating way from the sun's rays, and from electric action; and in a secondary or liberating way from burning, striking, rubbing, and some kinds of mixing. It is usually imagined to consist of molecules. which repel one another, and are attracted by all other substances. It 
always increases the bulk, but never the weight, of the things which it enters; yet expands different kinds of things, and different conditions of the same thing, in widely different degrees. An augmentation of it, more or less, in most known solids, converts them into liquids, - and in liquids, converts them into gases; and vice versa, the withdrawal of it, more or less, from most known gases, converts them into liquids, - and from liquids, converts them into solids. It is, therefore, the grand agent, whatever else may be a means, in all liquefactions, evaporations, and rarefactions; and conversely, or by diminution, in all condensations, congelations, freezings, and solidifications. Cold is simply the negation of heat; and what is powerful cold to one substance, as estimated by condensing or freezing effects, is mild or high heat to another.

The heat of the atmosphere, with exceptions which are trivial, and do not act steadily, is derived altogether from the sun's beams; and as these, for the most part, especially in clear climes and cloudless weather, do not divide into their component rays till they reach the ground, their heat is set free principally in the course of contact with sea and land, and particularly with herbage and earths. This is the reason why the atmosphere is warmer in the lower strata than in the higher, and in valleys than on mountains; and, together with the comparative directness or deflectedness of the line in which the beams descend in different latitudes, and at different hours, it is the reason also why the atmosphere is warmer in the torrid zone than in the temperate zones, and in three or four hours after mid-day than in the morning or in the evening. The air immediately over the ground raceives ail the 
developed heat, and undergoes continual replacement by cooler air from above; and the ground accumulates heat by excess of the quantity which it receives over the quantity which it "gives off, from sunrise till a maximum about two hours or so after noon. Hence, what is called the temperature of the atmosphereone of the grandest agents in its many magnificent wonders -is simply its ever-varying perceptible heat in different latitudes, altitudes, humidities, hours, and seasons. But the comparative amount of this at any place and moment, or the degrees and fluctuations of it in general, can be ascertained only by means of regularly expansible substances, such as the alcohol and the mercury employed in thermometers, and not at all by man's sensations; for what is a cold temperature of either air or anything else to a man in one set of circumstances, is a hot one to him in another; and even the same temperature-for example, of a basin of river water-may be cold to his right hand, which he has just been holding before a fire, and hot to his left one, with which he has just been handling snow.

Heat, under certain conditions, goes so into combination with substances as to become incapable of detection by either the senses or the thermometer, and is then said to be latent. A vast quantity of it, for instance, combines with melting ice or melting snow, in order to give it the steady form of water; and a still vaster quantity combines with vapourising or with boiling water, in order to give it the steady form of vapour; and all these quantities are again let loose when respectively the vapour resolves into rain, and the water solidifies into ice. Hence the curious fact that the air is much chiller during the commencement 
of a thaw than during the commencement of a frost; for, in the former case, it is losing the enormous quantities of heat which are going into combination with the melting ice or snow, while in the latter it is gaining just the same quantities which are coming out of combination with the freezing water. And, in general, whenever substances of any kind retain comparatively expanded forms with ordinary or comparatively low temperatures, they so hold quantities of heat in combination as to let not a particle of it out to any object which touches them, and then all at once let much or all of it go free under any process which suddenly reduces their bulk. Even a piece of cold metal, quite irrespective of the heat which it can take in and give out in rises and falls of temperature, possesses so large an amount of latent heat as to set free a perceptible quantity at every stroke of a hammer. And when equal measures of cold water and cold oil of vitriol are suddenly mixed, they jointly assume not a very great deal less bulk than the two measures, and yet develop so much heat as to set the mixture a-boiling.

The force which effects chemical action between two or more elements or substances, so as to transmute them into another substance with other properties, is called chemical affinity. But whether this be sometimes almost identical with heat, sometimes almost identical with electricity, sometimes almost identical with light, or always a primal power comprising all the three, or always a peculiar force different from them all, and only using them as means, or even a correlation between some pervading force over all things, and a various capacity in things themselves to 
accept its action, no mortal can tell. Be it what it may, it governs inanimate substances as mightily as life governs animated beings, and also according to as fixed and manifest laws, and also as wondrously, as wisely, as benignantly, and as mysteriously; so that, in the true, calm, ultimate view of chemical affinity, as in the true, calm, ultimate view of life, we must simply pronounce it the expression or working of the will of God.

Some substances have no observed affinity for one another, or have never been known to combine; some have but a chary affinity for one another, or combine only in extraordinary circumstances; and some have a very keen affinity for one another, or leap into combination wherever and however they meet. One can combine with only a few others; another can combine with multitudes; and almost every one has such a scale of likings, that it comes out of a first substance in order to go into a second, and out of a second in order to go into a third. Some things, as in the rusting of iron and in the decay of timber, combine slowly, and without any display; and other things, as in the burning of oil and in the exploding of gunpowder, combine rapidly or instantaneously, and with grand appeals to the senses. Some combinations look like annihilations, converting solid substances into imperceptible gases; others look like creations, converting imperceptible gases into liquids or powders; and multitudes look like deeds of magic, totally changing consistencies, forms, colours, odours, sapidities, and all other classes of observable properties. Hundreds of these magnificent changes go on in the common processes of kitchens and factories, and fail to be universally striking solely on account of being universally 
familiar. Thousands are performed in laboratories, some by way of experiment, some in the course of making drugs, and many so select and curious, as to dazzle and transport spectators who for the first time behold them. And millions, quite as beautiful, and generally far more complex, yet commonly slow, and rather wooing the attention of the wise than provoking the astonishment of the vulgar, are constantly going on in the air, in the sea, in the soil, in plants, in animals, in all the processes of growth, fructification, and decay, and in all the countless interchanges of dependence among the beings, and classes, and kingdoms of material things.

Who can tell the number of these changes? Who can estimate their aggregate force, their mutual intricacies, their all-pervading connection with the sustenance of the world, and of everything which the world contains? Only omniscience. Nor can less than omnipotence keep them going, or less than infinite wisdom adjust them to their ends, or less than divine love clothe them all and ever with their gladsome beneficence. A trivial blunder in the mimic laboratory of a chemist, such as the ill-timing of a mixture, or a little too much heat, has sometimes utterly smashed both process and apparatus, or blown the whole laboratory, chemist and all, into the air. But not an error, not a derangement, not a trace of the remotest mishap, ever occurs, or can occur, in the stupendous laboratory of the world. The worker here was also the maker. He who re-arranges the elements and substances here also created them. He who makes changes here gives every change both its origin and its commission. And he is "wonderful in counsel, 
and excellent in working," and does all things "according to the counsel of his own will." "He is of one mind and who can turn him?"

Chcmists can do no more than look earnestly into the open parts of the earth's laboratory, and draw inferences respecting its methods and laws, and imitate humbly and tinily the simplest kinds of its processes. They sce but a bricf way, and very obscurely; into any one of a thousand of its common complex operations. They are only now in profound study of such a thing as the forming of flesh and fruits, and know next to nothing concerning so seemingly plain a process as putrcfaction. Yet they have made many discoverics respecting the affinitics, and proportions, and properties of substances which sublimely illustrate the calm bcauty, and perfect order, and surpassing goodliness of the cvcr-changeful earth. And one of these may be quoted, both as a specimen of all, and as a grand illustration of chcmical action. It is this, that, whenever two substances combine in different proportions to form two or morc compounds, their proportions of second combination, and of every subsequent combination; are always an exact multiple of the proportions of the first. And this most beauteous law, together with a well-evinced theory respecting the ultimate particles of matter, has rendered chcmistry a science of calculation; so that all its masses of information, as to the myriad millions of changes which are continually in progress around us, takc the superbly interesting shape of arithmetical formulx. The chemistry of nature a mazy chaos, and yet a thing of arithmetic! Surcly here, as cvcrywhere in the wonderteeming universe, is the manifestation of Deity. un- 
searehable to a seraph, and at the same time revcaling itself to a ehild!

But we must give some details of ehemieal action; and we shall first instanee it in oxygen. This has litherto proved ineapablc of resolution into anything simpler than itself, and is therefore what the ehemists call an element. It is a eolourless, odourless, tasteless gas, rather heavier than eommon air. It nowhere exists in large quantity, out of eombination or out of mixture, yet can be casily separated by artificial means, and is eonstantly gushing in million-billion mimic streams throughout the processes of nature. It is one of the most abundant substanees in the world, and performs a thousand offices in every department of its ehemistry. It exists in mixture with nitrogen gas and carbonic aeid gas. to constitute about one-fifth of all the atmosphere. It cxists in combination with hydrogen gas to eonstitute about nine-tenths by weight of all water. It exists in eombination with almost all the metals, and with some other elements, to constitute not much less than one-fourth by weight of all the solid globe. It attaeks all sorts of substanees, and unites with them into all sorts of compounds. It comes freely and cverywhere out of eonditions, such as those of mixture in the atmosphere and in the sea, which are requisite to the ever-shifting ehanges of well-being on the world's surface; and comes most reluetantly, or ean with utmost diffieulty be made to come at all, out of eonditions, suel as those of combination with some of the ehief metals, which are requisite to the roek-inertia and unaltering stability of the world's interior. It unites eoyly with some things, and most keenly with others. It forms acids, earths. 
alkalies-is present in vitriol, sugar, soda, and in every bubble of aerated water, and every grain of marble. It supports the brcath of all breathing creatures, pervades the juices of all plants, and sustains the fire and flame of all burning things.

The oxygen of the atmosphere is prevented by the gases which are in mixture with it from acting with undue strength, yet is always and everywhere so infinitesimally diffused as to have ample scope for performing all its offices. It is evcr combining with carbon in the lungs of living animals, and therefore is ever generating there what is called animal heat. It is ever combining with things in the soil to prepare the food of plants; and ever combining with things within the plants themselves to carry on their growth, and flowering, and seeding. It is ever, in all burning of coal, and timber, and turf, and coal-gas, and oil, and tallow, combining with the carbon of these substances to form carbonic acid gas, and with their hydrogen to form watery vapour, and is all the while evolving heat and flame for our domestic and manufacturing uses. But if it existed in much larger proportion in the atmosphere, or could get readily out of its combinations with earths and rocks, it would attack all the three kingdoms of nature-animal, vegetable, and mineral-with excessive energy, and would speedily overwhelm them. An animal immersed in undiluted oxygen feels for a time high strength and lofty buoyancy, but has not system and resource enough to wear well under its stimulus. A lighted taper let down into a glass jar of it, burns with intolerable brilliance, and gives off uncommon heat; and an iron wire in the same situation, with the tip previously heated, bursts into 
dazzling flame, burns with intense and vivid light, and consumes away in blaze, and sparks, and scintillations. And when the metals which exist in combination with oxygen in soda and potash are separated from it, they cannot, without great care and difficulty, be preserved separate; and the moment they are laid upon waterfor, though metals, they happen to be a little lighter than water-the oxygen of the water leaps off from the hydrogen, violently seizes on the metals, and sets up with the one a ficrce splutter and a hissing noise, and with the other a beautiful violet red, restless blaze; thus, in the latter case, producing flame from cold water and cold metal.

Nitrogen is another elementary, colourless, odourless, tastcless gas, but has properties and offices widely different from oxygen. It occurs very scantily and fitfully in any of the liquid or solid parts of the earth. It cannot support either breath or flame. It serves in the atmosphere mainly to dilute oxygen, and to store up other gascs. It has few affinities, and no strong ones. It fits or induces every substance in which it is combined to decompose, and is the grand power in yeast and gunpowder, and in almost every other putrefactive or explosive. And yet it is much the largest constituent in the atmosphere; it exists plentifully in the nutritious parts of plants; it may be called the characteristic element in the blood and flesh of animals; and it does constant and prominent work in the broad, wondrous, cver-whirling circle of interchange and reciprocity among the lifeless and living things of the world, insomuch that, of late years, it has challenged prime attention from earnest philosophical inquircrs into the first principles of fertility and health. 
The merely mixed state, and not combined one, of nitrogen and oxygen in the atmosphere, is a striking instance of the adaptation which appears in all the works of God. The two gases, if combined, would not only lose all their proper powers, but become something useless or noxious. They have the capacity of uniting in five proportions; and in one of these, they form the famous laughing gas; in another, they form aqua fortis. The laughing gas makes persons who inhale it wild with merriment, full of glee and frolic, irresistibly disposed to caper, and dance; and utter peals of laughter; and, if it were to be constantly breathed, instead of the merely mixed gases of the atmosphere, it would, to say the least, render all serious pursuits impossible. And, as to aqua fortis, it is as virulent as vitriol, and would everywhere work death and ruin. Yet curiously enough, and very beautifully too, small portions of the oxygen and the nitrogen of the air, in the hot parts of the world, are occasionally combined into aqua fortis by the action of thunderbolts; and the result is a destruction of pestiferous miasmas, and a production of the aerial food of crops, to an amount which men of the counting-house would think worth millions of money.

Hydrogen, also, is an elementary, colourless, odourless, tasteless gas. It is the lightest of all known ponderable matter, nearly fifteen times lighter than common air, and serves admirably to carry aloft balloons. It exists largely in all plants and animals, principally, however, as a constituent of water, and of oils and fat. It escapes in a free or uncombined state from some processes of decomposition; and if quaintties of it accumulate in the upper regions of the at- 
mosphere, the instant combining of them with surrounding oxygen, by the action of flashes of lightning, may be the cause of such sudden heavy thunder-plumps as form dircetly overhead, without any previous perceptible approach of cloud, and come down apparently from enormous heights "like whole water." Hydrogen, in evolution from all ordinary combustibles, gives off the flame of fires and of artificial lights; and, both for that rcason, and because it is by far the most abundant flame-yiclding substance, it is commonly called the inflammable gas. Nor, of course, is it at all differcnt in nature when obtained from the decomposition of water; and hence has the question been much discussed of late, and also put to the test of some great experiments, whether water may not be made the easiest, cheapest, and most wholesome source of our artificial lights? How curious that the gas which gives flame, and the gas which supports flame, constitute the liquid which most readily destroys flame! They constitute it, too, or rather form it, or, at lcast, form the vapour which is identical with it, in the very act and process of combustion. Yet any quantity of the two, in the precise proportions for forming water, may exist in mixture in a cool undisturbed vessel during any length of time, without evincing the slightcst tendency to unite. But if the mixture be suddenly and violently compressed, or if it be heated up to a certain point, or if it be touched by a small flame, such as that of a tapcr, it instantly makes a tremendous explosion, and forms water. All burning of hydrogen yields much heat; and the burning of it with undiluted oxygen, in an apparatus so contrived as to prevent danger of explosion, gives the 
very powerful heat of what is called the oxy-hydrogen blowpipe.

Another elementary gas is chlorine. But this is yellowish green, twice-and-a-half heavier than common air, and most terribly pungent. An animal cannot inhale it and live-indeed, cannot inhale it at all. It. is a poison, and it exists in combination with another poison-the curious metal which we formerly spoke of as the basis of soda-in the form of culinary salt. The things, when separate, kill, yet, when united, constitute the most common, sapid, and healthful of condiments; and they thus afford a striking emblem of the power of union. Chlorine has a voracious affinity. for hydrogen, and can instantaneously abstract it from some of its ordinary combinations. If some oil of turpentine, which is a compound of hydrogen and carbon, be held in a phial, and a sufficient jet of chlorine be allowed to communicate with it, decomposition instantly occurs; the hydrogen and the chlorine flash together into the strong acid popularly called spirit of salt, and the carbon, set free, flies all round in a mimic shower of very fine black powder. But chlorine is best known for its high powers of counteracting putridity, and destroying vegetable colours. It is both the grand disinfectant and the great bleacher of modern times.

Carbon is a solid element, almosic exactly identical with diamond, and pretty nearly identical with charcoal or lamp-black. It abounds in most ordinary combustible substances, and commonly yiclds the red heat of burning, just as hydrogen yields the flame. It combines with oxygen to form carbonic acid; and this substance is to the full as interesting as carbon itself. 
Carbonic acid is a colourless, odourless, pleasantly sapid gas. It constitutes about a two-thousandth part of the atmosphere, and is held in solution, to a greater or less degree, by all fountain and river water, and is a principal constituent of limestone, and some other rocks. The decomposing of it by the leaves of plants, so as to retain the carbon, and give back the oxygen, is the chicf means by which they build up their woody fibre, and form a number of their most important secretions. The driving of it out of limestone by means of heat, is what popular phraseology improperly calls the burning of limestone. And the inducing of it in large quantity into mixture with water for a pleasant bevcragc, is what is called the aerating of water; for it constitutes the whole of the sparkling, brisk, and sharply racy property of soda-water, and lemonade, and ginger-beer; and it imparts to cider, ale; porter, and brisk champagne, the greater portion of their agreeable piquant pungency. Yet it extinguishes flame and arrests breathing. A mixture of it in com. mon air, to the amount of one-fifth of the whole bulk, destroys both flame and life; and either such a mixture, or any with larger proportion of the carbonic acid, constitutes the choke-damp of coal-mines, deep weils, and brewers' vats, which has, in such multitudes of instances, proved rapidly or instantaneously fatal to man. It is constantly going off in large quantity into the atmosphere from breathings, burnings, and vegetable decays, and might scem to be in danger of so accumulating as to oppress or suffocate animals; but, by a beautiful provision of the all-benignant Creator, it is drawn in and decomposed by plants in cxactly the same ratio in which other things and 
sources produce it; so that it always exists in the atmosphere in the same quantity-ever enough to feed plants, and never so much as to incommode animals.

Carbonic acid can be brought into a liquid state only under prodigious pressure; yet is sometimes forced into that state in the way of manufacture. The liquid can be preserved only in powerful little reservoirs; and when drawn off, it evaporates with prodigious rapidity, and, assumes a light, porous, massive form, similar to snow. If a small quantity of ether be put on this, such intense cold results as feels more insufferable than the heat of boiling water, and as will in a few minutes freeze mercury.

Water, in its several states of solidity, liquidity, and vapouricity, and in its transitions from one state to another, constitutes no mean proportion of the beauties and varieties and powers of the whole visible world. As it is one of the most common of substances, so is it one of the most wonderful. It frils to enrapture any man, either because he has never taken a comprehensive view of its wonders, or because he has let himself become stupidly familiar with them. If it were traced even as far as the present imperfect condition of science enables it to be traced, through the myriad offices and transmutations within minerals, within plants, and within animals, as well as in the open air, it would probably be pronounced a kind of universal medium, -a sort of circulating currency among all the ponderable powers of chemistry,-and at least a prime means by which electricity and heat and oxygen, atmosphere and earth, sea and land and organic being: achieve their ever-countless and everglorious offices. But from thousands of interesting 
facts respecting water, we are compelled to select, for even the briefest notice, only two or three.

The topmost film of a solidifying liquid contracts, becomes comparatively heavy, and falls to the bottom; the film which is then topmost does the same; and so do film aftcr film, till all the liquid is solidified. If water followed this law-which is the law of all liquids but itself-frost would solidify every river and lake and sea from the bottom upward, and would speedily leave not a drop of them liquid, and would, in the course of one wintcr, infix such a deep stratum of ice on all the higher and even middle latitudes and altitudes of the world, as no intensity or duration of summer heat could possibly thaw. But the Divine Being has here again interposed a special provision of benevolence: he has here said to a law which everywhere else is irresistible, "Hitherto shalt thou come, and no further." In cooling, till within seven and a half degrees of the freezing point, water contracts; and thence downward, it expands. The first solidified film is lighter than the liquid, and remains on the surface; and the next film, and every succeeding one, are also lighter, and cannot sink; and as successive films form, they acquire more and more the same power above the water which successive layers of snow possess above the soil,- the power of protecting it from frost, or of preventing its heat of liquidity, its proper warmth, from escaping. What signal beneficence is here!

The expansive power of freezing water is prodigious, and cannot be resisted, on any considerable scale, by the mightiest contrivances of human skill. Let water fill the bore of the strongest cannon, and freeze there, and it will burst the cannon; or let it fill the crevice of 
the hardest and most compact rock, and freeze there, and it will push aside or perhaps rend the rock. It is this power, acting through the innumerable particles of water in the interstices of wet or even moderately moist ground, which breaks up gravel walks in winter, tears and shatters public roads, and renders the furrows or surface of ploughed land hoven and spongy; and, though in this last instance it often does much harm by "throwing out" young herbaceous plants, it ever commends itself to the love and admiration of all reflecting farmers as a power of eminent value for pulverising clods, assisting mineral disintegration, and promoting general fertility.

The transition of water from the liquid state to the vapourous one, and from the solid state to the liquid one, afford a grand instance of the beneficent design of latent heat. If it were vapourised solely by means of sensible heat, every quantity of it heated in kitchens or factories, or other places for economical purposes, the instant it reached the boiling point, would fly all off like a puff of gunpowder. But each particle, on arriving at that point, is arrested there till it latently combines with itself between five and six times more heat than was requisite to raise it up from the very coldest liquidity; and therefore the water even amid the most violent fire vapourises slowly, and continues long available for use at boiling temperature. And if ice and snow were liquefied solely by means of sensible heat, all the icy coatings of lakes and rivers, and all the snowy coatings of valleys and mountains, the instant they reached the thawing point, would burst into water as if by magic, and would suddenly let loose wild torrents and roaring inun lations of awful 
force and most destructive action. But each particle, on arriving at that point, is held fast there till it take into latent combination rather more than half as much heat as is requisite to make the coldest water boil; and therefore, as so much heat for any considerable quantity of ice or snow can be obtained but very slowly out of the low temperature of the atmosphere, the thawing process is exceedingly tardy, and lets off rills of liquid scantily and regularly; and, in many a region of high latitude or of ligh altitude, makes the winter's supply of ice and snow maintain a flow of rivers and of irrigating streamlets through all the summer and autuinn. Thrs, while the remarkable chemical properties of ice protect the liquidity of the great body of water during frost, the equally remarkable chemical law of liquefaction prevents waste, and promotes most admirable economy of fertilising power, during thaw. How great and beautiful in this, as in everything else, is the Divine goodness!

If a little cold water be poured on smooth hot metal, it forms into globules which roll about, and do not become sensibly heated; and if a red-hot cylindrical piece of metal be lowered by a wire into a glass of cold water, it does not make the water hiss or boil, or otherwise show effects of semsible heat. In both these cases, a film of vapour intervenes between the metal and the water, and seems to restrict the action of the heat to the same kind of cold evaporation as talies place from wet surfaces in the open air. Many extraordinary feats of handling fire, and dipping the fingers in melted metal, witliout injury, can be accounted for on the similar principle of moisture on the living skin. Even one of the most seemingly 
magical of all possible things connected with heat-the freezing of water in a red-hot yessel-is not at all mysterious. A small quantity of cold water poured into a red-hot platinum cup will take the form of cold rolling globules, and if some liquid sulphurous acid, a kind of weak vitriol, be suddenly added, the water will freeze, and may, by a smart invertion of the cup, be thrown out in the form of a little bit of ice. Sulphurous acid exerts a high power in eliminating heat; and when poured into the cup, in the circumstances indicated, it occasions sudden violent evaporation, which again occasions sudden violent abstraction of heat; and hence the freezing. The relations of heat, in its sensible and latent states, to respectively the vapour of the air and the moisture of rain-clouds, afford a ready hint as to the formation of hail and of atmospheric ice by the mighty sudden action of free electricity.

Some of the solid elements, particularly sulphur, phosphorus, and a number of the metals, are to the full as wonderful as nitrogen, hydrogen, and chlorine; and thousands of compound substances, though in most instances comparatively rare in occurrence, display properties, and undergo mutations, quite as striking as those of carbonic acid and water. Any person who has taste and opportunity to trace chemical action through but an hundredth of its known achievements in all departments of the mineral world, -and especially any one who can follow it through but an hundredth of its ascertained wonders within the organs of plants and animals, and round all the circle of the living world's mutations, may see immeasurably more occasion to say devoutly to God than the poet 
did, when reflecting on the mere tide of created being, -

"My heart is awed within me, when I think

Of the great miracle that still goes on,

In silence, round me-the perpetual work

Of thy creation, finish'd, yet renew'd

For ever. Written on thy works I read

The lessons of thy own eternity.

Lo! all grow old and die; but see, again,

How on the faltering footsteps of decay

Youth presses-ever gay and beautiful youth,

In all its beautiful forms."

Chemical action, in fact, has all the brilliance of perpetual creation, and sheds that brilliance over all material things, and is ever, in every point and sparkle of its brilliance, the simple touch of the Divine finger, - the direct glance of the Divine eye. But unhappily we have no space to exemplify it farther in any inorganic substances, or to exemplify it at all in connection with plants and animals; and, before ceasing to speak of it, we can barely make room for a brief mention of two or three instances of its producing curious appearances which vulgar ignorance either cannot comprehend or regards as supernatural.

Nothing in chemistry more strongly strikes children than its command over colours. Several liquids, such as some of the juices of plants, rapidly change colour by simple exposure to ligint and air; several prepared colourless liquids suddenly become coloured by mixture with each other; and many coloured liquids and prepared fabrics undergo instant changes of colour, or series of changes, by merely the addition or contact of a few drops or a few grains of certain colourless sub- 
stances. Chemical feats in these things are now so common and well-known as to surprise few grown-up persons in civilised countries; yet they look in themselves like the most magnificent tricks of magic; and they were anciently performed by some impostors under impious claim of the miraculous. It is said, for example, respecting an old deceiver who wished to mix up paganism with Christianity, that he put white wine into three transparent glasses, and that, while he was praying, it became in one case blood-red, in another purple, and in the third sky-blue. "A very remarkable experiment of an analogous nature has been publicly exhibited in modern times. Professor Beyruss, who lived at the court of the Duke of Brunswick, one day pronounced to his Highness that the dress which he wore should during dinner become red; and the change actually took place, to the astonishment of the prince and the rest of his guests. M. Vogel, who has recorded this curious fact, has not divulged the secret of the German chemist; but he observes, that, if we pour lime-water into the juice of beet-root, we shall obtain a colourless liquid, and that a piece of white cloth dipped in this liquid and dried rapidly will in a few hours become red by the mere contact of air. M. Vogel is also of opinion that this singular effect would be accelerated in an apartment where champagne or other fluids charged with carbonic acid are poured out in abundance."

Natural "fields of fire" figure in many a marvellous story, and in old times were associated with debasing superstition. The chief one is in the vicinity of Baku, on the shore of the Caspian Sea, and has often been described. Any part of the ground within a circum- 
refence of about two miles may be inflamed by the touch of a live coal; and, if previously dug with a spade, it will set up an instant, furious, destructive conflagration. Inflammable springs occur at intervals; and in stormy weather they sometimes ignite and blaze aloft of their own accord, and send off to the sea burning streams which carry an invasion of fire on the waters to the distance of several leagues from the shore. All the country around Baku has at times the appearance of being mantled with flames. "It seems," we are told, "as if the fire rolled down from the mountains in large masses and with incredible velocity; and during the clear moonshine nights of November and December, a bright blue light is observed at times to cover the whole western range." The great old heathen community of Parsees, Guebres, or fire-worshippers, had their principal temple in a part of this region, over a kind of mimic volcano or great spouting spring of the flames; and the modern inhabitants, by means of the simple contrivance of stickirg slender tubes in the ground, obtain sufficient fire for cooling and for all other domestic purposes. Yet the sole peculiarity of all the region is the constant evolution from some carbonaceous strata in the depth below, and the constant escape thence upward to the air, of natural naphtha, - a compound of carbon and hydrogen, closely similar to the artificial naphtha which is now obtained from coal gas-works.

Natural decompositions of coal, or of other carbonaceous rock, within the bowels of the earth, sometimes yield occasional, temporary, or even prolonged supplies of inflammable gaseous matter very similar to manufactured coal-gas. Some of these are quietly 
used for economical purposes; and others, both in ancient and in modern times-catching fire and forking far into the air in prodigious tongues of flame-have not a little terrified the ignorant. Among many famous or remarkable instances, may be mentioned the triple monster sung by the Grecian poets and conquered by Bellerophon,- - the burning springs of Samos, Bathos, the vicinity of Phaselis, and other places in Greece,--some great fire-spouts and fire-fields in the south of Italy,--the temple of Chittagong in Bengal, - the fire-springs of Kiating-fou in China,_the Pit of the Wind in Germany, serving all the purposes of a small gas-work, - the lights which flit about the precipitous cliffs of the Acroceraunian Mountains before the blowing of the sirocco, -and the bright light at Maracaybo in South America, called the Lantern, which blazes long and steadily every night on an uninhabited mountain, and can be easily distinguished at a distance of more than forty leagues.

A certain decomposition of exuvix, dead worms, carrion, corpses, and all similar matter, produces a gas called phosphoretted hydrogen, which spontaneously burns in dark night in the open air with a cold lambent flame. It is, of course, most abundant in dunghills, graveyards, marshes, and the open drainage of towns and slaughterhouses; and, being very light and fitfully produced, it flits and flickers before the most gentle motions of the air. The light of it is the "spunkie" of the Scottish peasantry, the "dead light" and "corpse light" of superstition, the ignis fatuus of philosophy, and the "Will-o'-wisp" and "Jack-a-lantern" of common popular story. The ordinary ap- 
pearances of this light in Britain are well described in the following terms by Graham :-

"Sometimes from rushing bush

To bush it leaps, or cross a little rill

Dances from side to side in winding race.

Sometimes with stationary blaze it gilds

The heifer's horns; or plays upon the mane

Of firmer's horse returning from the fair,

And lights him on his way; yet often proves

A treacherous guide, misleading from the path

To faithless bogs, and solid seeming ways.

Sometimes it haunts the churchyard, up and down

The tombstone's spikey raii streaming, it slows

Faint glimpses of the rustic sculptor's art,

Time's scythe and hour-glass, and the grinning skull

And bones transverse."

It commonly has a pale bluish colour, and seems brightest at a distance; yet it varies greatly in both tint and brilliance. One, seen very long ago in the vicinity of Bologna in Italy, accompanied a person about a mile along a road, and generally shone like a large torch, about six feet from the ground, but was always inconstant_coming and going, rising and falling, contracting and expanding, separating and reuniting, and even assuming the form of a wave, and sending off brilliant sparks. And another, seen at Chapelle-aux-Planches about thirteen years ago, was a pale red pyramid ten or twelve feet high, emitting light enough to read by; and, after blazing half an hour, broke into pieces, and dispersed itself athwart a marsh.

Akin to the ignis fatuus, is the glowing light of phosphorescence. This, too, is luminosity without heat,always curious, and often most strikingly beautiful; and in some instances it differs little or nothing from the ignis futuus except in being confined to one spot. 
But it has great diversity of both seat and character; and it must be regarded not properly as one thing, but as a group of similar things. In some cases it probably arises from the evolution of latent light; in others, from various chemical action on mixed mineral substances; in others, from some ill-understood properties or functions of certain kinds of living creatures; and in others, from exactly the same or similar decompositions of dead animal substances as occasion the ignis fatuus. It is evolved in nild yet very diversified glory, now iridescent, now sparkling, and now brightly blue or green or red or yellow, from many kinds of minerals on their being struck or rubbed or much heated. It glows and sparkles on the bodies of putrefying fish. It is the fascinating fairy light of the lightning-bug and the glow-worm. It is the brilliant iris-flash which sometime leaps, like the revelation of an ocean-heaven, from a shoal of herrings or of pilchards. And most noticeably of all, it is a property of medusæe, zoophytes, and other small sea-animals, which makes all the wake of a ship, in a dark night, appear like a stream of liquid fire. Thousands of graphic writers have described the phosphorescence of the sea, but none with more simple power than Sir Walter Scott:-

"Awaked before the rushing prow,

The mimic fires of ocean glow,

Those lightnings of the wave;

Wild sparkles crest the broken tides, And flashing round the vessel's sides,

With elfish lustre lave;

While far behind their livid light

To the dark billows of the night

A gloomy splendour gave." 


\section{CHAPTER VI}

SOUND.

TUE NATURE AND LAWS OF SOUND-TWO SOUNDS PRODUCING SILENCE -THE CALLS AND SONGS OF BIRDS-THE MUSIC OF NATURE-THE ROAR OF STORMS-DIVERSITIES OF SOUND IN DIFFERENT POSITIONS AND CIRCUMSTANCES OF AIR AND LAND-SCNOROUS CURRENTS THROUGII GORGES, CREVICES, AND NATURAL APERTURES-MUSICAL IOCKS AND MOUNTAINS-ECIIOES.

Wrrat sound is, we do not certainly know. It is commonly said to be vibration of the air, produced either directly in the air itself, or indirectly through some other elastic substance, and acting mechanically on the organism of the ear. And it may be so. But assuming light to be a subtle fluid, sound may be a subtle fluid too, diffused through all vibrative substances, silent when in repose, and sonorous when put in motion. This theory is countenanced by several strong facts and reasonings; yet the common one serves perfectly well to explain all the known properties and laws of sound. And whichever be correct, the ear and the vibrating air are related to each other as certainly and intimately as the eye and the undulating light. Were there no ear or no atmosphere, or were ear and atmosphere differently related to each other than they are, we could have no acquaintance with the delights of voice and song, of speech and music, of the orchestra of human utterance, of the 
hallelujah of winds and waters and all vocal nature ever praising God.

Sound travels through hydrogen gas at the rate of 3000 feet per second, through water at the rate of 4708 feet, through tin at the rate of 8175 feet, and through glass and iron at the rate of 18,530 feet, but through the atmospheric air, in its ordinary or average conditions, at the rate of only 1142 feet. A series of sounds, following one another at the rate of not fewer than sixteen in a second, form a continuous sound; and, when of exactly similar kind, and following one another at regular intervals, they form a musical sound. The strings and orifices of musical instruments produce musical sounds simply by making uniform and regular series of vibrations; and they owe their respective pitch and power to the comparative velocity of their action. Sounds whose vibrations occur in precise ratios to one another, are harmonies; and two whose vibrations occur in the proportion of one to two, or of fifty to a hundred, are unisons. All other sounds than these we have named are noises and discords.

But we are not here dealing with the theory of music; we must not be tempted to dally with the wonders of the musician's art, no matter that these are so mightily fascinating and so surpassingly lovely; and we shall only notice, in the words of Sir David Brewster, what he calls "a property of sound with more of the marvellous in it than any result withinthe wide range of the sciences"- the property of producing silence by the joint action of two loud musical sounds. "If two equal and similar strings, or the columns of air in two equal and similar pipes, perform 
exactly 100 vibrations in a second, they will produce each equal waves of sound, and these waves will conspire in generating an uninterrupted sound, double of either of the sounds heard separately. If the two strings or the two columns of air are not in unison, but nearly so, as in the case where the one vibrates 100, and the other 101 times in a sccond, then at the first vibration the two sounds will form one of double the strength of either; but the one will gradually gain upon the other, till at the fiftieth vibration it has gained half a vibration on the other. At this instant the two sounds will destroy one another, and an interval of perfect silence will take place. The sound will instantly commence, and gradually increase, till it becomes loudest at the hundredth vibration, where the two vibrations conspire in producing a sound double of either. An interval of silence will again occur at the 150th, 250th, 350th vibration, or every second, while a sound of double the strength of either will be heard at the 200dth, 300dth, and 400dth vibration. When the unison is very defective, or when there is a great difference between the number of vibrations which the two strings or columns of air perfurm in a second, the successive sounds and intervals of silence resemble a rattle. With a powerful organ the effect of this experiment is very fine, the repetition of the sounds wow-wow-wow representing the double sound and the interval of silence which arise from the total extinction of the two separate sounds."

The calls and songs of birds rank high among the delights of nature, and not less high among its wonders. None, indeed, are wildly tumultuous or bewildcringly elaborate; but some are grandly piquant, 
some sublimely strong, like the serene influence of the sky, some gloriously beautiful, some cheering and melting and mighty over all minds; and the whole, by their aggregate richness and their endless variety, constitute a museum of sound whose strokes and rhythms have ever been the profound study of the Handels, and Mozarts, and Beethovens, and all other masters of melody. Even the most familiar have a witchery which affects all men except the most brutal, and is as evidently a provision of the Beneficent Creator to charm the ear, as colours or clouds or flowers are to charm the eye. Think, for example, of the trombone of the cormorant, the "shrill clarion" of the domestic cock, the chuck-chuck of the domestic hen, the cawing of the rook, the chatter of the magpie, the clatter of the fern-owl, the loud laugh of the woodpecker, the cooing of the dove, the peewit of the plover, the cuckoo of the summer-herald, the calls and chirrups of the common hedge-birds, the melodious chink-chink of the blackbird, the flute-like melody of the blackcap, the soft, plaintive, liquid song of the nightingale, the mellifluous thrill of the lark in the air and the throstle on the tree, the carolling woodnotes and throbbing lays of warblers and finches.

"Sweet birds, that breathe the spirit of song, And surround heaven's gate in melodious throngWho rise with the early beams of day,

Your morning tribute of thanks to pay:

You remind us that we should likewise raise

The voice of devotion, and song of praise;

There's something about you that points on high;

Ye tuneful tenants of earth and sky."

But, as a periodical writer beautifully remarks, 
"Nature seems to have mingled harmony in all her works. Each crowded and tumultuous city may properly be called a temple of discord; but, wherever $\mathrm{Na}$ ture holds undisputed dominion, music is the partner of her empire. The 'lonely voice of waters,' the hum of bees, the chorus of birds-nay, if these be wanting, the very breeze that rustles through the foliage, is music. From this music of Nature, solitude gains all her charms; for dead silence, such as that which precedes thunder-storms, rather terrifies than delights the mind:-

' On earth 'twas yet all calm around, A pulseless silence, dread, profoundMore awful than the tempest's sound.'

"Perhaps it is the idea of mortality, thereby awakened, that makes absolute stillness so awful. We cannot bear to think that even Nature herself is inanition; we love to feel her pulse throbbing beneath us, and listen to her accents amid the still retirements of her deserts. That solitude, in truth, which is described by our poets as expanding the heart and tranquillising the passions, though far removed from the inharmonious din of worldly business, is yet varied by such gentle sounds as are most likely to make the heart beat in unison with the serenity of all surrounding objects. Thus Gray-

'Now fades the glimmering landscape on my sight, And all the air a solemn stillness holds, Save where the beetle wheels his droning flight, And drowsy tinklings lull the distant folds!'

"Even when Nature arrays herself in all her terrors, when the thunder roars above our heads, and man, as 
he listens to the sound, shrinks at the sense of his own insignificance-even this, without at all derogating from its awful character, may be termed a grand chorus in the music of Nature. Almost every scene in the creation has its peculiar music, by which its character-as cheering, melancholy, awful, or lullingis marked and defined. This appears in the alternate succession of day and night. When the splendour of day has departed, how consonant with the sombre gloom of night is the hum of the beetle, or the lonely, plaintive voice of the nightingale! But more especially, as the different seasons revolve, a corresponding variation takes place in the music of Nature. As winter approaches, the voice of birds, which cheered the days of summer, ceases; the breeze, that was lately singing among the leaves, now shrilly hisses through the naked boughs; and the rill, that but a short time ago murmured softly as it fiowed along, now, swelled by tributary waters, gushes headlong in a deafening torrent. It is not, therefore, in vain that, in the full spirit of prophetic song, Isaiah has called upon the mountains to break forth into singing, 'the forests, and every tree thereof.' Thus we may literally be said to 'find tongues in trees, books in the running brooks:' and, as we look upward to the vault of heaven, we are inclined to believe, that

'There's not the smallest orb which we behold,

But in his motion like an angel sings,

Still quiring to the young-eyed cherubim.

Such harmony is in immortal souls;

But, whilst this muddy vesture of decay

Doth grossly close it in, we cannot hear it."

What this extract calls the "grand chorus in the 
music of Nature," is often a burst of magnificence, which a devout man of poetic mind, though he heard it but once in his lifetime, would remember to eternity. Mere thunder, as we noticed in a former chapter, is sometimes as truly the sublime in sound as a search in the heavens through a master telescope is the sublime in vision: and, when it is accompanied by the roar of hurricanes, the booming of volcanoes, or the hoarse hollow rumble of the earthquake, it is by far the most awe-inspiring of all sublunary things. Even the "chorus" of a mere storm, in the comparatively quiet latitude of the British Isles, sometimes sounds like the crash and tumult of all Nature's music. In the storm of the Moray Flood in 1829, for example, Sir Thomas Dick Lauder says, "There was something inexpressibly fearful and sublime in the roar of the torrents which filled the valley, and the fitful gusts of the north wind that groaned among the woods. The tall ornamental trees, one by one, had begun to yield. The noise was a distinct combination of two linds of sound: one, a uniform continued roar; the other, like rapid discharges of many cannons at once. The first proceeded from the violence of the water; the other, which was heard through it, and as it were muffled by it, came from the enormous stones which the stream was hurling over its rocky bed. Above all this was. heard the fiend-like shriek of the wind, yelling as if the demon of desolation had been riding upon its blast. The whole scene had an air of unreality about it that bewildered the senses. It was like some of those wild dramatic exhibitions where Nature's operations are out-Heroded by the mechanist of a theatre, where mountains are thrown down by 
artificial storms. Never did the unsubstantiality of all earthly things come so perfectly home to my conviction. The hand of God appeared to be at work; and I felt that, had he only pronounced his dread fiat, millions of such worlds as that we inhabit would cease to exist."

All ordinary sounds have very different intensity and conveyance in different positions and circumstances of air and land. In the thin light air of lofty mountains, the strongest effort of the human voice is not much louder than a good whisper, and the report of a pistol is not greater than that of an Indian cracker. In dry calm air of pretty uniform density, such as that of clear calm hours in the middle of the night, all sorts of sounds are much more distinct and loud than in air equally calm and dry, which is in a whirl of density from the rarefying action of a play of sunbeams. Falls of snow and rain make sounds dull; and hot fogs, in which the visible vapour seems dancing in the air, make them both dull and prolonged. A carpeting of newly-fallen snow sometimes absorbs sound or arrests it, seemingly in the same kind of way as in the muffling of a drum. A frozen surface of water, or a coat of ice or of hardened glassy snow on the ground, or a thin soil resting immediately upon rock, conveys sound very distinctly and far; insomuch that many a savage warrior, who has been a keen observer of everything in Nature which he can turn to the advantage of his pursuits, lays his ear to hard smooth ground, and gains from it ready telegraphic intelligence of the distant approach of his enemy. Strata of low clouds, especially if of great extent, and during a profound calm, occasion reverberations re- 
sembling mimic thunder. Diversities in the contour of landscape, in the windings of glens, in the form and position of woods, in the currents and conditions of air, and in other circumstances, many and common, which occur in moorish and upland regions, cause variations of sound always startling to persons unaccustomed to them, and sometimes so great and rapid as to excite momentary astonishment in even the practised ear.

Currents of air through gullies or crevices or apertures, either by mere friction and compression, or especially by differences of density between the air in the currents and the air into which they flow, produce sounds variously resembling detonations, thundrous peals, and musical swells. The career of a strong wind through some of the deep narrow gorges of mountainous regions, makes almost as astounding a roar as the cataract of Niagara. A vertical natural shaft, ascending from a large cavern in the face of a precipitous promontory on the north-west coast of Ireland, lets up spouts of a storm with such tremendous violence, that the water files aloft in a jet some hundreds of feet high, and the air makes reports louder than any piece of artillery, and sometimes audible in the city of Londonderry at the distance of thirty miles.

In the alpine road between-France and Savoy is an artificial gallery in the solid rock, about twenty-seven feet high and broad, nine hundreri and sixty feet long, and pier cing a mountain at an altitude fully one thousand feet below the summit, and about fifteen hundred feet above the valley. The declivities at the west end sink into shady, dark, cold ravines, and those at the other end decline into a comparatively open, sunny, 
warm valley; so that the mountain separates a mass of cold air on the west from a mass of much hotter air on the east. The gallery was cut from both ends; and when it was so nearly completed, that only a thin partition remained at its middle, the first opening made in that partition, by the stroke of a pickaxe, was instantly followed by a detonation like the shot of a great gun, or the springing of a mine. This was caused simply by the violent rush of the dense cold air into the thin hot air.

Baron Humboldt relates that, on certain granite rocks in the valley of the Orinoco, sounds are heard, from time to time toward sunrise, resembling those of an organ. The rocks are shelving, and have many very deep and narrow clefts, and undergo excessive change of temperature between day and night. The baron supposes that the difference of temperature between the air in the crevices and the air without, is greatest about sunrise; and he suggests, "May not these sounds of an organ which are heard when a person sleeps upon the rock, his ear in contact with the stone, be the effect of a current of air that issues out through the crevices? Dces not the impulse of the air against the elastic spangles of mica," the glittering silvery-looking constituents of granite, "that intercept the crevices, contribute to modify the sounds?"

In the mountain-ridge of El-Haman, in Arabia Petræa, not far from the Red Sea, is a remarkable hill of about four hundred feet which has obtained the name of the Mountain of the Bell, or the Musical Mountain. It consists, like the rest of the ridge, of a light-coloured friable sandstone, and rises pretty steeply and regularly from a dry drifting plain; but 
has a covering of sand almost as fine as road-dust, and is bounded by a semicircle of broken, abrupt, pinnacled rocks. Several scientific travellers have visited it, and give precisely similar accounts of its wonders, but do not clearly indicate their cause. Lieutenant Wellsted ordered an Arab of his party to ascend it, and seated himself on a rock at its base; to watch there the effects. When the Arab got a considerable way up, the loose sand came gliding down to the depth of a foot, not, however, in a straight-down stream, but with a lateral outspread. When it first began to descend, a sound was heard similar to the first faint strain of an Elian harp when beginning to catch the breeze; when it descended further and more rapidly, the sound became similar to that produced by drawing moistened fingers over glass; and when it approached the base of the hill, in full volume and momentum, the sound rang like the reverberation of distant thunder, and caused the rock on which Lieutenant Wellsted sat to vibrate, and struck such terror into the camels, notwithstanding their proverbial indifference to fear, that their drivers had difficulty in preventing them from running off.

The most curious thing in natural sound is the echo. This is the reflection of sound from any surface, whether wall, rock, hill, or cloud, of sufficient concavity to collect the diverging vibrations and to fling them back to a focus, without materially annulling or disarranging them. When there is but one reflecting surface, the echo is single; and when there are several reflecting surfaces, either receding up from one another in the manner of an amplitheatre, or curving parallel to one another in the manner of a winding vale or of stratified clouds, the echo is double or treble or mani- 
fold. The perfect echo of a speaker's voice upon his own ear is obtained only when he stands in the exact focus from the reflecting surface; and the finest instance of it occurs with a deliberate utterance, at the distance of 571 feet, and repeats as many syllables or words as can be spoken in a second.

Halls and arches give confused echoes, on account of their reflecting surfaces being too near. Whispering galleries, like the famous one in the dome of $\mathrm{St}$ Paul's Cathedral in London, are only a variety of echoing surface. Many vales and variegated landscapes in the clear dry clime of Italy give such distinct and prolonged echoes as to repeat whole strains of music. Caverns or vaults or subterranean arches, or even loosely filled excavations, often yield loud underground echoes to the sound of foot-falls and of carriage-wheels. The reverberating roll which accompanies the fall of an avalanche, and the reverberating roll of a thunder-peal, or even of the discharge of a great gun, among tortuous, tumulated, undulating mountains, are the most sublime of echoes. Nor is the underground rolling response to a stone-fall in some deep caverns a great deal inferior. "Perhaps of all noises which are augmented by continued reverberations," remarks Mr Gardiner in his Music of Nature, "none are more appalling than the experiment of rolling a portion of rock into Heldon Hole in Derbyshire. To stand on the brink of this fathomless gulf, and to hear the thundering mass fall from cavern to cavern, waking the frightful echoes in the vast chambers below, fills the mind with terror and dismay. This noise, more terrible than the whirlpool of Charybdis, is, in some degree, imitated by Haydn 
SOUND.

in a chorus in Judah, at the words, 'The Lord devoureth them all.' The sounds, sinking into an abyss of harmony, are penned with an effect wortlyy of the great Beethoven himself." 


\section{CHAPTER VII.}

\section{FORCE AND MOTION.}

FORCE-GRAVITY-ATTRACTION-VIS INERTIA-PROJECTION-RELATIONS OF THE EARTH'S ATTRACTION TO THE MASS AND POWER OF ANIMALS-GRAVITATION-THE MOTIONS OF THE PLANETS-THE TIDES-THE PRESSURE OF STILL WATER-THE PRESSURE OF THE ATMOSPHERE-EFFECTS OF ATMOSPIIERIC PRESSURE ON MINERALS, ANIMALS, AND MACHINES-THE ELASTICITY OF THE AIR-THE INTERDIFFUSIVENESS OF THE ATMOSPHERIC GASES.

Fonce is anything which alters motion, or produces it, or tends to alter or to produce it. It may be in equilibrium, holding a body in a state of rest; or it may act in any of the ways, or with any of the effects, popularly called pressing, rubbing, hitting, lifting, throwing, driving, pulling, splitting, and swelling. It may be viewed as remote or primary,-and then it exists grandly in the power of an animal's will over its muscles, and infinitely in the power of the all-creative mind of the Eternal over all physical things; or it may be viewed as proximate or secondary,-and then it exists grossly in the action of machines, more refinedly in the action of animal strength, and most definitely in heat, in electricity, in chemical affinity, and, above all, in what is called weight.

Yes, apart from the power of mind, the grand originator and sustainer of motion is weight. But what 
is this? We cannot tell. Philosophers call it gravity, and dilate upon its laws, but either say nothing about its nature, or treat it only in vague and conflicting speculations. As probable a theory as any identifies it with magnetism, or with something near akin to magnetism; but this, like everything else on the subject, is mere theory. Its properties or effects, however, are quite obvious, and perhaps appear all the more wonderful that the thing itself is unknown.

Two bodies, if free, or in the degree in which they are free, move toward each other by their mutual gravity-called in this respect their mutual attraction. But, when of different sizes, they move in proportion to their respective bulk,- - the smaller one moving much, and the larger one moving little. Hence do all pieces of matter set free in the air, in all parts of the world, fall straight to the ground,- - so that those in antipodal regions proceed direct toward each other, and none anywhere can fly off into space; and hence do even the largest appear to make all the motion of coming into contact with the ground,-for, though the earth really advances to meet them, it is so immensely bulkier than they, that the amount of its motion is incomputable and inappreciable. Whatever the pieces of matter be, even suppose them such widely different things as a ball of iron and a feather, if set free at the same height in the air, they tend to fall at the same rate of speed; and they are comparatively accelerated or retarded only by the different way in which they encounter the resistance of the air, so that, when dropped into a vessel or chamber which has had all air artificially pumped out of it, they actually descend through it with precisely equal velocity. All falling 
bodies, however, move slightly and slowly at the commencement of their fall, and gain increase of speed as they descend, and move always quicker and quicker till they reach the ground; and hence the vast pelting, pattering power of hail-showers, which come from no higher an elevation than a mile or two,-and hence the enormous depth to which small star-stones, descending, perhaps, through thousands of miles, have plunged into strata of sand or clay.

Any body in a state of rest, if never disturbed, will for ever remain in a state of rest; and any body, if set in motion by some other force than that of attraction, and never in any way interfered with, will for ever continue in motion. In other words, a body rests or moves only in relation to one or more other bodies, and has not any powers of its own to make itself either move or stop. This is called its vis inertia; and any force which sets it in motion otherwise than by attraction is called a projecting force. But every such force, or rather all motion produced by it, is modified by gravity. No body in any part of the universe, so far at least as men have been able to observe or conjecture, can move in such entirely free space as to be uninfluenced by other bodies. And certainly none in our world can move an inch without being mightily controlled both by the resistance of the air and the attraction of the earth. Any body projected aloft by the strongest force of man, or the strongest force of any engine he can possibly contrive, is so steadily resisted by the air and so powerfully attracted by the earth, that it gradually loses its upward speed, soon comes to a pause, and after an instant of equilibrium yields wholly to the earth's attraction, and begins to descend 
in the manner of a falling body. And the regular fusion of the forces which guide it, beginning with the full power of the projecting, and ending with the full power of the attracting, occasions it to describe the beauteous curve which all eyes admire and all tasteful artists delight to study.

All animals have mass and power in a certain relation of excess to the earth's attraction; for, otherwise, they either could not move at all, or would move with great difficulty, or with inconvenient lightness, in jerks and jolts, losing their balance, and wanting all necessary self-control. Other planets differ so greatly in size and density from the earth, that, in consequence merely of their correspondingly different force of attraction, all loose things on their surface, animate and inanimate, must have widely different forms and relations, and probably, also, widely different combinations of elements, from those of the earth. If our world were to be exactly what it is, with simply such an increase of bulk as to make it as large as Jupiter, it would attract all its animals with eleven times greater force than it does, and would therefore destroy them. "The lightness of the fawn, the speed of the hare, the spring of the tiger, could not exist with the existing muscular powers of those animals. For man to lift himself upright, or to crawl from piace to place, would be a labour slower and more painful than the motion of the sloth. The density and pressure of the air, too, would be increased to an intolerable extent, and the operation of respiration, and others which depend upon these mechanical properties, would be rendered laborious, ineffectual, and probably impossible. If, on the other hand, the force of gravity were much lessened, incon- 
veniences of an opposite. kind would occur. The air would be too thin to breathe; the weight of our bodies, and of all the substances surrounding us, would become too slight to resist the perpetually-occurring causes of derangement and unsteadiness; we should feel a want of ballast in all our movements. Things would not be where we placed them, but would slide away with the slighest push. We should have a difficulty in standing or walking, something like what we have on ship-board when the deck is inclined; and we should stagger helplessly through an atmosphere thinner than that which oppresses the respiration of the traveller on the tops of the highest mountains."

The force of gravity and the projecting force explain all the motions of the solar system. "To understand the operation of these in relation to each other," remarks Dr Duncan in his Sacred Philosophy of the Seasons, "first suppose a small body, placed at rest, in the neighbourhood of a large one, also at rest, both of them in empty space. The mutual attraction would immediately begin to operate, and they would move toward each other till they met, and that with a rapidity proportioned to the quantity of matter contained in each, the larger most powerfully attracting the smaller. Suppose, again, that the smaller body, instead of being placed at rest, was projected with a certain velocity in a direction different from that in which the other was situated. That velocity might be very great; and then, after a mutual disturbance, arising from the reciprocal attraction, the moving body would disengage itself from the other, and fly off into boundless space; or, it might be very small, and then the vis inertia would be overcome, and the two bodies 
would fall toward each other, and unite. But, if the projecting force were in every way proportioned to the gravitating force, the consequence would be, that there would be a certain point in the progress of the moving body in which the two powers would balance each other, and then that body would continue to move, indeed, but in a constant circuit round the attracting force, which would thus become its centre of motion; and its course would be in an oval or in a circle, according to the force and direction of the motion originally impressed. This is, in fact, the principle by which the whole planetary system is governed. The sun, a body of vast dimensions, is the centre of attraction to which all the planets gravitate, and into which they are prevented from falling only by the opposite power of inertia. The two forces, with the nicest exactness, balance each other; the former, in reference to this principle, being called the centripetal, and the latter the centrifugal motion; and thus the great machine is kept in action, and the planets wheel steadily in their respective orbits, and perform their various beneficent functions. I may add, that this is the principle, not of the solar system only, but the system of the universe.

' $\mathrm{O}$, unprofuse magnificence divine!

$\mathrm{O}$, wisdom truly perfect! thus to call

From a few causes such a scheme of things,-

Effects so various, beautiful and great,

An universe complete!"'

Attraction, or the mere force of gravity, produces the earth's tides. The moon attracts the hemisphere of the earth next to it more than the hemisphere opposite to it,- and the central parts of the hemisphere 
more than the outer parts; or, in other words, always draws most strongly toward itself the portion of the earth which is nearest, and least strongly the portion which is most remote. Waters obey attraction rather in molecules than in mass,-having no firm cohesion like land to obey it only in one rigid body; and therefore those directly under the moon in the up-hemisphere rise above the level of the surrounding ocean, and those directly under it in the down-hemisphere are left behind, so as also to appear to rise. And as their rise in both hemispheres is a constantly progressing one, in the course of the earth's constant revolution, it constitutes a double daily tide,-a continual series of great waves at the distance from one another of half the globe. If the waters obeyed instantaneously, the crest of the tide would always be right below the moon; but they are hindered by their own inertia, and by the friction of things in contact with them, from obeying even promptly, so that the tidecrest never arrives at any spot till some time after the moon has passed its meridian. The sun acts in the same way as the moon, but with only one-third as much power; and when sun and moon attract in the same direction, as happens at new moon and at full moon, they produce the conjoint full wave called a spring-tide,-and when they attract in transverse direction, as happens at the moon's first and third quarters, they produce the disjoint half wave called a neap-tide.

Tides, as a whole, however, are considerably modified by several things in the varying action of gravity, which we cannot take space to explain; and those of some localities are annulled, those of others vastly mag- 
nified, and those of almost all in some way or other affected by the earth's own relations of sea and land. The tides of the Baltic and the Mediterranean, for example, are scarcely appreciable; those of the central parts of the Pacific are only about two feet high; those of the Bay of Fundy rise to the amazing height of seventy feet; and those of the river Amazon are a series of ascending and descending currents, modifying one another in wondrous diversity over a distance of five hundred miles from the ocean. Those of the Solway Frith, however, are to the full as curious as any, and may be briefly noticed as an interesting specimen. The tide of the Atlantic rolls right against Ireland, and sweeps round its ends so as to enter the Irish Sea simultaneously at the northern and the southern inlets. Two tides are thus generated; and they rush into collision with each other at the extremity of Galloway, and form a sudden tumbling heap of waters, which flies furiously off to the long, broad, sandy hollow between Scotland and Cumberland. This is the Solway tide, - so swift and headlong as to be rather a career than a current,-rather a sweeping torrent than a wavy flow. A spring-tide, but especially a tide which runs before a stiff breeze from the south or the south-west, careers along at the rate of from eight to ten miles an hour. It is heard by the people along the shore upwards of twenty miles before it reaches them, and approaches with a hoarse and loud roar, and with a brilliance of demonstration incomparably more sublime than if the wide sandy waste were densely scoured with the fleetest and the most gorgeously appointed invading army of horsemen. Before the first wave can be descried from the shore, a long cloud or bank of spray 
is seen, as if whirling on an axis, and evanescently zoned and gemmed with mimic rainbows, and the rich tintings of partial refractions, sweeping onward with the speed of a strong and steady breeze. Then follows a long curved white and flowing surf. And when the magnificent banner of spray and this surfy pioneer have made distinct announcement, finally and suddenly appears the majestic van of the tide, a speckled and deeply dimpled body of waters, from three feet to six feet high abreast, roiling impetuously forward, and bringing closely in its rear a tumbling and tempestuated mass of marine vales and hillocks, glittering and gorgeous all over with the most fitful play of the prismatic colours.

The force of tides, of streams, of wind, of steam, and even of galvanic currents, as a power in nature which man employs for driving his machines, is too obvious and too well known to need any remarks. Yet the simple pressure of still water and the common pressure of the atmosphere, though also generally known, may be selected to show how beneficently great powers slumber, all ready for use, in quantities where an unreflecting mind would never suspect their existence.

The pressure of any body of still water is in proportion, not at all to either its own volune or its own surface, but solely to the extent of the bottom on which it rests, together with the height of a column of the water over that bottom. In a funnel-shaped vessel, for example, if the neck be the bottom, the pressure is equal only to the weight of the small column resting on the neck, and if the expanded end be the bottom, the pressure is equal to a column of the entire diameter 
of that end,-ay, and if the neck be prolonged upward by a tube of any length filled with water, the pressure will still be as great as if the whole were a cylinder of the same circumference as the bottom. Or, if in a vessel or cavity of any kind a tube rise from the surface and be filled with water, the pressure on the bottom will be the same as if the whole body of the water stood as high as that in the tube. Hence the famous experiment of bursting a strong cask by means of a few ounces of water. Let such a cask be filled with water; let a long tube of only a few ounces in capacity be screwed tightly into a hole in its top; let this tube be filled with water, and the cask will burst. A wellknown contrivance called the hydrostatic bellows, makes an ounce of water balance a thousand ounces of any solid substance; and a machine of the size of a common tea-pot, constructed on the same principle, can cut a bar of iron as easily as a slip of pasteboard.

The average common pressure of the atmosphere at the level of the sea and of low valleys, as we stated in the chapter on the Air, is about fifteen pounds on every square inch. This is not only a great force, but an all-pervading one on earth; and it works in thousands of ways that most men little dream of. It keeps close things tight, cohering things firm, and living things elastic; and is either the main force or a necessary subordinate one in most of the physical resistances and movements in the world. So strongly does it plug an orifice in any artificial vessel containing liquid, as, for example, a cask or a well-formed tea-pot, that none of the liquid, no matter what its weight be, can escape unless another hole, however small, elsewhere communicate with the atmosphere to 
lèt in the counteracting pressure. So sternly does it put together, and hold together, two perfectly polished surfaces, such as of the smoothest marble or the smoothest ground glass, coated thinly with oil; that, if particles of air cannot get access between them, no power short of about fifteen pounds for every square inch of this extent can pull them perpendicularly asunder. This pressure is, no doubt, the grand acting power in all cohesion by means of glues and lutes and mortars,- - these substances serving principally to fill -all pores which counter-pressing air could penetrate, and so occasioning all the exterior to be jammed fast by a force of fifteen pounds on its every square inch.

This force also co-operates with frost to seal up the underground waters in winter. The moisture of land, even in Siberia, is seldom truly frozen to a greater depth than two feet; but, when converted into ice on some soils to even but a tenth of that depth, it acts like a cement, just in the same way as mortar does in walls, and occasions all the moisture below, all the tricklings of water in the capillary tubes of the earth's interstices, to be locked fast by atmospheric pressure. Hence is it that, during even the comparatively mild, brief frosts of Britain, the wells and rills and rivulets, in many parts of the country, become almost dry; and hence, too, is it that, on the recurrence of a thaw, notwithstanding that slowness of the liberation of frozen water which we pointed out when speaking of chemical action, so ample and refreshing a supply of liquid bursts speedily into the water-courses from the relaxing earth.

Every kind of what is popularly called suction, arises from atmospheric pressure. A man dips his 
lips in water, and then draws the air within his mouth into his lungs, and immediately the water is pressed up into his mouth. But were he not to let his lips touch the water, he might pull with all his power for a twelvemonth, and not obtain a drop. An infant, in the same way, makes a vacuum round the nipple, and the atmospheric pressure on the parts adjacent forces out the milk. A boy's sucker, too, simply prevents the access of the exterior air, or lies on a smooth stone in the same way as two polished oiled surfaces of glass lie on each other; and if it have perfect contact to the extent of just one square inch, it will lift a weight of almost exactly fifteen pounds.

Limpets, periwinkles, and other molluses, select a smooth surface of rock, and fill their shells with such expansions of their own body, or such quantities of water, as completely exclude all air; and then the shells are held fast to the rock at the same rate of power as the boy's sucker on the stone. Two-valved molluscs, also, such as oysters and mussels, exclude all air, and therefore have their shells held so firmly together, that no power short of about fifteen pounds for every square inch of their surface can force them open. But let any one of them have a little hole ground into it, so as to let in the air and counteract the pressure, and it will readily open. Common houseflies, and other small creatures which have the power of walking on a vertical smooth surface, or the power of walking along a ceiling with their feet uppermost, owe that power to the very simple contrivance of squeezing the air from between their feet and the surface they walk on, so as to let themselves be held fast by atmospheric pressure. 
The air within substances, no matter how small in quantity, counterpoises the air without, and therefore holds them in perfect equilibrium. But for this, a porous substance would be at once pressed compact or crushed to powder; and a cavitous one would be at once squeezed flat or shattered to atoms. Let a syringe be tightly fitted through the cork of a tightlycorked, flat, empty phial, and let it be made to draw out the interior air, and the phial will speedily be smashed to pieces. The counterpoise of air within and air without, however, keeps things more secure than if no pressure whatever existed, just as a particle in the centre of a mass of any matter is more secure than a particle at the circumference. And, in the case of animals, it also produces elasticity and vigour, or at least serves jointly with the varying weight and varying expansion of the air within the lungs and throughout the body to act like sinews to the whole frame, and like wings to the legs and arms.

Atmospheric pressure forces the mercury up the tube of the barometer, and water up the bore of the common pump. It is the power by which the syphon conveys water from one reservoir to another over any intervening obstacle of less height than thirty-two feet. It acts in the forcing-pump, in the fire-engine, in the steam-engine, and more or less in every other machine which is worked in any way by water or vapour or air. It is the force which was brought into play in the great experiments, a few years ago, with what were called atmospheric railways. And though it was so undeftly used in these experiments as to sink into less favour than steam, it is nevertheless in itself so magnificent a force, so cheap, so facile, so everywhere 
available, so perfectly free from all risk and nuisance, and so purely, so directly, so beautifully a gift of the Divine beneficence, that it must surely, at no distant day, in a more advanced stage of mechanical science, become the choice moving power in many great classes of machinery.

The elasticity of the air is a force, in some respects, as wonderful as the pressure. It is the force, as we saw in a former chapter, which co-operates with heat to produce all the winds. It is the force which enables fishes to sink or rise in the water; for they have an air-bladder which, whenever they please, they can so contract as to make them sink, or so dilate as to make them rise. It is also, no doubt, one of the tremendous forces of natural rock-splitting, of land-slips, of the upheaval of islands and mountains, of the eruption of volcanoes, and of the rumbling and rending of earthquakes. And, as well as the atmospheric pressure, it is a facile, all-prevailing, mighty power, abundantly capable of being turned to strong, manifold, valuable, mechanical account. Ordinary air, at the level of low valleys, can be compressed into a space sixty times less than what it naturally occupies, and at the same time is capable of expansion into a space thirteen thousand times greater; so that between its extremes, under high compression and in complete racuity, lies a force of elasticity or explosiveness similar to the power of gunpowder.

The interdiffusiveness of aeriform substances is a force widely different from pressure and elasticity, and possesses beauties and wonders peculiar to itself. It maintains the gases of the atmosphere in equable diffusion, irrespective of their weight. It makes the 
same-kind of remarkable exception in regard to the gravitation of the gases as the peculiar law of the freezing of water makes in regard to the comparative bulk and weight of ice. It resists a law which everywhere else governs material things; and does so with most signally wise and beneficent results. It sends aloft the heavy carbonic acid, which would suffocate all animals if allowed to rest on the ground. It keeps down the lighter nitrogen as a necessary diluent of the too-exciting oxygen. It suffuses high and low the light vapour which is needed high and low and all between for the many purposes of weather. And, in general, it secures to the atmosphere that uniformity of cliaracter, throughout all its volume, amid all its commotions, and at all hours and seasons, which is essential to its million connections with light, electricity, chemical action, sound, land and sea, and all organic nature.

"Few perhaps of our readers," remarks a writer in the British Quarterly Review, "have considered how, but for this force, rain and dew would long ago have ceased to fall, and the green earth have been parched and dried up like a desert 'All the rivers run into the sea, yet is the sea not full. From the place whence the rivers came, thither they return again!' And why is it so? Even because this force of diffusion, when assisted by the sun, is able to lift up the ocean itself, and to make it thin air. We have all watched with delight a drop of dew lying in the cup of a flower; but few marvel at the fact, that the little drop returns to the air whence it came. Why should it not lie in its flower-cup for ever? A pearl lies at the bottom of the sea, and makes no effort to float up to the sur- 
face; and yet the difference in density between the pearl and the sea, is much less than that between the dewdrop and the air. A globule of quicksilver let fall into the ocean rests in its bed for ever, yet it is only some eleven times heavier than the water above it. The dewdrop is 815 times more dense than the air, and there are hundreds of tons of the latter pressing on it; but no sooner does the sun arise, than it brightens and exhales to heaven. It bounds up like a bird into the blue sky. The air opens its arms for it, and lifts it into its bosom, and by and by spreads it from pole to pole, and it encircles the world. The atmosphere thus solicits and encourages-nay, compels the rise of vapour, and keeps undiminished an embryo store of refreshing dews and warm showers for the earth, and so it ever holds good that the 'clouds come after the rain." "

"But for this force," says the same writer, "all other contrivances for maintaining the life of animals would have totally failed to secure that end; for respiration would have been impossible. To sentient beings, the atmosphere would have been as useless as the rnost dainty and nutritious food is to one who has not the power to swallow. There is this perplexing problem to be solved in the case of respiration. An animal has not two sets of air-tubes, as it has two kinds of blood-vessels along one of which (the arteries) the blood goes, whilst by the others (the veins) it returns. There is only one windpipe in animals, by which the oxygen may travel to reach the blood, and the carbonic acid return to reach the air. By the same channel we must constantly cause two counter or reverse currents to pass,-a stream of oxygen from the outer 
air to dissolve in the blood,-a stream of carbonic acid from the blood to dissipate into the air. The breathing tube of an animal is thus like a railway tunnel, through which trains are constantly passing in opposite directions, and yet there is but one pair of rails. There is no mechanical or vital device for effecting the transference of the opposing aerial currents, -no living alternating pump like the heart, which should this moment suck oxygen into the blood, and the next moment suck carbonic acid out of it. The muscles of the chest, by their action, alternately fill and empty the larger wind-tubes, or what we may call the lobbies of the air-galleries. It is only in the narrow passages and distant corridors, that the blood and air meet and act on each other. There, however, the pantings and heavings of the chest have no direct effect in filling or emptying the air-channels. It is all occasioned by the power of diffusion. The issuing carbonic acid acts like a vacuum to the entering oxygen, or, at most, neither gas resists the passage of the other, more than the pebbles in the bed of a stream do the water flowing over them. They glide past each other, impelled by an irresistible force which obliges them to change places; so that a certain volume of the one cannot by possibility travel in one direction, without permitting, nay, without compelling, a certain volume of the other to pass in the opposite one. The gases entering and leaving the blood are like weights hanging at opposite ends of a string suspended over a pulley, or like the buckets in a well. The one cannot sink without causing the other to ascend, or either move in one way without causing the other to move in the reverse one. There are animals in which the 
air-tubes are as rigid as iron, so that they cannot expand or contract to carry air to or from the blood. In these the force of diffusion alone maintains respiration; but without that force it could not go on in any class of terrestrial beings." 


\section{CIIAPTER VIII.}

\section{CONTINENTS AND ISLANDS.}

I.AND-HEMISPHERE AND WATER-HEMISPHERE-PROJECTIONS OF COAST-

LINE-TIHE OLD WORLD AND THE NEW WORLD-CHARACTERISIICS OF AFRICA, ASIA, AND EUROPE-THE GREAT MOUNTAIN CHAINS-THE CONTOUR OF CONTINENTS-THE FEATURES AND INFLUENCES OF ALPINE RANGES-THE SCENERY OF MOUNTAINS-THE ANTARCTIC CONTINENT-SINGLE MOUNTAIN MASSES-GREAT PLATEAUS AND GREAT PLAINS-THE PAMPAS, SILVAS, LlaNos, AND PRAIRIES OF AMERICA -FLat Landscapes-VALleys-Mountain PaSSES-GLENS AND GORGES-EARTH-CHASMS-GROTTOES AND CAVERNS-BASALTIC COLONNADES.

A GREAT circle drawn through the coast of Peru and the southern extremity of Asia, cuts the world into a land hemisphere and a water hemisphere. The former has Britain for its centre, and contains nine-tenths or so of all the inhabited land in the world; and the latter has its centre not far from New Zealand, and contains little other land of any kind than Australia, the islands of the Pacific, the southern point of America, and the recently discovered antarctic continent. Thus, in the grandest sense, is Britain the middle of the peopled earth.

All the great masses of land send off bold, highpointed projections to the south. All the great peninsulas, and even most of the smaller ones, look to the south, and have either lofty promontories or rocky headlands. And all the great continents taper to the 
south, and terminate there in high and massive abutments. All are flanked by an island or islands to the east of these abutments; all are invaded, at a far-up part of their west side, by a gulfous inroad of the ocean; and all expand toward the north, and possess there every variety of development in mountain and plain. How to account for these facts we do not know. The theory was once entertained that they arose from the action of powerful sea-currents running long and violently from the south-south-west; but this has been proved by geological investigation to be entirely erroneous.

The two great lines of coast which flank the Atlantic Ocean present a remarkable correspondence. The projections of the one curve parallelly to the recesses of the other,-Cape St Roque, for example, to the Gulf of Guinea, and the promontory of Cape Verd to the Gulf of Mexico. And the entire American coast looks, in a chief degree, as if it would fit into the entire coast of the old world. But if the thought should hence be started, that the two continents once formed a continuous territory, and were torn from each other by some tremendous convulsion, it would of course be ineffably absurd.

The old world has its greatest length from north-east to south-west; or, if Africa be leit out of account, it has its greatest length from east to west, and lies all north of the equator, and principally within the north temperate zone. But the new world has its greatest length from north to south, and ranges through the tropics, and on to the vicinity of the Antarctic Ocean. The old world has its highest watershed in a line from east to west, with long slopes of general surface to the 
north, and much shorter ones to the south; and the new world has its highest watershed in a line from north to south, with very long slopes of general surface to the east, and very short ones to the west. A very large proportion of the old world's surface consists of lofty plateaus; and a correspondingly large proportion of the new world's surface consists of low plains. Both worlds have a length of about 7500 miles; but the old is about twice as broad as the new. The two worlds, at the same time, differ widely in the subordinate influences of climate, territorial contour, encincturement by the sea, and exposure to stated winds. They therefore, as might be expected, present many and great contrasts in their physical transitions, their vegetable productions, their animal tribes, and their commercial adaptations; and were it not that they have one gravity, one mineral basis, one overmantling atmosphere, one natural chemistry, and consequently an entire common fitness for the uses of man, they might almost afford us some faint idea of the correlative yet contrasting characters of two coadjacent planets.

Even the several great divisions of the old world have surprising differences. Africa, not only is tropical while the other two divisions are temperate, but is almost closed against the sea,-has no large projections, no large marine inlets,_-and lies so enfolded within itself as to hold an enormous proportion of its interior in mystery from all the rest of the earth. Asia pushes whole countries into the ocean, and places these in luxurious enjoyment of subtropical heat; yet lifts vast ramparts between its central regions and the oceanic highways, and retains far-spread races of its 
people either on cold, lofty, impracticable plateaus, or on great northern plains, which communicate only with the frozen seas. Europe is an interweavement of land and ocean,-looks, over one half of its extent, as if it were dissolving into islands, - - has profusions and intricacies and endless varieties of coast-line,-is almost all a continual alternation of hill and valley, broken mountain and swelling plain,--and offers everywhere high stimulus to industry and ample facility for enterprise. A moment's reflection may discover the influence which these different configurations of the three great divisions of the old world have exerted on the history of their respective population, and are continuing to exert on their present social condition.

All the great chains of mountains extend nearly in the direction of the greatest length of their countries and continents. Thus, the chains of Scandinavia, of Central Italy, and of Southern India, run in the same direction as these peninsulas themselves; the grand watershed chain of the old world, comprising the Himalayas, the Hindoo-Coosh, the Caucasus, the Balkan, the Alps, and the Pyrenees, extends prevailingly from east to west; and the grand watershed chain of the new world, comprising the Rocky Mountains and the Audes, extends prevailingly from north to south. The great chain of North Africa, also, runs along the shoulders of that region, paraliel to the Mediterranean; and the prime chain of all the main body of Africa, east and south of the Sahara, seems, from the few hints obtained by recent discovery, and in defiance of the old theory about the Mountains of the Moon, to extend, in a grand series of magnificent summits, from the alpine basin of the Blue or Middle Nile 
right southward to the high tableaus of the Cape Colony.

Yet, while all thus serving as backbones, they have adjustments and diversities of position, slope, offset, and altitude which exert the grandest possible modifying influences on climate. We can take space to glance only at the relative height of their several regions. This, in a general view, is least in high latitudes and greatest in low ones, or increases onward from the frozen ocean to the tropics. Europe is computed to have a mean elevation of 671 feet above the sea; North America, 748 feet; South America, 1151 feet; and Africa probably about 1200 feet. But the mountain regions, or even the mean levels of South America and Africa, as compared to those of all Asia north of the subtropical Himalayas, are very much higher. Nor do the greatest altitudes, in any case, occur quite at or near the equator, but so far north or south of it as they are most needed,-in the Himalayas $27 \mathrm{deg}$. north of the equator in Asia, in the Peruvian Andes 18 deg. south of the equator in South America, and probably in great groups both a few degrees north and a few degrees south of the equator in Africa. "Here," to adopt the words of Arnold Guyot, the recent luminous expounder of the relations of earth and man,- "here is one of the great compensations, one of the great harmonies of nature. The effect of this law of arrangement is to temper the burning heats of these regions, and to give them a variety of climate, which seems not to belong to these countries of the globe. If this order were reversed, and the elevation of the lands went on increasing towards the north, the most civilised half of the globe, 
at the present day, would be a frozen and uninhabited desert."

The oldest chains of mountains are the least elevated; and the newest are the most lofty. The succession of ranges southward from the Frozen Ocean to the grand watershed of the Himalayas and the Alps, and westward from the Atlantic to the grand watershed of the Rocky Mountains and the Andes, is less a succession of comparative loftiness than a succession of comparative newness. The oldest, too, are the most softly featured; and the newest are the most abrupt, broken, rugged, precipitous, and sublime. Some sandstone ranges have wild fissures and mural fronts, and some limestone ones abound with fairy caverns and romantic tunnels; but most of the same class-formed by water deposit, and not much altered by any fiery convulsion-are tame and hummocky and rounded. Ranges of gneiss and mica-schist and clay-slate and other metamorphic rocks, which have been altered chiefly by slow upheaval and intense baking heat, are generally lumpish and hoydenish,--often massive but seldom picturesque. Ranges of upburst granite-flanked with other rocks through which the granite has leaped, and mounting to the heavens in mass over mass of the crystallised upburst-have commonly forms of rich grandeur and diversified beauty and romantic magnificence,--sometimes piled aloft like the cumulus cloud, sometimes rising sheer up, as if they were rock castles and titanic bastions of the sky, and sometimes walled and domed and elaborately carved, as if they were colossal copies of Roman architecture. But ranges of the newest eruptive rocks - the basalts and greenstones and porphyries 
and other traps which are near akin to modern lava -are the most picturesque of all, - the most varied and lovely and awful,--the most intricately interesting and most savagely sublime,-full of delights and terrors, of tranșitions and contrasts, sometimes embosoming a little paradise, and overhanging it with stupendous cliffs, and sky-piercing pinnacles,- - some. times struggling aloft amid glaciers and perpetual snow, and terminating in inaccessible peaks or in "a fiery crown;" and, in general, they rise with somewhat easy gradients on the side toward the older country, and fall precipitously and terrifically down on the new side.

Alpine mountains, therefore-besides attempering climates, arresting rain-clouds, and serving as magazines of water for the many long rivers which flow from them-exert a mighty though silent influence on human sentiment. Their scenery is all power and poetry; and wherever it possesses the bold, abrupt, diversified character of Switzerland and Peru, with air-cleaving peaks, sheer-down precipices, day-dark chasms, and sudden alternations of craggy pasture and flowery glen, of gloomy cavern and sunny slope, of sublime snow summit and profound lake or vaulting cataract, it makes large expansions of the human heart. On persons who first behold it in their mature age, after having spent all their previous life in low flat countries, it may. do no more than rapidly enlarge their habitual energies, or roughly evoke their slumbering poetic sympathies; but on such as have lived among it from their earliest years, and have ever aided its influence by athletic exercise over its tremendous surfaces, it stamps deeply and permanently greatness 
of emotion, strength of will, and indomitable love of liberty.

There is something in stupendous mountain scenery, too, which fires to intensity the devotion of all devout minds, and whirls to heaven the aspirations of even laggard worshippers. And as much with reference to this, no doubt, as with reference to mere conspicuousness of position, or even to ennobling influence on the mind, is it said that, "in the last days, the mountain of the" Lord's house shall be established on the top of the mountains." The low-backed Mount Moriah bearing the Lord's temple over the yawning glen of Kedron, or even its larger and loftier neighbour, Mount Zion, "the joy of the whole earth," was as nothing compared with the snow-streaked dome of Mount Hermon or to the heaven-piercing summits of the "goodly mountain Lebanon." These sublimest altitudes of Syria, soaring away some ten thousand feet or more above the level of the Mediterranean, and often mingling with the clouds, or oftener rising far in the blue air beyond them, may readily seem to even calm contemplative spectators to be floating masses in the heavens, - middle grounds between sordid earth and serene sky, - the fittest of all spots on which devotion may set foot, in order to make a leap aloft to the celestial glory. And the still sublimer dome-peaks of the Alps or the Andes, shooting aloft from ravines and precipices thousands of feet deep, lifting all their bulk into the altitudes of perpetual frost, and glittering far in the heavens like sculptured masses of the purest alabaster, may easily be imaged by a poetic mind into the very emblems or ministers of devotion. That man knows little of the true power of Nature's 
wonders who does not feel warm sympathy with Coleridge's address to Mont Blanc:-

"Thou stupendous mountain

That as I raise my head, awhile bow'd low

In adoration, upward from thy base

Slow travelling with dim eyes suffused with tears,

Solemnly seemest like a vapoury cloud

To rise before me-Rise, oh, ever rise,

Rise like a cloud of incense from the earth!

Thou kingly spirit throned among the hills,

Thou dread ambassador from earth to heaven,

Great Hierarch! tell thou the silent sky,

And tell the stars, and tell yon rising sun,

Earth, with her thousand voices, praises God."

Multitudes of the landscape-views within and around the great mountain-ranges are glorious far beyond the power of pencil to paint, or of poetry to describe; and all are multiplied into thousandfold diversity, as if through the shiftings of an earth-big kaleidoscope, by the ever changeful conditions of weather in which they are seen. One from Mount Rigi, contiguous to the Lake of Lucerne in Switzerland, may be selected as a specimen. "In clear weather," says one of the best in the great crowd of modern publishing tourists, "ten great lakes are seen from this position, and seven smaller ones. The Dole, a Jura Alp, in the canton of Vaud, is visible on the one hand, and the village of Biberach, on the Lake of Constance, in the opposite direction, the distance between them being about 210 miles. When the writer and his associates reached the summit of this height, a range of Alps was clearly visible on one side, extending possibly a hundred miles from one perceptible extremity to another. On the other side, a dense cloud, rolling at the very feet, for- 


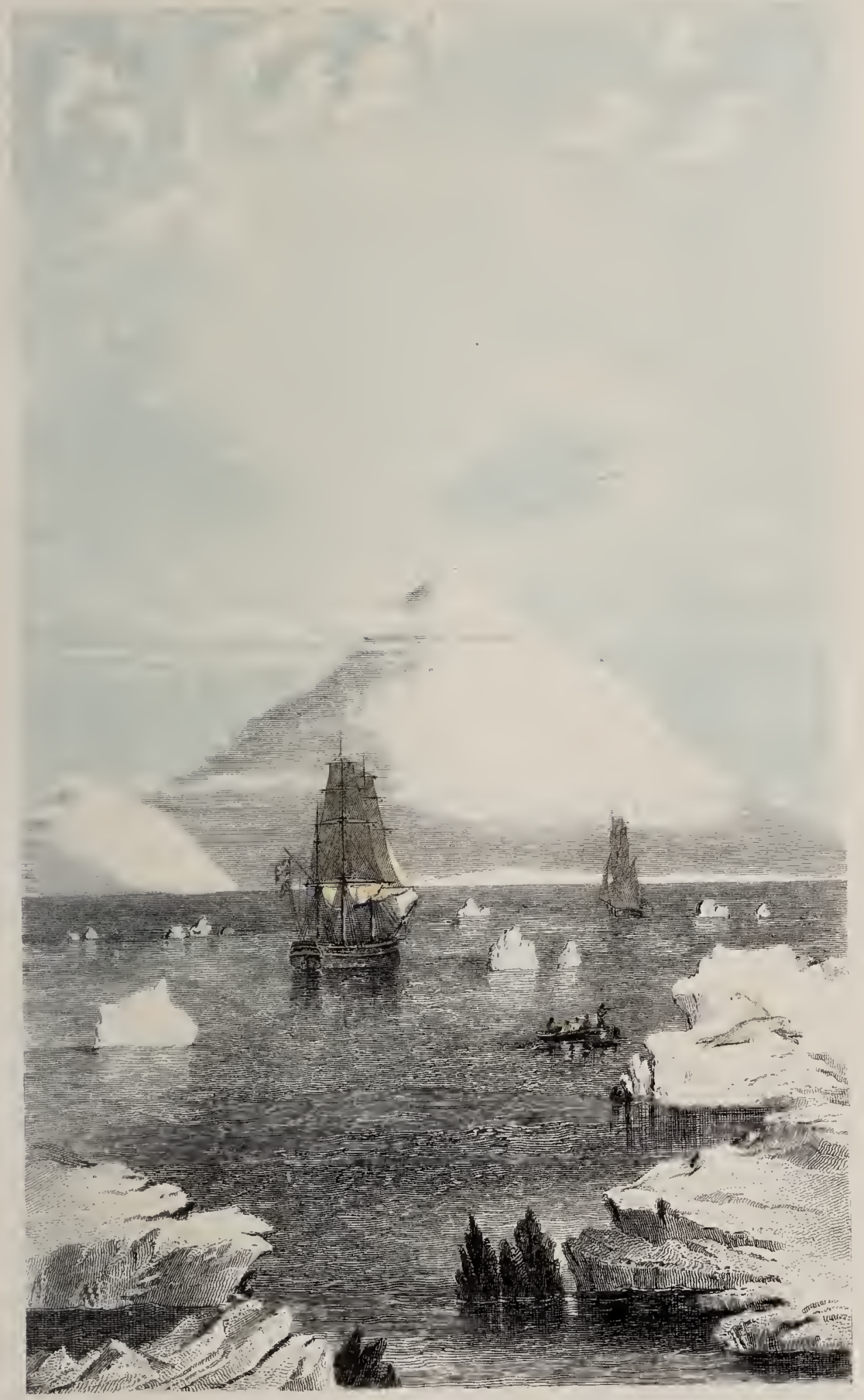

MOUNT EREDUS 

bade for a time all prospect. But while in the act of looking on this nebulous partition, as if struck by some invisible hand, it suddenly separated; part rolled to one side, part to another, and in an instant an immense country presented itself-rivers, forests, lakes, cities, belonging not merely to different cantons but different nations. Switzerland, Germany, and France, were all, to a greater or less extent, present in the survey, and brightened in general by unclouded "sunshine. The vast and splendid transition thus witnessed suggested to the writer's mind the more glorious change exemplified when the departing spirit, from looking into the darkness of death's valley, is instantaneously transferred to view the hills of holiness and tree of life and fountain of living waters in the paradise of God, illuminated by the cloudless beams of the Sun of Righteousness."

The coast of Victoria, the recently discovered antarctic continent, wonderfully combines the sublimities of alpine scenery with the horrors of the most frigid polar regions. Not an herb, not a moss, not even a lichen, variegates its everlasting coat of snow and ice. A vertical ice-cliff about one thousand feet thick, without a fissure, and with no other sign of relenting frost than gigantic icicles pendant on its projecting points, fronts it all, and forbids the touch of the foot of man. A stupendous mountain-range rises steeply up from the ice-cliff, peak above peak, nantled in perpetual snow, broken into countless masses, like an aggregation of colossal crystals, and presenting everywhere the fierce, rugged, sharply-featured contour of a volcanic origin. One peak, shaped like a vast crystal of quartz, lies aloft at a height of nearly eight thousand feet 
above the level of the sea. Steep escarpments and vertical precipices terminate the shoulders and offsets of the range; and, as they afford no surface sufficiently sloping for snow or ice to lodge, they present, amid the all-prevailing white frost, the intensely contrasted hue of jet black basalt. An active volcano, also, called Mount Erebus, soars to the altitude of between twelve and thirteen hundred feet, and discharges there picturesque, plume-like volumes of dense black smoke. This is figured in the accompanying picture.

Single mountains, whether rising sheer up from the sea as islands, or situated on plains or on plateaus, or on the shoulder-level of great ranges, are always grand features of a country, doing far more for its scenery than a tower does for a small town, or a St Paul's cathedral for a great city. But they are of rather rare occurrence, and the greater number are either active or extinct volcanoes. A few, like the Table Mountain of the Cape of Good Hope, have a tabular or altar-like shape; a few, also, are circular, or elliptical, or saddle-backed; but almost all the rest are more or less conical, either going regularly aloft like stupendous sugar-loaves, or remaining regular for a while, and then forking up in two or more summits, or climbing far in huddled and lumpish outline, and then shooting a spindly peak into the sky, or starting up slenderly and suddenly, and going through the clouds, and far beyond them, like a steeple many hundreds of times magnified. Mount Egmont, in New Zealand, is a grand example of the pure cone, ascending far above the line of perpetual snow, and visible at a great distance out at sea. Mount Ararat is a still grander example of the massive base and narrowing 
shoulders, with biforked summit; and at the same time possesses intense interest as the resting-place of Noah's ark. It rises from the plain of the Araxes, in Armenia, and lifts the higher of its two summits to the altitude of 17,210 feet above the level of the sea. The Peak of Teneriffe is a famous instance of the sky pinnacle, resting on tremendous escarpments, and looking down on the ocean from above the clouds. And the Peter Botte, in the Mauritius, though neither a regular nor very great specimen, is at least a very curious one, of the steeple mountain. A mural mass, fifteen hundred feet high, rises right up like a retaining wall from the plain; an esplanade about six feet broad, and sixty feet long, lies on the top; a cone of bare rock, so narrow as to look like a pinnacle, and upwards of three hundred feet high, goes right aloft from the end of the esplanade; and an enormous globular block rests on the apex of the cone, and overhangs it all round by several feet.

Great plateaus and great plains, were it for nothing but their vastness, are as truly wonders as great mountains. Most of Western Asia is little else than a tableland of from three to six thousand feet in height. All Central Asia, to the extent of 2400 miles in length, and 1500 miles in breadth, is a tableland of from five to fourteen thousand feet in height, flanked and traversed by immense mountain-chains, with the loftiest summits in the world. All Northern Asia, and most of Northern Europe, is an enormous plain, much of it a frozen waste, extending upwards of 6000 miles, all the way from the Pacific Ocean to the North Sea, through Siberia, European Russia, Germany, and the Netherlands. The south-west of 
Asia, throughout much of Persia, Mesopotamia, Syria, and Arabia, and also most of the Sahara of Africa, 2500 miles in length, and about 1000 miles in breadth, are flat, arid, burning deserts. Southern Africa, so far as known, is chiefly tableland; and at least twothirds of all Africa are supposed to be either tableland or plain.

These prodigious levels of the old world are almost as widely different as the loftiest hill and the lowliest valley, and even comprise most striking contrasts in their greatest characters; yet, with very small aggregate exceptions, they all agree in being wild and barren. But the great levels of the new world are, for the most part, exuberantly fertile. Vast plains constitute no less than two-thirds of all the surface of the Americas; and though ranging through every clime, from the middle of the south temperate zone to the neighbourhood of the arctic circle, they present little other differences than a diversity and rivalry of luxuriant vegetation.

The most southerly plains, called pampas, are chiefly flat, bosky, boundless expanses of tufted grass, spreading away like a slightly ruffled ocean to the utmost circumference of vision, and depastured by immense herds of wild horses and wild cattle. The plains of the Amazon, called silvas, are an undulated mass of woodland more than six times the area of France, and so densely occupied by tropical trees and shrubs and climbing plants, as to be penetrable by man only along the courses of rivers. "A death-like stillness," we are told, "prevails from sunrise to sunset; then the thousands of animals that inhabit the forests join in one loud discordant roar, not continuous, but in bursts. 


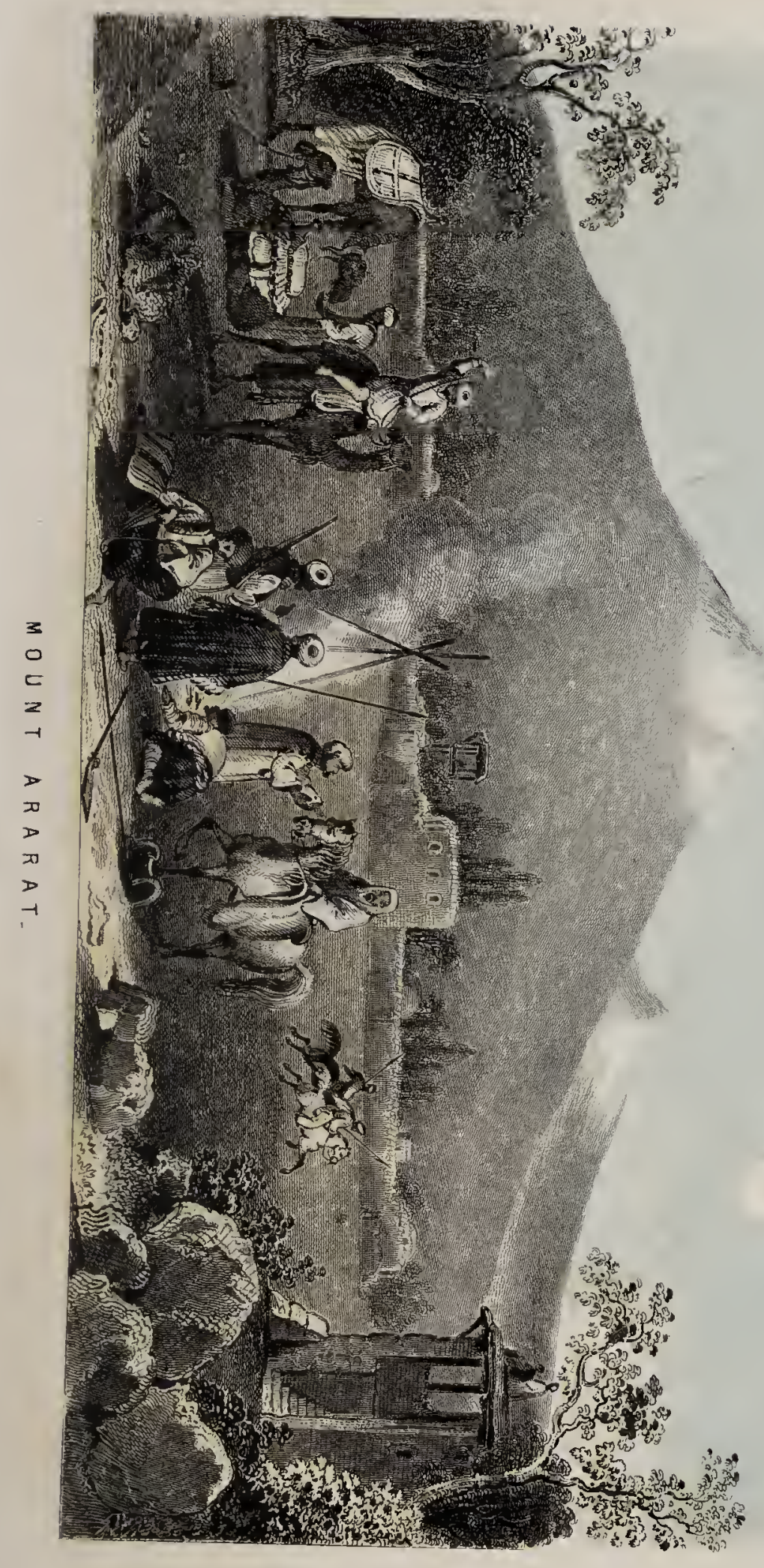



The beasts seem to be periodically and unanimously roused by some unknown impulse, till the forest rings in universal uproar. Profound silence prevails at midnight, which is broken at the dawn of morning by another general roar of the wild chorus. Nightingales, too, have their fits of silence and song; after a pause, they

'All burst forth into choral minstrelsy, As if some sudden gale had swept at once A hundred airy harps." "'

The plains between the equator and the tropic of Cancer, called llanos, are vast dead levels, at one time extensively overflooded by the swollen rivers, - at another reeking with red-hot evaporation under a cloudless vertical sun,-at another matted to denseness by the richest herbage,- -at another exsiccated to powder like a parched wilderness, - and occasionally, over a prodigious area, all in a blaze with accidental, furious, devouring conflagration. The prairies of North America-the characteristic portion of the immense and most luscious expanses which flank and re-flank all the stupendous river-system of the Mississippi-are best described by Bryant:-

"Lo they stretch

In airy undulations, far away,

$\Lambda \mathrm{s}$ if the ocean, in his gentlest swell,

Stood still, with all his rounded billows fix'd,

And motionless for ever. Motionless?-

No: they are all unchain'd again. The clouds

Sweep over with their shadows, and, beneath,

The surface rolls and fluctuates to the eye;

Dark hollows seem to glide along and chase

The sunny ridges. Breezes of the south, Who toss the golden and the fiame-like flowers, And pass the prairie-hawk that, poised on high, Flaps his broad wings, yet moves not-ye have play'd 
Among the palms of Mexico and vines Of Texas, and have crisp'd the limpid brooks That from the fountains of Sonora glide Into the calm Pacific-have ye fann'd A nobler or a lovelier scene than this? Man hath no part in all this glorious work; The hand that built the firmament hath heaved And smooth'd these verdant swells, and sown their slopes With herbage, planted them with island-groves, And hedged them round with forests. Fitting floor

For this magnificent temple of the sky,

With flowers whose glory and whose multitude

Kival the constellations. The great heavens

Seem to stoop down upon the scene in love-

A nearer vault, and of a tenderer blue

Than that which bends above the eastern hills."

Flat landscape in general, however, has no such inspiriting effect on men's minds as the prairies had on Bryant, but rather acts in a deadening way, and suits best a dull, prosaic, plodding population. Robert Hall's sensation at Cambridge, that his brain felt as if it were becoming as flat as the country around him, is well understood by every man of warm heart and springy mind, who emigrates from among mountains or hills to even a few days' residence on a plain. Yet the inhabitants of great flat fertile plains seem always impelled to wondrous stir and effort in the arts of useful industry or of cyclopean architecture. Hence much of the peculiarity of modern England, and nearly all the peculiarity of ancient Egypt, Babylonia, Assyria, and Central America.

Most valleys, whether great or small, and however replcte with interest, either consist mainly of plains, or owe their characteristics to blendings of plain and mountain. Yet a few are remarkable for very deep 
depression, the more so, too, for being occupied by water, and holding their very watery surface at a lower level than the level of the ocean. The basins of some of the lakes among the Alps have an enormous depth, and might be likened to millionfold magnified caldrons. The hollows occupied by several of the great American lakes appear to sink at least as low as the borders of the Atlantic. The surface of the Caspian Sea, and even the surface of a great extent of country round it, lies lower than the level of the ocean. The surface of the salt lake $A$ ssal, in the north-east wing of Africa, was recently ascertained to be between five hundred and six hundred feet lower than the surface of the ocean. And all the valley of the Jordan, from the Lake of Tiberias downward, lies below the level of the Mediterranean, and is by far the most depressed land in the world, and on that account is much hotter than probably any other tract at the same distance from the equator. The Dead Sea-lying like molten lead, in a deep black abyss, overhung all round by naked, straight-up, cindery precipices_has a level of no less than about thirteen hundred feet below the level of the Mediterranean, and at the same time has probably a depth within itself of as much more.

The passes through some mountain-chains from one lowland to another, or from lowland to tableau, are terrifically grand. Those of the Balkan, in European Turkey, are either most giddy and awful shelves along the face of precipices thousands of feet high, or dark, choked, and most rugged paths at the bottom of tremendous chasms, so deep and narrow as almost to exclude the light of the mid-day sun. The pass of the Terek, through the Caucasus, is overhung by walls of 
rock nearly four thousand feet high, and permits a view of only a ribbony band of the sky, dim and disguised, as if it belonged to another sphere, and often sustains the shock, and uproar, and dreadful peril of falling rock-masses, many thousands of tons in weight. The passes of the Himalayas proceed for dozens of miles above the line of perpetual snow, rarely culminating at a less height than three thousand feet above it, and are practicable in any way during only two or three months of the year, and never traversed without stern difficulty and fearful danger. At sixteen thousand feet above the level of the sea, the traveller is but beginning his toils; at higher stages, he now shudders beneath overhanging hills of rock, and now feels bewildered in a chaos of ice and snow; and, long before reaching the summit, he struggles on amid resistances as great as if he were both wrestling and in a fever. He totters in weakness, labours for breath, sinks several inches or a foot in the snow at every step, sits down exhausted to recover breath at every few yards, makes narrow escapes from falling rocks, and feels almost stiffening to a mummy in the folds of the freezing breeze. The passes of the Andes are, in some sense, more awful still, but have features of sudden transition-tremendous cliff, abysmal chasm, profound ravine, and wildness, savageness, sublimity all in the superlative, which a warm imagination cannot picture without dizziness, and no heart but the bravest can think of encountering without horror. A sublime view in the descent of one of their passes, overhung by peaks, and looking down upon the ocean, is shown in the accompanying picture.

The glens and gorges of many a mountainous region 



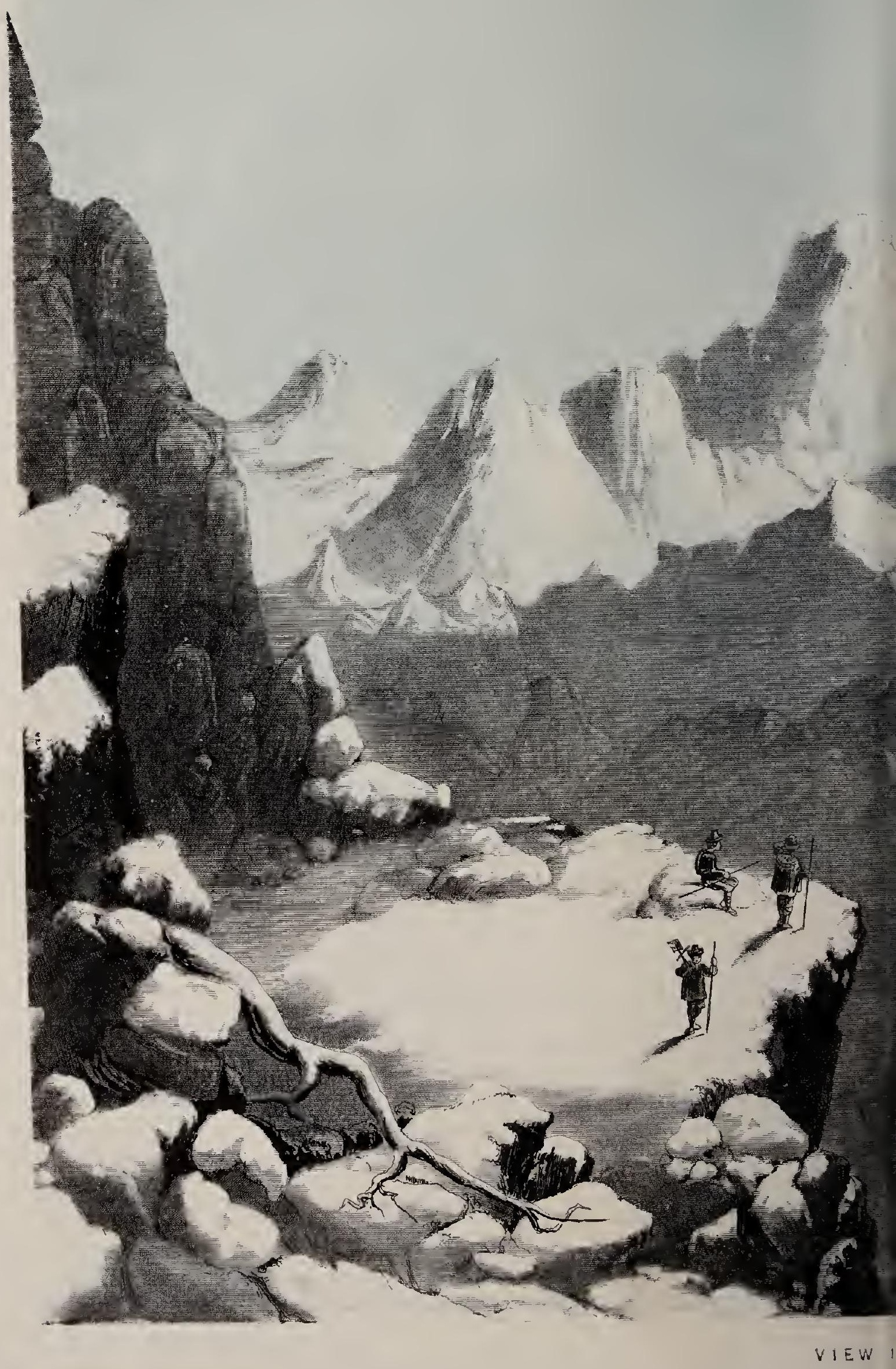



possess all the grandeur of the alpine passes without any of their dangers; and not a few, also, are right royally wealthy in the richest characters and strongest powers of landscape. Painters and poets are entranced by them; and the crowds of tourists who travel in "search of the picturesque," go to them as zealously as devotees do to a temple. As superb a specimen as we can select, though but a toy compared to thousands of sublime ones in other countries, is our own gorge of the Trosachs,- whose precipices are covered all over with ringlets, and festoons, and tangled masses of wood,- - whose central space is a tumult of fantastic, intricate, untraversable, tree-shagged rocky heights, and whose entire grouping seems a perfect revelry of the joys and wildnesses of defile scenery. Sir Walter Scott's description of it has been thousands of times quoted, yet, like the diamond from the mine, possesses such brilliance in the mere truth of nature, that no amount of handling can dim it:-

"The western waves of ebbing day

Roll'd o'er the glen their level way;

Each purple peak, each flinty spire,

Was bathed in floods of living fire.

But not a setting beam could glow

Within the dark ravine below,

Where twined the path, in shaduw hid,

Round many a rocky pyramí, Shooting abruptly from the dell Its thunder-splinter'd pinnacle: Round many an insulated mass The native bulwarks of the pass, Huge as the tower which builders vain Presumptuous built on Shinar's plain. The rocky summits split and rent, Form'd turret, dome, or battlement, 
Or seem'd fantastically set

With cupola or minaret,

Wild crests as pagod ever deck'd,

Or mosque of Eastern architect.

And high aloft the pine-tree hung

His shatter'd trunk, and frequent flung

Where seem'd the cliffs to meet on high

His boughs athwart the narrow'd sky.

Highest of all, where white peaks glaneed,

Where glistening streamers waved and danced,

The wanderer's eye could barely view

The summer heaven's delicious blue:

So wondrous wild, the whole might seem

The scenery of a fairy dream."

In some of the American prairies are profound narrow water-courses, which might be called subterranean defiles. They sink sheer down from the general level of the plains, and cannot be seen by a traveller till he arrives at their brink; and, except that they were slowly formed by the eroding action of the brooks which run along their bottom, they have all the character's of chasms in the earth. A very large one, described by a literary gentleman who accompanied one of the hostile expeditions of the United States against Mexico, is about a thousand feet deep, and from nine to fifteen hundred feet wide, and contains, in wild mixture with debris and ruin, a multitude of vast, beautiful, symmetrical forms, which look almost as regularly architectural as if they were works of art. Some of these are mere strata of hard clay, with the appearance of huge walls; but others look like bastions, columns, arches, castellated piles, and frowning turrets. "Niagara," says the discoverer of them, " has been considered one of Nature's wildest freaks, 
but Niagara sinks into insignificance when compared with the wild grandeur of this awful chasm. Imagination carried us back to Thebes, to Palmyra, and to ancient Athens, and we could not help thinking that we were now among their ruins."

Grottoes, caves, caverns, and naturel tunnels are, in some sense, clefts and chasms and ravines embowelled in the earth. They abound on many bold coasts, in many limestone countries, and in many trap-rock districts; and those of coasts and islands were formed chiefly by the action of the ocean billows; those of limestone districts by currents of air, and of fresh water; and those of trap-rock districts, by the heavings and outbursts of volcanic fire. Some, also, in all sorts of country, though principally among hills and mountains, were formed by the crash of land-slips and the roll of earthquakes. Many are wonderful for their very largeness; and multitudes of both the large and the small teem with both historical and natural interest. They are the "depths," the "clefts of the rocks," the "deep places of the earth," mentioned with such grand poetic power in Scripture; and they figure often and prominently in the most romantic passages of both sacred and civil history. Some have been the homes of "dwellers in the caves," some the retreats of the persecuted, and some the haunts of bandits, devotees, and heathenish impostors. A few are packed with the bones of quadrupeds who perished in them at epochs before the creation of man; and many have been used as places of human sepulture, - - the small ones as tombs, and several large ones as cities of the dead. Some are little else than tremendous holes, diving either direct down, or with a rapid descent, to an enor- 
mous depth in the earth. Others are horizontal crevices, winding to unknown distances within the bosom of great mountains. Others are tunnels through an island or through a hill; and one of these, in a lofty mountain of the Dodi chain, is so straight, and in such direction, that, in two months of the year, the sun looks through itas through a pipe, and sheds thence a curious and charming light on the valley below. A few are arched openings set round with basaltic colonnades. But the great majority of the largest and most wonderful are series of lofty and spacious halls, connected by narrow and winding passages, and, in some instances, extending for miles, or to unknown distances; and nearly all, whether large or little, which occur in limestone districts, possess groups. of stalagmites, stalactites, and other calcareous formations, white as snow, beautiful as alabaster, and intensely more interesting than the most richly chiselled collection of fancy architecture or grotesque statuary.

Two magnificent series of limestone caves exist in the United Kingdom, - the one called the Peak Cavern, in Castleton Dale, and the other called the Kingston Caves, in the county of Tipperary. But we select, as a specimen, the still larger and more gorgeous cave of Adelsberg, in the province of Carniola, between Trieste and Labiana. Prodigious caverns and enormous tunnels intersect all the mountains of that region, and ramify off in so many directions, and with such mazy windings, as utterly to defy exploration. The cave of Adelsberg opens along the course of a river, which wanders among them through an unexplored distance of at least fifteen miles. The entrance for visitors to the cave is through an aperture high up the face of a 
precipice; and the path inside has been followed several miles, and leads sometimes close along the river, and sometimes to places so far above, that its hollow, muffled roar can scarcely be heard. Two bridges, nearly a mile asunder, have been formed over the stream by the stalagmites, and the inner one hangs aloft at an altitude of from five hundred to six hundred feet. An American writer says:- - We advanced with ease through the windings of the cavern, which, at times, was so low as to oblige us to stoop, and at times so high, that the roof was lost in the gloom. But everywhere the most wonderful varieties of stalactites and crystals met our admiring view. At one. time, we saw the guides lighting up some distant gallery far above our heads, which had all the appearance of verandahs adorned with Gothic tracery; at another, we came into what seemed the long-clrawn aisles of a Gothic cathedral, brilliantly illuminated. The whimsical variety of forms surpasses all the powers of description. Here was a butcher's shop, which seemed to be hung with joints of meat; and there a throne, with a magnificent canopy. There was the appearance of a statue with a bearded head, so perfect, that you could have thought it the work of a sculptor. And further on, toward the end of our walk, the figure of a warrior, with a helmet and coat of mail, and his arms crossed, of the illusion of which, with all $\mathrm{my}$ efforts, I could not possibly divest my mind. Two stalactites, descending close to each other, are called, in a German inscription over them, with sentimentality truly German, 'the union of two hearts.' The resemblance is certainly very striking. After passing the 'Hearts,' we came to the 'Ball-Room.' It is cus- 
tomary for the inhabitants of Adelsberg and the surrounding country to come on Whit-Monday to this grotto, which is brilliantly illuminated; and the part called the ball-room is actually employed for that purpose by the peasantry. A gallery very appositely formed by nature, serves the musicians for an orchestra; and wooden chandeliers are suspended from the vaulted roof. It is impossible for me to describe minutely all the wonderful varieties - the 'Fountains,' seeming, as they fall, to be frozen into stone; the 'Graves,' with weeping willows waving over them; the 'Picture,' the 'Cannon,' the 'Confessional,' the 'Pulpit,' the 'Sausage-Maker's Shop,' and the 'Prisons.' I must not omit mentioning one part which, though less grand than many others, is extremely curious. The stalactites have here formed themselves like folds of linen, and are so thin as to be transparent. Some are like shirt-ruffles, having a hem, and looking as if they were embroidered; and there is one called the ' Curtain,' which hangs exactly in natural folds, like a white and pendant sheet. Everywhere you hear the drippings as of a continual shower, showing that the mighty work is still going on, though the several stages of its progress are imperceptible. Our attentior was so excited, that we had walked two hours without feeling the least fatigue, or being sensible of the passage of time. We had gone beyond the point where most travellers had stopped, and had been rewarded for it by seeing stalactites of undiminished whiteness, and crystals glittering, as the light shone upon them, like unnumvered diamonds."

The famous caves of the island of Staffa owe all their characteristic beauty to their basaltic colonnades. 
The whole façade of the island, and the arches, sides, and flooring of the caves, strikingly resemble architectural structures, and have been described by architectural terms. The great cave, or Cave of Fingal, in particular, is a grand hall of exquisite forms and wondrous symmetry-

"Where, as to shame the temples deck'd

By skill of earthly architect,

Nature herself, it seem'd, would raise

A minster to lier Maker's praise."

And even some of the bare spots on the summit-surface of the island present such a compact agglutination of the ends of columns, jutting up from the amorphous rock, as closely resembles a tesselated pavement.

A number of other places in the United Kingdom, however, to say nothing of other countries, exhibit ranges of columnar basalt in other styles, and to the full as interesting. The hills which environ the sweeping valley of Altivaig Bay, in the Isle of Skye, rise with surpassing magnificence, in tiers of basaltic colonnades, to the height of from one thousand to fifteen hundred feet. Long columnar ranges form a basement to the tiers, and similar long ones stand along the crest of the hills, and increase in height as the curvature recedes; and the three sets of colonnades-basement, tiers, and orest-make a display of́ Nature's architecture so sublime and mighty, as to dwarf the most boasted efforts of man, the Parthenon and the Colosseum and the Egyptian Temples, into insignificance.

The island of Rathlin, off the north coast of Ireland, contains basaltic columns in surprising variety of shape and position; and some of them lie curved, in conformity with the surface on which they rest, and 
look almost as if still soft and plastic, and in the act of cooling. The magnificent promontory of Fair Head, nearly opposite this island, comprises a mural precipice of colossal greenstone columns about two hundred and fifty feet high, and a shelving descent of several hundred feet thence to the sea, strewn with enormous masses of fallen rock, in the awful vastness and utter confusion of a chaos. The Giant's Causeway, twelve miles west of Fair Head, is as famous as Staffa, and as worthy of its fame. The coast contiguous to it, to the extent of nearly three miles, is a continuous gallery of columnar cliff scenery, partitioned into chambers by little indentations of the sea, and comprising grand colonnades, sublime abutments, and picturesque caverns, arches, and isolated stalks. The Causeway itself is a platform of about two acres in area, and from one foot to thirty feet above the level of the tides, projecting into the sea from the base of a basaltic cliff of about four hundred feet in height. Excepting the matter of whin-dykes, which cut it into three divisions, it consists entirely of columnar basalt, and it is computed to contain about thirty-five thousand distinct polygonal columns, altogether exquisite, both in their individual structure, and in their aggregate amassment. The cascade of Regla, near the famous mines of Moran, in Mexico-a waterfall first made known to Europeans by Humboldt, who visited it in 1803-is flanked by basaltic colonnades of singular elegance and grandeur. Most of the columns are vertical, but a fow are horizontal, and some lie at a variety of angles. The colonnades are crowned with shrubs and trees, and they combine with the cascade to form a most striking picture. 


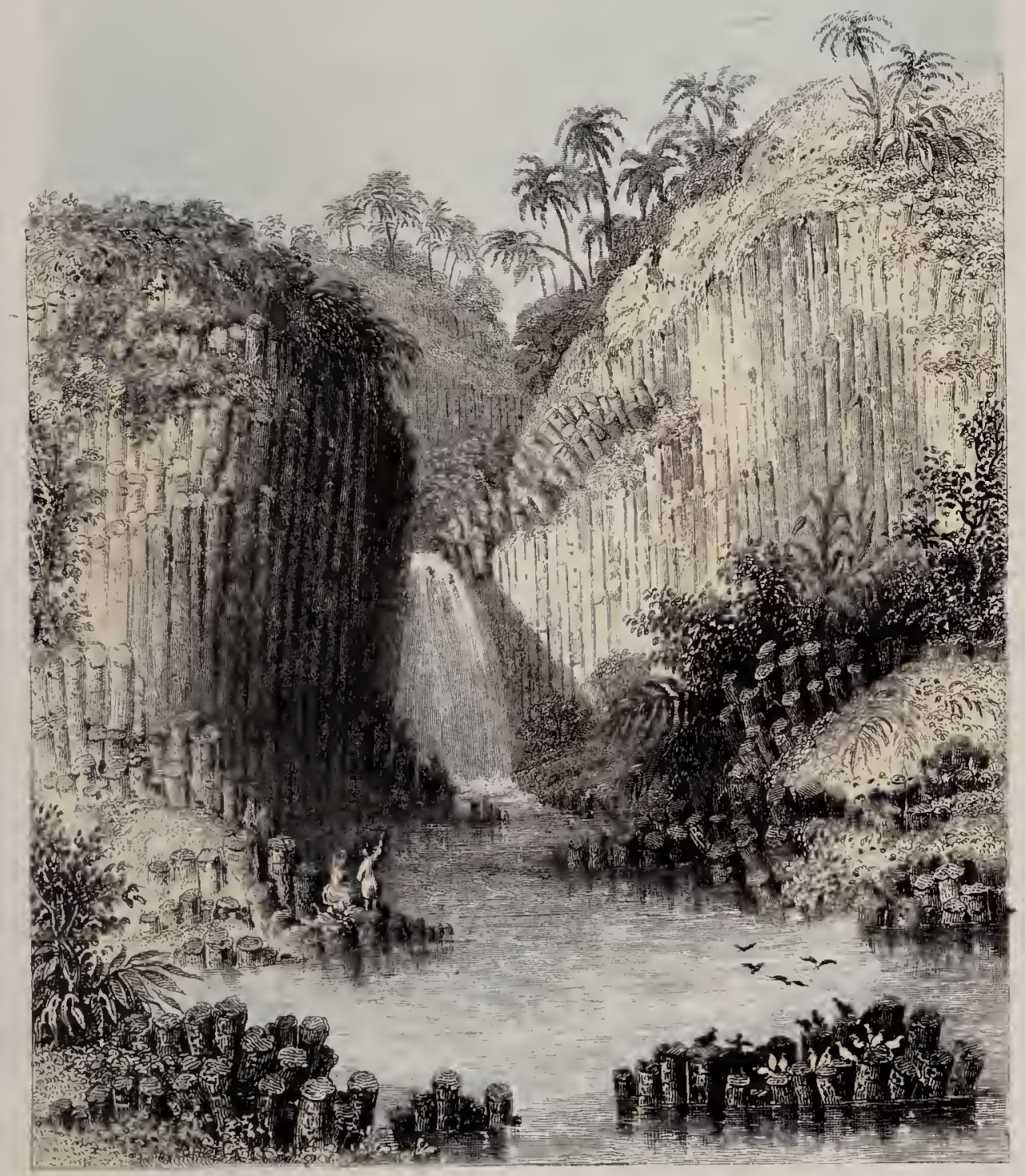

BASALTIC ROCKS DF REGLA 



\title{
CHAPTER IX,
}

\author{
LAND AND SEA
}

\begin{abstract}
GLACIERS-AVALANCHES - LAND-SLIPS AND MOUNTAIN-FALLS-EARTH* QUAKES-VOLCANOES-CAUSES AND USES OF VOLCANIC ACTION.GEYSERS-SPRINGS-RIVERS-CATARACTS - LAKES-TORRENTSFLOODS-SEA EROSION-ELEVATIONS AND SUBSIDENCES OF DRYLAND AND SEA-BOTTOM-THE OCEAN.
\end{abstract}

Is the preceding chapter, we have dealt with the firm parts of the world's surface; and in this we shall deal with the shifting parts. And we begin with glaciers.

These are slowly descending fields of viscous or slightly liquid ice. They commence at the snow-line of mountains which possess a great area within the altitudes of perpetual frost. They are formed and fed by the slow liquefaction and subsequent congelation of decending snow-masses; and may be regarded as offsets of the perpetual snow-fields, creeping down the hollows and declivities of the mountains. They move at no quicker a rate than from twelve to thirty feet in the year; but they move with prodigious power, tearing up the ground, transporting great blocks of rock, carrying everything before them, and even traversing the bottom of a glen, and forcing their prow some little way up the opposite acclivity; and they are believed by many geologists to have been the agents of some great changes on the surface of the globe. 
At least four hundred large ones occur in the regions of the Alps. These are the grandest glaciers in the world. They vary in length from three to thirty miles, and in thickness from one hundred to six hundred feet, but rarely have an extreme breadth of more than two miles. When seen from sufficiently elevated spots at a distance, they look like tumultuous torrents, suddenly arrested and solidified in their headlong rush down the sinuosities of their bed. Their entire mass is rent in all directions by profound fissures. Their upper parts have a whitish colour and a wildly rugged surface. Their middle parts display a gloriously blue tint sometimes passing into green, and are knobbed and pinnacled and turreted with numerous isolated ice-blocks of the most fantastic shapes. Their lower parts have the same bright cerulean hue as the middle parts, and undulate rapidly down like wavily flowing river's. And their sides, and sometimes portions of their interior, are surmounted by walls and cliffs of ice occasionally sixty feet or upwards in height, and usually beset with masses of rock. How strongly suggestive are these glaciers of the silent power and allimmersing glory of the Upholder of the universe! Well may we exclaim with Coleridge, in his Hymn before Sunrise in the Vale of Chamouni,

"Ye ice-falls! ye that from the mountain's brow Adown enormous ravines slope amainTorrents, methinks, that heard a mighty voice, And stopp'd at once amid their maddest plunge! Motionless torrents! silent cataracts ! Who made you glorious as the gates of Heaven Beneath the keen full moon? Who bade the sun Clothe you with rainbows? Who with living flowers Of loveliest blue, spread garlands at your feet? 
God! let the torrents, like a shout of nations,

Answer! and let the ice-plains echo, God!

God! sing ye meadow streams, with gladsome voice!

Ye pine groves, with your soft and soul-like sounds!

And they too have a voice, yon piles of snow,

And in their perilous fall shall thunder God!"

The glaciers sometimes invade cultivated tracts, and pass into near juxtaposition or immediate contact with grass-lands, corn-fields, orchards, and the habitations of men. The "silent cataracts" literally blend in very limited landscape with the "pine groves" and the "meadow-streams." But they do not always descend harmlessly; for such as creep down declivities terminating in precipices occasionally fling off masses of suffi-. cient bulk to do havoc upon anything which happens to be in the vicinity of their fall. A singular instance of this occurred in 1819, in the valley of Visp in Valais. A piece fell from a lofty precipice into that valley of so great size as to cover an area of one thousand feet in breadth and two thousand four hundred feet in length, to the depth of one hundred and fifty feet. In the neighbourhood of the place stood the village of Kanda; and the mere gust of wind produced by the fall destroyed the village, overthrowing the houses, breaking down a massive steeple, carrying away some roof-beams to the distance of nearly a mile, and whirling off millstones from the ground to a slope several yards above where they lay.

Snow avalanches, however, are vastly more destruciive, and are a chief class of the sublimities and terrors of alpine regions. Those which are persistent enough to slicle in one sheet, descend with little noise, yet sometimes make lodgments in the valleys which seri- 
ously alter the climate, and do not melt away for several summers, - and sometimes also uproot small forests, overwhelmn flocks, and destroy villages. In 1749, one came silently down in the night on all the village of Rucras in the canton of the Grisons; and the inhabitants, on awakening in the morning, remained a while ignorant of what had happened, and simply felt surprise that the day did not break. Sixty of them breathed well and long enough through the interstices of the snow to be afterwards dug out alive.

Drift avalanches, or those which consist of loose snow, are more tremendous by far than the sliding ones. They often descend from vast heights, and in prodigious masses, and with awful velocity. They were long supposed to be set agoing by even the most trivial vibrations of the air,-such as those arising from the tinkling of a bell or the foot-fall of a traveller; but they are now known to originate in violent gusts of wind striking suddenly agaainst the upper altitudes of the mountains, and unaccompanied by any current in the valleys. The first moving masses are sometimes very large, and often launched off with furious impetus; and, even when small and gentle, they rarely fail to drive before them an accumulation of bulk and force which comes roaring down like an orchestra of cataracts and thunders. The mere compression of air, or sudden local squall, produced by some of these avalanches is strong enough to uproot the largest trees, to fracture rocks, and to scatter loouses like chaff.

We naturally pass from avalanches to land-slips and mountain-falls; but shall first glance at the curious phenomenon of travelling bogs. A notable instance 
of this occurred, in the summer of 1821 , in the barony of Kilcoursey in Ireland. The bog had a depth of about forty feet, and an area of about five hundred acres, and was situated on a gentle slope, overlooking a narrow vale. The lower part of it was pulpy, and suffered a pressure of water from above, and suddenly broke bounds, and began to move away with the whole superstrata. The bog, once in motion, travelled with surprising speed down the slope and along the vale, and drove before it large slices several feet thick of coarse meadow-ground which lay in its way, turning them over and heaving them along like the surging of sea-billows. It was arrested for some time by a hill; but it eventually got round this, and went off at a right angle from its original course. Though twice arrested by subsequent obstacles, it surmounted them also; and continued to march so menacingly onward, that prompt and powerful engineering operations had to be performed to bring it to a halt.

Land-slips, in most instances, are caused by the loosening or wearing action of percolating water upon under-strata of sand or gravel. A singular one occurred a few years ago on the slope of a high conical hill in the state of Vermont, in North America; and, among other curious effects, carried a set of farmoffices, without injury, from their own farm into the grounds of a neighbouring proprietor. A gentleman, who was transacting business in the dwelling-house with the farmer at the time when it happened, thus graphically describes it:- " $A$ s we were in the act of reading over some papers preparatory to their being signed by us, we were startled by a sudden explosion. Our first impression was, that a piece of artillery had been dis- 
charged in the rear of the farm-buildings; but, after reflecting on the exceeding improbability of such an event, we referred the detonation to an earthquake, or some subterranean convulsion. For the next few minutes we sat in a state of considerable alarm, which was a good deal augmented on hearing unusual sounds from the byres and stables, as if the cattle were struggling to get loose. Just as we started from our seats, by a sort of instinctive resolve to ascertain the cause of this singular occurrence, we suddenly felt the house in motion. At first it was a violent jerk, then a movement onwards, not unlike the starting of a ponderous railway train. Gradually the motion increased, until we felt ourselves moving along at a rapidly accelerating rate. It was a clear, starry night, and I could see the boughs of the trees in the distance passing the windows, just as we perceive the transit of similar objects from the windows of a travelling vehicle. This continued for two or three minutes, and then there was a sudden stop, producing another violent jerk, which threw my friend and me to the opposite end of the room. We ran immediately to the door, and our astonishment may be more easily conceived than described on discovering ourselves in an entirely new locality. I saw at once that a land-slip had taken place; but, although I have read of similar occurrences in the districts around the Alps, I was not prepared for so remarkable an instance as had just taken place. We found ourselves at least a quarter of a mile from the original spot. The farm-house and out-buildingss were all entire. A range of poplars which grew in the neighbourhood of the barn, still occupied the same relative position to that building. The only change 
observable was, that a stream which flowed a little below the farm-houses had entirely disappeared."

One of the most awful mountain-falls on record occurred in the year 1248, about five miles south of Chamberry, in Savoy. A part of Mont Grenier, an abutment of the Alps, was precipitated into the adjacent plain. It is computed to have bcen four hundred millions of tons in weight, and to have come to the ground with a velocity of not less than three hundred fect a second. It fell from a height of threequarters of a mile, and flung its extremities to the distance of nearly three miles. It covered five parishes, and so dceply buried a town, that not a vestige of the place has cver been obtained, with the exception of a small bronzc statue. The noise and concussion of the fall must have been inconceivably terrible. The debris now exists in the form of small, conical hills; and a large standing portion of the mountain shows evident symptoms of rapid preparation for another catastrophe. A similar mountain-fall took place in 1806, in the valley of Goldau, in Switzerland, filling part of the Lake of Lowcrtz, burying four villages, and killing upwards of four hundred human beings and many hundred cattle. These appalling occurrences remind us of the withering terror of infidels at the last day, when they shall say to the mountains, "Fall on us, and hide us from thr face of Him that sitteth on the throne, and from the face of the Lamb; for the great day of his wrath is come, and who shall be able to stand?"

But far more dreadful than mountain-falls are great earthquakes and eruptive volcanoes. Thesc are now, and ever have been, the chief agents in sudden, violent, and extensive changes in the world's surface. 
They occur only at rare times, and at remote distances, and yet have, at some period or other, powerfully affected almost every part of the earth. They also excite in the minds of all classes of men the most intense interest, and give to all sorts of tales of wonders their most favourite topics; insomuch, that in countries where they have been little or not at all experienced since the creation of man, they are as well and almost as universally known as in regions which are frequently shaken with their terrors. Yet nowhere does their real nature, their grand design in the economy of the earth, or more than their superficial phenomena, provoke any very general inquiry.

The causes of earthquakes seem in a good degree, or perhaps altogether, to be the causes also of volcanoes. But what they are is not known. Something, no doubt, is due to the elastic action of gases in cavities and crevices of the earth. A cavity of more than a cubic mile in capacity is believed, on the evidence of subterranean noises, surface tremblings, and pendulum experiments, to exist at no great depth in the tableland of Quito; and similar cavities, far below the reach of human observation, are supposed to abound in many parts of the great womb, from which, in series of volcanic throes, epochs and epochs before the human era, the "mountains were brought forth." But gases in these, and in the fissures connected with them, possibly do not much more than give play to an explosion after one occurs. And the question returns, What are the explosive agents? As good a theory as any-one which has met much favour among many of the highest class of savans-supposes that masses of potassium, sodium, calcium, magne- 
sium, iron, and sulphur lie deposited at great depths in the carth, that copious percolations of water occasionally reach them from the ocean and from rivers, and that the oxygen of the water combines with them on so large a scale as to produce sudden violent combustion and sudden violent explosion. The behaviour of water with potassium and sodium was explained in our chapter on Chemical Action; and the behaviour of it with iron and sulphur may be understood from the fact that, if a small moistencd mass of iron nilings and sulphur be buried in the ground, it will gradually become heated, and eventually take fire and explode. No products of hot upburst from the bowels of the earth, whatever be the form in which the upburst takes place, are more characteristic than compounds of oxygen and the substances we have named. Most earthquakes, too, are well known to have their foci either below the occan or at spots wherc streams are subject to occasional long-continued inundations. Active volcanoes also are situated chiefly in the close vicinity of the sea; most new ones rise up within the limits of the ocean; and great ranges of extinct ones occur in the interior of continents, in positions which the long progress of geognostic change has rendered distant from both sea and inundation.

But be the causes of subterranean convulsion what they may, all men may most assuredly regard them as under the constant, minute, beneficent control of the all-gracious God. Earthquakes and volcanoes are doubtless managed with the same infinitesimal nicety as the germinating of a sporule and the hatching of an animalculc. The difference is, that, while the latter processes have reference cach to the simple being of 
only one microscopic creature, the former have reference to all the interests of innumerable billions of billions of all the kinds of creatures, vegetable and animal, small and great, irrational and intelligent, who inhabit the earth. And though occasional or incidental devastation accompanies the convulsions, this no more detracts from their beneficence than the point of the prickle does from the perfume of the rose, or the lash of storms from the glory of the seasons; but, on the other hand, it belongs to their moral phasis-to their connections with the moral history of man-to their instrumentality in the hortative, retributive, all-benign moral government of God, and therefore adds immensely to their significance. And in themselves they are directly a provision of food for incomputable throngs and successions of all the teeming life of the earth. Let any right-hearted man look up and around from the mere spot of an earthquake to all the vast hemisphere of being and of well-being which it affects, and he will speedily learn to think of it, not with profinund awe only, but with reverential wonder and loving devotion.

We cannot take space to follow out this thought; and we shall only add one or two leading hints. "Earthquakes," remarks the Rev. Thomas Milner, "unfold the long antiquity of the earth, teach us to contemplaterit in connection with an era compared to which an age is a span, and unfold the tendency of those milder agencies which are in incessant action upon it, and which, though slow workers, would effect extensive and disastrous changes in the succession of centuries, if there was no counteraction to them. Inequalities of the surface eminently adapt the globe 
to be the residence of man during his threescore ycars and ten, and of the myriads of different races of beings that inhabit it. But the waste of the elevated dry land is a gradual yet sure effect produced by the atmospheric and aqueous causes that constantly act upon it. These, without an antagonist power, would in time reduce the inequalities of alluvial countries ncarly to a uniform level; bring the habitable part of our planet down to the ocean line, and convert sccnes of fertility and busy life into vast lagoons and marshes, which only inferior orders of animals can occupy. The antagonist power is the subterranean uphcaving agency -a rare visitant_often at rest for ages-and then counteracting in the twinkling of an eye the effect of the rains, rills, torrents, rivers, atmosphere, and seas that have been preying upon the soil." And as to volcanoes, not only do they bring up from the interior of the earth vast supplies of the saline food of plants, the materials of what may be called the bones and sinews of plants, potash, soda, lime, magnesia, and compounds of iron, sulphur, and phosphorus, but they deposit them in exactly the forms and combinations which are most enduringly serviceable to the vegetable kingdom. Were these things to exist in beds like common salt, or in veins like metallic lodes, or in nodules like flints, or in superficial granular diffusion like the matter of clay and sand, they would speedily be all washed into the ocean, and leave all sorts of land plants to perish by famine. But in the manner in which they exist in the rocks of volcanic formation, and in other rocks which have been either thrown up or modified by subterranean combustion, they possess just the degree of solu- 
bility which makes them perfectly available for each race of plants, and at the same time prevents all waste. Thus are volcanoes and hot springs and all subterranean fires the storers-up of food for all land plants till the end of time; and either through the medium of dissolving waters, or through the medium of the esculent parts of these plants, or through the further medium of the smaller and less perfect ainmals in reference to the larger and more perfect, they are the storers-up also of the inorganic materials of the skeletons and the flesh of all generations of most kinds of the lowly organised animals, and of all kinds of the highly organised. The pre-adamite volcanoes, too, fashioned a large portion of the earth's surface into fit shape for the inhabitation of man, and put building materials and coal-beds and metalliferous rocks and most of the other great useful mineral deposits into positions of availability for the purposes of human society.

Many earthquakes are so slight as to be quite imperceptible; many more are barely strong enough to make themselves felt by very nice observers; and even some of the severe ones which are keenly felt by natives of the districts where they occur, or by other persons familiar with their action, are not perceived by strangers. Only the most violent-which are "few and far between"- do great havoc; and some of these tilt up rocks, overthrow precipices, overwhelm cities, absorb streams, and fracture, riddle, and other* wise alter considerable tracts of country. Their motion is sometimes vertical, in the manner of upward shocks, - sometimes horizontal, in the manner of undulations, oscillations, or tremblings,--and sometimes, 
though rarely, verticose, in the manner of a twisting or a partial whirling. Very few of even the violent earthquakes, however, do much damage at any considerable distance from their focus. And so surprisingly local are some earth-shocks, vertically as well as horizontally, that one has been felt at the surface, and not in a mine below, and one has been felt in a mine below, and not at the surface above. Yet the awful one which destroyed Lisbon, and which originated right beneath that city, did much havoc at such distant places as Cadiz and Algiers, and was perceptible by slight indications so wondrously far away as Seandinavia and the West Indies. Most modern earthquakes of any consequence occur in the vicinity of active volcanoes, and precede or accompany their most furious eruptions; and the worst, as to both frequency and force, agitate the chief volcanic regions of the Andes and the Pacific Ocean.

Volcanoes are generally conical elevations, terminating in a saucer-shaped summit or small hollow esplanade; and some may be regarded as systems,either extending in a chain along a mountain-range or along an island-range, or each with one grand central cone and a number of small subordinate cones. Those which became extinct before the creation of man, are innumerable; and, in some limited tracts of upland country, may be counted by the hundred. Those which are active at the present day, or which have at some recent time been in eruption, amount to nearly three hundred. Some occur in a line between the Azores and the Caspian Sea; a great number occur along the line of the Andes, and along the Mexican portion of the Rocky Mountains; and another great 
number occur in a sinuous tract between the most western points of North America, through Japan and Java, to the Bay of Bengal. Twenty-one are in Europe, eleven in Africa, one in the Antarctic continent, one hundred and fourteen in America, and one hundred and fifty-four in Asia and the Pacific. The grandest and most beautiful is Cotopaxi, a colossal summit of the Andes, lifting up a regular snow-clad cone nearly nineteen thousand feet into the sky; and the most singular and terrible is Kilauea, in the largest of the Sandwich Islands, a pyramidal, lofty, lumpish mountain-mass, hollowed into an abyss of nearly a mile in diameter, with numerous internal rents far down its tremendous, tumbling, boiling caldron.

A considerable eruption, in the case of any of the volcanoes, is a rare event; and happily is it so, for an eruption of the worst kind appals the bravest observers, and looks to the less brave like the dissolution of the world. Clouds of smoke darken the air; earthquakes shake or fracture the country; explosions in the bowels of the mountain make muffled roars louder than thunder; upbursts of flame and steam and stones leap aloft to the sky; streams of molten mineral, the red-hot liquidities of rocks, roll out from rents in the mountain's shoulders, and flow in sluggish fiery current down its declivities; and terrific volumes of ashes tumble up from the summit vent, and dispread themselves far and wide, and descend in murky showers over distances of many leagues. At the eruption of Tomboro, in the island of Sumbarva, in 1815, the explosive sounds were heard nine hundred miles away, whirlwinds on the island carried men and horses into the air, and the showers of ashes made the day as dark 
as midnight to the distance of three hundred miles, and laid great patches of cindery coat on the sea two feet thick at the distance of nine hundred miles.

Volcanic convulsions sometimes produce remarkable rents, upheavals, and subsidences. At the awfully destructive eruption of Etna in 1669, several fissures -one of which was six feet wide and twelve miles long-opened in the plain of St Lio, ejected vivid flame, and seemed filled with intumescent rock; and a town twenty milcs distant from the mountain was destroyed,-and two gulfs opened near its site, and began to vomit a quantity of sand and scorix, which, in the course of about three months, formed a conical hill of four hundred and fifty feet in height. In a single night, in 1759 , a tract of not less than three or four miles in extent, covered with sugar-cane and indigo plantations, in the plain of Malpais in Mexico, swelled into six mountain-masses of from thirteen hun-. dred to sixteen hundred and forty fect in height, together with numerous smaller cones; and the loftiest of the mountains thus suddenly formed is a permanent, ever-burning volcano,- the high-famed Jorullo. - At numerous periods, some of them.not many years ago, and at far asunder places, in the Mediterranean, in the Atlantic, and in the Pacific, new islands have appeared above water, accompanied violently and terribly by the characteristic phenomena of a great volcanic cruption; and in most instances, even when the islands were of considerable height and area, they afterwards slowly subsided, and left not a trace of their existence. In a night of 1772 , a luminous cloud enveloped the top and shoulders of the great volcano Papandayang, in the island of Java; and rapidly, with 
terrific convulsions and appalling noise, an area of the mountain and its environs, fifteen miles long and six broad, fell flat or hollow into the cavity below.

Some volcanic eruptions, among the loftiest Andes, where the belching cones ascend far above the line of perpetual snow, make astonishing jumbles of fire and mud and watery torrent. "Not only," says Humboldt, "does the sudden melting of the snow, in the course of an eruption, occasion destructive floodstorrents in which heaps of smoking ashes are floated away on blocks of ice: but the accumulation of ice and snow goes on producing its influence uninterruptedly, and by filtration, into the trachytic rocks, even whilst the volcano is perfectly quiescent. Caverns are thus gradually formed on the declivities or at the foot of the burning mountain, and these become subterraneous reservoirs of water, which communicate in various ways, by narrow mouths, with the alpine rivulets of Quito. The fishes of these alpine streams multiply greatly, particularly in the gloom of the caverns; and then when the earthquakes come, which precede all eruptions of volcanoes in the Andes, and the whole mass of the mountain is shaken, the subterraneous caverns at once give way, and pour out a deluge of water, fishes, and tufaceous mud."

A curious class of objects connected with volcanic action are boiling springs. Some of them boil very furiously; and others project their water, in the form of a jet, to a great height in the air. But the chief ones act in the way of intermitting burst. This probably arises from the absence of dissolved air in the hot water of the subterranean cavities, and can be artificially imitated, on a small scale, by exposing 
water deprived of air to a constant source of strong heat. The grandest instance occurs in what is called the great Geyser of Iccland. The basin of this is a smooth, silicious, saucer-shaped hollow, about fifty fcct wide, with a cylinder about eighty feet deep, and eight feet wide in its centre; and is situated on a large circular mound, whose outer skirts are profusely fringed with beautiful petrifications. At a burst of the geyser, explosions resembling cannon-shots take place below: the water in the basin sets a-boiling; a series of jets, each highcr than the preceding, leaps into the air; volumes of steam roll off from the jets, and shiver into foam and spray; thousands of streaks and archlets of the water glitter in all the colours of the rainbow: and the climactic jet, just before the geyser begins its relapse to quietude, forms, in its grandest instances, a magnificent round-topped column of from ninety to three hundred and sixty feet in height, all its sides seeming a garniture of gems, and all its summit looking as white as snow. This gorgcous phenomenon is fitly sung in the following lines of Montgomery:-

"He comes, he comes-the infuriate geyser springs

Up to the firmament on vapoury wings:

With breathless awe the mounting glory view-

White, whirling clouds his steep ascent pursue.

But, lo, a glimpse!-refulgent to the gale, He starts all nalied through his riven veilA fountain column, terrible and bright, A living, breathing, moving form of light. From central earth to heaven's meridian throne, The mighty apparition tower's alone, Rising, as though for ever he could rise, Storm, and resume his palace in the skies; 
All foam, all turbulence, and wrath below, Around him beams the reconciling bow, Whilst mist and spray, condensed to sudden dews, The air illumine with celestial hues,

As if the beauteous sun were raining down The richest gems of his imperial crown."

Springs of all kinds are interesting. They are fed by the percolation of surface water through porous strata in grounds elevated more or less above them, and are caused by such obstructions of the onward course of the water below as force it to rise through pores, or crevices, or apertures to the surface. They are hot or cold, according to the temperature of the strata through which the water runs. They are small or great, according to the extent of the subterranean basin in which tile water accumulates. They are regular or intermitting, perennial or seasonal, according to the character of the local climate, and the depth and closeness of the retaining basin. And they are hard or soft, fresh or brackish, common or medicinal, according to the nature of the mineral substances in the strata which the water takes into solution. Any very large one is simply the upburst of a subterranean river, and is fed by a system of affluents along an inclined basin in the bowels of the earth, exact.y as any ordinary river is fed by a system of affiuents along an inclined basin on the surfuce of a country. And, in some rare instances, the two things are combined: a stream forms from a surface river-system, dives into the earth, increases there from the rill-tribtues of a subterranean river-system, and then wells back to the surface in the manner of an enormous spring.

The river Robe, in the west of Irelind, is an example 
of this, and at the same time adds the fentures of large lake and curious cavern. Lough Mask extends in magnificence at what loose observers would call the mouth of the river; and the discharges of the lake, together with the rills which join them during a run of about four miles, traverse the tunnels of a wild region of cavernous limestone. They are heard, through various apertures, gurgling and whirling with muffled music far in the depths below; they prance and glitter for a moment at the bottom of several deep natural shafts, and then plunge anew into long caverns which eye of man never penetrated; and they eventually bolt up, at the ancient village of Cong, boldly and tumultuously in a vertical whirlpool as large in surface as a great pond. The whirlpool, the vast bubbling fountain, the river-spring, is as limpid as ether, as noiseless as a zephyr, and so. mighty in upburst, that all attempts to sound it have been vain; and, while it rolls in ceaseless convolution and in perfect beauty bcfore the eye, looking the very type of combined purity and power and perpetuity, it impressively illustrates those words of the ever-living and life-giving One-" My words shall be in him.a well of living water springing up unto everlasting life."

Streams have been the grand agents in forming and smoothening all sorts of natural tunnels, ravines, glens, vales, and valleys. They are the chief polisher's of the earth; and, though operating slowly, they operate steadily, and with prodigious eventual effcct. Earthquakes and volcanoes have not done more to shape the world's surface in the way of upheaval and convulsion, than streams, together with their auxiliaries of rain-fall and sea-current, have clone in the 
way of denuding, rubbing-down, disintegrating, cutting, scooping out, and levelling. Let any man look at the washed fields and turbid currents of any tract of country after a fall of rain, and he will see how streams are grinding down the earth every day; or let him look at the hundred ramified vales of any considerable river-system-their perfect relationship to one another, the short and narrow to the next in extent, the next to the larger, and the larger to the chieftheir exact fitness, in elevation, ramification, and direction, to the purposes of a general drainage into one trunk, and toward the sea-and their cuts, their gorges, their parallel lines, their decreasing gradients, their curving slopes, their slightly inclined expansions, their thousand indications of the long and silent abrasion of steady currents, - and he will see how streams have been grinding every region into pleasant contour, filling up its hollows, rendering its surface fit for the use of living creatures, and, if it be a coast district, pushing out its low, rich alluviums into the sea, ever since it was tumbled up in jagged outline or tumultuous mass by subterranean convulsion.

The Nerbuddah, in India, has worn a passage about a hundred feet deep through basalt. Several streams of the Eastern Alps have cut defiles six or seven hundred feet deep through horizontal conglomerate. The Moselle, in France, has cut a long winding ravine, in some places six hundred feet deep, through solid rock. The Niagara, in America, wears so rapidly the precipice at its celebrated falls, as to have made the cataract recede about a hundred and fifty feet within the last half century; and it flows for seven miles below the falls through an excavated rock channel which has all 
most evidently been formed by the same process of erosion.

The Ganges colours the sea with mud to the distanee of sixty miles from the coast, and is supposed to deposit daily beneath the tide a quantity of matter of equal bulk to the largest pyramid of Egypt. The Amazon, which is said to be forty miles wide at the mouth, and is computed to drain an extent of territory equal to five-sixths of Europe, eolours the ocean with mud to the distanee of about three hundred miles from the eoast. All the sea-inoseulating rivers are depositing beneath the oeean the materials of vast rock-formations preeisely similar to the sandstones and other stratified roeks of the existing continents; and all rivers whatever have, by deposits of debris and silt, at quite recent periods of the world's progress, formed most of the flat lands, no matter how extensive, whether marshses, meadows, savannahs, plains, or deltas, which lie at a small elevation above the present level of their banks. . Many rivers, also, have filled up deep or extensive lakes whieh at one time lay in their course, eonverting them into rich meadowy land; and many have elevated to a eomparatively great height the whole of the lower portions of their valleys, depositing on their original surface of rock or gravel thick fat strata of finely granulated earth. The Po-whieh reeeives numberless torrents from the Alps and the Apennines, and traverses the plain of Lombardy to the Gulf of Venice-not only has made vast deposits beneatl the tide, and pushed extensive eneroachments of land upon the sea, and formed the vast fertile fiats of all its great valley-but eontinues, since the time of . the close pressure of cultivation on its margins, to 
make such deep and constant deposits along its channel that the neighbouring inhabitants have long embanked it to prevent inundations of their country, and are in the practice of removing mud from its bottom to its banks, to the amount sometimes of one foot of depth in a season, and yet have been compelled progressively to increase the height and strength of the embankments, till at last all the lower part of the river's course has become a great aqueduct along the summit of a prodigious artificial mound, so lofty as to overlook the tops of the houses of Ferrara.

Not a few rivers, even some of the greatest, are, or have been, so wildly freakish as to indicate remarkable characters or striking changes in the configuration of their basin. The Orinoco, long after its volume has become great, splits into two streams, and sends one of them off as a tributary to the Amazon. The Oxus formerly flowed into the Caspian Sea, but now flows into the Sea of Aral. The young Tigris runs through the bowels of a mountain; the Rhone, soon aiter entering France, makes a dive under ground; and many small streams, in Derbyshire, in Connaught, in the Alps, in North America, and in other parts of the world, run along natural tunnels, or through vast caverns, or beneath great natural rock-bridges. The Mæander, the Forth, the Ouse, and some other streams, flow in mazy windings and serpentine folds, "in laby: rinth-like turns and twinings in tricate," often and often curving back upon their course, and "whirling themselves about," as if they would never reach the sea; and from the first of them our language has borrowed -its expressive word meandering. Other streams, such as those which conduct the melted snow down the 
abrupt side of alpine mountain-ranges, descend in mad haste, as right-down torrents and lcaping cataracts, falling in precipitous down-roar like rebel-angels flung out of heaven and rushing away from vengeance; insomuch, that one of those in the Swiss Alps makes a single leap of more than nine hundred feet free from the rocks, forming the famous Fall of the Staubbach:

" $O$ ' $\mathrm{er}$ the crags headlong perpendieular, Flinging its lines of foaming light along, And to and fro, like the pale courser's tail, The giant steed to be bestrode by Death As told in the A pocalypse."

Some rivers are curious from their colours, and other's from thcir conflicts with the sea. The Upper Mississippi is limpid; the Missouri looks like dirty milk, or as if it were full of chalk; the Ohio is greenish; and the Arkansas has a bright red colour: so that the Lower Mississippi is a blending of most diverse hues, from severally rocky, marly, meadowy, and clayey basins. The Rio Negro, an affluent of the Amazon, is dark brown. The two great head trunks of the Nile are respectively white and blue. Many a roaring, tumbling river is perpetually turbid. And some great turbid rivers, which always rush red and muddy into the ocean, with a force and volume as if they were runaway seas, kick up riots with the tides which terrify the boldest seamen. The Garnme and the Ganges are great examples of this; but the Amazon is the greatest. At the effux of the tide, that prodigious river goes down in style as if it thought to dispossess the Atlantic; and, encountering at right angles a powerful ocean-current which runs along that part of the American coast, the two bodies rear themselves up 
against eaeh other in roaring surges upwards of a hundred feet high.

The eataracts of streams-whether rapids, caseades, or stupendous falls-are a class of the most famous things in painting and song and story. We might speak with high interest of many-such as the cataracts of the Nile,-the rapids of the Shannon, the Geisbach, and the St Lawrence,- - the fall of Foyers in Inverness-shire,-the falls of Trolhetto in Sweden,the full of the Rhine at Schaffhausen,--the falls of Teverone and Velino and Terni in Italy,-the fall of Puppanassum in India,-and, above all, the falls of Kaaterskill, Trenton, Willberforce, Montmorenci, and St. Anthony, in North America. But we shall select only two,-first, a mere miniature one as compared to the sublime ones, yet a noble type of power and beauty in combination with other elements of the picturesque, the Falls of Clyde,- and second, the greatest waterfall in the world, the Fall of Niagara.

The basin of the Clyde immediately above the commencement of the falls ehanges both its superficial and its geognostic eharacter. Ifard erystalline roeks sucldenly eease to appear in its path; and horizontal sandstones, with some beds of shales, lying almost in the state in which they were clcposited in the early epochs of organie existence, form all its bed, and have allowed it to plough its way into a series of romantic gorges and stupendous leaps. Its flanks also are no longer either pastoral hills or meadowy plains, but bold or mural sereens of sandstone roek, tufted with wood, intricate with character, and overlooked by outspread or undulated surfaces of the richest valley. The river all at once ceases to be a plaeid stream, and beeomes a tur- 
bid, boisterous, frantic torrent, tumbling tumultuously down gloomy defiles, or vaulting headlong over perpendicular precipices-achieving altogether a descent of about two hundred and thirty feet within the region of its falls, and laying open a magnificent section of the earth's crust for the study of geologists, and the admiration of all lovers of romantic scenery. The first fall is Bomniton Linn, about two and a half miles above Lanark. It is a sheer leap of the whole river over a precipice of thirty feet; and has a projecting break in the middle of the breadth, which splits the descending mass of waters, and gives double power to their scenic efiect. The fall becomes an abyss, the abyss a river-torrent, and the river-torrent a rock excavator along a perpendicular chasm, of from seventy to a hundred feet in depth. This awful chasm continues for about half a mile from Bonniton; and everywhere jams in the roaring river to twilight darkness and the limits of a mill-race; and consists of such mural right-up precipices, that one of the earliest graphic writers on Scottish scenery aptly characterised them as stupendous natural masonry. At the end of the chasm, amid a sublime theatre of overhanging cliffs, salient rocks, and densely wooded surfaces, occurs the Corra Linn, the grandest of the falls. The river descends eighty-four feet, but is twice caught by ledges of rock, so that it makes three bounds, and becomes a vexed and weltering flood of foam. Its previous roar has now increased to thunder; its clouds of spray sometimes sparkle in all the hues of heaven; and its blendings of character with the crags and woods and witchery around it present a combination of sublimity and beauty which makes the imagination 
dizzy. The banks of the river soon assume a more soft and sloping character; and this they maintain over all the distance of about threc or four miles which intervenes to the last fall, sometimes bosky and luscious with wood, and sometimes cultivated to the water's edge. But at Stonebyres thcy once more become all rock and precipice, garlanded with wood. The descent here is a leap of about eighty feet, twice broken by shelvings of the precipice; the action of the falling flood is a compound of plunge and tumble, with circumstances of foaming uproar and deafening tumult; and the effect of the sccne upon eye and fancy is very similar to that of the Corra Linn, but less confounding, and more thrilling and ecstatic,-less replete with inages of power, but fullcr of magnificence and grace. And the lieart of a wise observer, who has looked on all the falls, adores profoundly at the feet of the Creator, and feels that the impressions it has received from this one spangle of the raiment with which he has clothed the earth, must glitter gloriously upon it for ever, and may serve well as a reminder of the unutterable and infinite things which exist in the beatific regions unknown to mortals.

The Niagara river carries the superfluence of the great central lakes of North America to Lake Ontario. It embosoms a number of low wooded islands, has generally a breadth of upwards of a mile, and is computed to discharge about an hundred millions of tons of water every hour. It derives little interest from the character of its banks, yet presents a majestic appearance in the mere might of its waters. Its current is smooth till about a mile from the Fall, then begins to ripple, then rushes into foaming rapid, then 


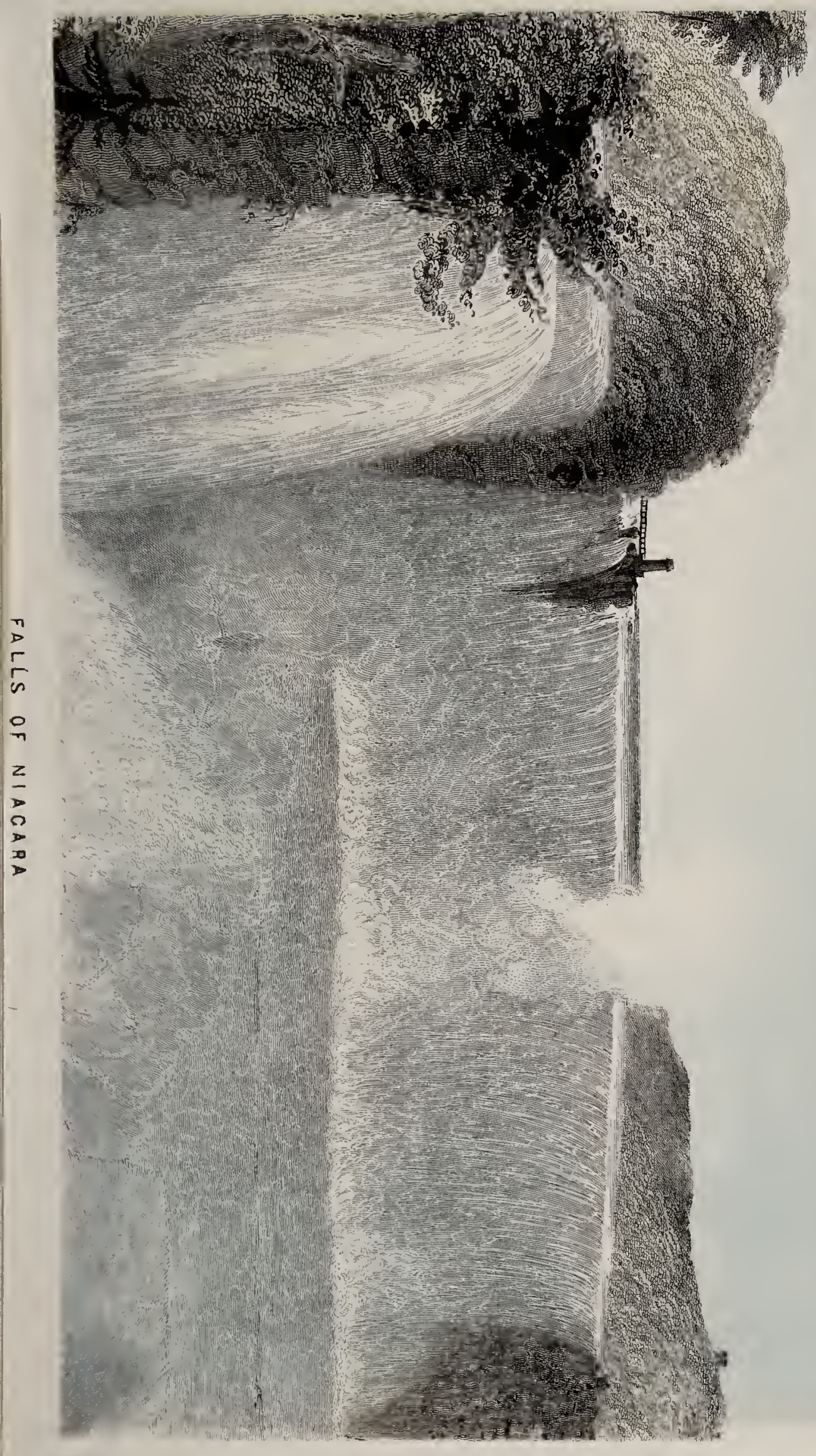



changes into sweeping roll, then splits at an island about 1000 feet in breadth, and falls headlong, in two masses, over a precipice from 150 to 164 feet deep. The lesser mass is 1140 feet broad,-the larger one, 2100 feet; and the former is called the American Fall, while the latter is usually called, from its shape, the Horse-Shoe Fall. The entire mass looks like a falling sea. It owes nothing to accompanying scenery, except that, as noticed in a previous page, it has been cutting regularly down the rocks beneath it; yet it awfully impresses every beholder by its plunge into the abyss, by the chaos of foam and whirlpool below, by the rainbowed clouds of spray above, and by its incessant, stupendous, rumbling roar, like muffed thunder.

"It would seem

As if God poured it from his hollow hand, And hung his bow upon its awful front, And gave its fall th' A pocalyptic voice, The sound of many waters, and enjoined Its flood to chronicle the ages back, And notch his centuries in the eternal rocks."

Lakes rival rivers in all varieties and attitudes of environing scenery; but have nothing to show against the wondrous characters and effeets of current. A few are remarkable for vast size; a few for lying in hollows lower than sea-level; and a few small ones for occupying tarn-holes on the cap of cones or at alpine elevations. But all the rest, amounting probably to nine hundred and ninety-nine in every thousand, lie in the path of streams, and are in course either of filling up, so as to become meadowy expanses, or of slowly sapping their lower barrier, so as eventually to make a sudden escape. An instance which occurred, in 1810, in the state of Vermont in America, may be selected to illustrate the phenomena of their bursting. 
A lake there, one mile and a half in length, thrce quarters of a mile in width, and from a hundred to a hundred and fifty feet in depth, suddenly made a breach in its barrier about a quarter of a mile in width, emptied all its contents in the course of a few minutes through the breach, tore up a channel a quarter of a mile wide, and from fifty to eighty feet deep, to a lower lake, drove down in a moment the lower lake's retaining mound or barrier, ploughed up a channel of from three hundred to six hundred feet in width, and from twenty to sixty feet in depth, along the bottom of a valley of five miles in length, and then divided itself into a number of divergent streams, and dispersed its spoils over an expanse of plain, yet, in one of its streams, retained so much power, at the distance of seventeen miles from the bed of the lake, as to transport a rock of about one hundred tons in weight several rods from its bed.

Some temporary torrents formed by sudden great falls of rain are not very dissimilar from this temporary torrent of the bursten lake. Those of Madeira are an instance. That island lifts masses of steep and mural rocks to the clouds, and is deeply furrowed down the brows and shoulders of its altitudes, by converging crevices, and configures the descent of the chief of these into one precipitous channel behind Funchal. A heavy fall of rain operates like the instantaneous opening of many great water-sluices, and almost fills the bed of the main-trunk channel at a stroke. The torrent, when in full play, seems the very ideal of irresistible power, hurls lightly along or jerks violently aside blocks of rock which the rapids of the St Lawrence could not move an inch, and makes the 
very ground tremble bencath the wcight of its terrible action. Its depth of mingled water and rolling stones is sometimes twenty feet; and its roar, cven in middlerate moods, resicmbles continuous thunder.

Floods of some kind or other occur in all rivercourses, but have a very diversified character; and some are curious, others tcrrible, and most beneficent. Those of most parts of the temperate zone are fitful, and arise chiefly from rain-storms; while those in the hot parts of the world depend on the regular periodical melting of alpine snows and fall of the intertropical rains. Some water-courses, as in Australia and South Africa, are flood-routes during part of the year, and dry beds or clains of ponds during all the rest. Some great rivcrs such as the Tigris, and the Mississippi, have two floodings in the year-the one from the summer melting of snows, and the other from the fall of seasonal rains. And all the great rivers which drain lofty regions within the torrid zone are mightily flooded once a-year by the rains of the torrid winter. Thus has the Nile its celebrated regular risings; thus have the rivers of Southern Asia and the rivers of Western Africa their great annualinundations; and thus do the Paraguay and the Amazon and the Orinoco periodically convert enormous tracts of South America into temporary fresh-water seas.

The descent of the annual flood in a dry river-course is usually a charming spectacle, and feels to the fainting life-world around it a visitation of all the reviving powers of nature. Sir Thomas Mitchell, describing one which he witnessed in the Macquarie, says, "At length, the rushing sound of waters and loud cracking of timber announced that the flond was in the next 
bend. It rushed into our sight, glittering in the moonbeams a moving cataract, tossing before it ancient trees, and snapping them against its banks. It was preceded by a point of meandering water, picking its way, like a thing of life, through the deepest parts of the dark, dry, and shady bed of what thus again became a flowing river. The water gradually filled up the channel nearly bank high, while the living cataract travelled onward, much slower than I had expected to see it; so slowly, indeed, that more than an hour after its first arrival the sweet music of the head of the flood was distinctly audible from my tent, as the murmur of waters and the diapason crash of logs travelled slowly through the tortuous windings of the river bed."

A land-slip may choke up the gorge of a river, and produce a temporary lake; and the lake may suddenly burst the barrier, and produce a desolating flood. During six months in 1842, the Indus was astonishingly low, as if its supplies had been cut off by a landslip; and then suddenly, without warning or portent, it came down in tremendous torrent as if it were a bursten lake. An eye-witness graphically says, "A murmuring sound was heard from the north-east, among the mountains, which increased until it attracted universal attention, and we began to exclaim, 'What is this murmur? Is it the sound of cannon in the distance? Is Gundgurh bellowing? Is it thunder?' Suddenly some cried out, 'The rivers come!' And I looked and perceived that all the dry channels were already filled, and that the river was racing down furiously in an absolute wall of mud; for it had not at all the colour or appearance of water. They 
who saw it in time easily escaped. They who did not were inevitably lost. It was a horrible mess of foul water, carcasses of soldiers, peasants, war-steeds, camels, tents, mules, asses, trees, and household furniture-in short, every item of existence jumbled together in one flood of ruin; for Rajah Goolab Singh's army was encamped in the bed of the Indus at Koolaye, three koss above Torbaila, in check of Poynda Khan. Part of the force was at that moment in hot pursuit, or the ruin would have been wider. The rest ran, some to large trees, which were soon all uprooted and borne away; others to rocks, which were speedily buried beneath the waters. Only they escaped who took at once to the mountain side. About five hundred of these troops were at once swept to destruction. The mischief was immense. Hundreds of acres of arable land were licked up and carried away by the waters. The whole of the Seesoo trees which adorned the river's banks, the famous Burgutt-tree of many stems-time out of mind the chosen bivouac of travellers-were all lost in an instant. The men in the trees, the horses and mules tethered to the stems, all sunk alike into the gulf, and disappeared for ever. As a woman with a wet towel sweeps away a legion of ants, so the river blotted out the army of the Rajah."

The action of the ocean's tides and billows upon coasts is similar to that of rivers, torrents, floods, and land-slips upon continents. By this, islands have been crumbled to ruin,--large limbs of continents have been washed away,-great sea-board districts have been broken up into groups of islets,_-broad regions of coast have been dissevered into series of sea-lakes and peninsulas,- - and mountain-masses, of cliff and coast-ram- 
part have been torn into fragments, part of them left as stalks and arehes and eaverns, and the remainder triturated into grit and powder. The roeky coasts of Cornwall, and still more the roeky islands of Orkney and Shetland, afford sublime examples of the terrific disintegrating power of the billows. The whole coast of Yorkshire, from the Tees to the Humber, and partieularly from Flamborough Head and Spurn Point, is undergoing regular demolition at the average rate of several feet in the year. The eoasts of Norfolk, of Suffolk, of Kent, of Sussex, and of Dorset, may almost be seen to erumble away beneath the eye of an oceasional visitor, and afford many remarkable instanees of quite reeent and eomparatively extensive demolition. A point in the harbour of Sherringham was, about sixty years ago, oecupied by a cliff fifty feet in height, and surmounted by houses, and is now a pieee of sea suffieiently deep to float a frigate. All the site of the ancient little town of Cromer is now part of the bed of the German Ocean. The town of Dunwich, formerly a place of great trade, a seat of large population, and the most extensive seaport on the coast of Suffolk, lias been washed down pieeemeal by the sea, till only the tiniest and most miserable vestige of it remains. The site of the old town of Brighton, in front of the existing Brighton cliff, has been wholly submerged. In the course of twenty-four hours, in the year 1792, a part of the coast of Dorsetshire, about a mile and a quarter in length, and one-third of a mile in breadth, sunk fifty feet from its previous level. But -to quote stupendously larger, though not so eertain instanees-England is supposed to have formerly been united to Franee at the Straits of Dover, Sieily is sup- 
posed to have been united to Italy at the Straits of Messina, Ceylon is supposed to have been united to the Indian continent across the series of shoals called Adam's Bridge, and the islands of Cuba, Jamaica, St Domingo, and the Caribbees, are supposed to be the fragments of a horse-shoe continent which enclosed the Caribbean Sea, in the manner of the Mediterranean.

But the sea builds up as well as grinds down. All the debris of the coasts and islands destroyed by it, just like all the mud brought from the interior of countries by rivers, either settles down in sandbanks, and as the material of future sedimentary rocks at the bottom of the ocean, or makes additions to beaches, meadows, and other flat land-surfaces along low-lying expanses of coast. The accumulations of debris in the bed of the German Ocean alone have been computed to be equal in cubic quantity to twenty-eight feet perpendicular of all the area of Great Britain. In the Gulf of Bothnia, sunk ships have been found within the subsoils of the shore, and some places which figure in record as coasts are now situated inland. And along the west of the Gulf of Venice, over a hundred miles from its head, the land has everywhere encroached on the sea, within the last two thousand years, to a breadth of from two to twenty miles. Ravenna, which was once a seaport, is now five miles distant from the shore.

Nor does the sea exchange places with the land only by the eroding and depositing actions of its own currents; but it does so also by the upheaving and subsiding efiects of forces beneath the crust of the earth. Great instances have occurred in our own day of the 
elevation of tracts of coast and of sea-bottom by the action of earthquakes. And what is more important, abundant evidence has been obtained, in the course of reeent geologieal investigations, that upheavals and subsidences, too regular or extensive to have been caused by earthquakes, have been oecasional or epochal in some of the great eoasts of the world, and that slow, constant, and not very small ones are now going on in regions which are not known to have ever once been affeeted by any kind of volcanie agency since the dawn of record. For example, raised sea-beaches, eontaining the shells of existing species of sea-molluses, occur at elevations of from twenty to two hundred feet above the present level of high water-and sometimes in suceessions, as if raised at diffurent epochs-on the coasts of Britain, Continental Europe, Southern Africa, and the West Indies; and indications are traceable, in the relations of landmarks to marine deposits, that a vertical oscillation is going on upward in the north, downward in the south, at the rate in some places of about four feet in a eentury, throughout at least one thousand miles of the eoast of Scandinavia. In fact, strong presumption, or, in some parts; absolute certainty, is afforded by the full detail of geologieal discovery, that elevation and subsidenee have been an ordinary eharacter in the world's physical progress, that all the matter of the present dry land lay originally under water,- that great tracts of rock-formation were alternately and repeatedly sea-bottom and dry land,- that all the stratified parement of the earth, notwithstanding that much of it is now the floor of plains and the material of mountains, was slowly formed under water,- - that the sea and the land have 
ever been encroaching on each other as we see them doing at the present day,-and that what is now landhemisphere was once water-hemisphere, and what is now water-hemisphere was once land-hemisphere.

The configuration of the bottom of the present seas and oceans, therefore, is probably not much different from the configuration of the surface of the present islands and continents. The great sandbanks at a distance from land correspond to plateaus; the remote islands, to the tops of alpine mountains; and the extensive profounds, to the plains and valleys. But the ocean-basins, with some remarkable exceptions, are shallow for a certain distance from the shore, and then sink rapidly or suddenly to great depths, and thenceforth, so far as known, are very irregular. The mean depth of the oceans seems to be more than the mean elevation of the continents; and the mean depth of districts of ocean adjacent to high land is more than the mean depth of districts of ocean adjacent to low land. The deepest sounding ever found is sixteen thousand feet, in the Southern Atlantic, nearly in the parallel of the loftiest peaks of America; and a sounding of twenty-seven thousand six hundred feet was made, without finding bottom, west of St Helena.

Such is the ocean. But where shall we find words to describe by a single touch or two its origin, its vastness, its power, its wealth of living things, its everchangeful aspect and ever-changeless nature? We have ample choice among the great uninspired masters of song; for it has provoked almost every one of them to give it some flings of their highest power. But the best, or even all together, make feeble harmony with its tempest-music compared to the thunder-melodies 
of the following strains:- "Who shut up the sea with doors when it brake forth as if it had issued out of the womb, when I made the cloud the garment thereof, and thick darkness a swaddling band for it, and brake up for it my decreed place, and set bars and doors, and said, Hitherto shalt thou come, but no farther, and here shall thy proud waves be staid?" "The earth, O Lord, is full of thy riches; so is this great and wide sea, wherein are things creeping innumerable, both small and great beasts." "The waters saw thee, O God, the waters saw thee; they were afraid; the depths also were troubled. Thy way is in the sea, and thy path in the great waters, and thy footsteps are not known." "The floods have lifted up, O Lord, the floods have lifted up their voice; the floods lift up their waves. The Lord on high is mightier than the noise of many waters, yea than the mighty waves of the sea." 


\section{CHAPTER X.}

\section{ROCKS AND FOSSILS.}

THE IAW OF DEVELOPMENT-THE GREAT AGE OF THE ESKTH-THB MOSAIC ACCOUNT OH THE CREATION-THE SUCCESSIONS OF CHANGE IN THE EARTII'S FORMATION-CRYSTALLINE ROCIS-SEDIMENTARY ROCKS-EFFECTS OF DISTURBANCE IN THE EARTH'S CRUST-FOSSILIFELOUS ROCKS-CHARACTERISTIC ORGANIC REMAINS OF THE SILURIAN, OLD RED SANDSTONE, COAL, NEW RED SANDSTONE, LIAS, OOLITE, WEALDEN, CHALK, AND TERTIARY FORMATIONS-SERIES OF CREATIONS IN THE WORLD'S PROGRESS, AND THEIR PROSPECTIVE ADAPTATION TO THE PRESENT CIRCUMSTANCES OF MAN.

Development, in the sense of one thing producing another, of inferior things producing superior ones, of a whole system rising out of little or nothing, and acting as its own creator and sustainer, is an atheistical, unphilosophical, raving absurdity. But development, in the sense of expanding series of Divine operations, commencing in small and simple forms, and proceeding gradually on to great and complex ones, seems to be the very essence of all concrete truth. It occurs in the formation of every plant and of every plant-seed. It occurs in every process of reproduction, and in the growth of every animal. It occurs in the expansion of man's intellect, and in the progress of all human knowledge, whether in individuals or in societies. It occurred in the revelation of the Divine will to fallen man, and in the execution of the Divine method of 
mercy for saving him; and it occurs still in all God's moral government over him, both in the processes within the soul, and in the scheme of things over the world. And it is proved by a thousand evidences in rocks and fossils to have occurred in the physical formation of the earth. But, in this last case, it proceeded slowly, and through a manifold series. Myriads upon myriads of years-periods of time far longer than any persons but practised inquirers can casily think crcdiblc-seem to have passed in fitting up the earth as a proper habitation for man; and several great cycles of both its mineral and its organic progress were complcted while the fitting up was going on.

But how are we to reconcile the earth's great age with the account given of its formation in the first chapter of the Bible? A fcw intelligent Christian's supposc that account to be a myth, having no historical character, but only propounding lessons in the enigmatical manner of a parable. A few suppose that the six "days" of the account are six epochs, and that, in some way or other, the several cycles of formation which geologists have discovered in the earth's crust may be reducible to a number and succession coincident with these epochs. Many suppose that all the periods of pre-adamite progress, howcver long and however many, are comprised in the opening statement, "In the beginning God created the heaven and the earth," - that a cataclasm, more or lcss extensive, transpired at the end of that progress and immediately before the creation of man, and is indicated in the statement, "And the earth was without form and void, and darkness was upon the face of the deep,"and that a special Divine process restored part, or all, 
of the smashed surface, and peopled it with the present races of animals and with man, and is alone referred to throughout the remainder of the chapter. And some feel unsatisfied with any of these solutions, and regard them all as premature, and think that scientific investigation on the subject of the earth's crust is yet too owl-eyed to be able to look steadily, or almost to look at all, on the dazzling light of the inspired statement; yet have no doubt that, whenever analytical geology and electro-chemistry and perhaps some entirely new science, or some new department of an old one, shall become keen-sighted enough to read fully the record written in the earth's rocks, every syllable of that record will be found perfectly and most eminently coincident with the words of Moses.

One striking thing is obvious, and deserves immensely more attention than it has yet received,that the order of development, as argued by the utmost reaches of science and as stated in the Mosaic narrative, seems exactly the same. First is chemical affinity, shot into the molecules of matter, rousing them into activity, and setting them all a-working to form multitudinous combinations. What this is-as was shown in a former chapter-no man can tell; but, be it what it may-as was also shown there-it lies locked within the same mystery as heat, light, and electricity. Accordingly Moses spcaks of light as the creation of the first "day," and designates it by a term which, besides meaning common light, is elsewhere used in the senses of flame, fire, and lightning.

Next in order, was the separation of the free gaseous substances from the liquid and the solid. Ścience cannot tell what was the state of the chaotic 
mass, in regard to the classes and proportions of its molecules, when chemical action began; nor can it make any clear conjecture respecting the number and arrangements of the substances which were formed in the earlier periods of the chemical action's progress. But it may assume that the mass contained, in some way or other, all the amount of all the elements at present embodied in the earth; and it shows that, so soon as these were combined, or even began to be combined, into the substances and forms of the earth's framework, a separation must liave taken place betwecn the gaseous and the non-gaseous ones, the former floating upward in the form of an atmosphere, and the latter gravitating coherently in the manner of a nucleus. And, in consequence both of the high temperature and of the nascent condition of things, an enormous proportion of what afterwards became liquids and solids must originally lave taken the form of gases and vapours, and probably rendered the atmosphere as dense and dark as if it had been a mixture of smoke and steam. The separation was on a vastly grander - scale than what exists now, and stupendously divided all the fluids which had the form of air from all the fluids which had the form of liquid. Accordingly the work of the second "day" in the Mosaic narrative was a firmament, which divided elastic vapours from gravitating waters, - the "waters above" from the "waters below."

The earth's crust, or non-gaseous surface, continued as yet a region of liquids, or at best a region of slowly forming and deeply-seated processes of crystallisation, probably as turbid as thin mud. But eventually rocks rose above the waters, disintegrating plants were 
created on the rocks, and debris md detritus and vegetation went on accumulating till soils and sediments abounded. Accordingly the work of the third "day" of the Mosaic narrative was the forming of dry land and the clothing of it with herbage.

Next came the preparing of the earth's surface in land, sea, atmosphere, and climate, for the sustenance of animals. This, in all its parts, was more or less a consequence of regetation, or a thing more or less done through its instrumentality. The necessary priority of plants to animals, viewed even in the most general way, is no mean point of coincidence between the Mosaic narrative and the showings of science, and has been powerfully argued by savans who make no refcrence whatever in their reasonings to that coincidence. One requisite thing which plants did was to set free from rocks the lime and silica and phosphates and other mincral matters which might serve to form the shells and bones of the first inhabitants of the sca. But a more striking thing was to make such elaborations from the gases of the atmosphere as should both provide suitable food for animals and render the air fit to be brcathed by them; and this effected great changes in the atmosphere, cleared it, and rendered it pervious to the rays of sun and moon and stars. Sunshine and the seasons now began; and accordingly these figure in the Mosaic narrative as the work of the fourth "day."

Next came animals, beginning with animalcules, molluses, and other inhabitants of the waters, and ascending through higher and higher types of being up to man. These, in prodigious quantity and in amazing variety, lie entombcd in the rocks of the present crust of the carth; and, as found there, they constitute the 
characteristic study of geology, - or at least of the significant department of it called palceontology; and perhaps if some such dividing line were adopted as the degree of coolness in the earth's surface and the degree of oxygenisement in the atmosphere suited to the life and health of the higher orders of animals, they might easily be grouped into two great classes corresponding to the fifth and the sixth "days" of the Mosaic narrative.

These remarks are made humbly and hesitatinglyout of dissatisfaction with existing interpretations, yet not with the view of shaking faith in them, but chiefly to suggest hope that vast wonders in this department of nature, or rather in the profound agreement of it with revelation, lie as yet undiscovered and unexplored. Yet the point which we have been noticing possesses interest as well for Christians who have, as for those who have not, made up their minds as to the true solution of the Mosaic narrative. For, even though the narrative were no more than a myth, or though it simply indicated the process of change after some great cataclasm immediately prior to the creation of man, it kindles into surpassing beauty and brilliance by perfect coincidence between the order of its details and the supposed or proved scientific order of development.

The traces of the original chemical action and the traces of the peculiar portions of the original atmosphere, except in such general or diffused forms as cannot now be identified, are of course all gone. But even all organic traces of the original vegetation - of every race of plants prior to the existence of the earliest animals, and indeed for long periods after- 
seem also completely lost. The deposits which contained them, though hardened into rocks, were, at various periods, so baked by powerful heat below, or so roasted by molten mineral masses bursting through them, as to be deprived of all vegetable contents except fused ashes. Even the rocks containing animal remains, though so distinct and successive as to be clearly classifiable into a multiform and most beautiful system, have been prodigiously áffected, in almost every conceivable way, by all the agencies of disturb-ance and change which we noticed in the preceding chapter as at work in the earth. Seemingly from the time of the earliest islands and continents, through every one of the many cycles which rolled on till the creation of man, gases and weather were eroding all sorts of surfaces and deepening all sorts of fissures, rills and torrents were wearing down crevices and slopes, rivers and floods and sea-currents were denudating land, slow upheavals and subsidences were altering the relations of territory and sea-bottom, and earthquakes and molten upbursts and volcanic eruptions were, in many a manner and with mighty effects, altering the general crust. Often might an intelligent observer, if any one existed then on the earth, lave said as Cowper did in the convulsive year, 1783:-

"Fires from beneath, and meteors from above, Portentous, unexampled, unexplain'd, Have kindled beacons in the sikies; and the old And crazy earth has had her shaking fits More frequent, and foregone her usual rest.

The props

And pillars of our planet seem to fail, And nature, with a dim and sickly eye, To wait the close of all!" 
Still the grand result was teeming life while the changes went on, and a firm, lovely, gorgeous mundane habitation for man in the end. And now the piled-up mountains and the floor of continents are one continuous museum of the many forms of thingsmineral, vegetable, and animal_w which characterised a long and diversified succession of epochs before the human.

Compact erystalline rocks, particularly all the several kinds of granite, seem to have solidified from a melted state at considerable depths, or under great pressure, and are generally regarded as the basement masses of the eartl's crust. But they are of all ages from the earliest to very recent ones; and some have been so far upheaved as to constitute massive lofty ranges of mountains. Porous and cellular crystalline rocks, comprising all the many varieties of trap, were thrown up in the same manner as modern lavas, and cooled either near or on the surface, and derived their porosities and other little cavities from the expansion of contained gases while they were cooling, or from exposure to the air. They, too, are of all ages down to the most recent; and some masses of them either overlie great extents of sedimentary rocks which they overflowed, or tower so piezcingly to the heavens as to constitute many of the most cublime and picturesque mountains in the world.

Whether any of the existing crystalline rocks on the earth's crust are older than the earliest rocks formed by sediment under water, we cannot tell. All were forced up by the expansive force of very powerful heat below; and most bear evident marks of having displaced, disrupted, fractured, overflowed, upheaved, 
or otherwise disturbed, great deposits of sedin ntary rocks. They are computed to occupy not a tenth part of the eartl's surface, - and can nowhere, or but very stintedly, be seen throughout many vast tracts of country, yet are presumed by most geologists to constitute to a great depth the interior shell of the earth.

Sedimentary rocks consist of matters which were deposited in the manner of mud at the bottom of lakes and seas. They often exhibit series of layers, and even series of beds, the mattcr of so many successive deposits, and are therefore said to be stratified. Their laycrs are sometimes as thin as paper, and sometimes many yards thick,-sometimes so loosely connected that they can be easily taken asunder by the fingers, and sometimes so closely joined that only much force and keen tools can separate them. The agencies which hardened them out of their original soft silt and incoherent debris, seem to have been variously chemical action among their own ingredients, the chemical action of infused gases, the chemical action of certain supcrinduced and percolating dcposits, and the jointly chemical and mechanical action of heat and pressure, all acting in ways and producing results morc or less similar to what is called among masons the "setting" of mortar.

Many of the sedimentary rocks were formed on nearly flat bottoms, and many on slightly descending regular slopes; and some of bot'h these classes may still be ouserved in the ir niginal direction. But not a few have been tilted and fractured and contorted into utterly altered position by the upbursts of the crystalline rocks. Some have cracks and crevices, filled with debris from above or with injections of 
molten mineral from below; some are split vertically up, and lie-higher on the one side of the split than on the other; some are turned half over, with their edges up, and resting sideways on masses of trap or granite; and some exhibit curious and beauteous curvatures, in the form of waves, saddles, or arches. The study of such instances, in a quarry, in a cliff, or in any other exposed vertical surface, is always delightful, and often reveals at a glance a long chapter in the liistory of the eartl's formation.

But similar instances occur also on a very large scale. Great extents of sedimentary rocks in uplands and mountains exhibit breaks and gorges and heights and hollows which, though no doubt greatly modified by the prolonged erosions of weather and water, must have mainly originated in the irregular or diversified action of the forces which upheaved them. Some of the gorges, and even some extensive ravines, look like sheer clefts, with face answering to face, and strata to strata, as if they could perfectly interlock; and seem clearly to have been simple vertical fractures in the course of upheaval. Many of the sandstone and limestone vales traversed by the head-streams of rivers are too precipitous or contorted to have acquired much more than their mere polish from water-erosion, and probably owe their main configuration to an upleaving force of the nature of a twisting earthquake. Some great regions of stratified rock, also, have a waving floor, or display a series of undulating valleys, and may be supposed to have been elevated by a force which, without fracturing them, acted more intensely along the lines of the altitudes than along the lines of the depressions. 
The earliest groups of stratified rocks, or at least the groups which are commonly supposed to have been the earliest, were at one time or other so powerfully baked or half melted by heat, and possibly also so much affected by elcctric action, that their entirc original character, with the exception only of their stratification, is lost. One of them called gneiss seems now to differ from granite in nothing but in being stratified; and others, comprising all the different kinds of glittering slates and clay-slates, look to be in all respects crystalline except in being laminated. These are the changed rocks to which we formerly alluded as having lost all the traces of soils and plants, and we may add most of the traces of animals also, which they must have originally contained; and, in order to indicate that they are not at all now what they once were, they are called, by common consent of geologists, metamorphic rocks.

All other sedimentary rocks contain organic remains. Some rare ones consist chiefly of the flinty coats of animalcules, so minute that forty-one thousand millions of them are compressed within one cubic inch. Some, as the coal-beds, consist chiefly of vegetables. Many of the limestones and chalks, cven when they constitute mountains hundreds or thousands of feet high, consist principally of shells and corals. And most others, as the claystones, the sandstones, and the grits, are mainly of mineral origin, and contain only markings, casts, or petrefactions of plants and animals.

The contents of these rocks constitute a clear history of successive formations, creations, and cataclasms, and afford ample evidence of the great antiquity of the earth. Their animal remains often possess as per- 
fect outlines and as delicate tissues as if they were still alive, and bear incontestable marks of having died on the spot in which they are found, and of having there become enveloped in mineral matter as softly and swathingly as in cerements. The rocks, viewed aggregately in Europe, from their lowest position in the bowels of the earth to their loftiest one on the shoulders or summits of mountains, are computed by geologists to have a thickness of not less than eight or ten miles. They comprise hundreds of distinct groups of strata,- " each group containing peculiar organic remains, and arranged in as much order, one above another, as the drawers of a well-regulated cabinet." Successive groups often rest unconformably on one another, the lowest most tilted up, the next less so, the next still less, and the next perhaps not tilted up at all. It is hence inferred that "there must lave been an interval of repose sufficiently long to permit the deposition of the second group, before the second elevation; then a second period of repose, succeeded by a third elevation; and so on to the top of the series." And the remains of plants and animals in the successive groups comprise a series of creations. And not only do these creations succeed one another in point of time, but they display wide diversities of structure, of feeding apparatus, and of general character, adapted to successive stages in the cooling of the climate, the oxygenisement of the air, and the aggregate fitness of the world for the sustenance of higher and higher orders of organised being. Each of the most characteristic, whether earlier or later, could propagate itself through only a portion of the long, long slow process of change 
in the conditions of the earth, and was then followed by another of different constitution, yet continued long enough to leave its remains throughout tardily accumulating deposits thousands of feet thick. No fewer than upwards of nine thousand species are computed to have become extinct before the epoch of the earliest ones which at present inhabit the earth.

The four oldest groups of strata exceed in thickness all the other groups taken together, yet contain few organic remains, and these chiefly shells and corals. The uppermost of them, however, shows distinct traces of a highly organised fish, similar to the existing dog-fish, and apparently about twice as big. The next group contains the bones of a magnificent creature, akin to the present sharks and sturgeons, and from eighteen to twenty-three feet long; and also abounds in small fishes of the same class, not much different in size from herrings, some with a brilliant surface like enamel, some with armature like prickly tubercles, and some with expansible members similar to wings. Hugh Miller, Scotland's princeliest geologist and one of her greatest of living men, says, respecting certain great beds of these small fishes, which lie in swarms and attitudes as if they had been suddenly struck dead in a calm sea, and made quickly fast in embalming mineral, "I have seen these beds as thickly covered with oblong spindle-shaped nodules as I have ever, seen a fishing bank covered with herrings, and have ascertained that every individual nodule had its nucleus of animal matter, - that it was a stone coffin in miniature, holding enclosed its organic mass of bitumen or bone,-its winged or enamelled or thorncovered ichthyolite." 
The coal strata, as formerly hinted, are remarkable for their vegetable remains. Some of these arc trces akin to the most picturesque of all existing conifers, the auracarias; some are colossal, out-swollen herbs, with stems jointcd in the manner of equisetums, and with a structure similar to reeds, and called on the latter account calamites; and some have a size and character which long occasioned them to be called tree-ferns, some figured all ovcr with marks like tubercular spots, and called stigmarias, some with marks like seals, and called sigillarias, and some with marks like scales, and called lepidodendrons. All indicate a climate of intense heat and circumstances of profusely luxuriant growth.

Some coal-mines have preserved them in wonderful perfection. Dean Buckland, speaking of those of Bohcmia, says-"The most elaborate imitations of living foliage upon the painted ceilings of Italian palaces bear no comparison with the beauteous profusion of extinct vegetable forms with which the galleries of these coal-mines are overhung. The roof is covered with a canopy of gorgeous tapestry enriched with festoons of most graceful foliage, flung in wild and irregular profusion over every portion of its surface. The effect is heightened by the contrast of the coal-black colour of these vegetables with the light groundwork of the rock to which they arc attached. The spectator feels himself transported as if by enchantment into the forests of another world. He beholds trees of forms and characters now unknown upon the surface of the earth, presented to his senses almost in the beauty and vigour of their primeval life. Their scaly stems and bending branches, with their delicate an- 
paratus of foliage, are all spread forth before him, little impaired by the lapse of countless ages, and bearing faithful record of systems of vegetation under conditions of our planet which exist no more."

A lively imagination, guided by correct and comprehensive seience, can easily "restore" the dense coal forests in their living state. Hence the following graphic sketch by Professor Ansted:-_" The forests may have been formed by a mixture of several different trees. We would see there the lofty and widelyspreading lepidodendron, its delicate, feathery, and moss-like fronds clothing, in rich luxuriance, branches and stems which are built up, like the trunk of the tree fern, by successive leaf-stalks that have one after another dropped away, giving by their decay additional height to the stem, which might at length be mistaken for that of a gigantic pine. There, also, should we find the sigillaria, its tapering and elegant form sustained on a large and firm basis, enormous matted roots, almost as large as the trunk itself, being given off in every direction, and shooting out their fibres far into the sand and clay in search of moisture. The stem of this tree would appear like a fluted column, rising simply and gracefully without branches to a great height, and then spreading out a magnificent head of leaves like a noble palm-tree. Other trees more or less resembling palms, and others like existing firs, also abounded, giving a richness and variety to the scene; while one gigantic species, strikingly resembling the Norfolk pine, might be seen towering a hundred feet or more above the rest of the forest, and exhibiting tier after tier of branches richly clothed with its peculiar pointed spear-like leaves, the 
branches gradually diminishing in size as they approach the apex of a lofty pyramid of vegetation. Tree ferns, also, in abundance, might there be recognised, occupying a prominent place in the physiognomy of vegetation, and dotted at intervals over the distant plains and valleys, the intermediate spaces being clothed with low vegetation of more humble plants of the same kind. These we may imagine exhibiting their rich crests of numerous fronds, each many feet in length, and produced in such quantity as to rival even the palm-trees in beauty. Besides all these, other lofty trees of that day, whose stems and branches are now called calamites, existed cliefly in the midst of swamps, and bore their singular branches and leaves aloft with strange and monotonous uniformity. All these trees, and many others that might be associated with them, were perhaps girt round with innumerable creepers and parasitic plants, climbing to the topmost branches of the most lofty amongst them, and enlivening, by the bright and vivid colours of their flowers, the dark and gloomy character of the great masses of vegetation."

Some rocks of a group above the coal strata-one called the new red sandstone-contain footprints of enormous creatures of the frog and salamander kind, and also footprints of various birds of the wading class, one species of them computed to be nearly twice the size of the ostrich. But the groups next upward contain the bones and almost perfect skeletons of still larger and more curious animals. One of these, the plesiosaurus, was a voracious sea-lizard about thirty feet long, and of such remarkable shape as to seem like a boa-constrictor threaded through the body of a turtle. Another, the ichthyosaurus, was both wonderful and 
terrible. This, in its largest type, was between thirty and forty feet long; it combined in its structure mechanical contrivances which are now distributed among three distinct classes of the animal kingdom; it had the snout of a porpoise, the head of a lizard, the teeth of a crocodile, the spine of a fish, the sternum of an ornithorhyncus, and the paddles of a whale; it fed in the sea, and lived chiefly there, cleaving the billows and stemming the currents, as freely as one of our steampropellers; it had enormous eyes, of both telescopic and microscopic power, keen to detect great things afar off and minute things close at hand,-and most mighty jaws, set with conical teeth, and so plated and cross-braced as to render their grasp as powerful as it was prompt; and the creature, living in turbulent tepid waters which swarmed with many forms of life, must have served the good purpose of holding the multiplication of all other species of animals under proper check, yet may readily be fancied by a poetic mind as the hideous, horrible ideal of a general scourge. Had Milton known geology, we might readily suppose him to have been thinking of the ichthyosaurus when he described Satan as

\section{"Talking to his nearest mate}

With head uplift above the wave, and eyes That sparkling blazed, his other parts besides Prone on the flood, extended long and large, Lay floating many a rood, in bulk as liuge As whom the fables name of monstrous size, Titanian, or Earth-born, that warr'd on Jove, Briareos, or Typhon, whom the den By ancient Tarsus held, or that sea-beast Leviathan, which God of all his works Created hugest that swim the ocean-stream." 
The groups of strata, from the earliest imbedded remains of the plesiosaurus and the ichthyosaurus up to the appearance of the earliest extant species of animals, present a wide range of novelty. Some of the things here are-the pterodactyle, a wing-fingered compound of bird, reptile, bat, and mammifer; the megalosaurus, a terrific carnivorous reptile, from forty to fifty feet long, which probably preyed on crocodiles and tortoises, and cut them down with a teeth-apparatus resembling saws and knives and sabres; first traces of suck-giving animals in a form akin to the existing kangaroo; the wing-covers of beetles and other remains of insects; continuous beds of petrified coral, in the position in which they grew at the bottom of the sea; the iguanodon, a stupendous freshwater lizard, supposed to have been seventy feet long; and a profusion of sponges, zoopliytes, star-fishes, molluscs, and echinites.

At the top of this series perished the most comprehensive of all the families of molluscs. These are the ammonites. They had beautifully convoluted shells, and got their name from the fancied resemblance of these to the sculptured horn on the head of Jupiter Ammon. The shells vary in diameter from half an inch to four feet; and occur in rocks at all altitudes from low plains to alpine elevations; and were long regarded by the learned as a lusus naturce, and by the vulgar as petrified ram's horns, or as beheaded and petrified snakes. They are light and thin, and were of such arched and buttressed structure that their inhabitants could at pleasure either skim the surface of the ocean or dive beneath the pressure of its profoundest depths. The ammonites comprised upwards of two 
hundred species, and possessed an amazing range of adaptation. They abounded in the seas of the oldest fossiliferous rocks, and continued to abound in those of groups after groups upward and upward till the point which we have indicated; and then all at once they ceased. Or, as Mr Richardson beautifully says,

"They sail'd all day through creek and bay,

And traversed the ocean deep;

And at night they sank on a coral bank,

In its fairy bowers to sleep!

And the monsters vast, of ages past,

They beheld in their ocean-caves;

They saw them ride in their power and pride,

And sink in their deep sea-graves.

But they came at last to a sea long past,

And, as they reach'd its shore,

The Almighty's breath spoke out in death,

And the ammonites lived no more!"

From the last of the ammonite formations up to the deposits which began at the human epoch, the groups of strata contain first a few, and then more and more, and at last a great number of the same species of animals which at present inhabit the earth. But they contain also the remains of many wonderful species, of gigantic size and prodigious power, which are now extinct. Some of these were herbivorous creatures of kinds which have totally perished; and some were of kinds allied to the deer, the ox, the horse, the rhinoceros, and the elephant. A chief one was the "great beast" or megathere. This was a most ponderous being, eighteen feet in length, fourteen and a half feet in girth, with head and neck like those of the sloth, and 
legs and feet like those of the ant-eater and the armadillo; and it lived in vast forests of tropieal America, and was admirably constructed in every way to find its food by wrenching off branches, overwhelming trunks, and tearing up the ground. A fancied glance at the haunts of this quadrupedal giant, in the times of its life and activity, affords a grand specimen of geological "restoration"; and is taken in the following brief, effective way by Dr King:-

"The megatheres are traversing the recesses of these strange woods; and the goodliest trees bend under their paws and quiver under their gnawings, as if seized with the terrors of irresistible destruction. And the toxodon is there-a pachydermata-rodent animal of gigantic' proportions-having so much in its complicated structure, both of the terrestrial and the aquatic, that it is difficult to say whether it moved on the land, or remained in the water. And the machrauchania, with a body about as large as that of a rhinoceros, and a neck nearly as long as that of the giraffe, is slowly crossing the level country - secure from human assault, for as yet there is no man. And the glyptodon, almost as colossal as the megatheres, but resembling in form the tortoise, or rather armadillo, and clad in a coat of mail which would have crushed an animal less powerful, clears away the vegetation which leaf-eating tribes of smaller capacity have spared."

By another kind of effort of the imagination, a comprehensive view can be taken of the records of the past as they lie embowelled in the earth. A man may fancy himself first to survey a luxuriant region of the world's existing surface, and then to penetrate by shafts and caverns far through the world's crust, so as 
to see the fossils of far distant epochs in direct contrast to the active agencies and living things of the present period. Mr Starkey has done this; and the following are some of the results of his excursion:-

"Silence brooded there

Throned upon adamant, save when there came The rumbling of the earthquake's chariot wheels

On some still deeper causeway, faint-then nearThundering in furious haste along, - and then

Faint, hurried off to some iuvisible goal Through galleries unknown.

But there was feeling, and I felt

Things like the images of things that were;

The same yet not the same.

There were the lordly ferns, with fronds dispread,

As I had seen them in the tropical sky,

There were the leaves, with every fibrous nerve

Distinct-yet dead; and there columnar reeds

Of calamite, now hard as the basalt

To which my fancy liked them at the first,

And huge stigmarix-cacter, whose stalks

Of bulk pre-adamite and wonderful

Shot blackly into blocks of solid stone,

Without a leaflet crush'd; as if their air

Were adamant. Life, too, was there, or had

Been there. The megalichthys, witl its tusk,

Almost a reptile, as it might be now,

Lurk'd in the rock, to seize its rocky prey;-

With shelly things - the ammonite, beside

The pecten, and the graceful nautilus.

It was the shadow of a world of light-

The complement of nature."

Throughout the long series of epochs at which we have been glancing, from chaos onward, nothing was done by chance, nothing by intrinsic material energs, 
nothing by necessary or self-acting force, nothing by delegated agency, but everything by the all-powerful, all-wise, all-benevolent Deity. The primal mass of elements was not a source of things, or a cause of things, but a creation. It sprang into being, came out of nothing, at the Divine fiat. "God spake, and it was done; he commanded, and it stood fast." The production of "light," the origination of the chemical forces, the setting up of crystallising processes, the forming and proportioning and separating of solids and liquids and gases, the adjusting and arranging of all mineral substances in their harmonies with one another, in their relation to the earth's cosmical position, and in their prospective adaptations to the races of organised beings of subsequent epochs,-all these also were creations, - or rather a continuous series of creation and providence. The plants, the fishes, the lizards, the mammals, and all other living thingsnot only as types or classes, but in all their orders, all their genera, all their species-were creations. The balancing of all substances, all vegetables, all animals, in their relations and subserviencies, all to each, each to all, and severally to one another, was a constant providence. The whole cosmogony was Divine operation.

The earth at present is "full of God's glory"; it displays everywhere, in its structure and inhabitants, in its designs and processes, in its subordinations and complexities, his power and goodness and "manifold wisdom." But it had similar glory, and made similar display, in all the epochs. Though it wanted the presence of man, and possessed but a portion of its eventual completeness, it had grander changes and mightier 
revolutions than in the human epoch, and was experiencing all, not only with perfect transient fitness to its passing state, butwith perfect prospective adaptation to each and all of its future conditions. Even its simplest earliest stage was, in a sense, the most wonderful. The ingredients of the earth's nucleus were made, not only with entire beauty at the moment, but with omniscient reference to the wants and forms of all epochs. When "light" shot through the chaos, a mundane laboratory was set to work, not merely for the liquids and crystals which were first evolved, but for all the successions of rocks and plants and animals, and with predestined adaptation to the constituency and the needs of all, till the end of time. What unutterable wonders of Divine operation, then, were there! And so, too, was it with the next epoch, and with every succeeding one. Glory pervaded each and all; and infinite wisdom, love, and power adapted their entire constitution and entire progress to everything earthly which should ever afterwards exist. With what profound impression and fervid devotion, therefore, may we contemplate the seemingly simple process of the crystallising of the first rock, as if it had been the corner-stone of the world, - the forming and aggregating of other rocks, like the extending of foundations, - and the rising of the rocky isles and continents into land, beneath the murky atmosphere, like stupendous bulwarks to repel the onsets of the sea amid the darkness of the night! And with what sublime effect did the Divine Being allude to these when he spake out of the whirlwind to Job! "Where wast thou when I laid the foundation of the earth? Declare, if thou hast understanding. Who hath laid 
the measures thereof, if thou knowest? or who hath stretched the line upon it? Whereupon are the foundations thereof fastened? or who laid the corner-stone thereof; when the morning stars sang together, and all the sons of God shouted for joy?"

A most remarkable feature in the prospective adapEations throughout all the periods till the human was a manifold, pervading, wonderful provision for the well-being of man as a fallen moral agent. The present adaptations of the earth as a human abode, are adaptations neither for the beatitude of sinless accountable animals, nor for the punishment of doomed ones, but for the inciting and soothing, the reclaiming and cheering of guilty and miserable ones, under a reign of mercy and redemption. Eden, or perhaps the entire superficial constitution of the world during the Edenic period, no doubt was perfectly suited to the circumstances of sinless men; but the earth, in its sub-strata-or rather the earth, in every respect, subsequently to the revolution made on its Edenic region or on its entire surface by the entrance of sin-is suited only and completely to guilty men who have received a respite, and are capable of being reclaimed and saved. Coals, metals, building stones, manurial earths, and all other matters deep in its crust, are exactly fitted to supply fallen man's physical wants, with the widest possible subserviency to his moral comfort, and with the best possible imposements of invigorating labour of both body and mind. The constitution of soils and subsoils, chemically and mechanically, together with the manner of the nutrition of plants, and the manner of man's physical sustenance mixedly.on vegetable and animal food, is a perfect provision to 
keep him in the golden medium between indolence and crushing toil, and to incite all his faculties-bodily, intellectual, and moral - to the healthiest exercise. The changefulness of climate, the vicissitudes of weather, the lash of storms, the stealthy sweep of pestilential virus, and the occasional catastrophe of hurricane, volcano, and earthquake,-contrasted to the prevailing delights of the gorgeous sky, the balny air, the glorious landscape, the vocal grove, the smiling crops, and the circling seasons, - and reciprocating, in a thousand ways, with the hopes and fears of agiriculture, and with all the other contrivances and efforts and enterprises of busy life,-are a superb apparatus of discipline for checking folly, arresting impetuosity, arousing heedlcssness, evoking reflection, stimulating diligence, maintaining vigilance, directing all the moral affections, and ministering to communities and individuals a constant adjustment of misery to misconduct and of cheeriness to well-doing. And the whole scroll of sky and sea and land is inscribed all over, and engraved deep down, with lessons for eternity. All, in their million objects of glorious beauty, but of plain significance, address man as a rational being of enfeebled mind; all, in their myriad demonstrations of "the eternal power and godhead " of the Deity, speak to man as a creature of conscience and soul; and at least the land and the sea, and in some respects the atmosphere, in their mighty agencies for inflicting pain and producing pleasure, and in their scenes of retribution and suffering and death, address him as a guilty being, with corrupted heart and erring mind, and at the same time as a respited sinner with wide capacities of hope and joy. In short, the ingredients and arrange- 
ments of things, in the total present constitution of the world, are a book of mercy to fallen mankind. They are love throughout, but love now smiling and then frowning, here encouraging, there expostulating, and everywhere evangelising-everywhere opposing sin, and silently yet certainly enforcing the Bible's idea of redemption-in order to man's spiritual well-being in time and for ever.

Now all were in progressive preparation for their sublime mission during long epochs before the first man was made. The prospective adaptations of them, from the earliest period, had reference to the human race in exactly the circumstances, moral as well as physical, in which it exists. The programme of creation, as surely as the purpose of redemption, foresaw man's fall, and made every requisite provision for his recovery. The two were but different phases of the same decree -the one the physical phase, the other the moral phase; and both together contemplating the salvation of men by the work of the God-man Redeemer, and placing the earth at his disposal as the scene in which that work should be performed. How grandly emphatic, therefore, is the declaration respecting the completed progress of each of the cosmogonical "days," - "God saw that it was good." For while each was positively good in its intrinsic perfection, and in the perfection of its relations to everything physical which was to follow, it was at the same time superlatively good as the erection of another stage in the prospective framework, the completion of another wheel in the eventual machinery of God's moral discipline over the subjects of his redeeming love. Just as the seventh day was "blessed" most of all in its looking forward 
to the Christian Sabbath and the everlasting rest, so each previous day was "good" most of all in its looking forward to physical connection with the interests and influences of the cross and crown of Immanuel.

Thus is there another reason than the true personal divinity of the Son of God-though that reason, too, is an essential and all-impressive one-for closely associating the works of creation and redemption, and our Lord's characters of Creator and Saviour. He, as Mediator, has had all things put under his feet,_- "all sheep and oxen, yea, and the beasts of the field, and the fowl of the air, and the fish of the sea, and whatsoever passeth through the paths of the sea." He, as Mediator, has had "all power given him in heaven and in earth," and is "head over all things to the church, which is his body, the fulness of him that filleth all in all." He, as Mediator, is extolled in the Divine word, and adored by the redeemed, for the work of creation: "In whom we have redemption, through his blood, even the forgiveness of sins; who is the image of the invisible God, the first-born of every creature; for by him were all things created that are in heaven and that are in earth, visible and invisible, whether they be thrones or dominions or principalities or powers; all things were created by him and for him, and he is before all things; and by him all things consist. And he is the head of the body, the church; who is the beginning, the first-born from the read, that in all things he might have the pre-eminence. For it pleased the Father that in him should all fulness dwell; and having made peace through the blood of his cross, by him to reconcile all things unto himself,-by him, whether they be things in earth or things in heaven." 


\section{CHAPTER XI.}

\section{MINERALS.}

THE NATURE OF MINERALS-THEIR ORIGIN-THE METALS-IRON, ITS OXIDES, ITS ORES, ITS AFFINITIES, ITS USES-ALUMINA-ALUMINOUS GEMS-OTHER ALUMINOUS MINERALS-CLAY-SILICIOUS MINERALS - Calcareous minerals-Reciprocation of matTer Between MINERALS AND LIVING BEINGS-THE CONTRAST BETWEEN INORGANIC AND ORGANIC THINGS IN REGARD TO LIFE.

Mrnerats are substances which have no cells or other characters of organisation. They are governed entirely by chemical laws, without any modifying influence from a vital force. Most exist in the shape of crystals; and many are constantly in the course of formation, and increase by processes of crystallisation. But none, in the proper sense of the words, have any capacity of reproduction or growth.

A few, such as saltpetre, several constituents of soils, and perhaps the remarkable substance called amber, are formed by the chemical recombination of elements let loose from the decay of recent organic remains. Some, such as natron and the contents of spar caves, are formed by the solidification of dissolved saline matters contained in cold water. And many, such as sulphur, bitumen, and the deposits of lot springs, are thrown up from the depths of the earth to its surface, either directly or indirectly, by volcanic action. But the grand bulk of then are results of 
ancicnt crystallisations beneath the hot seas of long-. ago epochs; and are either constituents of existing rocks, or constituents of debris, detritus, soils, and other substances which have accrued from the disintegration of rocks. Many of these, perhaps, exist now in the same crystals as at their creation, or were formed by primal combination of their elements. But some, such as the several kinds of coal, were formed mainly out of dead plants; and others, such as coprolites, coral rocks, molluscous limestones, and animalcular segregations, were formed either through the instrumentality of animals or out of their remains. All the aboriginal ones, too, secm to have been put into their eventual position by the agencies which formed rocks or altered them; for several and sometimes many kinds of them lic intermixed in even the crystalline rocks, and all the metals occur in situations and connections widely different from those in which the very agencies of primal rock-formation themselves would have placed tliem.

The case of metals, indeed, is a very curious and most instructive one; and has. been woll stated, as follows, by Dr King:- "They are found in mineral voins filling up fissures of rocks. These rocks are of all sorts-igncous and aqueous-more ancient and less ancient. The metals themselves are met with in great varictics of condition, now one only in a chink, now several, now each by itself, now mingled together; here diffused througl stone, there constituting an ore, and in a third instance forming detached lumps. Great difficulty has been experienced in accounting for the phenomena of these veins, as neither fire nor water; the two great agents in nature, possesses powers 
equal to the results. 'That many veins,' says $\mathrm{Dr}$ Macculloch, 'have a double origin, is only one of the numerous difficulties that beset this subject.' Of late it has been shown in a very decisive manner by Becquerel, that electrical action can produce such effects. The experiments of Fox indicate the same truth. Without entering into the controversies which have been agitated on the subject, or attempting to clear up its remaining mysteries, three facts I may state, on the authority of eminent geologists, as now well established: First, the rocks had originally no such veins. Second, the cavities in which the metals collect were caused by disturbance and dislocation; and here we have another of the many benefits attending on those convulsions of nature which appear so formidable. Third, the metals were separated from the general mass of the rocks, and deposited in the chinks provided for them, by very slow and imperfectly understood processes. What a laboratory then was here! what multiplicity and immensity of chemical operations! To outward view, the mountain would have seemed a slumbering and inert heap of matter, when all of it was passing, from its pinnacles to its foundations, from its surface to its centre, through busy transformations. The infiltrated water was permeating every pore; so were the gases which that water absorbed, while the electric stream, flowing with ceaseless constancy and resistless power, impresséd its influence upon all; and thus were the metallic particles disengaged from their earthy alliances, and conducted through their narrow and secret passages to their appointed store=chamber. And now when enlightened industry lays that chamher open to the light, the miner has little to do but 
gather up the metallic treasures prepared to his hand!"

Iron is the most abundant of the metals; and may be selected as a grand specimen, not of them only, but of all minerals. It abounds in almost every part of the world; and exists under a multitude of aspects and in multitudes of combinations. It has powerful chemical affinities, and seems ever to have exerted them in the course of the world's changes; so that it occurs in all sorts of positions, and under the most startling diversities and contrarieties of form. It is the cement of many rocks, the colouring principle of most lands, and the body or basis of not fewer than about sixty compound minerals, and also an element in hundreds of others. It occurs in rock veins, in rock strata, in rock masses, in soils, in marshes, in springs, in animalcular deposits, in living plants, and in living animals. Many a man has more iron in him than he dreams of; for it exists largely in his blood.

Iron has such a passion for oxygen, that wherever it gets access to air and moisture it takes oxygen out of them, and forms the powder popularly called rust. But that powder, according to the different proportions of oxygen taken up, is variously yellowish, brownish, reddish, and blackish. Hence the colours of the greater number of soils and rocks; and hence the changes in these colours a little after the soils are ploughed up and the rocks are broken. Hence, too, the accumulations of the pigment powders popularly called ochres. But the combining greed of iron, and especially its greed for oxygen, have occasioned nearly all of it to pass from its original condition. Exceedingly little uncombined iron can now be found; so 
little, indeed, as to be matter of high curiosity; and even that little, of course, cannot easily be kept from becoming less by rusting. Yet there is a remarkable exception. This occurs in the star-stones-the projected masses from other worlds to ours-of which we made some mention in our first and second chapters. All these contain uncombined iron; and the largest contain little else. And this iron differs much from the iron of the earth. It often has traces of cobalt, and always is mixed with from three to twelve per cent. of nickel-metals which never occur in connection with terrestrial iron; and it has a granular structure and silver-white colour, and can easily be cut with a knife, and is flexible and perfectly malleable without any aid from heat, and is not nearly so liable to rust as terrestrial iron. Some masses of it have external markings similar to the impressions made on a soft plastic body by hands and feet.

Iron ores are mineral combinations very rich in iron; and iron mines are immense quantities of some one or other of these ores in juxtaposition with substances which can be used to drive the iron out of combination,--such as timber or coal to serve as fuel, and limestone to serve as flux. And no slight proof of the beneficence of God, and of the prospective adaptation of the earth throughout all its epochs of change to the present circumstances of mankind, is afforded by such juxtaposition. The ore and the coal and the lime were formed in ways widely different from one another, and at periods far remote from one another-the first perhaps fitfully and by a series of electric processes, the second rapidly and by the amassing and baking of a world of vegetables, the third 
tardily and by the accumulated labours or reproductions of incomputable millions of zoophytes or molluscs; and yet, in many a locality throughout great tracts of precisely the kind of regions where iron is most needed for all the arts of civilisation, they lie as closely together, and as exactly fitted for each other, as if they hád been created at one moment, by a single fiat, for the express use of man. They serve all their joint purposes now most benignly and precisely; and at the same time served thousands of others throughout the epochs before man was made.

Two ores of prime importance to society, and especially to Britons, are those popularly called red iron ore and brown iron ore. But they are prodigiously various, as well as wondrously rich, and comprise things as widely different from one another in appearance as coarse compact stone from fine powdery pigment. And the very names of some of their varieties, as known to mineralogists, are a curiosity to ordinary readers. For the red ore comprises red ochre, red clay ironstone, red silicious ironstone, red hematite, iron mica, iron froth, oligiste iron, and anhydrous peroxide of iron; and the brown comprises brown ochre, umber, brown clay ironstone, yellow clay ironstone, brown fibrous hematite, rubinglimmer, pyrosiderite, lepidokrokite, gothite, bonerz, and stilpnosiderite.

One of the most interesting ores is the magnetic. This, as its name implies, is inherently possessed of magnetic power; and it acquires increase of that power by exposure to the air. It has a very dark colour, and grinds into a pure black powder, and often contains so much as eiglity per cent. of metal; and is the best 
kind of ore for making steel. It occurs chiefly in crystalline rocks, such as those of Sweden, and sometimes constitutes great beds and almost entire mountains.

The most generally distributed ore, and that which most readily attracts the vulgar eye, is iron pyrites. It is a compound of iron and sulphur, and has a bright yellow metallic aspect. It exists in many a crystalline shape, and in grains, little columns, and little globular masses; and is often mistaken by ignorant persons for gold. It abounds in many a crystalline rock and in many seams of coal and beds of clay; and is oftel associated with lead and copper and arsenic and silver; und is sometimes contained in ancient organic remains, both vegetable and animal.

A very curious ore of iron, but also a very rare one, and the only other which we can take space to notice, differs chemically from the brown ore only in the seemingly trivial character of holding a smaller proportion of water in combination. A nodule of it, about the size of a hen's egg, found in a trap rock in the vicinity of Greenock, had a reddish brown colour and a silky diamond-like lustre, and consisted of very fine needles slightly diverging from one another like the hairs of a painter's brush.

In the course of smelting, or of exposure in any other way to strong heat, iron exerts its keen affinities, and goes readily into combination with metals or combustibles or other things which happen to be present. It amalgamates with metals to form what are called alloys. It always absorbs more or less carbon from fuel, so as to take on the same kind of properties as steel. And it rusnes into union with any quantity of sulphur in coal, or with the sulphur of 
any bits of iron pyrites, to form a substance which differs entirely from everything properly metallic. The keenness of the combination, in this last case, may be understood by rubbing a stick of brimstone on a bar of iron at what blacksmiths call a welding heat; for the brimstone and the iron will instantly melt into each other, and fall down in drops of the new substance. In the laboratory and the factory, too, iron goes into wonderful unions, and, in many instances, becomes partaker in shapes and hues and transparencies which a person ignorant of chemistry and mineralogy would imagine to be as alien from it as from dewdrops or sunbcams.

Need we say anything of the uses of iron? They are univcrsally known. It is met with everywhere and in almost everything. Society cannot do anything without it. Artists are as truly dependent on it as artisans. Physicians and dyers and fancy manufacturers use it, in some of its combinations, as essentially as any of the workers in steel. Even quilldrivers cannot get on without it; for, though eschewing metallic pens, they still have iron in their ink. Iron, in fact, is the very badge of civilisation; for all the usages of society which are other than savage employ it, and cannot but employ it, in some one or other of its metallic conditions; and even the greater number of civilised refinements employ it, and cannot but employ it, both as a metal and in some one or many of its thousand combinations.

Alumina may be taken as a good specimen of the earths, as iron is of the metals. It is the characteristic matter of clay. It exists in most rocks, and is a chief ingredient in many, It more or less characterises not 
fewer than ah,uut one hundred and forty species of minerals, and constitutes the main bulk of not a few. Yet it nuwhere occurs by itself; and it takes its name of alumina from the circumstance of being readily obtainable from alum. When quite or nearly pure, it has no smell, little taste, and little astringency, and would not be suspected by an ignorant person to have any relation to either alum or clay. The nearest natural approach to it occurs in sapphire. This beautiful gem, well known to be harder than any other mineral except diamond, consists of pure alumina, and a very small proportion of colouring matter. When the colour is blue, the gem is a proper sapphire; when green, it is an emerald; when yellow, it is a topaz; when violet, it is an amethyst; and when red, it is a ruby. Many other of the most precious gems, as we shall afterwards see, consist almost solely of silica, the characteristic natter of sandstone; so that, with the exception of diamonds, Darwin is singing only of the essence of clay and sand, when he says-

"Soft cobweb clouds transparent onyx spreads, And playful agates weave their colour'd threads; Gay pictured mochas glow with landscape dyes, And changeful opals roll their lucid eyes;

Blue lambent light around the sapphire plays, Bright rubies blush, and living diamonds blaze."

The substances called corundum, adamantine spar, and emery, though widely different from sapphire and from one another in appearance, are constitutionally the same. Emery is grey, opaque, lustrous, and so hard as almost to defy the file; and, when reduced to fine powder, is much used for polishing hard bodies. Some 
of the most notable of the compound minerals which take their chief bulk or main character from alumina, are fuller's earth, garnet, felspar, kaolin, talc, soapstone, potstone, green earth, pearlstone, obsidian, and mountain leather.

Fuller's earth gets its name from being employed in scouring cloths; and it owes all its cleansing power to the affinity of its alumina for oily and fatty substances. It has generally a greyish, ashy, brown colour, but is sometimes greenish, and may be found of all varieties of tint, from very pale to almost black. It is firm and compact, and has a rough and somewhat dusty surface, yet feels soft to the touch, and does not stain the hands; and, when immersed in water, it swells in bulk, and falls into a fine soft pulp.

Garnets are beautiful crystals, of great variety of at once colour, weight, and constitution. One of them is the carbuncle of the ancients. The common garnet has a dark, reddish, brown colour, but is sometimes greenish or yellowish; the green garnet has the hue of asparagus; the black garnet looks like velvet; the precious garnet is red; the Bohemian garnet is dark blue red; and the brown manganese garnet is tombac brown and granular. They are a curious group, and owe much of their peculiarities to the presence of lime and iron.

Felspar is a crystalline constituent of all granite rocks, and abounds also in trap and metamorphic rocks, and has been one of the most general and plenteous sources of fertile soil. It is vastly various in form and colour, but always contains much potash and earth of flint. A precious kind of it, called the avanturine felspar, has a colour like honey, and is 
everywhere penetrated by littlc golden spangles; and another kind, when cut in a certain way, reflects from its interior a floating changeful pearly white light, and is popularly called moonstone, or fish's-eyestone. The purest kinds of felspar are extensively used in potteries for porcelain pastes and enamel; and a decomposed kind of it is a chief material of the best porcelains. This is kaolin or porcelain earth. It has a white colour, often with a shade of ycllow or red, and consists of dusty, slightly cohering particles, and occurs throughout disintegrated granite, in represcntation of the original felspar.

Talc is one of the softest of compact minerals. It comprises many varieties, but is characterised in them all by complexity of constitution, and by the presence of much magnesia. It is comparatively abundant, and sometimes constitutes entire mountains. One of the most curious kinds is soapstone. This consists of particles as minute and dclicate as those of the finest powder, and has a whitish colour, mottled with green and purple. When first raised, it may be kneaded like dough; and, after being exposed for some time to the air, it consolidates throughout, and becomes translucent on the edge, yet still continues soft enough to be scratched by the nail. It has a soapy lustre, and an unctuous feel; and it is used by the Arabs, in their baths, as a substitute for soap. Another kind of talc, called potstone, has been in use from time immemorial for making many kinds of utensils, and is specially serviceable in the fabrication of stoves and furnaces. A third kind, or perhaps several kinds, are used by semi-savage tribes in various parts of the world as an article of food. One found among seclimentary rocks, 
four thousand feet above sea-level, in the island of Java, is kneaded into small rolls, and dried over a charcoal fire, and eaten with great avidity, and as a delicacy; and this has been ascertained to contain a good many species of fossil animalcules. One found on the banks of the Orinoco is even said to form almost the entire sustenance of a tribe of natives during three months of the year; but it really possesses few principles of aliment, and possesses these scantily, and must necessarily be accompanied by the use of some other food. A substance akin to the talcs, and sometimes reckoned one of them, is green earth, the characteristic constituent of the geological deposit called green sand, and the pigment known as mountaingreen in water-painting.

Pearlstone occurs in some trap rocks, but is not plentiful. It consists of roundish balls, from one to two inches in diameter, with very thin concentral coats, somewhat like the bulbs of onions, and has a strong lustre, shining and pearly. Obsidian occurs sometimes along with pearlstone, and sometimes in streams of lava. It presents exactly the appearance of a mass of opaque glass, and has a velvet black colour. Mountain leather is both very rare and very curious. It consists of fine threads felted like a hat, and has a light buff colour, and feels soft and tough and very flexible, and looks to the eye exactly like leather, and imbibes water in the manner of a sponge, and then looks like leather thoroughly wetted; and, when attacked by the strong steady heat of the blowpipe, it curls up, and fuses into an opaque bead.

But immensely the most important and in some 
respects, even the most curious representative of alumina, is clay. This, indecd, is not one mineral, nor, in general, a mixture of only two or threc minerals. It is sometimes a rock, sometimes a comminuted debris from many rocks, and always a very compound substance, both as to the number of minerals comprised in it, and as to the diversities of combinations in their elements. Still it is characteristically aluminous, and serves as a grand and expressive type of all other aluminous things, not even excepting the garnets and the mountain leather. Alumina has the singular property of excessive greediness for water at low temperatures, and excessive aversion to it at high ones; and this property it always develops with great force in clay, so as to give it a very marked distinctness of character from all the other mixed substances which constitute soil. Hence the constant wetness and plashiness of clay lands during winter, and their contractions, crackings, hardness, and aridity in the droughts of summer.

Some clay deposits are so extremely aluminous, so very sticky in winter, and so very stony in summer, that nothing short of expensive and laborious georgy can render them fertile, or even arable. Some, also, are deficient in the proper aliment of plants. But the great majority of clays áre rich in exactly the kinds, and in all the kinds, of solid matters which conduce most to luxuriant productiveness in corn; and either mainly by themselves, or, better still, in free mixture with sand and mould, they play a mighty part in all the plant-feeding and animal-supporting offices of fruitful land.

Nor are they less conspicuous in their connections 
with the manifold ministering occupations of the potter and the builder. "The porcelain clays," remarks Liebig, "are those which are refractory in the fire, and do not melt when exposed to the strongest heat of our furnaces. The difficult fusibility of the porcelain clays depends upon their proportion of the alkaline bases, potash, soda, lime, magnesia, and protoxide of iron. When we compare the other kinds of clay with the porcelain clays, we find that the infusible clays, or clays poor in potash, are of rare occurrence. The clays diffused through the most kinds of rocks, those occurring in arable land, and those in the beds of clay interspersed with the layers of brown and mineral coal, contract when exposed to heat, and become vitrified in a strong fire. Loam also melts in a similar manner. When the oxides of iron are not present in the clays, their fusibility is in direct proportion to the amount of their alkaline ingredients. Clays arising from the disintegration of the potash felspars, are free from lime; those formed from Labrador spar, the principal component of basalt and lava, contain lime and soda." How admirably did some of the old and otherwise ignorant nations understand the practical working of these properties!

"Hence ductile clays in wide expansion spread, Soft as the cygnet's down, their snow-white bed; With yielding flakes successive forms reveal, And change obedient to the whirling wheel. First China's sons, with early art elate, Form'd the gay tea-pot and the pictured plate; Saw with illumined brow and dazzled eyes In the red stove vitrescent colours rise; Bade on wide hills her porcelain castles glare, And glazed pagodas tremble in the air. 
Etruria! next beneath thy magic hands

Glides the quick wheel-the plastic clay expands;

Nerved with fine touch, thy fingers, as it turns,

Mark the nice bounds of vases, ewers, and urns,

Round each fair form in lines immortal trace

Uncopied beauty and ideal grace."

The results of these actions of different kinds of clay have long been seen to possess eminent interest to society, and are applied in a thousand ways in the arts. And the simplest of all, the hardening of common clays into brick, figures from the earliest ages in the front of vast social improvements and great national organisations. "Indispensable," remarks Macculloch, "as this property and the arts derived from it are to those countries which are deprived of stone, which, nevertheless, from this very cause, their alluvial nature, with their consequent fertility, have been the earliest and most crowded seats of civilised man, so is it in those that the clays abound most, as the art of converting them into stone seems coeval with man himself. Still more remarkable may it be considered, that, in the most ancient and noted of all inhabited lands, the clay deposited by its great river is convertible into brick by the mere power of the sun, without which peculiar appointment and command Nineveh and Babylon would scarcely have been; while these great cities occupy a space and a time far too important in the history of man to permit us to doubt that they were ordained-they, and the very means of their erection and existence. On so apparently insignificant a property, in an insignificant earth-the refuse of the mountains, the produce of apparent casualty, the deposit from a river breaking its seemingly appointed 
bounds-have been founded the greatest and the most powerful, as the most ancient of empires, producing all those extraordinary consequenees which, but for this, would never have existed. Can the hand of the Creator be seen in this? Let the reader conclude for himself."

We might, if we had space, illustrate silica as we have done alumina. It is the characteristic matter of true, hard, crystalline sand. It abounds in granitic and metamorphic rocks, and is the chief ingredient in quartz rocks and sandstones. It constitutes one-half or more of the entire bulk of a large proportion of soils, both barren and fertile. It is nearly identical with flint and with flinty slate. And with the exception of minute variable quantities of water, and sometimes slight traces of one or more other substances, it constitutes the entire body of many gems-the transparent rock crystal, the violet amethyst, the green prase, the yellow Cairngorm stone, the grey calcedony, the red carnelian, the layered onyx and sardonyx, the blood-spotted heliotrope, the apple-green chrysoprase, the moss-like mocha-stone, the intricate agate, the milk-white opal, the sombre jasper, and the velvet-black Lydian stone. Yet in itself, when perfectly freed from every admixture, it is a bright, white, rough powder-one of the most prosaic, unpretending objects on which the eye can look. In itself, too, it sternly refuses either to melt in water or to fuse in fire; and yet it glides so into other things within the soil, as to ooze into plants, and circulate through them, and form the main strength of the hard glassy coat of all the grasses.

We might also, if we had space, write largely about 
lime-follow it through chalk and marl and madreporite and peastone and travertine and marble and all the limestones-through gypsum and alabasterthrough the many beautiful kinds of spar-through asparagus stone and colophonite-and through numbers of other minerals of either curious character or startling contrasts; and we might follow it further to its place in shells and bones, as the incombustible. main-prop of the strength of animals, and to its functions in agriculture and masonry, in manufactures and the fine arts, as one of the chief substances in both the utilities and the decorations of human society. We might likewise speak largely of carbon, together with diamond, plumbago, coal, and bitumen; of magnesia, together with serpentine, mountain cork, and Epsom salt; of lead and copper and silver, together with their curious ores and wonderful salts and surprising uses; and of many other representatives of chemical genera of minerals, together with thousands of remarkable things in the little worlds of wonders which they severally represent.

But we must close this chapter with a brief remark or two on the aggregate function of the whole mineral kingdom. This is nothing less than to maintain a constant and complete reciprocation of matter with living beings. Minerals must be understood, as most mineralogists understand them, to comprise all things inorganic,--all gases and liquids, as well as all powders and crystals; and, thus understood, they pass into plants and animals, and come out of them, in a myriadfold process of perpetual circulation. The inorganic things are fashioned into the organic; and the organic are fashioned back into the inorganic. Even the three 
kingdoms, the mineral, the vegetable, and the animal, in most respects, run continuously into one another, the first into the second, the second into the third, and the third into the first; insomuch that the artificial acceleration of the process, by urging on the soil to yield up its molecules to regetation, and by putting the rejectamenta and remains of animals into the circumstances where they will most rapidly mineralise, and most rapidly pass again into the form of aliment, constitutes the main work of multiplying the plants and animals which are most useful to man.

All the matter with which plants form and maintain their tissues is derived either from the debris of rocks, the gases of the atmosphere, or the nascent minerals which result from the decomposition of animal remains; and most of the matter with which animals form and maintain their tissues is derived directly or mediately from plants,- - the farinaceous portions of it directly, and the milk and flesh parts through the medium of other animals. But animals also take in much mineral matter directly,_-oxygen in breathing, water in drinking, salts and earths as condiments, and dissolved and silty substances along with water; and they likewise take in great variety and vast amount of minerals, such as iron, lime, carbon, and phosphorus, in disguised or combined forms in their vegetable aliment. Thus are they perpetually and in many ways receiving all sorts of inorganic things into their framework. Nor do they make their returns to the mineral world only or chiefly in the final bequeathment of their carcass; but they make them also in their outbreathings, in their insensible perspiration in their sweatings, in their evacuations, 
and in their offcasts of hair and nail and scarf-skin,some of which things assume at once the mineral form, while others pass into it more rapidly than the final remains. And vegetables, too, continually take in mineral matter through a thousand microscopic orifices, and continually give it out by as many more; and at the same time make grand contributions to it, not only through the medium of animals, but also by their own excretions and decays. The commission, therefore, which Darwin fables to have been given to the gnomes, was founded on true philosophy:-

"You! whose fine fingers fill the organic cells With virgin earth, of woods and bones and shells; Mould with retractile glue their spongy beds, And stretch and strengthen all their fibre-threads.Late when the mass obeys its changeful doom, And sinks to earth, its cradle and its tomb, Gnomes! with nice eye the slow solution watch, With fostering hand the parting atoms catch, Join in new forms, combine with life and sense, And guide and guard the transmigrating ens."

Minerals, then, have an immensely grander ministry than is dreamed of by vulgar minds. As the Creator formed the orderly and beauteous world out of chaos, so he forms the wondrous and exquisite structure of organised beings out of the world's inert matter. A given quantity of a given kind of rock, together with air and water, possesses as definite relations to amount of produce in corn or in flesh, though the imperfect state of our knowledge does not yet enable us to compute them, as a given quantity of given kinds of provisions bears to the sustenance of a certain number of men during a certain amount of time. Hence do all 
the thousand sorts of minerals exist in exactly the proportions and the distribution in which-apart from the uses in the world's own economy and uses in the outward affairs of human soeiety-they are needed for the universal and diversified support of the vegetable and animal kingdoms. And hence, too, are those, such as lime and phosphorus, whieh form rigid and long retained portions of organised frames, rendered slow and eircuitous of attainment; while those, sueh as air and water, which constitute matter of rapid circulation, are rendered yielding and subtle and easily to be had. The all-wise and all-gracious Framer of creatures has perfeetly adapted every partiele and property of every mineral at once to the entire circle of its affinities among inorganie things, and to the entire eirele of its subserviences and actions in every kind of plant and animal.

But sinee the principles in minerals and the principles in organised beings are the same, may we not infer that minerals themselves and organised bcings themselves are also the same? Not so. The absenee of life in minerals and the presenee of it in organised beings makes a stupendous difference. Chemists can easily follow chemical aetion through even its most complcx operations in mincrals, but are speedily perplexed and overwhelmed when they attempt to trace it bcyond the very simplest of its performanees in plants and animals. Life eontrols it in every living body. And though life itself is entirely different from everything with which ehemistry is acquainted, and follows laws and wields powers which chenistry is utterly unable to comprehend or explore; yet it exerts so miglity an influence upon chemieal ageney as to bring 
out from each of many hundred sets of its affinities or contacts totally contrasted results to those which arise from them in its absence. A living being, whether animal or plant, maintains all its integrity in the same position in which a dead one would decay and disappear; or thrives and grows in the same circumstances in which a dead one would putrify; or forms solid and sapid and alimentary products under the same chemical conditions in which a dead one would resolve itself into noxious gases; or enjoys constant and important aids to vigour and development from the action of the same chemical compound which would dissolve and dissipate it if dead. What life is we know not, farther than as it is the energising constitutional law of an organised being,-the exponent of the will of the Creator respecting the organisms and functions and products of each organised species: but, even in this view, it is almost as intelligible as it is sublime, and goes all lengths to account for the profound mystery in which all the uiterior inquiries of organic chemistry are enveloped. "No person," remarks Dr Thomson, "has been able to detect the formative agent in plants, nor even the principle which is always so busy in performing such wonders, nor to discover him at his work; nor have philosophers been much more fortunnate in their attempts to ascertain the instruments which he employs in his operations." We simply know that life is a direct emanation from the Living One,- - that it conveys throughcut all organised matter a constant and irresistible commission from Him "who upholds all things by the word of his power," and "in whom we live and move and have our being,"- - and that, in the, case of every individual organised crea- 
ture, it arises out of precedent life and parentage, and exists under peculiar conditions of organisation, aliment, aeration, and temperature, and passes on to extinction in death, and then abandons to dissolution the whole of the mass of wondrous organisms which it had hitherto built up in strength and beauty, and maintained in the constant exercise of a thousand energies. "During life, all is activity: in plants, absorption, assimilation, and distribution of fluids, with growth and development of parts,-in animals, prehension, digestion, and assimilation of food, with growth, locomotion, intellection,-and in man the faculty of speech, referable to the agency of that subtle, invisible, and incomprehensible something called life; which counteracts and controls mechanical and chemi cal agencies, and converts them to its own purposes. But in death there is no longer any resistance opposed to these agencies, no living action, no spontaneous motion, no exercise of organic function; chemical and mechanical agencies wholly possess the fâbric, exerting themselves in their full strength, and reducing it sooner or later to the primordial and elementary principles out of which it was originally formed." 


\title{
CHAPTER XII.
}

\author{
PLANTS.
}

FLOWERLESS PLANTS-SPORULES-LICHENS-FUNGUSES-SEA-WEEDS AND OTHER ALGE-FERNS-GRASSES-'PALMS - ALOE-PLANTSTULIPACEOUS PLANTS - TULIP-FLOWERS - ORCHIDS - THE WATERSOLDIER AND VALISNERIA-CHARACTERISTICS OF ENDOGENS AND EXOGENS - CONE-BEARING TREES - AURACARIA AND NORFOLK ISLAND PINE-THE NETTLE FAMILY-THE NETTLE STING-THE CON-TREE-THE BANYAN-TREE-THE PITCHER-PLANT-THE RAFFLESIA-THE PRIMROSE . FAMILY-THE NIGIITSHADE FAMILÝTHE CACTI-MANGROVES-TEA-PLANTS-CAMELIAS-MAGNOLIA AND LIRIODENDRON-SILK-COTTON-TREES AND ADANSONIA - VICTORIA REGIA AND OTIIER WATER-LILIES-THE FORMS AND MORAL INFLUENCES OF FLOWERS.

THE simplest plants have no flowers or seeds, and are propagated from exceedingly minute bodies called sporules. They exhibit little of the breadth of fea. ture, the grandeur of form, the brilliance of colouring, and the complication of organism which distinguish the higher grades of plants. Some appear to the naked eye mere specks or powder; some mere slime or mucus; some mere clusters of minute threads or minute cells; and some the seeming moulderings of stones or random dashes of green paint. Yet even these, and much more the larger kinds, perform high offices in the world's economy. "They serve to complete and to keep up the integrity of the vegetable creation, whether it be by decomposing putrid and fecal matters, or by preparing a soil fit for vegetables of a higher order. They are scattered over all cli- 
mates and all quarters of the world, replenishing both earth and sea with vegetable life, and ascending even into the regions of the air by the very levity of their sporules, to be wafted on the winds till, drenched with moisture, they descend again towards the earth, ready to cling to the soil that suits them, if it should be even the surface of the flinty rock, or to spread themselves over mountains of eternal snow, or to immerse themselves in the waters of the ocean." The chief families of them are lichens, funguses, sea-weeds, fresh-water-weeds, mosses, horse-tails, and ferns. The sporules of the smallest ones, and even those of some of the larger ones, are produced in immense numbers, and multiply with amazing rapidity. A single pouch of a dust fungus, such as that of smut, though the pouch itself is quite or almost microscopic, has been computed to contain no fewer than ten millions of sporules.

Lichens are the primal disintegrators of hard rocks - the primal formers of all dry and undrifted soils. No fewer than between four hundred and five hundred kinds of them inlabit Britain. They look very mean to the naked eye, but display many a gorgeous magnificence through the microscope. They are the small, patchy, leathery, crumpled looking things everywhere seen on rocks, the trunks of trees, and the bare surfaces of barren ground. They grow where no other plants could get a hold; and in alpine regions they flourish at altitudes up to the very verge of perpetual snow. They have a boring apparatus for infixing themselves into the hardest rock, and a spongy texture for alssorbing and retaining moisture; and they spend their existence in compounding particles of 
rock and molecules of moisture into a sort of living paste; so that, when they die, they bequeath their remains as a primal stratum of soil. The first ones are followed by larger ones or by mosses, and these by ferns or by grasses, and these again by larger plants and larger, till at length the humblest lichens are succeeded by the loftiest trees.

"Sporules to us invisible, can find

On the rude rock the bed that fits their kind;

There in the rugged soil they safely dwell,

Till showers and snows the subtle atoms swell, And spread th' enduring frondage: then we trace The frecliled surface on the flinty base. These all increase, till, in unnoticed years, The sterile rock as grey with age appears With coats of vegetation thinly spread, Coat above coat, the living on the dead; These then dissolve to dust, and make a way For bolder foliage nursed by their decay."

Funguses differ much in both appearance and constitution from all other plants, and have been regarded by some naturalists, though erroneously, as possessing an intermediate nature between plants and animals. Between two thousand and three thousand species are known. They range in size from a point scarcely visible by the naked eye to an umbrella-like body nearly three feet in circumference. They delight in moist shady situations, and grow on dead trees, on the decaying bark of living trees, on the leaves of all plants, on decomposing animal products, on the surface of fermented liquids, and on all other substances in a transition state between the organic and the inorganic; and they have been appropriately designated 
"the scavengers of the world," sweeping away the putridities and putrific gases which, if allowed to accumulate, would seriously impair the health of the animal kingdom. They spring into being and do all their work with prodigious rapidity. Crowds of them are often developed in a single night; and though most live several days or longer, some live only a few hours, and some only a few minutes. All have a peculiar odour, which instantly and strongly indicates their presence; and as many as are large enough to have been subjected to anatomical examination and chemical analysis, have both a fleshy texture and a fleshy nature; so that they may be compared variously to muscle, gelatine, leather, sponge, cork, and soft wood, but never to anything herbaceous. Some which abound in cellars, caves, and mines, are beautifully phosphorescent in the dark, and give to natural subterranean arches the appearance of enchanted vaults, gorgeous all over with indescribable splendour. A few live in the interior of plants, and are analogous to intestinal worms; and the sporules of some, or perhaps of many, are supposed, or have been all but proved, to circulate in the fluids of living animals, ever ready to develop themselves in certain kinds of disease or at death.

Some funguses constitute the mildew, the smut, and the rust of corn-plants. Some are the damp, thready, webbed, malodorous patches on unhealthy green crops. Some are the mould of pastes, jellies, fruits, and bread. Some are the colouring matter of red suow and of other extraordinary onfalls. Some form on liealthy grounds and hilly pastures the remarkable circular belts of deep verdure popularly 
called fairy rings. Some are the curious objects known as puff-balls,- - discharging their millions of sporules in visible form, like puffs of very fine powder. And multisudesare the tubercularand stool-shaped bodies called mushrooms,- - a few of which are eatable; while all the rest are acrid or poisonous, and even the eatable ones liable to become noxious by the imbibition of putrid matters in their vicinity. The most pleasant fungus is the truffle, shaped like an egg or a kidney, with a sort of warty surface, growing out of sight within the soil, possessing a highly aromatic and delicious flesh as firm as the kernel of an almond, and served up as a rare luxury at the tables of the wealthy, either roasted in a fresh state somewhat like potatoes, or dried and dressed as an ingredient in soups and ragouts. But even this, when not taken at the very pitch of proper ripeness, rapidly becomes as disgusting a thing as urinous smell and wormy putrescence can make it. We care not to be a little outspoken here; for we would warn every person against ever putting a fungus of any kind to lis mouth as decidedly unsafe. Funguses have a mission, not at all to feed man, but ever and eagerly to absorb from the ground and the atmosphere things which might injure his health.

Sea-weeds and flowerless fresh-water-weeds are the chief vegetable wonders of the waters. But they have scarcely one character in common except frondage in the place of foliage; and this itself is in some of them gelatinous, in others thread-like and jointed, and in others leather-like and jointless. Their colours are lively, and vary from the lowest green to the highest red or purple. Some live only a few hours, and others live during several years. Some are so small that 
they can be seen by the naked eye only when they exist in heaps; and others are hard, strong, leathery masses many fathoms long. Some float on the surface of wells and ditches like a patchy decoration; and others clothe great sea-depths with a far-spread and massive vegetation, in the manner of an oceanforest. All are destitute of any true root; and the very strongest possess in lieu of it an organ of mere mechanical attachment either on rocks or on one another's own stems. Some exhale oxygen; and others are scented like violets. Some copulate like animals; and others have a motion similar to that of worms. All doubtless perform great reciprocations of well-being with the animal inhabitants of the waters, just as all land plants maintain a mutual balance of health and food with the animal inhabitants of continents; and many of the sea-wceds are, in a number of ways, eminently serviceablc to man.

Some of the most curious allies of the sea-weeds and the flowerless fresh-water-weeds are a mongrel group which belong variously to salt waters, to fresh waters, and to land. These are the nostocs. They have a jelly-like appearance, and some of the more conmon have been the subject of very curious and conflicting speculations, on the part of both peasants and philosophers, in both remote and recent times. Parcellus ranked them with manna, and thought they dropped from heaven. The alchemists supposed them to afford a menstrum for gold, and ascribed to them other wonderful qualities. Some modern observers, who make considerable pretensions to scientific attainments, imagine them to be frog spawn in a premature state, or the substance of frogs eaten and ex- 
cremented by herons and other birds. And whole classes and groups of population have variously called them star-shot, witches'-butter, flowers of the air, and other names equally superstitious or fantastical. Even the ablest of the botanists of quite recent periods, while distinctly recognising their vegetable nature, have felt uncertainty and bewilderment as to whether they were not funguses, lichens, or some other kind of plants very different from what they are now known to be.

Ferns are as really flowerless plants as any at which we have glanced; yet they differ from all in delicacy of hue and in branching, waving, feathery, intricate beauty of form. Some of the tropical ones are the handsomest things on the earth, and, despite of total want of both grandeur and brilliance, may challenge comparison with many of the proudest flowering plants. Even the common British bracken, though one of the coarsest of ferns, is, in circumstances of favourable development, as princely an object as can be found in some of the palmiest or spiciest regions of the world. And our lady-fern, with its transparent stem, its multiplex, feathery fronds, its light, soft, graceful curves, its "texture as frail as though shivering with fright," may extract, not from poets only, but from the most prosaic describers, the praise of being "exquisitely and super-eminently beautiful."

Some ferns, too, especially those of New Zealand, soar to a great height, and present a near resemblance to the lofty, tufted, palm-like tree-ferns of the coalformation epoch, and are both so abundant and so conspicuous as to give a peculiar character to the landscape. And the inward anatomy of all ferns cor- 
responds in intricacy to the elaborateness of their outward development. If, for example, the lower part of the stem of a bracken be cut across, it will be seen to exhibit bundles of vessels in the form of an oak ox of a double-spread eagle. Altogether, ferns, though themselves flowerless, clearly occupy an intermediate station between flowerless plants and flowering ones.

Among flowering plants, the grasses are naturally the first to challenge our attention. They constitute probably about one-sixth of the whole vegetable kingdom. They comprise all the plants which bear corn, most of those which form pasture, some of the best which yield sugar, and not a few which abound in useful secretions, grateful juices, and fragrant odours. They are a stupendous instance of the adaptations of plants to the uses of man and the lower animals, and demonstrate in ten thousand ways, by their organisms, their chemical transmutations, their relations to soil and light and air, and the mighty and manifold connections which they maintain between crumbling minerals and living animals, the providence, wisdom, and benignity of the Creator. All in cool countries are remarkable for swardiness and verdure,-insomuch that grasses are regarded by many a European as almost identical with the green carpet of the earth. But some in the tropics are scarcely less remarkable for a strength and size like rods or saplings. Such are the bamboos. A strong, jointed, creeping, subterranean root-stock serves as the trunk or stem; and strong, light, graceful, straight, rod-like shoots, soaring from the root-stock to a great height. appear to be stems, and are popularly called so, but really possess the character of branches. When these 
have attained their fall height, they send off horizontally, or at right angles from themselves, a series of rigid lateral branches; and any full-grown series of shoots and offshoots, or of chief vertical branches and subordinate horizontal ones, is in consequence a dense tuft of rigid, straight-lined regetation. The shoots are externally hard, and coated with a powerful silicious secretion, resembling flint; they are internally a series of cylinders, separated from one another at the nodes by strong horizontal partitions; and the cylinders are occupied generally with water, but sometimes with an opaque, white, flinty secretion, called tabasheer, and possessing some curious optical properties. One species frequently attains the surprising height of from sixty-five to a hundred feet; and both this and others are used for a far greater variety of purposes in basketry, carpentry, and general house economy, than any kind of timber is in Britain.

Palms are somewhat near akin to grasses. Though most are trees and the rest are shrubs, all have culmlike stems, resembling far more the branches of bamboos than the stems of any European trees. They are one of the grandest, most imposing, and most useful family of plants in the world. Their graceful outline beautifies many an arid landscape; their foliage affords a grateful shade from the scorching play of the tropical sun; their stems form houses, furniture, and utensils to man; their leaves form roofs and cord. age; their sap produces wine and cooling drinks, their pith yields nourishing and delicious farina; their fruit yields food, drink, condiment, and oil; and their habits and economy afford a thousand evidences of the beneficence of Deity, and some fascinating illus- 
trations of the sacred record. A mother who possesses a little knowledge of palms, may charm her children with descriptions of oriental scenery, with accounts of sago, dates, cocoa-nuts, palm-oil, and other common exotic commodities of our markets, - with hundreds of startling and brilliant instances of the skill and loveliness of God's physical works,and with explanations of some of the most significant of the Bible's emblems of constancy, patience, prosperity, and triumph. Palms inhabit the warm and happy regions which combine tropical light and heat with the streams of fountains and a profusion of dews. Most love the margin of rivers; a few flourish in the oases of the wilderness, or on the tops of tropical mountains; and some collect in large forests, while others grow singly or in clumps, among woods or on the plains. Few species extend beyond a very limited range of territory; and probably so many as a thousand different species are in existence. The stem of most is lofty and majestic, and that of all is unbranched and perfectly erect. Their wood corsists of longitudinal fibres, and is soft and pulpy in the centre, but as hard as horn at the circumference. Their leaves or fronds rise in a plaited bundle out of the crown of the stem, and spread magnificently out like a vast umbrella cut into pinnæ or stiff and regular shreds. Their flowers are produced in elub-like masses, and burst suddenly out with an evolution of the most fragrant odours. And their fruit is a drupe, with either a fibrous or a fleshy coat, the mass of its kernel consisting of oily albumen, soft enough in the cocoa-nut to be eaten, but as hard in almost all the other species as the hardest portion of the wood. 
The cocoa-nut-tree is one of the most interesting of the palms, with stem not a foot in diameter, yet sometimes seventy or eighty feet high, and with a superb cupola of pinnated leaves, each about eighteen feet long and three or four feet broad. Date-trees, also, though seldom half as tall, charm every mind by their associations with the scenery and customs of the oldest historical countries of the world, figuring as they do like wands of witchery in all our imaginings of the landscapes and oases of the East,-

"Those groups of lovely date-trees bending

Languidly their leaf-crowned heads,

Like youthful maids, when sleep descending

Warns them to their silken beds."

But the palmyra-tree of India, in consequence of having had few or none of the illusions of poetry thrown round it, is a much better specimen of the ordinary comprehensive usefulness of its magnificent family. The stem of this palm is from twenty to forty feet high; its leaf or frond is about four feet long, situated on a spiry leaf-stalk of about the same length, and divided into seventy or eighty ragged rays; and its fruit is somewhat triangular, is as large as a child's head, has a thick, fibrous, sappy rind, and contains three seeds, each about the size of a gooseegg. Young plants of the palmyra-tree are used by the people of India as pot vegetables; in some districts, they are dried and pounded into a sort of meal; and in most, they are boiled and eaten with a little of the kernel of the cocoa-nut. The leaves of the full-grown trees are used for house-thatch, fans, baskets, hats, mats, umbrellas, buckets, temporary huts, and a substitute for writing paper; and when 
employed for the last of these purposes, they are written upon with an instrument of steel. The outer wood is brown, very hard, capable of longitudinal division, and susceptible of a fine polish; and it is fre. quently employed for making bows. The wood of a particular variety, usually procured in other parts of India, from Jaffnapatam, is hard, close-grained, and dark-coloured, and is considered a valuable timber for house-building and other purposes. A clear, gelatinous, pleasant-tasted pulp is obtained from the halfgrown fruit, and used as a condimental food; and a very copious sap is drawn from the whole plant, and either manufactured into a cooling and aperient wine, or evaporated into agreeable and nourishing syrups and sugar. Behold the emblem of a true Christian! "The righteous shall flourish like the palm-tree." Everything about him is of value. All the varieties of his moral produce-not the fruit only, but the fibres, the sap, and the foliage-are of service to the world. He is not an upas-tree, shaking poison from his branches,-he is not even a mere fruit-tree, yielding good produce only of one kind, and only in autumn; but he is a palmyra-tree, or a date-tree,-allproductive, in all his constitution,-all the year through, in youth and in age; and "the more he is oppressed, the more he flourisheth,-the ligher he grows, the stronger and broader is his top," - -and the longer he lives, the more abundantly does he yield fruits of faith and love, for the multiplying of "trees of righteousness," that God may be glorified.

Two interesting families of plants belonging to the same general class as the grasses and the palms are the day-lily family and the pine-apple family; and 
very curious specimens of these are respectively the drug-yielding aloes and the American aloes. The drug-yielding aloe-plants have a clubby, stumpy, cylindrical stem of three or four feet in height, and sharp, saw-edged, sword-shaped leaves, of nearly two feet in length, rising in clusters from the top of the stem, and a tall flower-stalk shooting aloft from among the leaves, and unfurling a display of flowers around its summit. They have a very singular appearance. And so too, and similarly, have the American aloes. But the latter grow for thirty or forty or even eighty years without ever rising much from the ground, or producing a single blossom, or a mouthful of pleasant sap, and then suddenly soar away to the height of twentyfive or twenty-six feet, display all at orce hundreds or even thousands of beautiful flowers, pour out gallons of delicious and nourishing juice, and then die abruptly and irretrievably down in the manner of mere annuals.

The aloe-tree of Scripture, however, is a totally different plant from any of these, and has so odd a character as to group alone, yet seems to be akin to the pistachia-tree, the sumachs, and the mimosas, and exhibits a general resemblance in height and form to the olive-tree. It is very rare, very handsome, a tropical evergreen, and quite as precious and almost as famous in our own day as in the days of Solomon. Its outer wood is black, compact, and heavy, and is frequently called eagle-wood; its inner wood is clarkcoloured, fragrant, shining, exceedingly light, and combustible like wax, and is usually called calambouc or calamba wood; and its heartwood, or that which lies next he pith, is surbassingly odoriferous, but 
exceedingly scarce, and is commonly called tambac. Both the tambac and the finer sorts of the calambouc are often sold in the East for their weight in gold, to be burnt in censers like incense; and even the inferior kinds of the calambouc are inported at a great price into Europe, and held in high esteem for their delicious odour and for the making of pastiles. One most glorious passage of the Bible lifts these fragrant aloewoods into association with the mightiest of moral and everlasting truths,_- "Thy throne, O God, is for ever and ever; the sceptre of thy kingdom is a right sceptre; thou lovest righteousness, and hatest iniquity; therefore God, thy God, hath anointed thee with the oil of gladness above thy fellows; all thy garments smell of myrrh and aloes and cassia, out of the ivory palaces, whereby they have made thee glad."

The tulip family comprises fritillaries, crown-imperials, dog's-tooth violets, yuccas, gloriosas, tulips, and all true lilies, and is therefore a bright and broad blaze of floral glory. But, except for arbitrary and trivial distinctions made by the ruling botanists, and disapproved by botanists as learned as they, it fully comprises also a multitude of other gorgeous groups; and it is therefore the galaxy of the floral heavens. Our Lord probably referred to most or all of it, when he said, "Consider the lilies of the field how they grow; they toil not, neither do they spin; and yet I say unto you that Solomon in all his glory was not arrayed like one of these." The "asphodel and hyacinth" of Adam and Eve's couch, "earth's freshest, softest lap," belonged to it. The narcissuses and amaryllides and alstrœmerias and ornithogalums and many other bulbous-rooted favourites of the garden, not excepting 
even the snowdrop, "whose modest form, so delicately fine, is nursed in whirling storms," are members of it. Warton's "flowery fields of joy," where Youth and Mirth "nodded their lily-crowned heads," were mainly studded with it. And Milton's cry for a grand outburst of vernal magnificence, though he does not name them, would be answered better by them than by any other family of flowers, and could be answered ill or not at all without them:-

\section{"Return, Sicilian Muse,}

And call the vales, and bid them hither cast Their bell s, and flowrets of a thousand hues. Ye valleys low, where the mild whispers use Of shades, and wanton winds, and gushing brooks, On whose fresh lap the swart star sparely looks, Throw hither all your quaint enamell'd eyes, That on the green turf suck the honied showers, And purple all the ground with vernal flowers."

The tulip itself, or at least the common garden tulip, is a worthy type of the whole tulipaceous tribe. Nor is it the less deserving of admiration that it was once the subject of the famous tulipomania. This commenced in a spendthrift passion for new and fine varieties of the tulip, and eventually became a gambling delirium which bought and sold rare bulbs at the price of great gems or of small estates, and turned thousands of florists into raving fools. It was ridiculed and despised at the time by multitudes of calm observers, and has ever since been proverbially quoted as a marked instance of epidemic absurdity; and, when it passed away, it afforded indolent aristocrats and ignorant pretenders a feasible pretence for deriding all love of flowers as undignified and foolish. Another 
mania then arose, grosser and more irrational than the tulipomania,-a contemptuous feeling for one of the most beautiful and heaven-proclaiming objects in the vegetable world; and this has left broad traces over great tracts of fashionable society, in stupid, stolid indifference to some of the superbest "lilies of the field." But the tulip is sure to live on, repeating the Saviour's sublime lesson till the end of time, and will yet again command the wonder of all eyes, and direct to heaven the lindlings of all hearts. Hamilton, with beautiful suggestiveness, speaks of God as "spreading the tulip's parted streaks;" and Cowper must have been thinking of it more than of any other denizen of the field or the garden, when he said,

"Not a flower"

But shows some touch, in freckle, streak, or stain, Of his unrivall'd pencil."

A family almost as eminent for beauty as the tulipacex, but in a widely different style, and eminent at the same time for grotesqueness and fragrance, are the orchids. The flowers of not a few present very striking resemblances to the heads or bodies or general shape of insects, birds, and other animals; and the roots and stems and leaves and growing economy of very many are odd and wonderful. Great numbers are epiphytes or air-plants, sitting far aloft from any soil; and these abound in the damp, hot, shady forests of the torrid zone of both the Old World and America, hanging on the branches of trees, clinging to rocks, or creeping among moss close to the spray of waterfalls. Not fewer than about three hundred species have been found in the single island of Java; and are described 
as there overmatting the trees by thousands, and combining with huge climbers and gigantic grasses to maintain among the forests a perpetual gloom. "In the midst of airy garlands of aristolochias, bignonias, convolvuluses, and passion-flowers, where innumerable ferns hang down in plumes or festoons or the gayest lace-work, and where vast quantities of bromeliaceous plants, and especially tillandsias, form broad patches of verdure upon a sombre ground, there live the orchids, each particular species seeming to haunt its own peculiar plant."

Not much different from the orchids in structure and strangeness, though almost a perfect contrast to them in tastes and habits, are a small family of water plants represented by the frogbit. These play as curious pranks in the water as the orchids do in the air. One of the best known of them is the water-soldier, an inhabitant of pools and deep ditches in England, sometimes seeming to cram its home with an armoury of sword-like leaves, but at other times sufficiently scarce to challenge warm admiration of its large, white, and handsome flowers. It floats on the surface of the water during summer, sinks to the bottom after blooming, and sends out long simple runners on the mud; and each runner terminates in a bud or young plant, which first forms several long radical fibres, and effects an anchorage in the mud, and then in summer rises to the surface of the water, there to go through the process of flowering; and after having bloomed, it sinks in the water, matures its seeds, sends out runners, and dies.

The spiral valisneria, a native of ditches and rivers in Italy and the south of France, is still more curious. 
This exhibits, in a very manifest and somewhat unique way, one of those exquisite contrivances which exist by the million in every department of creation, and evince the surpassing wisdom and provident care and infinite intelligence of the Almighty. It carries a large heavy flower, which requires always to float on the surface of the water, and would speedily perish either if much submerged or if left dry or pendulous; and it at the same time inhabits streams which are subject to great and sudden changes of volume, often alternately rising several feet above, and falling several feet below, their ordinary dimensions. The flowerstalk, therefore, though slender, is very long; and of a spiral or cork-screw form, and so highly flexible as very easily to extend or contract; and it so readily and uniformly lengthens with the rise of the water and shortens with its fall, that the head or flower constantly and neatly lies on the surface. Nor is this all. For the body of the plant, both before going into bloom and after forming the seed, inhabits the mud at the bottom of the water; and the plant, too, is a duplicate, or what the botanists call diœcious,_-an impregnator and a seeder, each perfectly distinct from the other; and the impregnator first sends its flower to the surface, and keeps it there till it ripen, and then the seeder sends up its flower to catch the former's scattering pollen, and to mature itself into seed; and both plants have the admirable distensible spiral stem for keeping their flowers exactly on the surface.

All the families of flowering or seeding plants at which we have glanced, as well as nearly thirty more at which we have not glanced, have seeds with only one lobe, and leaves with parallel unbranching veins; 
and so many of them as have woody stems, or as form cylindrical increments of growth, are coated, not with any bark, but with a hard flinty secretion, and effect all their cylindrical increase by deposits along their centre. In other words, they are what botanists call monocotyledons and endogens; and they possess a medium character, in elaborateness of organisation, between the lowest grades of plants and the highcst. But we proceed now to make a few selections from the greatly more numerous division of the vegetable kingdom called dicotyledons and exogens,-most of which have seeds with two lobes, and leaves with ramified veins, while all the woody ones sheath their stems and branches with bark, and form thcir increments of cylindrical growth by deposits around their exterior,-deposits which so harden during the season of annual repose, as, in ordinary circumstances, to constitute as many concentric rings in a tree's timber as it has had years of growth.

One of the simplest, oldest, and most important families of exogens are the conifers. All these are trees and shrubs. Some extinct species, as we saw in a former chapter, belonged to the epoch of the coal formation; and the existing ones comprise at once the commonest, the strangest, and the tallest of modern forests. Their seeds have no covering, and are attached to a kind of hardened swollen small leaves, and possess an intermediate structural character between sporules and covered seeds; and they grow in groups which have generally the outline, more or less, of cones. Hence the name of the family,-conifers or conebearers. But, in some instances, as in junipers and yews, the cones are so compressed and juicy as to pre- 
sent the appearance, and take popuiarly the name, of berries.

All the conifers secrete a turpentine fluid, of eminent service in many ways to man, and have tubular vessels throughout all their wood for containing it. Most are stern, sturdy, useful-timbered evergreens, living, or capable of living, in climates too severe to permit the existence of any other trees, and clothed with a needle-shaped foliage which allows the most furious tempest to sill freely through, and gives it not hold enough to tear them from their anchorage in even the most shallow soils. Who has not heard with wonder of the great pine forests of alpine mountains, and of far-north regions?

The imbricated auracaria, however, - a conifer entirely unknown to our great-grandfathers, - is a rare plant, and as curious as it is rare. It is a native of South America, and has not long been introduced to Britain, yet is rapidly multiplying through our parks and shrubberies as a most arresting ornament. It displays a foliage, not in the least like leaves, but like a lancety armature, set edgily and angularly in thick array along all its branches; and it looks altogether so odd and ancient as almost to seem a resurrection from the epoch of the coals. The Norfolk Island pine is nearly allied to it, and has the same kind of pyramidal outline, but differs totally in foliage, and is as eminent for gracefulness as the other is for grotesqueness. It attains, on Norfolk Island, a height of upwards of two hundred feet, and expands to a corresponding bulkiness; and is there, beyond all question, one of the most beautiful and magnificent trees in the world. And even tho 
few dwarf specimens of it which grow within the narrow limits of our conservatories, though pitiful representatives of the massive and soaring tree, instantly strike every eye as the very beau-ideal of dendritic elegance.

The next family we shall notice is one represented by the common nettle. This family is so exceedingly diversified as to put popular faith in botanical classification severely to the test. It ranges through all habits of plants, and through all parts of the world. It comprises small herbs and stupendous trees, unsightly weeds and vegetable wonders, great masses of the most worthless herbage and large groups of the most valuable plants. Yet it is all pervaded by a strict family character, which a moderate degree of botanical knowledge readily and everywhere recognises. Here are crowds of things notable only for their stings. Here is the hemp-plant, whose tubular vessels, naturally overlying one another, and artificially separated from the cellular masses below them, constitute the well-known fibre of the ropemaker,and which differ little or nothing from corresponding vessels in the nettles. Here is the hop-plant, whose strobiles or seed-forming flowers are so famous in the manufacture of malt liquors, and whose fibre-forming tubular vessels, as well as those of the nettles, are natural rivals of the fibre-forming tubular vessels of the hemp-plant. Here is the mulberry-tree, so valuable for feeding the silk-spinning caterpillar, popularly called the silkworm. Here is the fig-tree, whose well-known produce, commonly regarded as a fruit, is really a succulent sugary pouch containing many fruits naturally introverted into it while grow- 
ing in a cluster. Here is the bread-fruit-tree, whose produce, of similar nature to the fig, but larger than the cocoa-nut, constitutes an important article of food to many human inhabitants of the torrid zone. Here is the half-fabulous upas-tree, whose exhalations are unhealthy to persons breathing them, and were once believed to be terrifically deadly. And, without naming any more instances, here are the cow-tree and the banyan-tree, each of which we shall make the subject of a short paragraph.

A nettle sting, when examined through a microscope, is seen to be a stiff, highly polished, finely pointed tube, resting on a pedestal. It is not, like a pin or a needle, solid throughout; but is perforated through the point, and hollow in the centre, and communicates with a spongy mass at its base, containing an extremely acrid or venomous fluid; and, when touched by any person, it instantly pierces his skin, and injects through the wound a portion of this fluid. The wound is so minute that it would scarcely be felt; but the poison irritates and inflames it, and occasions the well-known pain. The pedestal on which the sting stands is cellular or spongy within, and performs the office both of gland and poison-bag; and the sting itself is poised at the top of it on a sort of universal joint, and may be moved by the slightest pressure to either side or round in a circle; so that, whenever the sting's point is touched from any direction, the spongy pedestal is pressed by the sting's base, and the venomous fluid rushes up to the tube, and spurts out through the terminal aperture. Stings are totally awanting in many of the exotic species; but are exceedingly virulent in a few,-far more so than in our 
indigenous nettles; and those of one spccies, in particular, are said to procure it the local name of devil's leaf, and sometimes to cause, not only disease, but death.

The cow-tree grows on the rocky steeps of the northern Andes, and is an evergreen of from fifty to a hundred feet high, with fan-shaped leaves and great girth of bole. It takes its name from yielding a fluid of similar nature to cow's milk. This is obtained by incisions in the trunk,-and flows most copiously when these are made about the time of sunrise; and it is eagerly collected by the natives in vessels, and used in the same manner as cow's milk is used in Europe. It is not so thin as milk, yet mixes easily with water; and is similar in both consistency and taste to sweet cream. It can be separated by heat into two portions, which have a chemical resemblance to respectively butter and cheese; and when boiled, it forms a thick pellicle on the surface, yet it cannot be made to curdle. European travellers have drunk it, and spoken highly in its praise.

The banyan-tree is an Indian evergreen, of the same genus as the fig-tree, and is sometimes called the Indian fig. It seldom has a greater height than about thirty feet; but it flings its branches horizontally like the divergent rafters of a circular ceiling, and sends down from them perpendicular offshoots, which strike root in the ground; so that, in course of time, it becomes a "sylvan temple, with airy aisles and living colonnades." A famous specimen of it, called the Nerbudda Banyan, has about three hundred large stems and about three thousand small ones, and is said to be capable of sheltering seven thousand 
merı. The appearance and habit of a large banyan are well described by Southey in his Curse of $\mathrm{Ke}-$ hama:-

"6 'Twas a fair scene wherein they stood, A green and sunny glade amid the wood, And in the midst an aged banyan grew.

It was a goodly sight to see

That venerable tree,

For o'er the lawn, irregularly spread, Fifty straight columns propp'd its lofty head;

And many a long depending shoot, Seeking to strike its root.

Straight like a plummet, grew towards the ground, Some on the lower boughs, which cross'd their way,

Fixing their bearded fibres, round and round, With many a ring and wild contortion wound;

Some to the passing wind, at times with sway

Of gentle motion swung;

Others of younger growth, unmoved, were hung Like stone-drops from the cavern's fretted height.

Beneath was smooth and fair to sight;

Nor weeds nor briars deform'd the natural floor; And through the leafy cope which bower'd it o'er

Came gleams of chequer'd light.

So like a temple did it seem, that there

A pious heart's first impulse would be prayer."

The celebrated pitcher-plant of India and China is a kind of cousin-german of the nettle family, and a considerably closer relation to the passion-flowers, but has scarcely any brotherhood or sisterhood. It is of a half-shrubby nature, and can grow to the height of from twenty to thirty feet. Its leaveswhich are the wonderful parts of it-are green, smooth, entire, and about three inches broad and two feet long; and they come out stragglingly, and half 
embrace the stem. The mid-rib of each has a rustybrown colour, and is very prominent behind, and is prolonged at the tip of the leaf into a tortuous, pendulous, rusty-brown tendril; and this tendril bears at its extremity a perpendicular dingy-brown pitcher, from six to nine inches in depth, and about five inclies in greatest circumference. A very distinct lid surmounts the pitcher, and joins on to the back part of the rim; and it continues closed while the pitcher is young, and stands open at about a right angle with the mouth when the pitcher becomes old. A quantity of pure sweet water, varying from a drachm to several ounces, is always found in both the opened and the unopened pitchers; and seems to be a secretion from minute glandular scales with which the lower half of the pitchers is lined. Some animals of the monkey family in Ceylon are well acquainted with the liquid-containing character of the pitchers, and never scruple to frequent them as convenient pleasant wells. A pitcher-plant at Chatsworth was described, a number of years ago, as more than twenty feet high, as suspending nearly fifty full-grown pitchers from the points of its strongest leaves, and as presenting a most magnificent and exceedingly singular appearance.

A somewhat near relation of the pitcher-plant, but as scarce of brethren, and to the full as curious, though in a totally different way, is the rafflesia. This is all flower together, without either root or stem or foliage, yet weighs about fifteen pounds, and has a breadth of upwards of three feet. It grows on some crack of the stem or root of a vine or other woody climber. folded like a cable on the largest trees of 
the tropical forests. It is therefore the parasite of a parasite; and yet is much the largest known flower. in the world. The natives of Sumatra, where it was first discovered in the year 1818, call it krubut, or the great flower, and ambum-ambum, wonder-wonder, or the flower of flowers. Its first appearance is that of a round knob; its further development exhibits the flower within sheathing folds; and its onward progress pushes off the folds, wears them away, unrolls the flower in due form, and matures it to full expansion. The thing then has pistils nearly as large as cow's horns, and a nectary or cup of capacity enough to hold twelve pints, and five segments or petals of a brick-red colour, with yellowish-white protuberances, - each segment a foot long from base to apex, and standing at an interval of about a foot from each of its neighbours.

The primrose family are a charming contrast to these curiosities of the tropics,-perfectly familiar to all men, and yet wonderful for their never-ceasing loveliness, their power over all hearts, their constant ministration to man's happiness in cold and blustring climes. Though chiefly lowly, dwarfish, hardy herbs, without one character of stem or shape or foliage to distinguish them from the most common weeds, they command universal admiration, and enkindle universal delight, by the mere tints and pencillings and forms of their flowers. "Nothing," remarks Loudon, "can be more lovely than the little delicate alpine primulas, androsaces, aretias, and soldanellas, with their little modest blossoms, sometimes rivalling the whiteness of the surrounding snow, sometimes emulating the intense blue of the empyrean, as if the one had bor- 
rowed its hues from heaven, and the other from the spotless mantle of the earth." Nearly twenty groups of them-or what the naturalists call genera-occur in British gardens, and are familiar to florists; while many single kinds and sub-groups, and even some entire groups, such as cowslips, polyanthuses, auriculas, cyclamens, pimpernels, American cowslip, androsaces, and soldanellas, are the glory of spots or beds or compartments in all sorts of flower-gardens from the most cottierly to the most princely. No flowers are more truly than they "the blue and golden stars that in earth's firmament do shine"- - the lights of love "everywhere about us glowing,"- "the poetry of earth, impulsive, pure, and wild,"-the ministers of heaven "to whisper hope, to comfort man, whene'er his faith is dim." And even the common primrose is accepted by all men as the emblem-proclaimer of a summercalm after the winter-affliction of life, or at least as a literal gladsome token that the season of snow-storms and hurricanes has passed away, - the prime-rose whom,

"When young Spring first question'd Winter's right, And dared the sturdy blusterer to fight,

On a bank he threw,

To mark his victory."

The nightshade family is remarkable for the diversity of manner in which a large number of its members are treated by man. It abounds in acrid juices and sickening odours, and has all more or less a noxious character, and comprises several violent poisons, and is manifestly adapted, as a whole, to admonish man and to warn him, but not at all, or at least very slightly, to serve him in any economical way. 
Yet, by his perversity or caprice or ingenuity, he has dragged it into a more varied prominence among the matters of his daily life than almost any other family of plants. For example, here are the petunias and the brugmansias, which have been worked by the arts of the florist into showy companionship with the denizens of the greenhouse. Here are the capsicums, whose acrimonious, biting, fiery berries, the red and cayenne peppers of commerce, are relished by dyspeptics, gourmands, and lovers of hot stimulant so much better than all the spices. Here are henbane and deadly nightshade, whose fell poison is diluted down by physicians into a powerful drug. Here is tobacco, one of the keenest of narcotics, a mild but stinking and most naseous opiate, which the thoughtlessness and bad taste of multitudes of men have converted into a common nuisance of society and an extensive shortener of human life. Here is the potato, whose tubers when freed from noxiousness by heat, constitute an eatable compound of water and starch and potash, with a gout of flavouring matter, and a slight, small, diffused quantity of flesh-forming substance, for the sake of which the plant has been pushed into cultivation on a scale so immensely beyond its proper merits, as more than once of late years to have occasioned terrible derangement in the food-market of all central and northern Europe. And, to name no further instance, here is the mandrake, which many persons, amid the light of the nineteenth century, absurdly imagine to possess certain curious medicinal properties, and which multitudes, in darker ages, regarded with abject superstition. A famous liorticultural writer, speaking of the mandrake about 
A century ago, says, "As to the resemblance of a human form, which the roots of this plant are said to carry, it is all imposture, owing to the cunning of quacks and mountebanks, who deceive the ignorant with fictitious images shaped from the fresh roots of bryony and other plants; and what is reported as to the manner of rooting up this plant, by tying a dog thereto, to prevent the certain death of the person who should dare to attempt it, and the groans it emits upon the force offered, \&c., is all a ridiculous fable."

The cactus family are singularly juicy, hairy, prickly, and grotesque. Most are as leafless as mushrooms, and yet as juicy as sedges and as prickly as briers, and at the same time abundant bearers of brilliant flowers and fleshy, watery, insipid fruit. Some are globe-shaped or egg-shaped, or have a lumpish base with tubercular or pap-like offshoots, and are not more than a few inches high; and others have flattened or channelled or jointed stems, in great variety of form, and ascend strangely aloft to heights of from less than a foot to twenty or even forty feet. They have a wondrous capacity of collecting moisture from air and dew and soil in the most arid climates, and an equally wondrous power of maintaining long possession of it by resisting exhalation. They abound chiefly on hot, dry, sandy plains, or hot, dry, rocky districts, in torrid and sub-tropical regions, where plants of a less absorbing or more perspiring nature could not exist. They have such a tough close skin, and such strong internal reservoirs, that they can sustain unhurt the fiercest play of vertical sunshine, and the most ardent radiation of it from acljacent sands 
and rocks. And they serve both to afford cooling nuiriment to man in places where drink and ordinary food cannot be obtained, and to produce a vegetable soil on surfaces which, but for their growth and decay, would for ever remain arid wastes. The multitudes of small kinds stud the sands and rocks and dry forests of tropical America in so vast profusion and with such blood-spilling gripes as to render travelling among them difficult and disastrous; and the few tall kinds lift their gaunt, grotesque, angular, leafless, spinearmed stems far above the surrounding stunted vegetation, and form a bizarre and rueful feature of a sunscorched landscape. The common opuntia, or prickly pear, through many of the hot countries of the Old World, and several other opuntias in South America, are planted for fences in the same manner as the hawthorn is in Britain; and they speedily elongate and amass themselves into such dense, jagged, powerful, living vegetable walls as neither man nor beast can penetrate. Many of the cacti are high favourites in the glasshouses of British gardens, - some for their startlingly odd appearance, and some for their large dazzling flowers, of crimson, pink, blush, or snow-white hues.

The mangroves are large trees of the silty shores and muddy tidal rivers of the torrid zone. Their seeds germinate before dropping from the branches. The young plants develop in the air, and fall down with rootlets ready formed into the mud adjacent to their parents, and speedily shoot aloft and expand into tree-dignity. The roots of all ascend far in convergent arches before forming into stem; or, to state the case differently, the stem-bases diverge in the air, and pass down in many ramifications to the tops of nume- 
rous roots. At high water, every tree-top sits like a great basket of foliage on the surface of the tide; and at low water, it stands perched on the apex of the many open root-stems, meeting one another like so many flying buttresses. A growth of mangroves arrests the washing away of silt, and contributes powerfully to the forming of new land; and it also builds up and spreads abroad on the mouths of many rivers a matted and bosky and sylvan system of barricades too strong and close to be penetrated by ships.

"Such is the mangrove, which, at full-moon flood, Appears itself a wood upon the waters;

But, when the tide leaves bare its upright roots, A wood on piles suspended in the air."

The tea-plants of China are interesting not a little to all tea-drinkers, and very much to all inquirers into the tea-manufacture and the tea-trade. They belong to the camellia family, and are handsome, white-flowered, evergreen shrubs of from four to six feet high. European botanists distinguish two kinds, the black and the green. But the Chinese distinguish only one wild kind, which they call bastard tea, and a long-managed, highly-wrought, cultivated kind, which they call true tea; and were they to study botany and plant-culture after the European style, they would very likely pronounce their cultivated tea-plants to stand related to their wild tea-plant in nearly the same way as our orchard apple-trees do to our wild crab, or as our cultivated cabbages and coleworts and borecoles and cauliflowers do to our wild cablinge. In their practice of preparing different kinds and qualities of tea for the market, too, they are dependent far less on different varieties 
of plant, than on different stages of growth, different seasons of the year, and different methods of drying and flavouring; and they manufacture black tea and green tea, not from the leaves of two species or two varieties corresponding to those of our greenhouses, but from different growths or kinds of the leaves of one plant, or by different methods of drying even the same growth of leaves.

The leaves of the tea-plants, in their fresh or unprepared state, are said to possess an intoxicating property; but they lose it on being exposed to the fire and kept during a twelvemonth. All the varieties of the tea of commerce are prepared for the market by more or less application of artificial heat; and some are highly or repeatedly torrefied. The bohea derives its name from Vovyee, the country in which it grows; congo or cong-foo, signifying "great trouble," from the operose method in which its leaves are gathered; pelzoe or pe-how, signifying "white-leaf," from its consisting only of the leaves of the tenderest of the trees of three years' growth, gathered just after they have bloomed; and souchong or scouchong, signifying "small good thing," from its being the scarce produce of trees of three years' growth on particular kinds of soil. The leaves which are gathered earliest in the spring afford the strongest and most valuable varieties; those which are gathered late in the year afford the inferior varieties; and those of any season can be made into the green or hyson varieties by peculiar and abundant torrefaction. All the leaves naturally possess an unctuous quality; and they lose almost all of it in the process of drying.

The chief of the camellias is a representative which 
does the tea-plants the most ample honour. It appears to have been long cultivated and highly admired by both the Chinese and the Japanese; it figures, in common with hibiscus and chrysanthemum, in a large proportion of Chinese paintings; it abounds in the gardens and groves of both China and Japan, not only as a beauteous shrub, but as a superb and soaring tree; and it has been so carefully and scientifically managed by the Chinese, as to exist among them in a great number of perfectly distinct and permanent varieties. No healthy human eye which looks upon it can fail to admire it. Many scores of varieties of it are now a grand glory of British conservatories. Its very form is elegant; its glossy deep green foliage is charming; and its pellucid, glittering, circular flowers, whether the snowy white or the brilliantly red, especially the imbricated ones, look like the most beauteous of roses smoothened down and purified from all the rufflings and taints of earth. Mrs Sigourney, in her impassioned ode on the love of flowers, finds direct utterance for the names of only the violet, the rose, and the camellia, and figures the first and the second as a decoration for a maiden "better than all Golconda's mine," and the third as a decoration still richer for a bride:

"Above the floating veil

The white camellia rears

Its innocent and tranquil eye,

To calm young beauty's fears.

And ey'n when hoary age recalls

The memories of that hour,

Blent with the heaven-recorded vow

Will gleam tlrat stainless flower."

The magnolia family are in some sense perfect 
rivals of the camellias, but in another style; for they affect the forest rather than the coppice, and the warm wall or the open park rather than the conservatory or the shrubbery. The large-flowered magnolia is the superbest showy-blooming evergreen in the world. It rises in the woods of Carolina and Louisiana to the height of a timber tree, with an upright stem and a regular head. It is all over a mass of glittering foliage,-with leaves thicker than those of the cherrylaurel, and many of them ten inches long and four inches broad. Its flowers are as large as a child's face, and have a pure white colour, and diffuse a very strong and most delicious fragrance. Its fruit is nearly as large as a hen's egg; and its ripe seeds have a fine scarlet colour, and hang dangling on the tree upon long threads. This magnificent plant is unhappily too tender to grow as a standard in most parts of Britain. But a brother of it, the tulip-tree or liriodendron, is hardier, and only a degree or two less superb. This grows in North America to a towering height and enormous bulk; and it has leaves of almost exactly the outline of a saddle, and hangs out from the extremities of its branches a gorgeous display of flowers, somewhat similar in appearance to tulips, and spotted with green, red, white, and yellow.

The bombax or silk-cotton-tree family are the titans of the forest for bulk, and not a great deal inferior to the loftiest conifers for height. Two kinds of bombax, the one belonging to the Old World and the other to the New, are stupendous features on the most fertile spots of the banks of intertropical rivers. Both have very siraight and prodigiously massive stems, admirably suited to be hollowed into canoes; 
and one is densely covered with an armature of short spines. Columbus, at his first visit to America, saw a bombax canoe of such enormous capacity as to contain one hundred and fifty men. And Philip Miller says, "Some modern writers have affirmed that there are bombax-trees now growing in the West Indies so large as not to be fathomable by sixteen men, and so tall that an arrow cannot be shot to their top." The famous adansonia or baobab of West Africa, is one of the bombax family, and, though inferior to the repre. sentative bombaxes in height, equals them in symmetry, and far excels them in bulk. It looks, in comparison to European trees, like an old oak-tree to an ash sapling; and it is believed to excel most of them as much in long-livedness as in size. A number of specimens of it were measured by the French discoverer, Adanson, whose name it bears. And the trunks of these had a girth of from sixty-five to seventy-eight feet; their lower branches were very numerous, and went off somewhat horizontally, at the height of from twelve to fifteen feet from the ground, and were from forty to forty-five feet long, and all as thick and massive as middle-rate European trees; and their roots, so far as they could be traced in places where they had been laid open by a stream, and exclusive of further portions which had not been laid open, extended to a dis. tance of one hundred and ten feet.

But the greatest of vegetable wonders, in the estimation of the present amateurs and sight-seers of Europe, is the victoria regia or royal water-lily. It belongs to the nymphæa family. It was long ago described and figured by the German botanist Poppig; but it is very rare, very tender, and very refiactory to artificial 
treatment, and seems to have become generally forgotten till the year 1837, when it was rediscovered by Mr Schomberg in the river Berbice in British Guiana; and now it is an object of intense interest to all admirers of hothouse culture, and has been brought successfully to flower in enormous specially constructed tanks, in at least five places in England. Each of its leaves is salver-shaped, from four to six feet in diameter, of a bright green colour above, and vivid crimson below; and has round its margin a rim from three to five inches high, corrcsponding in colour to the two surfaces of the leaf, green on the inside and crimson on the outside. The flower-stalk is an inch thick, and studded with sharp elastic prickles. The flower-cup or calyx measures fully a foot across, and comprises four thick leaves, each upwards of seven inches long, white inside and reddish brown outside. The flower itself, or corolla, is an absolute mass of magnificence, completely cover's the flower-cup, and displays many hundreds of petals passing in alternate tints from pure white to rose and pink. But it is only the glory of a day, and no sooner unfolds its gorgeousness than it begins to perish,-an impressive emblem of the evanescence of all sublunary royal grandeur.

The effect of the victoria regia in a tank is powerfully aided by a fringe of other water-lilies. Though none of these can for a moment compare with it in size, yet many equal it, and several excel it, in beauty and brilliance. The showy nelumbium, in particular, is very stately in height and appearance, and carries luscious, rose-coloured, fragrant flowers, each ntedrly a foot in breadth. This plant, too, is interesting by 
its associations, - treated as sacred by the Hindoos, making high claims to be the ancient Pythagorean bean, and true ancient Egyptian lotus, and often called at the present day the sacred bean and the holy cyamus. Even the white nymphra, the common water-lily of the clear ponds and slow clear streams of Britain, is one of the loveliest objects on which the eye can gaze,-its leaves oval heart-shaped, smooth and floating on the water, and its flowers snowy white, with contrast of yellow in the filaments and other colours in the calyx, and about four or five inches wide:-

"That peerless lily to the light

Her chalice rears of purest white.

Oh, I could sit beside the brink

Of that bright lake, and soothly think

Of Him who made the mountain high,

Yet bends on earth a watchful eye,-

Who made the flower of peerless white

Uplift her petals to the light,

That stand like burnish'd pillars round

To guard from harm her fairy ground,-

Of Him who, when on earth he trod,

Drew oft from flowery brake or sod,

Or warbling bird, in glade or glen,

Lessons of truth for anxious men."

Flowers-not indeed in their organisms or living functions or chemical actions or economical uses, though in all these respects they are wonderful_but flowers, in their tints and forms and fragrance, in their arresting power upon the human eye and their magical influence on the human heart, constitute not a few of the plant-wonders at which we have glanced, 
and a vastly larger proportion of thousands of plant. wonders at which we have not glanced. Yet, as regards all their showy properties, they are very slightly or not all required fur any of the proper uses of their plants, and seem to have been created expressly to give pleasure to man and to breathe into him tlie poetry of holiness. How benignant in God to make them so wondrously lovely! and how shameful for man that he is so little moulded by their influence! "A love of these beautiful things of nature," remarks Mrs Sigourney, "has been sometimes assumed as a criterion of the health of the mind. Those who are under the habitual influence of evil tempers do not approximate to the spirit and language of flowers. In vain do they reach forth their sweet clustering blossoms-envy, hatred, and malice are beyond the reach of such charmers, 'charm they never so wisely.' But he who, amid the care and weariness of life, finds daily an interval or disposition to commune with the dew-fed children of heaven, to devise their welfare, and shelter their purity, has not yet been injured by the fever of political strife, the palsy of the heart, or the eating gangrene of the inordinate desire of riches. Err they not, therefore, who consider a taste for the charms of nature a waste of time? The railroad machinery of a jarring world, bridging its abysses and tunnelling the rocks of political ambition,-her steamboats rushing to the thousand marts of wealth, silence with their roaring funnels its still small voice. But let it be heard by those who meditate at eventide, when the rose closes its swect lips and the tired babe is lulled on the breast of its mother. Let it be a companion to those who, in the morning-prime, walk forth amid the 
dewy fields, loving the beauty of the lily which Omnipotence stooped to clothe, and from whose bosom, as from a scroll of heaven, the Redeemer of man taught listening multitudes the lessons of a living faith."

The mere forms of flowers are eminently instructive. We speak not of the beau-ideal of grace and symmetry which fancy florists set up for every special favourite of the parterre; though that, too, challenges high admiration for its sublimating power upon the feelings of cultivators, and for the refined instance it affords of the goodness of the Creator in endowing the organic beings which he has made subject to man with capacities of improvement under skilful cultivation. But we speak of the types of form which characterise vast groups and families of flowers; and we refer to them as the simple, suasive, all-beauteous models of the great majority of the graceful and useful mouldings and sculpturings and fashionings of art which have ever been practised, or ever will be practised, by the human race. The leaf of the acanthus is well known to have been the model of the capital of the Corinthian pillar,-the most elaborate decoration of pure Grecian architecture. But what is that compared to the forms of flowers? Think, for example, of the peerless combinations of curve and contour in the tubes of the Cape-heaths,-in the saucers and vases of the ipomeas and convolvuluses, - in the laughing mouths of many of the labiates,-in the wings and keel and banner of the butterfly-shaped pod-bearers, -in the waving folds of the irises,-in the tracery of the passion-flowers, - in the turbans of the martagon lilies,-in the trumpets of the bignonias,and in the bells of the campanulas and squills. These 
last are particularly beautiful, and have ever won the love of peasant and poet, of child and philosopher, for their simple grace and heart-wooing elegance. O how powerfully, too, do they ring into the soul suggestive music about the glories of the Creator! Many a fine use has been made of them in odes and lyrics; but none half so fine as the following:-

"Your voiceless lips, O Flowers! are living preachers,

Each cup a pulpit, every leaf a book,

Supplying to my fancy numerous teachers

From loneliest nook.

'Neath cloister'd boughs each floral bell that sivingeth, And tolls its perfume on the passing air, Makes Sabbath in the fields, and ever ringeth

A call to prayer,-

Not to the domes where crumbling arch and column Attest the feebleness of mortal hand,

But to that fane most catholic and solemn

Which God hath plann'd,-

To that cathedral, boundless as our wonder,

Whose quenchless lamps the sun and moon supply, Its choir the winds and waves, its organ thunder,

Its dome the sky." 


\section{CHAPTER XIII.}

\section{THE ECONOMY OF PLANTS.}

CONTRASTS BETWEEN PLANTS AND ANIMALS-FALSE AND TRUE ANALOGIES BETWEEN THEM-ELEMENTARY CELLS OF PLANTS AND ANIMALS-AGGREGATIONS OH VEGETABLE CELLS-THE STRUCTURE AND FUNCTIONS OF ROOTS-THE STRUCTURE AND FUNCTIONS OF LEAVES -THE structure, FUNCTIONS, AND USES OF SEEDS AND FRUITSSUMMARY VIEW OF OTHER WONDERS IN THE ECONOMY OF PLANTS.

Plants live and grow; yet, in several great characters, are contrasts to animals.-They feed; but have no digestive system,--no stomach, no intestinal canal. They receive their food in a state nearly ready for assimilation, partly in the form of gases out of the atmosphere and partly in the form of liquid out of water or out of the ground; and they have leaves or equivalent organs aloft in the air for taking in the gases, and roots or equivalent organs down in the water or in the ground for taking in the liquid.-And they move in a variety of ways, yielding to the breeze, pushing their rootlets, unfolding their buds, and, in many instances, making special efforts for forming or dispersing their seeds; yet they have no muscular system,no power of will over their fibres,-no apparatus of Incomotion. All their food is brought to them, or deposited under and around them; and they obtain it best, and best secure their entire well-being, by standing as firm fixtures on one spot.-Again, they have 
irritability, but no capacity of sensation,-contractile fibres, but no nervous system.-And they have ample appliances for the distribution of their aliment through all the interior of all their organs; yet have no circulating system,-nothing corresponding to the heart and arteries and veins of animals. They suffer little or no waste of their main substance, and employ thcir aliment principally in making additions to that substance, in forming new organs, and in restoring temporary and fallen ones; so that they need no more complex an apparatus for distributing their aliment than something to carry up the liquid from the roots to the leaves, and something to carry down the elaborated liquid and gases from the leaves to the flowers and branches and stem and roots.-And they both inhale gases and exhale them, yet do not breathe. They operate powerfully on the atmospheric air, yet have no respiratory system,-nothing analogous to the airpassages and the lungs of animals. They need no nitrogen for any substance similar to blood or muscle, and very little for any of their constituents; nor do they need a very great deal of oxygen either for making formations within them, or for any other purposes of their economy; but they need enormous supplies of carbon and hydrogen for building up their woody tissues, and for forming all their oily and resinous and starchy secretions; and they therefore reciprocate gases with the atmosphere, not only in a different series from animals, but in a converse series. Plants are essentially carbonaceous, while animals are characteristically nitrogenous; and the former live largely by drinking in carbonic acid, and the latter as largely by brcathing it out. 
These contrasts are readily observed between all the higher and middle classes of plants, and all the higher and middle classes of animals. But they are not so easily observed, and indeed some of them do not always exist, between the lower classes. "The vegetable kingdom and the animal kingdom," it has been remarked, "may be compared to two mighty pyramids, which touch each other by their bases, while their opposite vertices diverge to two infinitely remote points." A number of the very lowest kinds of plants so closely resemble a number of the very lowest kinds of animals that the line of demarcation between them has, in some instances, been matter of doubt or of dispute among the keenest and most competent observers. One of several startling anomalies is, that some things which are proved to be plants have for a time a power of locomotion, while some things which are proved to be animals never have that power. Yet a doubtful object under examination, except in a very few instances, may be readily known to be plant or animal by the following rule:- "If it be irritable to the touch, and move spontaneously, to satisfy its wants, -if it be not deeply rooted in the soil, but only adhere to the surface,-if its body be provided with a central cavity, -if it putrefy after death, - if it give out the ammoniacal odour of burnt horn,--and finally, if in its chemical composition there be found au excess of nitrogen over carbon,-_then we may be certain that it is an animal. But if, on the contrary, the doubtful being under examination enjoy no lasting or spontaneous power of motion,-if it be destitute of an internal cavity,--if it be deeply inserted in the soil._if. when detached, it speedily fade and die,- 
if, when dead, it merely ferment but do not putrefy,if it burn without the odour of a burnt quill or horn, -and if its residue be very considerable and chiefly carbon,- then we may venture to declare it to be a plant."

An attempt is sometimes made to show that what we have pointed out as one of the great contrasts bebetween plants and animals, the manner in which they respectively manage the internal distribution of their aliment, is really an analogy. The process of distribution; it is said, is a circulation in both,- - a circulation of sap in plants and a circulation of blood in animals. But this is a mere play upon a word. The motion of liquid within a plant is simply the ascent of sap and the descent of cambium, - the free ascent of the liquid in one form, and the fixational descent of it in another form. We speak of the circulation of moisture in the soil, when we mean merely the descent of rainwater and the ascent of aqueous vapour; and we speak, in a precisely analogous manner, of the circulation of sap in plants; but we do not imagine, for a moment, that these are true circulations; nor ought we, for an instant, to compare them with the constant flow of the slowly changing vital blood in an animal. Yet a highly distinguished phytologist of the present day assumes, first, that the ascent of sap and the descent of cambium are the same phenomenon as the circulation of the blood,-next, that the flow of the sap and the cambium forms all organs and wields the power of all organic functions,-next, that the sap constantly rises by capillary attraction, when any proper force is at work for removing obstructions from the top of the capillary tubes,-and next, that a pre- 
cisely proper force of this kind is in constant action in the chemical play which goes on within the leaf; and on this most unphilosophical series of assumptions, all based on the fancied analogy between vegetable and animal circulation, he crcets the monstrous doctrine, that life is a chimera of the dark ages, and that what we usually designate life is only a combination of capillary attraction and simple chemical action! How dismally and most humblingly true does it continue to be, that "the world by wisdom knows not God!"

But still more fanciful analogies respecting.structure have been set up betwcen certain great groups of plants and certain great groups of animals. And though the best of these are founded only on remote resemblances between a minute part of one thing and the entire of another thing, or between a few anomalous plants and a few anomalous animals on the very outskirts of the two kingdoms, they possess an absurd charm for enthusiastic theorists in their sheer wildness and incomprehensibleness, and grievously tend to bewilder or mislead plain people. All plants and all animals possess life; all have organisation; all elaborate great chemical changes in their interior organisms; most grow or enlarge their substance by assimilating alimentary matters obtained from without; many, perhaps most, throw off in an excrementatious manner such proximate elcments as are unsuited to their own substance; most plants and nearly all animals propagate their respective species by fecundation; the epitome of any floworing plant, when buried as a seed in the soil, rots and reproduces the whole plant, and the epitome of the 
human body, when buried in its final terrestrial form in the earth, rots, and will eventually rise again in glory. These are true analogies; and they afford exquisite mutual illustrations of the constitution of the two great classes of organised bodies. But all remoter analogies are more or less unreal, and can neither add to the knowledge of any man, nor do any good to his moral feelings. Persons who cannot understand analogies between an oak-tree and an ox, or between a pea-plant and an oyster, may assure themselves that they get no harm from their ignorance. Better to know one truth than to affect to know ten thousand absurdities.

The elementary forms of all plants are cells. These are so exceedingly minute that philosophers, even with the aid of the most powerful microscope, can ascertain nothing about them except their shape. Yet they prove themselves by their energies to be immensely various in vital force, in chemical action, and in functional process. They arrange themselves not only into the constituencies of all the myriad different kinds of plants, but into the constituencies of all the countless organisms of every member of every plant. They collect into millions of millions of different forms, and go into array for myriads of myriads of different chemical actions, and combine in systems for thousands of thousands of different vital functions. They display no uncertainty, no chance-work, but pass all up to their several destinations, with an aim as sure and a result as determinate as the evolutions of the solar system. Every sporule is a cell, and will produce nothing but its own species, - is a cell of prodigiotisly compound power, and surely sets agoing the evolu. 
tion of all the series and societies of cells which belong to the growth and perfection of its species. Every one of the thousand or myriad constituents of every seed is a cell; and all come together in the precise way to form that seed, to form it perfectly, and to form nothing else. And the sced, in its turn, comprises the leaders of all the companies of cells, the masters of all the crafts of them, requisite to build up its plant, and arranged for the building up of that plant and no other; so that, be it the seed of whatever species it may, it produces solely, strictly, and perfectly "according to its kind." Nor are the mere leaders of all the societies of cells present in the seed, but also the incipient societies themselves, the embryons of all the parts of the plant.

"Lo! on each seed within its slender rind

Life's golden threads in endless circles wind;

Maze within maze the lucid webs are roll'd, And, as they burst, the living flame unfold.

The pulpy acorn, ere it swells, contains

The oak's vast branches in its milly veins;

Each ravell'd bud, fine film, and fibre line,

Traced with nice pencil on the small design.

The young narcissus, in its bulb compress'd,

Cradles a second nestling on its breast,

In whose fine arms a younger embryon lies,

Folds its thin leaves, and shuts its floret eyes;

Grain within grain successive harvests dwell;

And boundless forests slumber in a shell."

The elementary forms of all animal substances also are cells. And hence loose thinkers have leaped to the conclusion that the vegetable kingdom and the animal kingdom are essentially the same. But as the cells of every order and class and family and group 
and species of plant differ in sure distinctive characters from those of every other order, every other class, every other family, every other group, every other species, is it not obvious that all differ also in broader and equally sure distinctive characters from those of every kind of animal? No one reproductive vegetable cell will take to do with the perpetuations, with more than the mere muling, of any species of plant than that from which it was derived; still less will a reproductive cell of any plant of one family take anything to do whatever with the reproduction, nor even with the slightest muling or modifying, of any plant of another family; and incomparably less, may we suppose, can any kind of vegetable cell hold any character, exert any force, or perform any function in common with any animal cell. Two facts alone come out,-that the cells which constitute the primal forms of all organic things are so prodigiously minute and so exceedingly simple as to be uncharacterisable through the microscope, and yet prove themselves to be as diversified in form and destination as all the parts of all the organs of all the species of all plants and all animals. But what an immensity of wonder is here,-in simplicity with sublimity, in unity with diversity, in the unfolding of oneness of design through infinity of execution! Nor would the wonder be less if it were assumcd that the primal cells in all instances are the same; for, as they are secn to work as surely in their countless diversity of direction as if they visibly possessed corresponding countless diversity of character, they would, in that case, take their diversity of direction, together with the accompanying diversity of form and function, directly from the will 
and bidding of the omnipotent Deity. View them as we may, all these microscopic living cells, just as truly as the grandest aggregations of them in the bodies of the blood-bought sons and daughters of redeeming mercy, "live and move" in God, and in Him "have their being." And if the infinitely loving One cares for these, how much more does he care for even the least of his ransomed, regenerated, glory-destined people! "O ye of little faith!"

A ggregations of cells, in diversities of arrangement, - with passages amongst them, and with nutrimental fluids and secreted products, constitute the entire substance of flowerless plants, the principal substance of flowering herbaceous plants, and a considerable or even prominent portion of the substance of the leaves, flowers, succulent fruits, and other soft parts of shrubs and trees. But this substance, even when seen through a powerful microscope, appears to an ordinary observer merely an assemblage of granules lying on a bed of paste. "It is only when viewed minuteily, and with a good glass," remarks Keith, "that its true structure is to be detected. Malpighi describes it with his usual accuracy, and compares it to an assemblage of inflated threads or bladders containing a juice. Grew describes it under the appellation of parenchyma, and compares it to the bubbles formed upon the surface of liquor in a state of fermentation. Duhamel represents it as consisting of a network of fibres interspersed with small and granular or bladder-like substances occupying the interstices. Such were the descriptions of the earlier vegetable anatomists. But later anatomists have been more minute. Mirbel describes it as being composed of clusters of 
small and hexagonal cells containing a juice. This was an important step in advance, as exhibiting a correct view of that modification of figure which is perhaps the most frequent in the composition of cellular tissue. After all, we believe the spheroid to be the original and normal form of all cells; all other forms such as the square, the prismatic, the oblong, the columnar, being occasioned merely by the compression or extension of the primitive spheroid."

Functional products of cells in the form of vessels, additional to segregations of cells thomselves, characterise all the flowering or seed-bearing plants, and are specially prominent in the veins of their leaves and in the fibres of their branches and stem and roots. One set of them are simple tubes, studded with small globules, but without any valves or lateral intercommunication; and these abound in the wood of exogenous shrubs and trees, particularly between the concentric layers of different years, but do not occur in the pith or the bark; and they are the channels through which the sap ascends from the roots to the leaves. Another set are short, oblong, spindle-shaped tubes, swollen in the middle, pointed at the extremities, and often divided by transverse plates; and these are arranged in longitudinal series along the bark and the sapwood, and have a porous wall and lateral openings; and they conduct the ambium. or elaborated sap from the leaves downward through all the spray and branches and stem and root. Three other sets exist, but are less prominent, and perform suborainate functions.

The roots of plants present amazing diversity and woldrous beauty. Some of the minutest fluwerless 
fresh-water weeds, indeed, have no apparent root; some of the flowering water-plants have only such roots as float in water; many flowerless plants, such as the lichens and the mosses, have fixing and boring appliances in place of roots; a few flowerless plants, such as truffles, and some other funguses, look as if they were all root; many flowering plants, such as the tropical orchids, have only such roots as live high aloft on trees; and a few flowering plants, such as some of the irises, as also a few flowerless ones, such as some of the ferns, have roots of the nature of prostrate, thickened, underground stems. But all other plants, comprising the enormous majority of the vegetable kingdom, have compound basal organs, which serve the double purpose of anchoring them in the ground, and taking in their liquid nourishment from the soil. These organs are true roots. They strike into the ground, in some direction or other, with as unvariable and stubborn a tendency as if dragged into it by gravitation; and, while totally destitute of everything suited to swinging and feeding in the air, they possess most ample appliances, diversified according to the character and needs of the different kinds of plants, for pushing and feeding in the soil. Some, as all the carrot-shaped, the bulbous, and the tuberous, are very cellular and succulent, and have large storages for laying up nourishment, and are very specially adapted to feeding; and others, as those of all the large woody exogens, are fibrous, cordagy, ramified, and very specially adapted to anchorage. But both classes in the gross, as well as thousands of wide varieties in each, serve the two purposes in exactly the methods and proportions which are best suited to the circumstances 
of their respective plants. Let us illustrate them in the case of any ordinary exogenous tree:-

The feeding roots are the terminal fibres. These look like small threads or woolly hairs, and are prodigiously numerous. They sprout from every rootbranch and root-twig beneath the ground, and push fieely through the pores of the soil, and weave and mesh themselves through every accessible clod with the closeness of a mat. Not a spadeful of their seat can be turned up without disclosing them by the hundred. Nearly three thousand exist in an adult potato plant; and several millions must exist in a large tree. All are tubes or ducts for conveying liquid nourishment out of the soil into the plant; and all are provided at the end with minute sponges, which imbibe the liquid; and, ever as they grow and extend, they renew the sponges, and so drink from fresh fonts with unabating vigour. The dispreading of them through the soil is usually great and intricate and multitudinous in proportion to the plant's size, and continues both downward and sideways as long as the plant increases. If one thousand rootlets, each with its bibulous mouth, be sufficient for a young sapling, twenty thousand may be required when it begins ta branch, and one million or more when it begins to bear fruit; and all the vastly increasing numbers are developed from lengthening and ramifying root-stems, and make a steadily increasing enweavement among all the surrounding soil. The rootlets of the young sapling may be contained within a cubic foot; and those of the bearing-tree may occupy several scores of cubic yards; and yet all the latter, just as much as all the former, lie in contact with every clod, and 
drink up the liquid from every crevice. A perfect increase of rooting accompanies every liealthy increase of the plant's growth; an extension of root-branches, with their countless rootlets and spongelets, keeps pace with the elongation of the plant's stem and the eulargement of its head; a pushing of new rootlets into new nooks and crevices of the ground, makes provision for every new effurt of the plant to increase its fruitfulness; and thus the whole root-system below the ground always corresponds in amplitude and resources to the whole head-system above the ground, in its extent and wants.

All the wants of the feeding-roots, both as to the food itself and as to the preparing of it, are fully supplied by the soil. One part of plant-food consists of certain soluble mineral salts; and this is furnished by the slow and steady disintegration of some of the soil's own earths. Another part consists of decayed organic matter, both vegetable and animal; and this is furnished either by natural deposits or by artificial manurings. A third part consists of certain liquids and gases, which are furnished by rain-water and the atmospheric air. And all these are cooked up together, and worked inte one another, and sent through processes of decomposition and recombination, with the aid of heat and light and currents, in a manner similar to the most wondrous processes of the laboratory; and are at last presented to the little sponges at the ends of the rootlets in the form of a liquid, as uniform in quality and as well digested as the chyle which comes down from the stomach of animals to be taken in by the absorbent vessels as the raw material of blood. Now the soil has ..ll the perfect capacitics of perfectly 
preparing them; and it also maintains a steady supply of the resultant liquid, and holds this in constant readiness to the mouth of every one of the countless rootlets; and it therefore has been called "the stomach of plants." And indeed it does perform a similar office for plants to that which the stomach does for animals; but it both does this more elaborately, and accompanies it with additional offices. It reduces the ingredients of food, not only in all ways analogous to what the stomach does, but also with the aid of light and air and currents; and it likewise contributes part of its own substance to the ingredients, and invites the plant's innumerable absorbents to push and lodge throughout its pores, and holds continually to the mouths of all of them a supply of perfectly prepared nourishment. It is at once cook and chemist, food and feeder, sustenance and sustainer; and in all its fitness for these offices, and all the while that it performs them, it is the seat and home of the whole rootsystem, and subserves all the growth and all the interests of the entire plant.

The anchoring roots are the root-stem and the rootbranches; and these are proportional in strength and length and number to the resistance which the tree's head makes to the wind, and go boldly into the ground, in the manner best fitted to obtain the strongest mechanical support. In some instances, the roots penetrate or travel far in order to fix themselves in the cracks and crevices of rocks; in others, they spread abroad like radii, and run a long distance horizontally, and send offshoots downward and sideways, so as to form thousands of rivettings and claspings throughout a space wider and broader than the tree's 
head; and, in all, they adapt the circumstances of their situation to the peculiarities of the tree, and combine enormous strength of fixture with elasticity of resistance, and carry everywhere around them and along with them the all-voracious, ever-active, food-receiving system of rootlets. They therefore infix the tree to the soil almost as vitally as the branches are infixed to the stem, or as the limbs of an animal body are infixed to the trunk. The grounding of a tree by them is stronger security by far against all the ills of storm and tempest, than the mooring of a ship by its anchors, or the seating of an edifice by its foundations. Though the spray and foliage offer a resistance to the wind as great as the outspread sails for propelling many hundred tons, the roots lie all so firmly fixed, that, amid the very frenzy of a hurricane, not one of them, not even a twig of them, or a rootlet, in the case of any ordinarilysituated tree, is shaken in its bed. And all this results as well from the properties of the ground as from the habits and capacities of the roots. While all soil is sufficiently powdery and porous to let the rootlets push through it, and to perform the offices of a pabulum, some have a strong anchorage of rock below, some have a binding intermixture of blocks and boulders, some have a powerful cohesionof clay or of dead vegetable fibre, and all, in some way or other, let the roots clench and rivet themselves together with a strength and intricacy vastly exceeding the fastenings of the grandest piece of human art. The soil wondrously combines every requisite provision for nourishing a plant with every requisite provision for grounding it; and thus makes all the process of continual feeding by the rootlets coexistent and reciprocal with con- 
stant protection of the head and branches from injury by the winds. How brilliantly do these facts illustrate Paul the Apostle's prayer for the Ephesians, that "they might be rooted and grounded in love!"

Leaves exhibit such prodigious varieties of shape and arrangement, that we cannot take space to describe them. Yet all have a close similarity of internal structure, and perform their functions on one plan. Their stalks and veins comprise vessels for the ingress of the sap and the egress of the cambium; one of their surfaces is pierced with minute holes for communication with the atmosphere; and their interior, all between the veins, comprises layers of cells and intervening cavities for operating on the nutrimental gases and liquids, - and the layers next tlie one surface are different from those next the other. A cross section of even the thinnest leaf, seen through a powerful microscope, appears a very complex and most beautifully constructed object.

The sap as it comes in from the tubular vessels is suffused through the interior of the leaves, in a way somewhat similar to that in which the blood of animals is dispersed over the lungs; and, in the case of all rapidly exhaling plants, most of the water of it is there driven off by evaporation, so that little else than its dissolved saline matter remains. The leaves, at the same time, inhale gases from the atmosphere, decompose them, and return one element of them to the atmosphere, and combine another with the residue of the sap. The chief of these is carbonic acid; and this is everywhere and always in a state of equable mixture through the air. It flows round every plant, every 
leaf, every leaf-pore. It as constantly presents itself to all the absorbents of leaves, as the digested liquid of the soil does to all the absorbents of rootlets. And while the leaves of any plants are constantly receiving an influx or rather upflux of sap from within, they are constantly absorbing a gush of carbonic acid from without; and with every reduction of sap to a state of concentrated solution, they also make a reduction of carbonic acid to its elements, and send back the oxygen of it to the atmosphere, and combine the carbon with the concentrated solution. Two other gases, and perhaps more, are in a similar predicament, and pass through the same process to one grand result; but they are much less prominent, and need not be particularly specified. The new substance formed within the leaves departs through the bundled vessels, and goes down to minister nourishment to all the plant; and in the course of its descent it visits every portion of every member of the plant, making deposits wherever they are required, and gradually diminishing in its own bulk, till, at the extremities of the roots, it becomes wholly expended, or passes out as an excretion.

Nor do the functions of leaves more surely minister in a direct way to the sustenance of plants than in an indirect one to the well-being and even life of animals. The carbonic acid which they abstract from the atmosphere is not fit to be breathed by animals; and the oxygen which they give back is their vital element. Only about one part in two thousand of the atmosphere, in its ordinary condition, consists of carbonic acid; and if this proportion were increased but a very little, it would incommode all animals, and it in- 
creased a little more, it would suffocate them. Yet so constantly does carbonicacid evolve from breathingand burning and decay, that, but for the equally constant absorption of it by the leaves of plants, it would very speedily accumulate to the fatal proportion. All the emission of it, too, from whatever source, implies a consumption of oxygen; so that, while the suffocating gas would accumulate, the vital one would diminish. But the leaf-system maintains a perfect equilibrium. It abstracts all excess of carbonic acid, and so prevents it from ever becoming hurtful to animals; it separates and retains the carbon, so as to build it into the framework of the trees and herbs which shelter and support them; and it gives back the oxygen, so as always to keep up a competent supply of it for their free and healthy breathing. And thus the very presence of plants in the air, and the way in which they feed from it, and the largeness with which they draw their sustenance out of it, are essential to its subserving the life of other orders of creation. But for plants being what they are, no animals could live. Here is a striking one of the countless and wondrous reciprocities of action by which the all-wise and all-beneficent God maintains the perfect balance of perfect well-being among the million orders of his creatures.

Nor, while plants are consumers of what would be noxious to animals, do they themselves ever or anywhere suffer any scarcity in their air-food. For the myriad gases of any field, or the myriad herbs of any mountain, or the myriad trees of any forest, when inhaling the gases with all their energy through all their pores, are only sharing, with all other plants in all 
other parts of the world, the gifts of a supply which has practically no limits, and can never be diminished. It is above and around and through them, and extends upwards and away from them into the viewless void; and however multitudinous may be the trees of any region, or how indefinitely soever they may be multiplied, and no matter how broad they grow, how low they trail, or how high they soar, it is ever present with all the leaves and leafpores of each, from centre to circumference, and from the topmost twig to the lowest. And all the leaves of all the healthy ones are ever active to take it in. They flutter and ripple and waft and sail and toss athwart the air, in continual restlessness, ever shifting every pore from the spot where it imbibed the last molecule of gas, and ever putting it in contact with other and other molecules. Even if they all stood still, and were as rigid as iron, they would receive constant supplies from the mere currents of the atmosphere and the mere elasticity of the gases; but they would do their office sluggishly,-and therefore they twitter and oscillate in perpetual activity, in order that not a millionth part of a moment may be lost by any pore in the intervals of its inhalations. And what is more wondrous still, those of every plant work out an elaboration of aliment for all its organs, all its secretions, and all the classes and successions of its wants. The differences in these are immense in kind and vastly numerous. A tree's wants at any time count by the thousand,-and those of one season, or one month, or one stage of growth or of function, have very little in common with those of another. The bark differs widely in constitution from the sap- 
wood; the sap-wood from the heart-wood; the heartwood from the roots; the roots from the leaves; and all these from one another, and from the flowers and fruit and seeds. How different also are the gums and bitters within the bark, the resins within the wood, the salts and alkaloids within the roots, and the dyes and oils and scores of other things within all the parts of fructification! Yet all are perfectly formed and fed,--all in their season, and to their utmost limits, all with as appropriate elements, and in as nice an adaptation, as if each had a separate apparatus of supply. A thousand different secretions, some absolute contrasts to others, are at any one moment going on; and one-half or more are soon superseded by as many others, equally diversified; and all, nevertheless, are maintained from one fluid, elaborated by one leaf-system, out of the sap and the atmospheric gases. Be the soil what it may in which a tree strikes root, and the climate what it may in which it rears its head, it elaborates from sap and air a perfect aliment for its innumerable needs and organs and productions.

Every part of the nutritional process-the absorption of the sap, the ascent of the sap, the inhaling of the gases, the forming of the cambium, the descent of the cambium, the distribution of the cambium, and the depositing of each atom of wood and bark and filament-is a mystery to philosophers and a glory to devout men. A propelling force pervades all, which no science can explain; a chemical power, an electric energy, an intelligent selectiveness, are unitedly and profoundly at work in ways incomprehensible to philosuphy; and any of the phenomena, but especially all 
of them viewed together, can be resolved only into life,-a strong, vivid, instinctive, infallible vitality, which is but another name for the will and working of the all-wise Creator. And, in the actions of the leaf-system-especially in their ever-eager and all-perfect use of the limitless supplies of their invisible food -a grand illustration may be found of another part of Paul the Apostle's prayer for the Ephesians, that "they might be able to comprehend with all saints what is the breadth and length and height and depth, and to know the love of Christ which passeth knowledge."

The reproductive economy of plants is to the full as wonderful as their nutritional economy. Every flower, whether it contain ornamental parts or not, comprises two organs or sets of organs for reproduction,- the one to arouse the other into activity, and that other to form either a seed or, in most instances, a carpel containing seeds. The vital and chemical doings of these organs-mas also of the ornamental parts of flowers-seem. to be a mimic world of prodigies, but are too intricate and filmy to be distinctly within the reach of any man's present instruments of observation. A pouch is situated at the base of the seedforming organ, and becomes the sole seat of the reproductive process subsequent to the rousing of that organ into activity. Nourishment is conveyed into it through a special canal; the secretions within pass gradually on from rudimental pulp to full-formed seed; and the integument, in the great majority of unstances, gradually hardens and expands into the character of a carpel envelope. The flower speedilv fades, and the young carpel becomes perceptible, and then, in gardener's 
phrase with reference to the plants of the orchard, "the fruit is set;" and when the carpel attains maturity, and is possessed of all the organism and substance requisite for independent existence, it drops, or is otherwise removed from its place.

The forms, surfaces, and composition of seeds are amazingly diversified, and possess the most minute and comprehensive adaptation to their respective circumstances, and exhibit myriads of most beautiful manifestations of the wisdom and goodness of the Creator. All contain embryons of their plants, and food and appliances for sustaining them in the infant stages of their development. Most, at the same time, are so plentiful and of such a nature as to serve as food or medicine to the higher animals and to man. Some, in one and the same process, reproduce their own plants and yield food to other beings. Multitudes are the grand apparatuses for bringing out the vegetable kingdom's elaborations of fine mineral matter, and laying it up in store for the sustenance of animal life. All the thousands of different species, too, have their multiplicity of different principles, whether starch, sugar, gum, oils, acids, salts, nitrogenous ingredients, or any number of countless peculiar compounds, in such proportions and arrangements as, in all diversities of climate and situation, to achieve best the main. taining of vitality, the resisting of injury from weather and insects, and the accomplishing, efficiently and comprehensively, of all the purposes of their economy. The history of one kind of seed, if fully gone into, might form the subject of a volume; and the history of all kinds, even if very moderately detailed, could not be written by the cleverest penman in a lifetime. 
Nor are the fruits less interesting than the seeds. All, whether they contain one seed or many, and whatever be their shape, have the same general character as the esculent apples and berries. They comprise grains, capsules, pomes, drupes, nuts, berries, pods, catkins, and cones. They comprise also some anomalous forms, - such as figs, which hold many fruits within one common envelope, and strawberries, which are cushions with the seeds set outside. All pass through remarkable chemical changes in the process of ripening; and the berries and pomes, in par. ticular, abound at first in acids, and pass on to the possession of great quantities of grape sugar, and all the while absorb oxygen from the air, and evolve carbonic acid, thus doing the reverse which leaves do, and the same as animal lungs.

The dispersion of seeds, and in some instances of the fruits containing them, is essential to the obtaining of space and of fresh soil for the plants which grow from them. But how is it effected? "Not only are the winds and the waters and animals put in requisition, and unconsciously employed in the operation of sowing and planting; but the seeds themselves are endowed, in many cases, with certain mechanical properties which aid their dispersion. Thus the awn of an ear of barley is so sensible to moisture, that it lengthens in damp and shortens in dry weather; and by this alternate extension and contraction, aided by the short and thick-set prickles by which it is serried, it will in the course of a few mornings drag away the seed to which it is attached to some distance from its parent stalk. Thus, again, the seeds of the thistle and dandelion have a species of downy wings attached to 
them, by means of which they float through the air, and are carried by the wind to great lengths. And thus, too, the pods of the broom and furze are furnished with an elastic spring, which, on being acted on by the heat, forcibly ejects the seed, and with a considerable report, to a distance from the spot. 'Who,' says Sir J. E. Smith, 'lhas not listened in a calm and sunny day to the crackling of furze bushes, caused by the explosion of these little elastic pods, or watched the down of innumerable seeds floating on the summer breeze, till they are overtaken by a shower, which, moistening their wings, stops their further flight; and at the same time accomplishes its final purpose by immediately promoting the germination of each seed in the moist earth? How little are children aware, as they blow away the seeds of the dandelion, or stick burs in sport upon each other's clothes, that they are fulfilling one of the great ends in nature?' The ocean itself serves to waft the larger kinds of seeds from their native soil to far distant shores. While in ordinary cases, also, plants drop and disperse their seeds in dry weather only,-which is just the kind. of weather most favourable to its success, for the seed, according to the farmer's adage, 'loves a dry bed,'--there are some plants, natives of arid deserts, which act according to a different economy. Thus, the cup of one plant of the desert has springs to close in dry weather, and to open only in the coming of moisture. Thus, also, the seed-vessel of the rose of Jericho is rolled by the winds along the wilderness until it meets with a moist spot, and then, but not till then, it opens and parts with its seeds. How wonderful all this arrangement and contrivance! 
Here is not the footprint of blind chance, but the finger of God."

"With such unerring skill does Nature fling All seeds abroad, blow them about in winds, Innumerous mix them with the nursing mould, The moistening current, and prolific rain."

The wonders of vegetable economy which we have pointed out are a very small selection. Multitudes more may be found in the skin, bark, bulbs, tendrils, thorns, and other organs and parts of plants; in the sprouting of seeds, the growth of roots and stems, the development of buds and flowers, the irritability of leaves, and the all-pervading and diversified display of the vegetable vital force; in the characters, classes, adaptations, and distribution of the woody matters, starchy matters, sugary matters, gums, resins, oils, acids, salts, and other secretions of plants; in the relations of the vegetable kingdom to geography, to climate, to soils, to weather, and to the mighty and manifold influences of cultivation; and in the subordination of certain great classes of plants to one another's uses, the subordination of still greater ones, in multitudes of ways, to the uses of animals, and the subordination of all, immediately or remotely, and morally as well as physically, to the uses of man. Most distinctly and gloriously, in all these respects, in all plants, and in all things which concern them, may be seen the fingerprints of God.

"He inspires

Their balmy odours, and imparts their hues, And bathes their eyes with nectar, and includes In grains as countless as the sea-side sands 
The forms with which he sprinkles all the earth. Happy who walks with him! whom what he finds Of flavour or of scent in fruit or flower, Or what he views of beautiful or grand In nature, from the broad majestic oak, To the green blade that twinkles in the sun, Prompts with remembrance of a present God," 


\title{
CHAPTER XIV.
}

\author{
ANIMALS.
}

SILICIOUS-COATED ANIMALCULES-BLOOD-LIKE SPOTS ON HUMAN FOOD

- Other animalcules-ZOOPhytes-SPONGES-COrallines aNd

CORAL-ROCTS - ANIMAL-FLOWERS - SEA-NETTLES - ENTOZOONS WORMS-INSECTS-THE TRANSFORMATIONS, COMBINATIONS, AND INSTINCTIVE SKILL OF INSECTS-ANTS-APHIDES-CRUSTACEANSMOLLUSCS-MOLLUSC-SHELLS-CUTTLES-FISHES - FLAT-FISHESELECTRIC-FISHES-REPTILES-TRANSFORMATION OF FROGS-SHELI OF THE TORTOISE-CONFORMATION, BEAUTY, AND CLASSIFICATION OF BIRDS-SPECIMEN INSTANCES OF BIRDS-CHARACTERS AND CLASSES OF MAMMALS.

INCONCEIVABLE numbers of minute organised beings, consist of small clusters of single elementary cells. Two vast families inhabit respectively fresh water and salt water; and are regarded by some naturalists as plants, and by others as animals. These are so surpassingly small that millions could be contained within the space of one cubic inch; and yet they have aggregately made a far greater figure in the world than all elephants and whales. They exhibit striking mathematical outlines,-circles, triangles, and parallelogrammes; and have often a most elaborately sculptured surface. All, in the course of development, abstract silica from water, and form it into a coat of flint; and many display transparencies and tintings as beautiful as the alternations of clear and stained glass. Every cell seems to be vital ether within and flinty 
membrane without, in some such way as every oyster or other molluse is pulpy flesh within and limestone shell without. A cell multiplies its species first by prolonged contact with another cell, - next by accumulating a mass of embryon cells in its interior,--and then by bursting to set them free. Some kinds have not been observed to move; but others make constant, regular, and very curious motions. The bodies of all are indestructible by either water or fire; and they gradually accumulate at the bottom of lakes and of the ocean, to assist in forming soil for the use of future epochs of the organic kingdoms.

These creatures are diffused over all the world, and look as if they belonged to all time. They are identical with the oldest known fossils, and continue unaffected by all the changes and cataclasms which have occurred in the earth. "From the first dawn of animated nature up to the present hour, they have never ceased their activity. Extensive rocky strata, chains of hills, beds of marl, almost every description of soil, whether superficial or raised from a great depth, contain their rcmains in greater or less abundance. Some great tracts of country are literally built up of their skeletons. From their silicious nature, they resist even the strong heat of volcanoes; and their remains are found thrown up in the pumice and dust from the crater. In fact, it is difficult to name a nook on the face of the earth, or in the depth of the sea, where they are wholly absent either in a dead or living state."

Some rare and curious kindred of these minute wonders of the waters have had quite as much to do as the minute funguses with the producing of certain 
extraordinary appearances which the ignorance of former ages regarded as preternatural. We shall give an instance, but cannot afford to give more than one. Vivid red spots, closely resembling spots of blood, have at various times appeared profusely and pertinaceously on human food, and occasioned great alarm. They appeared on the bread of Alexander the Great's army at the siege of Tyre, and then agitated the heart of that mightiest of conquerors. They appeared on some of the pastry of the Roman Catholic mass-service in the early part of the sixteenth century, and were then ascribed by the superstitious and persecuting priesthood to the sorceries of Jews, insomuch that thirty-eight Jews were arraigned, condemned, and put to death for the alleged crime of causing them. They appeared in 1819 on the maize porridge of the inhabitants of Padua and its environs, and then gave occasion to special prayers and exorcisms and public investigations for their removal, and were at last pronounced by a scientific investigator to consist of myriads of microscopic funguses. And in 1848 they appeared at Berlin, and were then ascertained by Ehrenberg, the greatest micographer in the world, to be collections of animalcules,-little, little, little animals, - Each consisting of only one cell, and all so amazingly small, that from forty-six to eight hundred and eighty-four trillions of them could be contained in the space of one cubic inch.

But Ehrenberg, thirteen years before, had become acquainted with no fewer than seven hundred and twenty-two species of animalcules. Some of these, like their brethren of the blood-like spots, consist each of a single cell, and appear under the microscope the 
minutest possible spherules or mere moving points. But a large proportion have a multitude of parts and an intricate organisation, and display an amazing variety and strangeness of form. One drop of some kinds of water, magnified by a microscope of very high power, exhibits an animated world of as much stir as the central streets of a great city, and with shapes of being as novel and diversified as the warmest imagination may conceive to exist in the most curious of the planets. One animalcule looks like a long slender thread, another like a coiled-up eel,one like a funnel, another like a bell,--one like a plate, another like an egg,-_one like a cylinder, another like a series of articulated reeds; and many have such peculiar, grotesque forms as to be totally unlike any object known to ordinary observers. Some also can change their shape at will, and so widely, as to appear at one moment almost a contrast to what they appear at another. Nor are they at all similar in size, in motion, in propagation, in longevity, and in general economy. Some are-so small that five hundred millions of them could be contained in a drop of water; and others are so large that one looks in a drop like a gold fish in a crystal vase. Some move in continual gyrations, some in waving curves, some in vaulting leaps, some in light-like flashes, and others go with utmost difficulty from spot to spot, or remain fixed in perpetual slumber. Many are hermaphrodites; and some propagate by eggs, some by living fœtuses, and multitudes by some kind or other of budding from their bodies or of division of their clusters. Some live as long as many insects, and bequeath their bodies to the dust; and others live but a few seconds, and re- 
solve promptly into air and water. Some form immense societies,- -vaster far for animalcules than a Babylon was or a London is for men, and yet appearing to the naked human eye only a bit of scum attached to the stalk of a water-plant; and others pass through cycles of reproduction with such lightning speed as in comparison would reduce the whole human epoch into the span of a few hours,-for, in four days, a single individual or cluster can be multiplied into one hundred and seventy billions. Yet these surpassingly tiny and evanescent creatures; whether in water or on land, on plant-leaves or in the air, have as delicate a structure and as symmetrical parts and as elegant forms, and perform their functions as well, as any of the bulky and most beauteous orders of the animal kingdom. "I tell thee," says Shelley,

"I tell thee that those living things,

To whom the fragile blade of grass,

That springeth in the morn,

And perisheth ere noon,

Is an unbounded world-

I tell thee that those viewless beings,

Whose mansion is the smallest particle

Of the impassive atmosphere,

Enjoy and live like man;

And the minutest throb

That through their frame diffuses

The slightest, faintest motion,

Is fix'd and indispensable

As the majestic laws

That rule yon rolling orbś."

The most simply organised animals, and those most liable to be mistaken for plants, if we except only the 
simplest of the silicious-coated animalcules, are the zoophytes. They consist of little else than mouth and stomach; and they take their name from their nearness of position to the boundary-line between the vegetable kingdom and the animal kindgom; for the word zoophyte signifies animal-plants or plant-animals. Most aggregate themselves closely and curiously into compound bodies, resembling. ramified plants, insomuch that one observer may pronounce an assemblage of them to be a true community or society, and another observer may pronounce it to be strictly though complexly a single individual. Most of them also project from their mouth, as from the top of a cylinder or from the aperture of a bag or from the centre of a discous cavity, a series of flexile feelers for seizing and taking in their food; and they are thence called polypes. But other and less simply organised creatures, who live always as separate individuals, are also polypes; and others again still more highly organised, as for example the star-fishes and many of the animalcules, have their parts or members arranged in the same rayed form as the feelers of the zoophytes; and all these-together constitute the rayed or radiated sub-kingdom of animals, - the rest of the animal world being divided into the articulated or segment-bodied sub-kingdom, the molluscous or soft-bodied sub-kingdom, and the vertebrated or backbone-bodied subkingdom.

The most simple of the polypes, if indeed they can claim even the dignity of polypes, are the sponges. These are fibrous, flexile, fixed, torpid beings, with scarcely any trace of true animal organism, and of nearly the same appearance after death as during life. 
They spend their existence in fixture on rocks, and exhibit less sign of feeling than many kinds of plants. A small quantity of tenuous gelatine or thin jelly-. flesh occupies their pores, and seems to perform some animal functions; but, on their being removed, it promptly dries off, and ceases to be visible. They have also a chemical composition akin to the animal kingdom; yet they decompose carbonic acid in the manner of plants, and give off an excess of free oxygen to the water around them. They altogether are very curious beings; and they assume exceedingly different shapes according to their several species, and variously present resemblances to globes, tubes, vases, fans, horns, shrubs, and other objects.

But corallines and madrepores are still more curious; for, while occupying almost as medium a place between plant-character and animal-character, they take a prodigious deal to do with the formation of rocks. Who has not heard of corals, and of coral reefs and coral islands? Or who does not think of them as the grand ornaments and wonders of the sunniest seas of the world? "It is chiefly in the great Pacific Ocean," says a popular writer, "that we see the enormous structures erected by an obscure and almost insensible animal,-a worm possessea of a life scarcely more than vegetable, deprived of locomotion, and dying rooted in the narrow. cell which gave it birth. With dimensions often not equalling a pin's head, with a life which probably does not exceed a few months, without apparent organs of sense, and with hardly other parts than those necessary to form its own cell, this animal, working slowly and blindly, is yet enabled, by its numbers and succession, without 
design, and yet guided by that Design which cannot err; to erect structures before which the greatest works of man are as nothing, which are even the rivals of the mountains themselves." But, says $\mathrm{Dr}$. Macculloch, "This is the obvious appearance. Yet, in reality, the entire coral plant is one animal. A continuous animal structure pervades the whole; and the calcareous matter, in whatever form, must be viewed as the shell, being a secretion or deposition of earth in its substance. And though in one sense this may be viewed as an original colony, all the polypes are but parts of one whole, as flowers are of a plant; while the resemblance would be perfect if the flowers were to produce the plants instead of being produced by it."

But the polypes of the coral rocks comprise many species and broad diversities, and perhaps work more wondrously and variously than is yet known. All, in some way or other, to use the words of Professor Jones, are "fixed in large arborescent masses to the rocks of the tropical seas, and throw out their ramifications in a thousand beautiful and plant-like forms; and with calcareous earth, separated from the water which bathes them, silently build up reefs and shoals." But they exist only in clear and very deep seas, chiefly amid the profounds of the Pacific Ocean, and yet work only at the surface of the water, or quite shallowly below it; and wherever they rest on much depth of coral rock, they seem to be the progeny of many successive generations who have built tier over tier of their houses and tombs along the summit of very slowly subsiding submarine mountains, - the last remains of quondam islands and continents; and they 
produce varieties of configuration.in their plant-like "shells," according to the diversities of their species, and varieties in the form and outline of their "reefs and shoals," according to the diversities of the sunken mountains. They abstract lime from the sea, and fashion it into coral by a very tardy process; and yet they have laboured so long, so steadily, and in such prodigious numbers, as to have produced an aggregate architecture vastly greater than all the masonry of man. One continuous coral reef along the east coast of Australia is about three hundred miles long; a series of coral reefs and islands, with occasional interruptions, situated between Australia and New Guinea, is about seven hundred miles long; and certain great groups in the Pacific lie scattered through spaces of from eleven hundred to twelve hundred miles long, and from three hundred and fifty to four hundred miles broad. Montgomery, though mistaking some of the facts respecting these wondrous formations, grandly describes them as a new creation reared by a Frand invisible in the secret deep, and adds, as to a reef,-

\section{"A point at first}

It peer'd above the waves, - a point so small

$I$ just perceived it, where all was floating, And when a bubble cross'd it, the blue film

Expanded like a sky above the speck;

That speck became a handbreadth; day and night

It spread, accumulated, aud ere long

Presented to my view a dazzling plain,.

White as the moon amid the sapphire sea."

Many fleshy and gelatinous polypes, which achieve no such feats as the corallines, are nevertheless eminently curious. Most can propagate either like ani- 
mals or like plants,-either by eggs or by buds; and some when cut asunder not only are not killed, but form a perfect living individual out of each of the sections. Some also have the power of changing their position; and, though not possessed of eyes, are so fond of sunshine that they change place or make movements to enjoy it. A group called actinias or seaanemones are so very beautiful in shape and colour as to be popularly termed animal-flowers. They appear to grow upon rocks in the sea, but show great eagerness for prey, and when fishing for it exhibit their beauteous attractions. They vary in diameter from about two lines to upwards of seven inches, and have variously the shape of cylinders, trumpets, vases, figs, mimic palms, and display vivid and variegated tints of green, yellow, blue, red, and orange.

The creatures popularly called sea-nettles, seajellies, and jelly-fishes, are not a little curious. They comprise many varieties and many sizes, from things not much bigger than pin-points to outspread masses of seven or eight pounds weight; and all, from the least to the greatest, are among the least solid of organic beings, and seem to be little else than filmy living bags of sea water. When any of the heavy ones is cast on the shore or lifted out of the sea, it speedily diminishes to a mere cobweb, and becomes little heavier than grains for pounds. The minute kinds are immensely numerous, and mingle with all the sea like an ingredient in its water, and are a main source of the beauteous marine phosphorescence at which we slightly glanced in our chapter on Light. Some other kinds shine with an intense white luminosity many feet below the surface; and a kind called the girdle 
of Venus glides rapidly along, and presents on the edge of the wave an undulating ribband of flame.

Entozoons are animals who live essentially and wholly within other animals. They have forms and structures expressly adapted to their peculiar mode of life, and cannot exist in open water or in open air. They comprise great family groups, and multitudes of different and contrasted kinds. Most inhabit particular members or viscera or fluids or secretions of some of the higher orders of animals, and have special organisations nicely and exclusively suited to their respective circumstances. Some live in the skin or outer integuments; some in the intestines; some in the liver; some in the kidneys; some in the blood; some in the lungs; some in the muscles; some in the eye; some in the brain; and others in other organs and fluids so many and remote, that scarcely a single part of the body can be pronounced free from their presence. And they differ from one another in all the parts of any one species, and in the same or corresponding parts of all different species. So prodigiously numerous are they, that a competent and distinguished writer has declared them more than equal to all other living classes of animals taken together.

Multitudes are necessarily very minute; but a good many have a very considerable size; and all which have been examined possess a highly complicated organisation. They propagate in the same way as birds and quadrupeds, - some oviparously and some viviparously; and, what is not a little remarkable, they have the reproductive system so enormously developed, that raw microscopic observers are liable to mistake it for a very main part of their body. They 
are also very prolific; and some who cause diseases, or work in connection with them, give off their eggs by contact or otherwise so rapidly that these diseases appear to fall upon a flock like a furious epidemic. Yet they were adduced, hotly and speciously, by some ardent philosophical speculators in former years of ignorance,-and continue to be boldly and bootlessly adduced by a few reckless sceptics in the present age of information, -as alleged instances of the organisation of organic beings irrespective of either vital force or special creation!

Many of the entozoons undergo regular transmutations from one form of being in embryonage or in youth to another and very different form of being in their mature age; and one who inhabits certain waterfowls, and produces its young alive, goes through the most remarkable transmutations which are anywhere known in the animal kingdom. "In the intestines of the young of this creature, there is a certain part already existing during their stay in the ova within their parent, which is changed in the most extraordinary manner into another intestinal worm, apparently belonging to quite a different genus. Thus, in the bird, the worm has a young one, in which a third is developed; but the young one is soon after its birth destroyed by the youngest, which thus becomes free. This very singular enclosing of one generation within another has been interpreted by some authors as a multiplied spontaneous development, or as a series of abortive attempts of the formative power. The constancy; however, of the fact, forces us rather to consider it as a series of metamorphoses; and the rather, as more than a single worm is never included 
in each individual, and this one invariably. As the young in the last observed stage are still as different from the parent as in the former ones, it may be a question whether this metamorphosis is the last."

Multitudes of animalcules, a few small insects, and the larvæ of some of the larger insects, live in the same way as entozoons, and constitute along with them the world of internal animal parasites. Most of the members of that world reflect the glory of the Creator in the same direct, quiet, happy manner as the animals they inhabit; and either do no harm to these animals, or act as purifiers and elevators of their well-being. But some are keen castigators of man and his flocks. Certain small ones, for example, burrow under the skin, and produce the most disgusting cutaneous diseases; a large one lies under man's skin for years, and eventually causes anguish or convulsions; a still larger one develops itself to the length of many feet or even yards in the human intestines, and causes very great distress; certain fine thread-like ones infest and obscure the eyes of men and horses; and various kinds, of various sizes, in various ways plagtie horses and cattle and sheep, and act as awful fatal scourges of ill-conditioned, ill-conducted stock-farms. Yet all these noxious internal parasites, just as surely as the innoxious ones, and perhaps on a far grander scale and with far mightier results, serve benign purposes in the world; for they are punishers of filth, incenters to cleanliness, prompters to precaution, and monitors of prudence, and serve both to correct man's follies for the present life and to suggest to him momentous instruction for the life to come. 
Worms are often confounded with entozoons and with the larvæ of insects, but really differ very much from both, and possess some interesting characters of their own. They are the only animals who combine the presence of red blood with the absence of a backbone or internal slzeleton. They have a contractile body, composed of numerous rings; and most of them travel by means of little bundles or tufts of minute, stiff, moveable hairs. Almost all except the common earthworms live in water; and several bore holes or construct tubes in the bottom mud, or envelope themselves there with a tubular calcareous shell, or spend the winter in a torpid state among the thick-matted roots of aquatic herbage. The best known of these is the common medicinal leech, which inhabits marshy ponds, and is remarkable for its great power of resisting destructive chemical agency,-_living many days in poisonous gases, or among other poisonous substances, or in vessels totally deprived of oxygen.

The common earthworms are so well known that we need not describe them. Yet, strangely enough, they are utterly misunderstood by many of the class of persons who oftenest see them and have high interest in understanding them. "Lands that are subject to frequent inundations," remarks White of Selborne, "are always poor; and probably the reason may be, because the worms are drowned. The most insignificant insects and reptiles are of much more consequence, and have much more influence in the economy of nature, than the incurious are aware of, and are mighty in their effect. From their minuteness, which ren-, ders them less an object of attention, and from their numbers and fecundity, earthworms, though in appear- 
ance a small and despicable link in the chain of nature, yet, if lost, would make a lamentable chasm. For, to say nothing of half the birds, and some quadrupeds, which are almost entirely supported by them, worms seem to be great promoters of vegetation, which would proceed but lamely without them, by boring, periorating, and loosening the soil, and rendering it pervious to rains and the fibres of plants, by drawing straws and stalks of leaves and twigs into it, and, most of all, by throwing up such infinite numbers of lumps of earth, called worm-casts, which, being their excrement, is a fine manure for grain and grass. Worms probably provide new soil for hills and slopes, where the rain washes the earth away; and they affect slopes probably to avoid being flooded. Gardeners and farmers express their detestation of worms, - the former because they render their walks unsightly, and make them much work; and the latter because, as they think, worms eat their green corn. But these men would find that the earth without worms would soon become cold, hard-bound, and void of fermentation, and consequently sterile."

"Each worm, each shell, each insect holds a place

Important in the plan of Him who form'd The scale of beings, - holds a place, which lost

Would breals the chain, and leave a gap

That Nature's self would rue."

Insects are an immensely numerous class of segment-bodied animals; and, in several respects, the most interesting class of creatures in the whole animal world. Their numbers, their variety, their structure, their colours, their habits, and their powers, all 
rivet attention and exeite astonishment and admiration. "When we consider attentively these little things," remarks Kirby, "the multiplieity and diversity of their organs, whether of sense or motion, of offenee or defence, for mastication or suction; or those constructed with a view to their several instincts, and the exercise of those functions devolved upon them by the wisdom of their Creator; the different kinds also of sculpture, which is the distinction of one tribe, and of painting, which ornaments another; the brilliant colours, the metallie lustre, the shining gold and silver, with which a liberal and powerful hand has invested or bespangled many of them; the down, the hair, the wool, the scales, with which He who careth for the smallest and seemingly most insignifieant works of his hand, hath elothed and eovered them; when all these things strike upon our senses, and become the subject of our thoughts and reflection, we find a seene passing before us far exeeeding any or all of those that we have hitherto eontemplated in our progress from the lowest towards the lighest members of the animal kingdom; which, for its extent and the myriads of its mustered armies (each eorps distinguished, as it were, by its own banner, and under its proper leaders), infinitely outnumbers all the members of the higher classes; and which stands, as it were, between aquatic and terrestrial animals, many of its tribes under one form inhabiting the water, and under another the earth and the air."

The mere transmutations of the greater number of insects are eminently wonderful. They eomprise three stages of being-larva, pupa, and perfect insect-all broadly different from one another in both form and 
function. The larva crawls about like a worm, and feeds with voracity, and rapidly increases its bulk and weight, and makes inward development and transition toward the future stages of existence. The pupa lies almost as still as a dead thing, and looks in many a case like a bit of the soil around it, yet carries on an inward process of preparation for a sudden, total, future change. The perfect insect has either wings or other organs of rapid motion, and bestirs itself alertly, yet takes little food, makes little increase of bulk, and serves chiefly to delight the eye of man by its beauty, and to form and lay eggs for the continuation of its race. The successive forms are peculiarly striking in the case of butterflies. The larva there is a grovelling caterpillar, feeding with a greed and power as if it could never have enough; the pupa is a chrysalis, lying buried in the earth; and the perfect insect is a gay and gorgeous winged one, painted and powdered all over with magnificence, and starting suddenly up from the temporary tomb to float on the summer breeze and to revel among flowers. Men, in all enlightened times, have been charmed with the butterfly transmutation; and the early Christians were not slow to see in it a beauteous type of the resurrection of the just.

Insects, in the exercise of their power-some in the state of larvæ, and others in the state of perfect insects -are remarkable for combination, perseverance, and instinctive skill. Many kinds of them are utterly feeble as individuals, and yet amazingly and overwhelmingly strong as societies. The corn-weevil, which eats out the flour from grain, will speedily reduce the stores of the largest granaries to empty chaff. 
The white ant of the tropics sometimes, with as much effectiveness as fire or flood, swecps away whole clusters of houses. The locust converts, in a single night, an entire district of vegetation into naked soil, and often for days together defeats the efforts of man to place a limit to its devastations. These instances, which might easily be multiplied, admonish man of lis littleness, and teach him how dependent he is on God for protcction against even the most trivial foe. Often does he proudly call himself "the lord of crcation;" and yet is he baffled and bcaten by some ot the smallest of its denizens. But other insccts, either combinedly or singly, confer great benefits on man. Beetles sweep away an excess of vegetable production. which the health of animated nature requires to be periodically destroycd. Tropical insects, by lodging their larvæ in the skins and carcasses of the larger animals, consume much of the corrupt animal matter which, if unremoved, would speedily infect the atmosphere with pestilence. Flies, grubs, caterpillars, and all the little agents of petty annoyance which exist in our land, exert an essential influence, and act no unimportant part, in the great processes of recombination, by which vegetable and animal cxistence is pcrpctuated and maintained. Many inscets-the bce, the silkworm, the gall-fly, the cochineal, and others-work out beautiful fabrics or valuable productions for the comfort and health of man, which no manufacturing skill can imitate, or rcsources of chemical knowledge supply. Who docs not see, in the abundance of these little artificers of good, a display of the divine beneficence? or who that reflccts on their own complete and wonderful organisation, on the perfection of their 
anatomical structure, and on the amazing intricacy, combined with the remarkable littleness, of the animal mechanism of their frame, does not admire the omniscient wisdom, and the divine power and benevolence, displayed in peopling small spots of ground with whole communities of animated beings, and investing them with capacities and practical energy subordinate to the welfare of the largest and the most important tenants of the earth? Yet insects, regarded individually, are so small, so frail, so ephemeral, as to be utterly incompetent to effect any noticeable result. Their influence ariscs-in the case especially of ants, wasps, bees; and other remarkable groups-from the combining of their numbers, and even, in some surprising particulars, from the adoption of minute social laws, and the principle of the division of labour. Insects afford a practical and truly wonderful illustration of the maxim, "Union is strength." If the sluggard may learn industry from the ant, and the philosopher may take lessons from the bee, what hints of practical wisdom may not the quarrelsome, the unsocial, the vain, and the ambitious, learn from any one of a hundred species of the tiniest creatures that exist?

The displays of insect energy, connected with perseverance and instinctive skill, are so numerous and remarkable, that volumes have been written to describe them. A beetle, through steady continuation of unaided effort, will in two days bury beneath the soil a substance forty times its cwn weight and bulk. A single wasp will lay the foundation, sketch the outlines, and construct the elements, of an intricate habitation, exercising, at the same time, all the care, and 
performing all the offices, of the foundress of a colony, and the parent of a summer's offspring of thirty thousand of her species. The silkworm spins an unbroken double thread of silk, nearly one thousand feet in length, and coils it with such compactness round its body as to render it a sheath impervious to damp and air, affording complete protection while the insect passes from the condition of a larva to its matured state of a winged moth. The cayenne wasp manufactures a card so strong, so smooth, and of so uniform a texture, as to rival many a production of the human pasteboard-maker, and so curiously employs it as a covering for its nest, that rain-drops never rest upon its hard and polished surface. The bee continually, in the constructing of its comb, solves the difficult geometrical problem:-A quantity of wax being given, how shall there be constructed similar and cqual cells, of the largest size in proportion to the bulk of matter employed, and so disposed as to occupy the least possible extent of space? Hundreds of instances like these might be produced, exhibiting the effects of industry or of instinctive wisdom,-all illustrating how "very good" are the small, as well as the great, works of the Creator, and all suggesting to lazy, self-conceited, or blundering human beings many a lesson not merely of persevcrance and prudent care, but of practical or even manufacturing skill.

One great division of insects is the wingless, comprising the fleas and parasites and some others; another is the two-winged, or flies; another is the scalywinged, comprising butterflios and moths; another is the sheath-winged, or beetles; and others are the straightwinged, the nerve-winged, the yoke-winged, the equal- 
winged, and the unequal-winged. Let us, for fuller illustration of the whole class, give a specimen-view of the ant-family belonging to the yolke-winged division, and of the aphis family belonging to the equal-winged division.

All ants live in assemblages of nests which have not inaptly been termed cities; and though the British ones perform none of the stupendous feats which have rendered some of the foreign ones so famous, even they do combined works which are not a little marvellous. The members of each community comprise males, females, and workers, besides eggs, larvæ, and pupæ. The males and females, on emerging from the pupa state, have each four delicate transparent wings; and they perform little or no work in connection with either the feeding or the protecting of the community. The workers are neuters, or imperfect females, and never have any wings; and they feed the larvæ, protect the females, bring in provisions, make roads, construct bridges, and, in general, conduct the various operations of building, foraging, devastating, defending, and fighting.

The ants of the warmer countries of the world, particularly those of Africa, South America, and the West Indies, construct large, intricate, and wonderful dwellings, which have astonished travellers, and challenged the admiration of the most phlegmatic naturalists. But the ants of Britain, though very various in habits, construct abodes which are more remarkable for their annoyance to man, or their mischievousness to the soil, than for either size or intricacy. The turf-ant, a small dusty-brown insect, frequent in commons and pasturefields, usually selects a tuft of herbage, piles up small grains of earth into the partitions of cells and chambers, 
and makes the stems of the herbage serve as jrops and the grassy leaves as covering. The yellow-ant gnaws portions of wood into saw-dust, mixes this with earth and spiders' webs, and employs the mixture in constructing the chambers, stages, and galleries of its mimic city. The fallow-ant - the largest of the British species, and not uncommon in woods and pleasure-grounds -constructs very numerous galleries and chambers in a series of successive storeys, from an excavated base to some height above the surface of the ground, and gives the whole such an exterior finish as to make it resemble a considerable mound or little lillock of sand and earth, with bits of wood, leaves, twigs, and grains of corn in apparently indiscrininate mixture. The redant, common in gardens, and not unfrequent in pasture-fields, makes burrows and chambers under stones or in the ground. The brown-ant ingeniously and industriously constructs habitations with a series of storeys in clay. The jet-ant excavates horizontal galleries in a series of storcys in the trunks of old oaks or willows; and these galleries are all eventually stained black, and sometimes have the appearance, though on a mimic scale, of elaborate carved work. Hence, says Clare,

"What wonder strikes the curious, while he views

The black-ant's city, by a rotten tree

Or woodland bank! In ignorance we muse;

Pausing, annoy'd, we know not what we see;

Such government and thought there seem to be;

Some looking on, and urging some to toil;

Dragging their loads of bent stalks slavishly;

And what's more wonderful, when big loads fail

One ant or two to carry, quickly then

A swarm flock round to help their fellow-men.

surely they speak a language whisperingly,

'Too fine for us to lrear." 
The males and females of an ant's nest usually emerge from their pupa state in August or September; and they may then be seen commencing a new course of existence, issuing from their nest, rising into the air, and settling on posts, gates, and stones, and sometimes forming little clouds, which whirl and twist through the air, and seem to comprise thousands or even myriads of beings. The males have neither stings for defence nor sufficiently strong jaws for labour and the collection of food; and they speedily perish. A vast proportion of the females, in common with all the males, are either devoured by birds or driven into rivers, lakes, and ponds; and some of the remaining portion of the females re-establish the old nests, some found numerous new colonies, and all speedily lose their wings, and commence laying eggs.

Ants are singularly fond of the sweet juice popularly called honey-dew, exuded by aphides; and colonies of them, particularly of the yellow-ant, often appropriate particular trees or branches of trees for the sake of their honey-dew, or actually enclose groups of aphides, and keep them as their peculiar property, angrily and steadily resisting the encroachments of all other ants upon their premises. Rival colonies of the fallow-ant sometimes engage in battle, thousands on each side; and they occasionally fight with such engrossing pugnacity and such pertinacious obstinacy, as to be incognisant or careless of human observation. The workers or neuters of the rufescent and sanguineous ants, common on the Continent, though very rarely, if ever, found in Great Britain, compel the workers of two other species to serve as their auxiliaries or slaves. 
Some of the tropical ants make emigrations, and occasionally march over a country in incredible millions, and with the most stubborn will. About half a century ago, the sugar-eating ant did an exploit in the island of Granada which rivalled some of the boasted feats of desolation done on many a land by ruthless human armies of conquest. Absolute torrents of that insect descended from the hills, filled the roads and the plantations for miles,--destroyed whole estates of sugar-canes by eating through the roots, -killed rats, mice, reptiles, birds, and domestic quadrupeds, - and in some instances dammed up rivulets, and formed with their accumulated carcasses mounds or bridges for surviving myriads to pass the streams with safety. Large fires were lighted in their path to arrest them, but were extinguished by their progress. A reward of twenty thousand pounds was offered to any person who should discover an effectual mode of destroying them. And had they not been providentially swept away in the torrents of a terrific hurricane, they probably would have converted the island into a wilderness.

The aphis family-or, as they are called in the plural number, the aphides-are the minute creatures who inhabit the foliage of plants, and produce some of the plant-diseases which are popularly called blights. They are far more multitudinous, and much more generally diffused, than any other family of insects. They inhabit every sort of plant, from the smallest grass to the most stately tree; and sometimes exist in myriads on a single herb of not more than two or three feet in height. They comprise a vast number of different kinds,--probably not fewer than twelve 
or thirteen hundred; and were once thought to be as various as the groups or diversities of plants. They often work prodigious havoc, and sometimes are scarcely less terrible than locusts, and always more or less provoke the vigilance of gardeners, hop-growers, and general husbandmen. Yet they are individually insignificant,-_rarely so large as mustard-seeds, and frequently mere moving points. But, when seen through the microscope, they disclose wondrous organisms, gorgeous tints, and an astonishing economy of gay and happy life,--looking in the hollows of perfumed leaves and in the cups of honied flowers like societies of the blessed in the valleys of Paradise.

Three of the most familiarly known kinds are the black ones on the top of bean plants, the slaty grey ones on cabbages and turnips, and the green ones on the leaves and young shoots of rose plants. But the only one we shall particularly notice is that popularly called white blight or woolly blight. This infests apple-trees, and sometimes reduces entire orchards to sterility. It is of comparately middle size, and has a pitch brown colour, but envelopes itself in a white silky down. In spring, a slight hoariness appears upon the branches of infested trees; as the season advances, this hoariness increases, and becomes cottony; and, about the middle or toward the end of summer, it looks like a vestment of thick down upon the lower sides of the branches, and is sufficiently long and pendulous to be at times sensibly. agitated by the air. A multitude of small wingless insects, the woolly blight aphides will be found, on examination, to lie concealed in this downy substance, and to be preying beneath it upon the bark and juices of the tree. The sap-wood, 
being wounded by them, rises up in excrescences and nodes; the branch, deprived of its nourishment, becomes sickly, loses its leaves, and perishes; branch after branch is assailed, becomes leafless, and dies; and finally the stem and roots, deprived of every connection with living leaf and branch, decay beyond all reach of remedy. In autumn, the insects are dispersed by the winds and rains, and hide themselves in the crannies of any neighbouring substance. "Should the savoy cabbage be near the trees whence they have been dislodged, the cavities of the under sides of its leaves are commonly favourite asylums for them. Multitudes perish by these rough removals, but numbers yet remain; and we may find them in the nodes and crevices, on the under sides of the branches, at any period of the year, the long cottony vesture being removed, but still they are enveloped in a fine, short, downy clothing to be seen by a magnifier, proceeding, apparently, from every suture or pore of their bodies, and protecting them in their dormant state from the moisture and frosts of our climate."

All the aphides have a very extraordinary economy of reproduction. A female who has paired produces eggs or egg-like pupæ; the eggs produce female insects; each of these is the parent of from five to eleven generations of females; and all carry on the process of multiplication without a single male being produced or otherwise appearing till toward the end of the season. And the numbers of insects who have descended from each egg-laying parent are prodigious. One naturalist estimates the aphides of the ninth generation, in one season, from a single mother, at no fewer than three hundred and fifty thousands of billions; 
and another estimates them so high as twenty-five trillions. And hence, though as small as dust, aphides are sometimes so stupendously plentiful as to powder the ground or almost obscure the air. One learned observer records that, in the autumn of 1829, he saw swarms of the white blight aphides alighting in clouds, and covering every kind of herb and tree within the space on which they alighted. Another says, "I once witnessed, to my great annoyance, an emigration of aphides when travelling in the Isle of Ely. The air was so full of them that they were incessantly flying. into my eyes, nostrils, \&c., and my clothes were covered by them. And in 1814, in the autumn, the aphides were so abundant for a few days in the vicinity of Ipswich as to be noted with surprise by the most incurious observer." And White of Selborne says, "On the first of August, about half-an-hour after three in the afternoon, the people of Selborne were surprised by a shower of aphides which fell in these parts. They who were walking the streets at that time found themselves covered with these insects, which settled also on the trees and gardens, and blackened all the vegetables where they alighted. These armies, no doubt, were then in a state of emigration, and shifting their quarters, and might perhaps come from the great hop plantations of Kent and Sussex-the wind being that day at north. They were observed at the same time at Farnham, and all along the vale at Alton."

The devastations of the aphides are effected by means of what is styled, in popular language, their beak or their sucker. This is best seen in the aphis which inhabits the saplings and shoots of oak-trees, -a much larger insect than almost any other of the 
family. The sucker of the creature is much longer than the body, and, when unemployed, is carried in such a manner as to project behind, and look like a slightly upward-curved tail. It terminates in so minute a hole, that Reaumur could not observe it with his most powerful microscopes, and proved its existence only by pressing out from it a drop of fluid. Two instruments of a brownish colour have been observed within the tube, and were conjectured by Rcaumur to act like the piston of a pump. The insects, when forcing the sucker into the bark of a plant, press down their head and elevate the hinder part of the body, and, in consequence, exert considerably more power than if they were to maintain a horizontal attitude; and, after they have pierced a hole, they continue at it night and day, without any locomotion, so long as they can obtain through it a sufficient supply of food. They usually station themselves on the youngest shoots and the underside of the leaves, apparently because these are at once the juiciest, the most nourishing, the most accessible, and the most pervious parts of the plants; and they therefore abstract the cambium, or elaborated sap, immediately after it is prepared, and prevent it from making such a descent through the downward organisms as is essential for maintaining vegetable life and the performance of the vegetable functions. Entire plants are thus robbed of their nourishment; and either the leaves shrivcl up, as in the cabbage, the plum-tree, and the currant-bush, or the blossoms drop, and the fruit does not set, as in the bean and the hop.

Several species of the soft-billed birds, particularly the yellow-wren, the gold-crest, the babillard, and a 
number of others, feed upon the aphides, and generally make such havoc upon the garden kinds that they may be emphatically regarded as the gardener's friends. The beautiful beetles popularly called ladybirds and lady-cows prey, in both their larva and their perfect state, most conspicuously upon the aphides, and sometimes destroy entire swarms. "Their method of attacking the aphides," says Mr Curtis, "is curious. I have seen one of the latter struggling whilst this little insect-alligator threw his fore-legs about it, and was' greatly amused at the skill it exhibited; for, fearing that the aphis might escape, it gradually slid along to the wings, which were closed, and immediately began to bite them, so that in a very short time they were rendered useless, being matted together; it then returned in triumph to the side of its helpless victim, and, seizing the thorax firmly in its grasp, it ate into the side, coolly putting its hind-leg over those of the aphis, whose convulsive throbs annoyed its relentless enemy." The lady-birds are often attracted in myriads to feed upon the aphides of the hop-plantations, the gardens, and the orchards; and in some seasons when the aphides were unusually multitudinous, they have appeared in some districts in such enormous numbers as to alarm the ignorant and superstitious; and yet these useful destroyers of . the aphides, as well as their fellow-labourers, the softbilled birds, have been assailed and destroyed by ignorant gardeners and farmers, as the supposed inflictors upon plants of the very mischiefs which they alleviate or prevent. The grubs of the lace-winged flieseasily recognisable by their slow flight, their broad, greenish, gauzy wings, their bad odour, and their' 
shining amber-like eyes-are so voracious devourers of aphides as to have been designated by Reaumur. aphis-lions; and a number of other insects, particularly some of the wasp-flies, some of the ichneumons, and all the earwigs, either in their larva state or in their perfect state, or in both, vie with one another in doing the work of aphis-destroyers.

The instructions suggested by the natural history of ants and aphides are both numerous and valuable. Among the more obvious are,- - that the structure, beauty, and instincts of these minute creatures wonderfully display the wisdom and beneficence of the Creator,- that their microscopic smallness and their inconceivable numbers evince the Creator's all-pervading care,-that their constitutional habits of feeding operate as salutary checks upon the excessive cultivation of such plants as are more relished by man's palate than conducive to his health and vigour, -that their occasional swarmings and devastations serve, in Divine Providence, both as stimulants to man's industry and as chastisements of his sins, that their being the ready prey of other insects and of birds, generally without any apprehension or pain to themselves, is a link in the great chain of mutual dependence and subordination among creatures,that their living upon the juices of plants involves elaborations of both vegetable and animal chemistry almost as numerous and profound as occur in the ordinary physical economy of human society,-and that, therefore, that Glorious Being, that Living and All-Loving One, who so wondrously frames and feeds each of these little creatures, will a million times rather beautify and bless for ever each human soul 
which was purchased with the blood of his own Son, and made anew by the power of his own Spirit.

Crustaceans may be regarded as the insects of the sea; but they are much larger than the true insects, far less numerous, and clothed with shells. Familiar examples of them are shrimps, crayfish, crabs, and lobsters. Considerable changes take place on their form between hatching and maturity; but, excepting in a few instances, these are not nearly so striking as the transformations of insects. But a remarkable thing peculiar to themselves is the moulting of their shells. These fit close to their body and limbs, joint by joint; and, in the progress of the creatures' growth, they become too small, and are cast off to give place to new ones. When an individual is about to moult, he lays in a store of carbonate of lime, becomes sick, and retires to a hiding-place; and he then throws off his shell, lies carefully concealed, and very speedily exudes from all his skin enough of calcareous matter to. form a new lard coat. His preparational store of carbonate of lime lies in his stomach in the form of what are popularly called "crab's eyes;" and it is promptly used off to clothe him with his new shell; so that immediately before moulting he is rich in "crab's eyes," and immediately after re-coating he has none. Crustaceans, too, have the remarkable power of speedily reproducing any member or "claw" which happens, either at moulting or at any other time, to be broken off or seriously injured.

Molluscs, or soft-bodied animals, comprise a very wide range of groups from the neighbourhood of polypes to the neighbourhood of fishes. All have a very soft consistence,-- some not more than mucus, 
and none so great as white-fish flesh; and all are enveloped in a soft elastic skin, lined with muscular fibres, and technically called a mantle. They consist mainly of stomach and intestines, and have little organism of either motion or sensation. Many are complete fixtures, living wholly on food brought to them; many wander slowly and sluggishly from spot to spot, eating voraciously what they find; and capable of enduring very long fasts; and only a few have sufficient power's of locomotion to go actively in search of sustenance. Some hare no other protection than their mantle, and others are sheathed in shells secreted from their mantle; and so little different are the shell-less from the shelled ones that sometimes two kinds, as, for example, a slug and a snail, can scarcely, if at all, be distinguished from each other, except by the cir.. cumstance that the one has not a shell and the other has. The great majority live in the sea, and the shelled ones there constitute, along with the crustaceans, what are popularly termed shell-fish.

The shells are so exceedingly diversified as to form the subject of a separate science-the extensive and fascinating science of conchology; and multitudes are so chastely beautiful, or so elegantly lovely, in form anid sculpture and colour and markings and enamel, as to charm all observers, from the prattling child on the sea-beach to the solemn savan in tho museum. They have a compact texture, an enamelled surface, and sometimes splendid variegation of tint and outline; and they consist almost entirely of carbonate of lime, with layers of coagulated albumen, or with a soft animal substance similar to gelatine. But those of the sluggish or stationary kinds of molluscs are the most 
solid and massive; and those of the active linds are commonly light and thin and very fragile. The shells of the molluscs of former and early epochs, as we hinted in the chapter on Rocks and Fossils, are among the most prominent and interesting records in the rock-history. of the earth. Some molluses are remarkable for pro. digious boring powers; some for the emitting of extraordinary sounds; and some, such as the pearloysters and the pearl-mussels, for their precious gemlike secretions. But the most remarkable of all are the shell-less group, called cuttle-fishes, more elaborately organised than any of the others, and most nearly akin to true fishes. The largest of these, called the great cuttle-fish, and inhabiting the Indian Seas, may be selected as a master-specimen of all the molluscs; and is described in the following terse terms by the Rev. W. Tiler:- "The Latin name of this surprising creature is sepia, which signifies ink, from the liquid that the cuttle-fish has the power of discharging at pleasure, and which, indeed, resembles ink so much in appearance and quality, that it is said the Romans used it instead of ink, and that it forms a principal ingredient in Indian ink also. The animal is often called the ink-fish from this circumstance. Lord Bacon has remarked, "How strange it is that the blood of all birds, beasts, and fishes should be entirely of a red colour, with the exception of the cuttle alone, whose blood is as black as ink!' As every creature is formed by the All-wise Creator most suitably to its nature and wants, so the cuttle, placed in an element full of enemies that are peculiarly eager after it, has this liquor for the purpose of self-defence, which it accomplishes by squirting it out very copiously into 
the water, which it darkens to such a degree as to elude the pursuit of its foes. Those who darken counsel by words without knowledge are, by a certain writer, compared to the cuttle, hiding themselves in their own ink. Hence, too, persons who spend their time and abuse their talents in blackening the characters of others have the name of cuttles. Of this kind of cuttle there are far too many on land and sea. With this ingenious, but by no means unnatural or uncommon, mode of defending itself by blackening and blinding its adversaries, it has very formidable means of offending and playing the tyrant over those below, as it is tyrannised over by those above it. These means it has in eight long arms or claws, which are furnished on the interior side with little serrated cups, by the contraction of which, in the manner of suckers, as children drop a piece of moist leather upon a stone with a string, it lays fast hold of anything that comes in its way. Besides these eight arms, it has two others, four times longer than the rest, armed with suckers like the other claws, which, when they adhere to anything, it is extremely difficult to remove, so that they are very formidable from these circumstances. These arms are frequently used by them to resist the motion of the waves in a rough sea. In hot climates these creatures are found of an enormous size. The Indians affirm that some have been found twelve feet broad over their centre, and each arm above fifty feet in length. When the Indians navigate

- their little boats, they are in constant dread of these dangerous animals; and, lest they should fling their arms over and draw them under water, they always carry an adze or a hatchet with them to cut them off. 
"The body of the cuttle presents the appearance of an open purse, into which it can probably draw and shut its head whenever exposed to danger. The head is as wonderful as any part of it; for, besides the peculiarity of its two great eyes, it has a mouth horny and hooked like the bill of a parrot, and which is so strong that the animal can break to pieces with it the shells of limpets and other shell-fish upon which it feeds. The eyes project to a great distance below, and are surrounded with several silvery rings. They are as large as the eyes of a calf, but more resemble those of the crab. The body is of a reddish brown colour, and nearly round. The belly is soft, smooth, oblong, of an ash and faintly yellowish colour; and about the middle of the body there is a fin spread out on both sides, and coming to a point at the tail. By this fin it moves itself in swimming, having no other means for that purpose. The female cuttles lay their eggs in clusters, like bundles of grapes, upon sea-weed or plants. Immediately after they are laid, they are white, but, after they have been impregnated by the males with a black liquor, they grow larger, and resemble black grapes.

"The cuttle, though so strange an animal, is frequently used for the purposes of food, and is far from being disagreeable to the taste. When dressed, it is served up in its own liquor, which, from boiling with the addition of nitre, becomes red. It is noticed as having a phosphorescent quality, as, if taken into an apartment and cut open, it illuminates the whole place. From what has been said of these creatures, it might be supposed that they would not be very readily taken; and it is said that their noise, when 
dragged out of the water, resembles the grunting of a boar. There is a bone in the animal which is converted into that useful article of stationery called pounce, and is used also by silversmiths to form moulds. The structure and habits of these animals furnish the mind of the devout naturalist with many subjects of instruction, while truly thankful for the goodness and the grace that has made himself to differ. Whilst we cannot but adore the wisdom and power displayed in the creation and sustenance of the inferior animals, we should never forget to be grateful for our superior station and privileges among the works of God!"

True fishes comprise all water-inhabiting creatures who have a backbone. They are the least perfect of backbone-bodied animals; and some have a comparatively rude and simple skeleton, while others, including all the sharks and sturgeons, have skeletons not properly of bone, but of cartilage. Yet fishes are prodigiously various, -and range from very simple to very complex, from beautiful to grotesque, from graceful to monstrous; and all possess a perfect adaptation of structure and organism, not only to waterlife in general, but to the sea or shore, the salt water or fresh, the depth or shallowness, the activity or sluggishness, in which the several kinds respectively live. Their form of body gives the best possible resistence to progression, and the utmost possible aid to propulsion; their tail acts like a powerful sculler, and their fins serve variously as oars and balancers; their breathing apparatus suits exactly to take in the small proportion of vital air which is diffused through water; and their thousand diversities of shape and fins and 
finny arrangements and internal structure correspond exactly to the thousand diversities in the places and habits and pursuits of their life. How gracefully do they all glide through the water! And how unutterably superior is the mechanism of the humblest of them to the coarse, rumbling, struggling machinery of the grandest artificial fabric which man ever set afloat!!

Some fishes live sluggishly at the bottom of the waters; but others rush through the deep in sporttiveness or migration, at the rate of twelve or sixteen miles an hour. Some appear stupid and intractable; but others can be trained in the manner of domesticated animals, and may be taught to come for their food at the ringing of a bell. Some have no armature of defence, and live in peaceful retreat as timidly as hares; but others exercise methods of escape or wield weapons of war fully as curious as any which are known among the beasts of the forest:' For example, the flying-fish leaps out of the water, and remains for a while suspended in the air, to elude the pursuing dolphin; the chretodon shoots drops of water, to the distance of from three to six feet, upon insects, to clog their wings and bring them within its reach; and the sword-fish runs his long, serrated snout like a bayonet into the body of his foe. The snout of a sword-fish once went so fiercely and far into the hulk of an East Indiaman as to make a hole big enough to have foundered the ship; but it happily stuck fast and broke off, so that no harm ensued; and the piece of the hulk, with the snout embedded in it, is preserved among the curiosities of the British Museum.

The flat fishes are among the most defenceless of 
the order, and have not even the dilatable bag, called a swimming-bladder, by which most other fishes are enabled to rise or sink at pleasure; and the manner in which they enjoy life and escape danger is a fine instance of the peculiar adaptations of each of the multitudes of several groups and linds to its peculiar circumstances. "Living on sandy and muddy shores," says Yarrell, "their place is close to the ground, where, hiding their bodies horizontally in the loose soil at the bottom, with the head only slightly elevated, an eye on the under side of the head would be useless; but both eyes placed on the upper surface affords them an extensive range of view in those various directions in which they may either endeavour to find suitable food or avoid dangerous enemies. Light, one great cause of colour, strikes on the upper surface only; the under surface, like that of most other fishes, remains perfectly colourless. Having little or no means of defence, had their colour been placed only above the lateral line on each side, in whatever position they moved, their piebald appearance would have rendered them conspicuous objects to all their enemies. When near the ground, they swim slowly, maintaining their horizontal position; and the smaller pectoral and ventral fins on the under side are advantageous, where there is so much less room for their action, than with the larger fins that are above. When suddenly disturbed, they sometimes make a rapid shoot, changing their position from horizontal to vertical; if the observer happens to be opposite the white side, they may be seen to pass with the rapidity and flash of a meteor, but they soon sink down."

But the most surprising kind of adaptation among 
fishes is a power possessed by a few of them of inflicting a severe electric shock, elther in self-defence or in assault upon a prey. A small degree of this power, indeed, exists in some other animals, and electrical conditions more or less analagous to it occur perhaps in all animals; but the power itself, as a regular weapon, is mainly characteristic of what are called the electric fishes. The most energetic of these is the gymnotus, a native of the rivers and lakes of South America, five or six feet long, and shaped somewhat like a common eel, but comparatively much thicker. This creature can give a shock at pleasure, and can send it in any particular direction, and can render it specially strong by circling itself round the object in the manner of a coil. The shock is so powerful as to kill small fishes, and to stun a man or a horse: and it is capable of magnetising needles, of decomposing water, and of yielding the electric spark. But the creature becomes quite exhausted by giving shocks, and needs rest and nourishment to acquire the power of giving more. The torpedo, a famous ray-fish of the Mediteranean, possesses the power in a very high degree, though not so high as the gymnotus, and is noted for it in the writings of naturalists and poets from very ancient times. A person who touches this fish with a walking-stick gets a benumbing shock from it; and an angler is exaggeratingly described by Appian as perfectly lightning-struck by catching it with his hook:-

"The hook'd torpedo, with instinctive force,

Calls all his magic from its secret source;

Quick through the slender line and polish'd wand

It darts; and tingles in the offending hand. 
The patsied fisherman, in dumb surprise,

Feels through his frame the chuling vapours rise;

Drops the lost rod, and seems, in stiffening pain,

Some frost-fix'd wanderer on the polar plain."

Reptiles are distinguished from fishes by their breathing the air directly, and not through the medium of water; but they have cold blood and only half a heart, and are therefore inferior creatures to birds and beasts. Very many live indifferently or alternately on land and in water; a very few live wholly in water; and the great majority live in morasses, swamps, sides of stagnant waters, damp shady jungles, and dark humid retreats, caves, and holes in the earth. They have prodigious powers of endurance as to either heat, cold, hunger, or injury. Some can so well withstand heat, that they have been fabled to live in flames and furnaces; others can live incredibly long in fast seclusion from food and air; and many continue to live and move and perform their functions in defiance of most terrible bruises and fractures. All, too, are more or less remarkable for strength or noxiousness. Some are sheathed in ball-proof coat of mail; others have offensive power of teeth or muscle which can promptly crush a middle-rate beast or man himself to a mummy; others eject acrid humours or fetid odours most disgustingly vile; and others carry stings and poison-bags, and can in a moment inflict on man or on any large animal a dangerous or deadly wound. And, to crown all, they are the ugliest creatures on the earth; for, though immensely diversified in form, and though in many instances freckled and beautiful with gorgeous colourings, they are all in some way or other hideous; and the beauteous ones look all the more 
horrible for their very beauty. Their great powers of endurance explain how creatures of the same structure as they were main inhabitants of the hot seas and swamps of former epochs of the world; and their strength and noxiousness and hideousness are ample reason for the most prominent of them-serpents and dragons-being treated in the Bible as a type of the arch-fiend and his legions.

But the serpent kinds and the dragon kinds-the former with rattlesnakes and boa-constrictors at their head, and the latter. with alligators and crocodiles at their head-are incomparably the worst, and at the same time are the most numerous. The frog and salamander kinds are comparatively harmless; and the turtle and tortoise kinds are, to some extent, agreeable. A very curious thing about the frog is its transformation-the young ones, or tadpoles, having the organisation and habits of fishes, while the old ones are as real reptiles as any snakes or lizards. And a wondrous thing about the land-tortoises is their beautiful, powerful, well-known coat of mail. "This covering," we are told, "consists of two broad and hard plates of horn, one above, and the other below, joined together at each end; but leaving space sufficient between the upper and lower shells for the legs and head to protrude themselves. These the tortoise can easily draw under cover as it retires to rest, or secures itself from danger. The creature's head bears a stronger resemblance to that of a bird than of a quadruped; and projects in a very awkward manner from the shell as it is travelling. The under shell is something less than the one above, being flat or nearly so, while the back plate is round. The upper 
shell is divided into a number of square sections, by its markings; thirteen of these appear in the middle, and twenty-four at the edges, where the two shells join. The whole shell is fastened to the animal by its connection with the bones of the back, ribs, and others. The head, tail, and legs of the tortoise are its only moveable members, except as the whole body moves. It travels very slowly, almost at a snail's pace, although it appears more active and at home in the water. The security, therefore, does not consist in escaping by fleetness from the enemy, or in vigorous and active opposition, but in passive resistance; trusting to the thickness and strength of the shell for defence and safety. From the extreme broadness of this covering, should any accident or any enemy turn the tortoise on its back, there it must lie perfectly helpless. This is the way in which the large green turtles are secured; they travel out upon the beach at night, to a considerable distance, and are sought at that season by fishermen, with lanterns and torches; and, when found, they are turned upon their back by means of poles and levers, prepared for the purpose, and they are then taken away at the leisure of the captors. The largest and best are found about the islands of the Indian Archipelago, where they grow to upwards of four fect in length, and four or five hundredweight each. Those of the West Indies are said to be even still larger. These have great strength, as several men have been known to ride upon the broad back of a tortoise, without any appearance of being a burden to the creature. The motions of these resemble the slow and stately movements of an elephant, to the legs of which their own are not very dissimilar." 
Birds are more highly organised than reptiles, but less so than mammals; and they possess perfect and most admirable adaptations for buoyancy and flight. Their heads are small, and pierce freely through the air; their vision is keen, and discerns their way-marks and destination and food at great distances; their head and shoulders are gently swelling, and cleave the atmosphere with the least possible resistance; their frame is small, light, and curved, and suits alike to ascend in the air and to float on the breeze; their interior has air-bags and cavities which make them almost as buoyant as balloons, and at the same time maintain a very extensive respiration for the double purpose of ligh heat and lofty vigour; their under plumage is soft and downy, and prevents their heat from silling out of them during flight; their upper plumage is strong and imbricated or overlapped, and also in most instances lubricated with an oily secretion, which protects them from injury by rain or storm; their wings, while made of a light material, are worked with muscles of very strong power, and strike the air with most impulsive force; and their tail has a relative adjustment similar to the rudder of a ship, but with greater activity and incomparably freer command, and steers them like life, steadily and promptly, in the precise line of their wishedfor course. Every feather is a wonder, and every wing a museum. The wing of a swan has power enough to break a man's leg, and the wing of an eagle could stretch him lifeless on the ground. Yet the material of them is mere feather; and the muscles which wield them are poised on a framework of not many inches in diameter. 
Bat birds are also surpassingly beautiful and charming. They amount to thousands and thousands of kinds, and yet are all lovely, all an endless diversity of grace and gorgeousness and song. They look rather to belong to Eden than to the sin-defaced earth, and are ever suggestive to good men of an everlasting paradise in the heavens. How paramount above all statuary are their forms! How rich above all festoonings and draperies are their waving plumes and feathery ringlets! How glorious above all pictures, how far beyond comparison with anything except flowers and winged insects, are their tints and burnishings of colour! And how immensely superior to the rough measures of human music, how entirely like the faint far-away responses of the primal paradise to the hymns of cherubs, are the thrillings and warblings of their melody! Nor can any great reason, or scarcely any reason at all, be discovered by physiologists, why they needed such exquisite beauty, or any of their fine hues, or of their powers of song. They clearly possess all their attractions as a ministry of pleasure to man. "They embellish our forests, and amuse our walks; and whether we saunter around our home or wander to a distance, some of them always attend us, to please our eyes and ears, and to raise our admiring thoughts to the God of nature and of providence."

Some birds, such as the ducks and the gulls, have webbed feet and low body, suited to swimming. Others, such as the herons and plovers, have long legs and long necks, suited to wading. Others, such as the ostrich and the casawary, have powerful legs and undeveloped wings, suited to running. Others, such as the pheasants and common poultry, have a heavy gait 
and a short flight, suited to granivorous feeding. Others, such as the woodpeckers and the parrots, have level-based poising toes, suited to climbing. Others, such as vultures and falcons, have claws and crooked beak, suited to pouncing on prey and seizing it. And others, comprising the song-birds and swallows and crows and humming-birds, and multitudes more, have a form of foot suited to grasping or perching. Yet birds as a class are so like one another-so far from the wide diversities of structure and appearance which occur in other classes of animals - that we need take no more than two or three specimens to illustrate their special wonders, and may select these almost at random. .

Eagles are pre-eminent among even the largest birds for at once size, strength, beauty, daring, and longevity. They have a strong and hooked beak, sharp, incurved, and powerful talons, exceedingly ample and mighty wings, a rapid and soaring flight, and a bold, magnanimous, and indomitable disposition. They repose in calm dignity on the beetling summits of alpine crags; they soar into the upper atmosphere, through showers of sunbeams, with a strength of eye and a power of wing peculiarly their own; and they sweep down from crag or cloud, upon a minute object of prey, with an accuracy of aim, a suddenness of descent, and a might of pinion, which astonish and overawe even practised observers. They are popularly, and not with any exaggeration, regarded as the princehood, the royal family of the feathered kingdom, maintaining similar authority over birds to that which the lion possesses over the quadrupeds of the wilderness. 
"The eagle proudly careers its course with joy,

Firm on his own mountain vigour relying,

Breasting the dark storm, the red bolt defying.

His wing on the wind, and his eye on the sun,

He swerves not a hair, but bears onward right on.

Ever may the eagle's flight be mine;

Onward, and upward, and true to the line."

The golden eagle is the noblest species of his family; and he was at one time abunclant in all the mountainous districts of England, and may still be frequently seen in some parts of the Scottish Highlands, and of the western mountains of Ireland. He has a dull brown plumage, a horn-coloured beak, a bright golden red crown, and firm and massive wings of about eight feet in expanse. The female's nest or eyry is usually built on some inaccessible crag or pinnacle of a lofty mountain, and consists of twigs, heath, rushes, and other similar materials; and her brood are usually two or at most three, and are commonly fed on the warm blood of lambs, kids, ducks, or smaller and less domestic animals, which she has just seized on the plains, and carried swimmingly aloft to her eyry. She excels the male in size and courage; and at least equals him in power of flight and vision; and she is far superior to most birds in both the tenderness and the sagacity of her natural affection. The inspired writings compare the shortness of life to the fell sweep of her flight; the moral energy of lively Christians to her vigour and longevity; and the care of God for his people to her wise and untiring solicitude for her young. "When an eagle sees her young ones so well grown as to venture upon flying, she hovers over their nest, flutters with her wings, and excites them to imitate 
her, and to take their flight; and, when she sees them weary or fearful, she takes them upon her back, and carries them in such a way that the fowlers cannot hurt them without piercing her own body." Now, "as an eagle stirreth up her nest, fluttereth over her young, spreadeth abroad her wings, taketh them, beareth them on her wings, so the Lord alone did lead Israel, and there was no strange God with him; he made him ride on the high places of the earth, that he might eat the increase of the fields." "Ye have seen," said the Most High, "what I did to the Egyptians, and how I bare you on eagles' wings, and brought you unto myself."

\footnotetext{
"God led his people Israel forth, Even as the eagle's parent care Hangs o'er the lofty nest, And flutters fondly o'er her young, And spreads lier guardian wing, Then leads them from the eyry forth, And biàs them face the sun."
}

The blackcap is one of the most melodious songbirds of Europe. It belongs to the same family as the nightingale, and is scarcely inferior to that celebrated songster in the richness and variety of its warbling. It is delicately formed, and nearly six inches in length, and has a silvery white throat, a black crown, and a mouse-coloured body, tipped and variegated with brown and green. It frequents hedges, orchards, and gardens; it builds its nest in low bushes, or among nettles or brambles; and, when pouring its flute-like music through the air, it sits ensconced among dense foliage, and can very seldom be seen. 
It exquisitely imitates all other song-birds, and frequently executes a compound of their melodies, beginning, perhaps, with the call of the swallow, and ending with the powerful mellifluous song of the blackbird. It is called in some districts of England the mock-nightingale, but it is rather the rival than the mocker of the prince of song; and old Isaac Walton's devout exclamation respecting the nightingale, might quite as justly be uttered respecting the blackcap: "When I listen to the sweet descant, the rise and fall, the doubling and redoubling of its voice, I cannot but say, Lord, what music hast thou provided for thy saints in heaven, when thou affordest bad men such music on earth!"

Larks are a delightful group of little song.birds, belonging to the melodious family of finches, and remarkable for singing on the wing, and carolling upward to the far blue sky. The skylark soars aloft in circling sweeps and spiral ascents, pouring around him his joyous lay, till both his body and his melody seem to be absorbed into the clear ether; and he starts before the dawn, mounts away to sun himself in the first beams of the morning, and twines his matin hymn round the earliest rays of the rising sun.

"The morn hath just look'd forth and smiled, And the lark starts forth from his grassy nest, And is up and away, with the dew on his breast, And a hymn in his heart, to yon pure bright sphere, To warble it out on his Maker's ear.

Ever, olı! may my morning lays

Be found, like the lark's, to my Maker's praise."

But this far-soaring melodist is as lowly in his dwelling as he is lofty in his flights; and, when 
mounting from his nest among the grass, he sometimes has difficulty to breast his way upward through the wind. "I have often," says Jeremy Taylor, "seen him rising from his bed of grass, singing as he soars, hoping to rise above the clouds; but, beaten back with the sighing of an easterly wind, his motion becomes inconstant, and he descends, notwithstanding the vibrations of his wings, till he is fain to sit down and pant; after which, he takes a prosperous flight, rising and singing. So is often the prayer of a good man when he would speak to God. His thoughts are of the earth, earthy; and, looking to that which distracts him, a tempest rises, his words ascend, but his wandering imagination recalls them; then he sits and sighs, till, by thinking of things above, he forgets the little vain passages of his life, and his soul, becalmed, softly ascends on the wings of the Holy Dove; and, dwelling with God, returns, like the bee, laden with blessings and the dew of heaven."

The birds of paradise, in point of beauty, occupy the foremost place among the feathered glories of creation. They are natives of New Guinea and the adjoining islands, and make the most gorgeous contributions to the graceful forms and effulgent tints which distinguish at once the flowers, the insects, and the birds of the tropics. The names popularly given to some of the well-known species-the king bird of paradise, the magnificent bird of paradise, the superb bird of paradise, the golden bird of paradise, and the emerald bird of paradise-are neither pompous nor magniloquent designations of their combined gorgeousness and beauty. "When first brought to Europe, they were regarded as aerial sylphs, whose 
home was the bright expanse of sky, where all the functions of life were carried on, their only mode of rest being that of suspending themselves occasionally from the branches by the filamentous feathers of the tail; legs they had none, and they never touched the earth; their food was the morning dew." But the facts of their form and habits are more charming than even this fable. The king bird of paradise, for example, though one of the smallest of the group, and only about the size of a sparrow, is almost an impersonation of the most glowing daydreams of both painting" and poetry. "Its upper foliage is intense purplish chestnut; a zone of golden green extends across the chest; from each side under the shoulder springs a fan-like plume of six or seven dusky feathers, tipped with the richest golden green; from the tailcoverts spring two long slender shafts, each elegantly terminating in a broad, emerald web, rising from one side only of the shaft, and disposed into a flat curl." Other species are still more magnificent,-some with all manner of brilliant tints and shining iridescence, and some with light, large, and superb ruffs, plumes, and floating trains; and all seem to luxuriate in purity, avoiding everything which can soil them, performing frequent ablutions, and often examining their plumage to detect, if possible, a single stain. Even a dull imagination has little difficulty in figuring to itself one of these pure and lovely creatures as an emblem of a love-clothed mind, and as a messenger from the paradise of divine mercy to our fallen world.

"Thou must come, sweet bird, from some happy spot,

Where sin, and sorrow, and care are not; 
Where all is bright as thy starry wings, And heavenly music for ever rings;

Where the rays of the sun on the verdure rests,

Like the gem and gold on thy painted breast;

Thou belong'st not to a world like this,

For thou art an emblem of perfect bliss."

The mammals or suck-giving animals are the highest order of creation in our world. They ascend by intricate gradations from half-bird-like creatures up to man. They comprise the grandest tenants of the ocean, all the four-footed beasts of the earth, all creatures whatever of loftiest instinct, and the organic part of the race who were made "after the image of God." Their diversities of structure and adaptation, their wonders of bone and muscle, of teeth and nutrition, of nerve and brain,- - their grandeurs of sense and curiosities of habit,- - their class characters and distinctive peculiarities,- - their relations to one another and reciprocities with the lower creations and subserviences to man, would form ample matter for a cyclopædia of the wonderful. We clearly cannot give space for illustration of the interesting things about them, in either meagerest outline or scantiest specimen; and must do no more than offer a closing hint sufficient to induce young readers to look out for accounts of them in some of the popular books on animated nature.

Here is the ornithorhyncus, with bill like a duck and body like an otter. Here are kangaroos and opossums and wombats, with wide and odd diversities from one another, but all with a pouch for carrying their young. Here are oxen, sheep, camels, and other ruminants, with their four stomachs, their domesticating tendencies, and their economy of converting herb- 
age into the kinds of milk and flesh most suitable for human food. Here are the thick-skinned mammals, some of which, as the hippopotamus and the sea-cow, are most curious inhabitants of tropical rivers, while others, as hogs and horses and the elephant, possess qualities eminently serviceable to man. Here are the sloth, living suspended on trees; the armadillo, with its tesselated coat of mail; and some other odd anteating creatures, who have no incisor teeth. Here are mice, hares, beavers, and other numerous, small, harmless creatures, with a gnawing mode of feeding, and with strong, cunning, curious instincts. Here are the dolphins and the whales, with such exterior and habits as to look to the vulgar eye like fish, yet really constructed on the same general type as horses and cattle, and only adapted to live in the ocean, and to make very long dives in the intervals of taking breath at the suriace. Here are the beasts of prey, formed to seize other animals and to masticate their flesh, but with structure and habits of remarkable diversity,_-seals and morses living in the sea,-bears, of slow action, rearing conformation, and nocturnal life, -weasels and ferrets, worm-shaped in body and most bloodthirsty and bold,-Cats and dogs, powerfully domesticable, and the latter singularly sagacious, -and hyenas, panthers, tigers, and lions, the most awful terrors of the wilderness and the forest. Here are moles, hedgehogs, and other small shrinking creatures, of hidden life, feeding upon insects, and furnished with peculiar teetl and armature suited to their condition. Here are the bats, with membranes so woven over their long fingers and from limb to limb, as to enable them to fly and live like birds. 
Here are the lemurs, apes, baboons, and monkeys, with their four hands, their climbing cleverness, and their grotesque, ludicrous mockery of man in form and gesture. And here is man himself,-a single species, dispersed through all climes,- "made of one blood" through all the earth, and everywhere linked to higher worlds, not only by the possession of accountable and immortal mind, but by solemn need of the redeeming mercy of God through the Divine Saviour, and yet so prodigiously various in some of his highest physical conformations, and especially in his speech and customs, that the science of arranging him into his several classes is to the full as intricate as the science of classifying all the mammals. 


\section{CHAPTER XV.}

\section{THE ECONOMY OF ANIMALS.}

EPECIFIC LIFE-AGGREGATIONS OF CELLS-THE CIRCULATING SYSTEM

-BLOOD-RESPÍRATION-THE ALIMENTARY SYSTEM-THE TOOTH SYSTEM-SUMMARY VIEW OF OTHER THINGS IN THE STRUCTURE AND INTERNAL ECONOMY OF ANIMALS-DOMESTICATION-ANIMAL PROGNOSTICS OF WEATHER-MOULTING-MIGRATIONS-HYBERNATION-THE GREGARIOUSNESS OF BIRDS AND BEASTS-THE SOCIAL PRINCIPLE IN MAN.

THE fundamental wonder in the economy of animals is specific life. "Every organised body," says Cuvier, "independently of the qualities common to its tissue, has a form peculiar to itself, not merely general and external, but extending to the detail of the structure of each of its parts; and it is upon this form, which determines the particular direction of each of the partial movements that take place in it, that depends the complication of the general movement of its lifeit constitutes its species, and renders it what it is. Each part co-operates in this general movement by a peculiar action, and experiences from it particular effects, so that in every being life is a whole, resulting from the mutual action and re-action of all its parts. Iife, then, in general, presupposes organisation in general, and the life proper to each individual being presupposes an organisation peculiar to that being, just as the movement of a clock presupposes the 
clock; and accordingly we bchold life only in beings that are organised and formed to enjoy it; and all the efforts of philosophy have never been able to discover matter in the act of organisation, neither per se, nor by any external cause. In fact, life exercising upon the elements which at every moment form part of the living body, and upon those which it attracts to it, an action contrary to that which, without it, would be produced by the usual chemical affinities, it seems impossible that it can be produced by these affinities; and yet we know of no other power in nature capable of re-uniting previously separated molccules. The birth of organised beings is, therefore, the greatest mystery of the organic economy and of all nature; we see them dcreloped, but nevcr being formed; nay more, all those whose origin we can trace have at first been attached to a body similar in form to their own, but which was developed before them-in a word, to a parent."

Another wonder is the development of the body, the building of the frame, the forming and maturing of the system, of each individual animal. All this is done by the aggregation of cells, and by the subsequent action of the fibres and laminæ into which they are aggregated. But how immenscly diversified is it in the different spccies, how amazing in the simplest, and how prodigiously admirable and inconceivably complicated in the higher! Multitudes of cells are ela* borated into the tissues and stomachs and secreting organs of the microscopic animalcule. Millions are worked into the fibres and flesh and vesscls and membranes and integuments of the tiniest insect. Difier-. ent combinations of them deposit the rock of the 
corallines, fling off the phosphorescence of the seanettles, form the external skeleton of the crustaceans, and fashion the mantle. or the shell of the molluses. How prodigious, then, must be the myriads, the various arrangements, the ultimate powers of those which build up the muscles and ressels and ligaments and cartilages and bones of any one of the reptiles or birds or mammals!

Another wonderful thing is the circulating system. This cannot be discerned in the lowest kinds of animals, but is very plain in worms and spider's, and becomes increasingly outspread and ramified in the higher and higher orders. It carries nutritive fluid in continual diffusion, in a system of cylindrical vessels, through all parts of the body, and makes deposits of that fluid at every one of the million points which require additions to their organism or repair of their substance. It moves from a centre to the extremitics in one set of vessels called artéries, and back from the extremitics to the centre in another set called veins; it performs its course variously in one, two, and three circles; and, in all the higher orders, but most elaborately in the highest, it is kept going at great velocity by the powerful, ever-acting, complex engine of the heart. The ramifications and networks and lateral communications and functional forces of its vessels, in every animal, and especially in every mammal, are great and wondrous, far above any ordinary thinker's conception. So minute and manifold are they in man, that a needle's point can nowhere be driven through his skin without piercing one, and letting out its blood; and so powerfully do the large ones near the heart do their office, that the 
blood travels through them at the rate of nearly nine thousand feet in an hour.

Another wonderful thing is the blood. This, in insects, is a whitish fluid; and in all the backbonebodied animals is red. . In fishes and reptiles it is cold; and in birds and mammals, is warm. In every case, red blood is formed from liquid silling into the veins from digested food, and contains all the elements and principles requisite to build and sustain the whole frame, but is liable to mighty modifications by bad feeding and morbific influences. It comprises a thin. serous fluid, which goes easily off at all points of the body to form juices and exhalations, and a much thicker and heavier substance, which has a disposition to coagulate, and trickles slowly out to form flesh and the other solids. All red blood contains the beginnings of life, or is the state of things in which the inorganic product of feeding becomes animated; and it therefore truly lives. When any of it, especially the thick portion, fresh drawn from a living animal, is examined through a magnifying-glass, it is seen to contain multitudes of small globules, of character corresr onding to the elementary cells of organic being; anc the liealthier it is, it contains the more. But it stonds only a brief time till it loses them all,-,or, in othor words, sustains the effects of the loss of life.

Anoulher wonderful thing is respiration. This consists in taking in atmospheric air, combining the oxygen of it with the blood, and giving back nitrogen, carbonic acid, and, in the case of land animals, watery vapour. Part of the oxygen unites with carbon and with hyo drogen in the blood to form the carbonic acid and the watery vapour which are ejected,-and, in doing 
this, it both generates the heat requisite for the whole living body, and abstracts what otherwise would speedily become a suffocating load in the system; and probably part also, in several ways, prepares the permanent blood for making its many different kinds of nourishing deposit in the course of the arterial circulation. The respiration of the low aqueous animals seems to be carried on by the simple process of absorbing water with its contained air, and ejecting liquid with the refuse-gases. That of insects is little more than an internal ventilation through elastic vessels called tracheæ. That of fishes is effected by a constant pumping flow of water from the mouth over the surface of the series of delicate filaments, called gills, which are protected by a covering, and communicate outwardly by apertures behind the head. And that of birds and mammals is carried on by inhalation and exhalation through a windpipe, and by the affusion of the inhaled air over the large outspread surface of the two soft, spongy, elastic lobes called lungs, situated in the cavity of the chest. The mechanical part of the process, in the last case, is effected by the action of the ribs and the diaphragm. "In the natural state, the ribs are inclined downwards, and when this series of moveable hoops is raised by the action of the muscles, the cavity of the chest is enlarged. The descent of the diaphragm by its contraction increases this effect, and the air therefore rushes in to fill up the vacant space; the ribs then descend, and the diaphragm rises, and the air is necessarily driven out in consequence of the resulting contraction of the chest. About twenty respirations take place in a minute, and from thirty to forty cubic inches of air are in- 
haled at each inspiration. A man consumes about a gallon of air in the same timc."

Another wonderful thing is the system of nutrition. This comprises vessels and functions for taking in food, digesting it, and giving off its alimentary results to the blood. The organisms constituting it or connected with it are a prominent part of the interior of all animals. A feeding tube and a containing central cavity cxist in the gelatine or organised pulp of the very zoophytes. Several stomachs are observed in a large class of animalcules. An intricate digestive laboratory can be seen in worms and larve and molluses. And a complicated alimentary canal, consisting of many parts, and expanded or ramified or convoluted in its progress into great bulk, traverses the trunk of all the higher animals from mouth to base. The diversities of the organs, too, in form and number and comparative size, are many and great according to the different modes of feeding and the different kinds of food. Serpents take several days or even weeks to digest one meal; while birds and mammals take only a few hours. Herbivorous mammals have great length of intestines, and a large abdomen to contain them; while carnivorous mammals have short intestines and a small abdomen. The ruminants have four stomachs, and throw up their food bit by bit to re-chew it; while other quadrupeds have only one stomach, and dispose of their food in a single process. All the different sorts of animals, also, mouth their food in different ways, and have modifications or actions of the alimentary canal more or less peculiar. But man's system of nutrition may serve well to illustrate the system of nutrition in 
them all. "In his mouth, the food is subjected to the mechanical action of the teeth, and is mixed with the secretions of several neighbouring glands. It is then transferred to the stomach along the gullet. In the stomach it remains for some time, where it is subjected to the action of the fluids of that organ, and converted into a pultaceous mass termed chyme. This gradually passes into a cylindrical canal, the intestine, in the first portion of which it meets with the bile from the liver, and with a fluid furnished by another large gland called the pancreas. After this a white milky-like fluid, the chyle, is separated from the general mass, and is drunk up by the innumerable vessels which open on the surface of the intestine as it passes along. Having traversed the long winding canal, the smaller intestine, and the nutritious particles having been absorbed, the mass is next transferred to the large intestine, termed the colon, where the last efforts are made to abstract nourishment from it; and lastly, the remainder, when time and opportunity are convenient, is rejected. The chyle, on being taken up by the absorbent vessels opening on the internal surface of the intestinal canal, is conveyed by these vessels through a number of small glands, after which it is collected into a receptacle, from which it is conveyed by a tube through the chest, and poured into the great veins, as they are proceeding to the right side of the heart. From the commotion to which it is exposed by the concussion of the right side of the heart, it is intermixed thoroughly with the venous blood, and propelled to the lungs, where it is perfected into arterial blood."

Another wonderful thing is the tooth system. "The 
teeth," says $\mathrm{Dr}$ Aitken, the writer from whorn we quoted in the preceding paragraph, "present great diversities in form, number, situation, and the purposes to which they are subservient in the different tribes of animals, - - so much so, that naturalists have selected them to furnish characters for the distribution of mammalia into orders and familes. Some of the mammalia are without teeth, as the ant-eaters and armadilloes. In some of the whale tribe, they consist of a series of horny plates proceeding from the upper jaw, well known under the name of whalebone. These plates are placed vertically, present sharp edges externally, which overlap each other like tiles, their internal edges being furnished with long hair-like fringes, which serve as sieves whereby they entangle the food on which they subsist. The whole class of birds are devoid of teeth. Their bills are variously modified for seizing or tearing their food; but, where it is necessary that it should be subjected to trituration, their stomach or gizzard is furnished with powerful muscular apparatus, lined with a hard insensible horny covering; and, in order to aid in the reduction of the food, they instinctively swallow pieces of quartz and other hard substances.

"The teeth of venomous serpents present the most deadly weapons with which animals are furnished. The poison fangs are of a curved form. When the animal is tranquil, they are retracted by an elastic ligament, like the claws of a cat; but when it is about to inflict a wound, they are erected by a muscle; they are also provided with a tube, opening by a fissure, through which the poison, secreted by a peculiar gland, is injected into the wound. 
"Teeth in carnivorous animals, such as the lion, tiger, \&c., are dreadful weapons; so are they in the wildboar. The elephant employs them as means of defence. In the narwhal or unicorn, a single tooth only is in general developed, its fellow being rudimental; it is remarkable for its length and spiral form, and has been conjectured to serve as a weapon. These powerful tuslss in the elephant, narwhal, and walrus, are only fully developed in the male, the female having them in a rudimentary state. These animals are all gregarious; and the defence of the herd falls principally upon the males, which are thus armed accordingly.

"In carnivorous animals, their food not requiring trituration, the teeth are adapted for seizing their prey, for lacerating and tearing it to pieces; they are conical and pointed, and lock into each other, so that their points do not come in contact, and thus preserve their sharpness. In the squirrel, the beaver, rats, mice, \&c., there are two long cutting teeth in each jaw, furnished with a thick deposit of enamel anteriorly, but devoid of it posteriorly, the bony portion behind being more easily worn down than the anterior enamel. The edge is preserved in the proper degree of sharpness; they exactly resemble chisels, and although they may be employed for years in gnawing very hard substances, in opening nuts, or in felling forest trees, yet they never become blunted. Besides these chisels, animals of this order are furnished with grinding teeth for properly reducing their food.

"Granivorous and herbivorous animals are supplied with cutting teeth in both jaws, as in the horse; or they are confined to the lower jaw, as in oxen, 
sheep, and deer. The former seize upon their food as with two rows of nippers; the latter, with the aid of the lips, tongue, and dense gum of the upper jaw, cut the grass close to the ground while browsing in the fields. They possess, besides, a series of excellent grinders, whereby they reduce their food to a minute state of mechanical division, and thus prepare it for being more readily acted upon by the organs to which it has subsequently to be presented."

In their composition, too, as well as in their form, the teeth of different kinds of feeders are so nicely adapted to the different kinds of feeding, that a thoroughly intelligent naturalist, on finding merely a bit of one, can accurately infer from it the precise class and character, or entire form, organisation, and habits of the animal to whom it belonged,--even though that animal were one of a race who can be traced in only a fossil condition, and all perished many cycles of ages before the creation of man.

Many other things in the structure and internal economy of animals, are quite as wonderful as those we have noticed; but we can take space to indicate only the chief of them, and in the briefest terms. One is the apparatus of prehension,- - the means of seizing food and putting it into the mouth,-varying from the feeler of the polype to the proboscis of the elephant and the hand of man. Another is the adjustment of the skeleton, endlessly diversified and everywhere admirable, whether in the silicious envelope of animalcules, in the articulated coats of crus. taceans and insects, or in the spine and skull and ribs and limb-bones of the vertebrated animals. Another is the wide varieties and striking adaptations 
$\sigma_{2}$ the forelimbs of mammals, apparent in such instances as the paddles of whales, the hook-handed arms of sloths, the spade-like paws of moles, the wings of bats, and the powerful clutching fore-feet of beasts of prey. Another is the muscular system, its power, its contractility, and its simple, perfect, mighty adjustments to each of the prodigiously numerous kinds and forms of supporting skeleton. Another is the systcm of skin or integument, so immensely various in different classes, so prodigiously furnished with applianccs of protection without and of vital function within, and so millionly perforated with pores and tubes for the curious processes of absorption and exudation. Another is the system of glands, all more or less similar to kidneys, yet of millions of kinds in different animals, and of many kinds in one animal, for the forming of all sorts of secretions, such as tears, bile, musk, and milk. Another is the nervous systcm, from its lowest traces in the least sentient animals, up to its highest developments in connection with the spinal cord and the brain, comprising a range of wonders which has much to do with several of the highest sciences, and lies partly, or perhaps mainly, beyond the ken of them all. Another is the system of vision, with the apparatus of eyes, discernible in some very small animals, amazingly complicated in some insects, and one of the grandest of all sub. jects of philosophy in birds and beasts and men. Another is the sense of touch, so exquisite in most. needful parts where an unreasoning observer would scarcely expect it to at all exist, as in the whiskers of cats, the disc of the snout of hogs, the finger of the proboscis of elephants, and the entire skin 
of the body of men. Another is motion, its many kinds, its many apparatuses, its amazing velocity in the flight of some birds, its amazing force in the leaps of some insects, and its amazing persistence in the activity and longevity of some quadrupeds. Another is reproduction, the various methods of it from the lowest orders of animals to the highest, generation, gestation, foetal life, the birth and infancy of the born-. alive, the constitution of eggs, and the development and hatching and rearing of young fishes and reptiles and birds. And another is the play of mind-not soul or moral sense or strictly reasoning intelligence, for that is peculiar to man-but mind in the lower animals, - will, instinct, sympathy, memory, teachableness, and sagacity, - a subject which might be illustrated by volumes of tales as entertaining and almost as marvellous as those of the Arabian Nights.

Crowds of wonders present themselves in the subserviences of living animals to the uses of man. These appear in thousands of ways, not only in animals whose substance is good for food and clothing, but in those whose carcases are useless. Dogs, for example, serve a hundred purposes of amusement and protection. The dogs of the hospice of St. Bernard, near the line of perpetual snow, on one of the great passes through the Alps into Italy, are famous for discovering - fallen travellers among the snow, carrying to them cloaks and food, rousing them from deadly torpor, and conveying them safely to the hospice. One of these dogs restored a frozen child to animation, and bore him away on his back to the hospice; and the same animal, during his career, saved the lives of twenty-one 


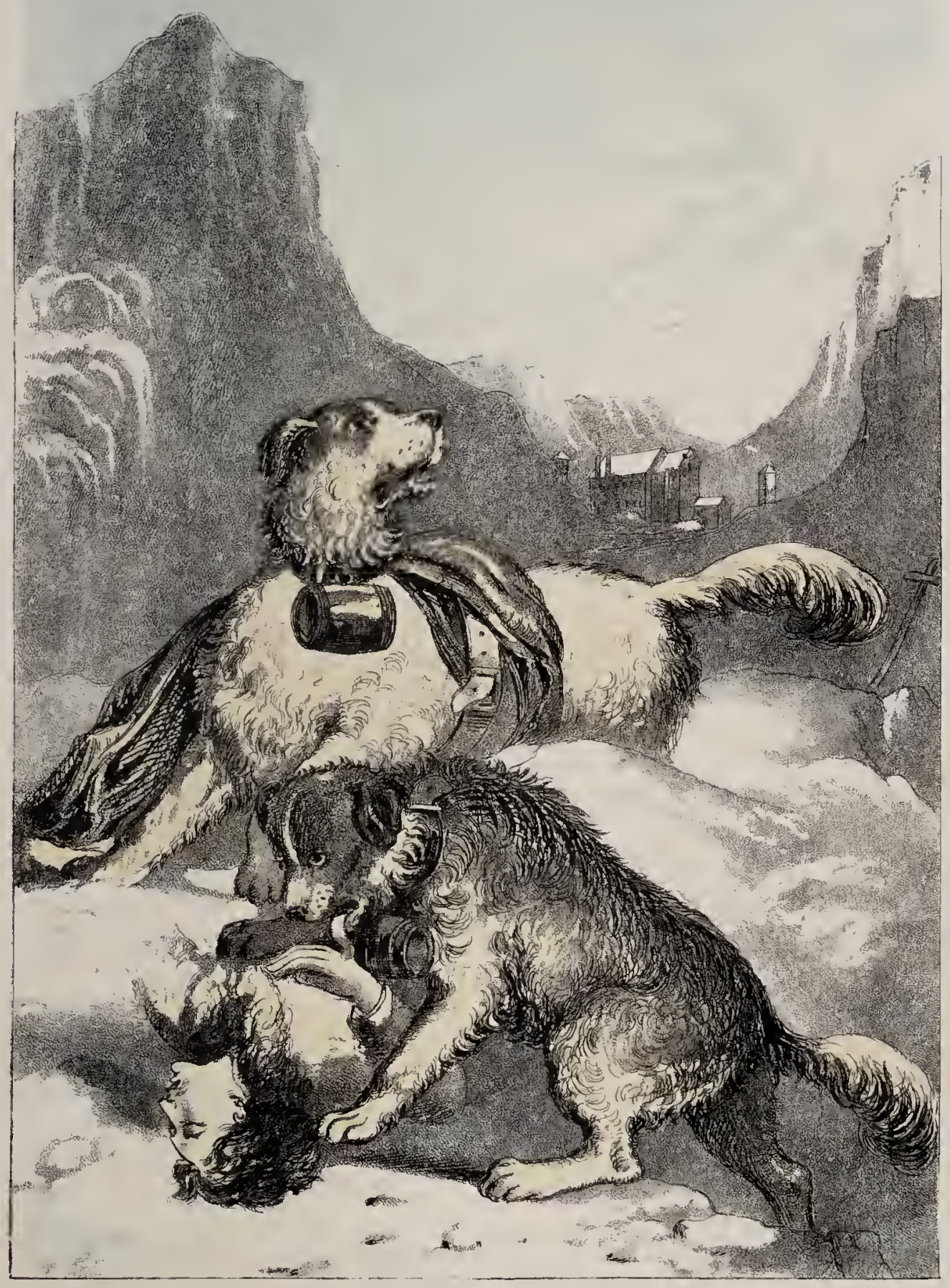

DOCS OF STBERNARD 

other persons who, but for his aid, would have perished in the snow.

Many wonderful things likewise exist in the changes which are effected in the higher animals by domestication. Great are the marvels, though none but curious or interested eyes observe them, which the Divine beneficence has ordained to be worked on the forms and habits and values of the finest birds and quadrupeds by the instrumentality of the moulding hand of man. The most luscious and various apples of the orchard do not differ more from the sour crabs of the forest than the many improved domestic brecds of sheep and oxen and horses differ from even the best of wild cattle. There are curious things, too, in the habits of animals which have been turned loose from a domesticated state into the forest, and cspecially in the habits of vast wild flocks of their descendants. But we must pass by all these matters, and many others, in order to leave space for a few paragraphs on the external economy of animals, in their relations to the weather, their migrations, their hybernations, and their gregariousness.

Many animals, through the influence upon them of temperature, humidity, and electricity, are strongly affected by vicissitudes in the atmosphere. Hence have men, in all ages, made observations on certain acts of animals as a very sure and instructive kind of weather prognostics. A summary view of the chicf of these in Britain we have given as follows, in the article Weather, in the Rural Cyclopædia:-

"When rain is approaching, horses and cattle snuff the air, and congregate in corners of ficlds with thcir heads to leeward, or seek shelter in sheds,-oxen lick 
their forefeet,-sheep reluctantly leave their pastures, - goats seek sheltered spots,_-asses frequentlybray and shake their ears,-_dogs are apt to become very sleepy and dull, and to lie all day before the fire, showing a reluctance to all kinds of food except grass,-cats turn their backs to the fire, and wash their faces,pigs cover themselves more than usually in litter,-rats and mice are more than usually restless, and forsake the fields and ditches,-cocks crow at unusual hours, and often flap their wings,-_hens chuckle,_ducks and geese are unusually clamorous, and fly backwards and forwards, and frequently plunge into water,- - pigeons wash themselves, and return slowly to their houses,peacocks squall loudly from trees,-the guinea-fowl makes a constant grating clamour,-sparrows chirp loudly and clamorously, and assemble in crowds on the ground or in the hedge,- - swallows fly low, and skim their wings in water,- - the carrion-crow croaks solitarily, and is late in roosting,-water wild-fowl oftener than usual dip and wash,-moles are busier than usual in throwing up their hills,-frogs croak more than usual, and toads issue from their retreats in great numbers,-bats begin to squeak and enter houses,- - the singing-birds take shelter,-the robin approaches very near the dwellings of man,- - tame swans fly against the wind,-bees cautiously leave their hives, and fly but short distances,-ants are busily engaged in carrying their eggs,-flies severely sting, and become troublesome,-numerous earthworms crawl about on the surface of the ground,the larger sort of snails appear,-and all sorts of insects are more than usually stirring.

"When fair or fine weather is approaching, or may 
be expected to continue, cattle lie in the open field or in the courts instead of the sheds,--sheep lie on the brow of a knoll during the night,-_pigs lie down for the night on the top of their litter,-peacocks roost on the tops of houses,-the raven sails round and round high up in the air,_-singing-birds carol till late in the evening,- the corn-crake utters his peculiar cry among corn or grass,- the partridge calls in the evening to his mate,-kites hover high in the air,-larks rise high and sing long, - redbreasts sing loud in the open air,-small flies flock together in great numbers about the beams of the sun a little before it sets,snipes boom in the air during the evening,-gnats form a vortex in the shape of a column,- -spiders' webs are on the ground or float in the air,-bats fly more numerously than usual, and early in the evening,-and glow-worms appear in unusual numbers.

"When high winds are approaching, cattle frisk and jump and toss their heads, - sheep frisk and leap and box one another in sport,- - hogs squeal, and carry straw in their mouth,- - cats scratch trees or posts,geese expand or flap their wings, and seem as if trying to fly,-pigeons, in flying, smartly clap their wings behind their back,-crows make somersets in the air, and at the same time are unusually noisy,magpies assemble in small flocks, and utter a chattering noise,-and swallows fly in the leeward side of trees. And when a storm or tempest is approaching, porpoises come in great numbers near the shore,sea-gulls come in flocks on the land, and make a noise upon the sea-board,- -and the merle-thrush, popularly called the storm-cock, sings loud and long."

Many beasts and birds have variations of dress 
suited to climates and seasons. The dogs and sheep of inter-tropical countries are almost naked; while those of the north of Europe have long, thick coverings. Even the sheep of England are clothed only with wool, while those of Shetland and Iceland have the additional protection of interspersed long hairs. And the cattle and horses on low sea-board districts, where the climate is comparatively mild, have a shorter and thinner fur than the same breed of cattle and horses in contiguous high inland districts, where the climate is comparatively sharp. But beasts, both tame and wild, of any one district, acquire an increase of fur on the approach of winter, and throw off all that increase on the approach of summer; so that the same creatures are shaggy in January and sleek in July. And, what very strikingly manifests the Divine beneficence in the exact measure of their clothing, they undergo their changes of dress differently in different years according to the difference of temperature, and are always more thickly clothed in a severe winter than in a mild one, and more thinly in a hot summer than in a cold one. In some cases, also, the colour of the dress undergoes a change from pure white, which hinders the heat of the body from being abstracted by the frosty air in winter, to some tint which maintains a suitable balance of temperature with the hotter air of summer. Thus, the fur of the ermine and the fur of the alpine hare are as white as snow in the dead of winter; while, in the heat of summer, the former is pale reddish brown and the latter tawny grey. And similar is it with the moulting of stationary birds. A total moult generally takes place once a-year; and a partial moult accompanies the 
clange of tints in the plumage, which certain species undergo at the time of breeding. A new dress is developed at every moult, suited in density and character to the needs of the approaching season; and in many species the dress of winter has, either partially or totally, a different colour, or different sets of colours, from the dress of summer.

Some quadrupeds, in order to accommodate themselves to change of temperature and supplies of food, make periodical or occasional migrations. The lemming rats of the north of Europe, when a severe winter is approaching, migrate in prodigious numbers southward, always proceeding in a straight line, and never allowing themselves to be stopped by lake or river or other hindrance. The bisons of the North American prairies, and the herds of wild horses in the south, sometimes in great numbers, make long journeys. And the rein-cleer of Siberia spend the months from the end of May till midautumn in the plains contiguous to the sea, and then return in many companies, of each from two hundred to three hundred, arrayed in a grand column about fifty miles broad, to obtain winter food and shelter in the forests of the south.

But animals who move in air or water encounter greatly fewer obstructions to travelling than land quadrupeds, and therefore present vastly more numerous instances of migration. The great bats who inhabit England in summer go to Italy in autumn, and remain torpid there during winter. The seals who spend the summer on the coast of Greenland, spend the winter round the shores of Iceland. The cod-fish move in vast multitudes, about the month of May, 
from the northern seas toward Newfoundland. Shoals of herring, mackerel, pichard, anchovy, and other seafishes, make great periodical movements from region to region, or from deep sea to shallow. Salmon, and some other river fish, have totally different homes and haunts at one season of the year than at another. And even clouds or armies of aphides, locusts, ants, and other insects, at certain seasons or in certain circumstances, travel from place to place with a power of combination and an obstinacy of purpose which no efforts of man, and none but the most tremendous outbursts of storms, can thwart.

But birds are the grand migrators. They have been observed in every country to be present at one season and absent at another. Men, in the earliest times, marked and marvelled at their periodical jourweys. Sunrise and new-moon were regarded by the ancient Israelites as not more sure than the annual advent of certain birds. "For," said one of the prophets, "the stork in the heavens knoweth her appointed times; and the turtle and the crane and the swallow observe the time of their coming." All birds are keenly affected by temperature, and most can find food only where it lies fully exposed to them,- the leaf on the tree, the fruit on the shrub, the seed on the herb, or the larva on the ground,--so that they are necessarily carried northward at one time and southward at another, on the great annual tidr of the seasons. "Birds of passage" is just as household a term as "birds" itself.

Some birds are much hardier than others, and migrate either within a comparatively small range, or only on extraordinary emergencies of cold or scarcity. 
A few of our British ones have quite range enough within our own island; and several who make considerable migrations in lofty inland regions of any given mean annual temperature, where the difference between summer heat and winter cold is great, make none whatever in low maritime regions of the same mean annual temperature, where the difference between summer heat and winter cold is less. In the winter of 1821-1822, which was very mild in the middle of Europe and unusually cold in the north, many birds who scarcely ever quit Scandinavia made their appearance in Germany, and some birds of Bohemia went to Switzerland; and in the following winter, which was much colder in Germany than in Sweden, some birds who commonly winter in the former country wintered in the latter.

Birds who statedly migrate every year have been very generally supposed to come and go, not so much under exigencies of temperature and food, as with some mysterious reference to precise points of the calendar. But they really act on just the same rule as the more occasional migrators. "The periods of arrival and departure, even in the same species," says Dr Fleming, "do not always take place at exactly the same day or even month of the year. In different years these vary several weeks or even months, and evidently depend on very obvious circumstances. The meanest rustic, in regard to the summer birds of passage, is aware that cold weather prevents the arrival of these messengers of spring; and that the early arrival of our winter birds of passage indicates a proportionally early winter. The same circumstances of temperature which retard our summer visi- 
tants, also check the progress of regetation. Hence, in all probability, we might be able to prognosticate the arrival of these birds, by attending to the time of the leafing or flowering of particular trees or plants. As the state of vegetation depends on the temperature of the season, and the life of insects on the state of vegetation, we may safely conclude that the movements of the phytivorous and insectivorous birds must be dependent on the condition of plants."

About four-fifths of all the known kinds of birds migrate; and the large majority of these travel considerable or great distances. When the sun approaches the northern solstice, birds then in the north temperate zone migrate toward the arctic circle, birds then in the tropics migrate into the north temperate zone, birds then in the south temperate zone migrate to the tropics, and birds then in the antarctic regions migrate into the south temperate zone; and when the sun approaches the southern solstice, birds then in the arctic regions migrate into the north temperate zone, birds then in the north temperate zone migrate to the tropics, birds then in the tropics migrate into the south temperate zone, and birds then in the south temperate zone migrate toward the antarctic circle. Such at least is the law of the migrations. They take place twice a-year, and all in one direction in both hemispheres: either all northward during the sun's northern declination, or all southward during his southern declination. But some kinds of birds travel at widely different times from others, and go to far greater distances, and make far longer residences,some in their summer quarters, and others in their winter ones. And many of the most loved sunmer- 
birds of Britain-both the richest in song and the gayest in plumage, such as the nightingale, the blackcap, the yellow wagtail, and the marten-are known to spend their winter months in the Mahomedan or heathen regions of Africa. Hence has one of our poets beautifully said,

" ' Ye birds, whose wing like the lightning's ray

Just dazzles the eye, then away, away!

Why will ye fly from our peaceful isles, 0 'er the fitful waves for a stranger's smiles?

Ungrateful birds! how like to the rest Of this fickle world is your callous breast;

All mirth and song in the summer day, But one tear, one cloud, then away, away.?

' Ungrateful birds! Oh call us not so, 'Tis our love, our thanks, to display we go; Grateful and glad we follow the star, In whose light we live both here and afar.

Like us, do thou leave the world's gay bowers; To dwell with thy God, quit thy choicest flowers:

Leave all thou lov'st, to display His power To minds as dark as the midnight hour.

Haste to the land of thraldom, and chant Of the Holy One, till dark bosoms pant Through faith to gain the glorious prizeAn unfading crown in yon lovely skies." "

Some birds, such as the swallow, the lark, the goldfinch, the woodpecker, the wren, the titmouse, and the crow, perform their migrations by day; othe:'s, such as the owl, the woodcock, and the blackbird, perform them by night; and others, such as the swan, the crane, the stork, the plover, the yellow-hammer, and the wagtail, perform them both by day and by night, 
moving continuously on. Most, unless when obliged by fogs to keep near the ground, fly very high. Some of the fishing-birds shape their course over the sea, and pick up food from the waters while on their journey; and some of the land-birds shape their course over forests, and occasionally seek rest and refreshment on trees; but many even of slender frame and seemingly feeble power.move straight to their destination, and seem never to relax a feather till they have reached it. Some of heavy flight, such as the moor-hen and the rail, travel partly on foot; and others, such as the penguin, the diver, and the guiliemot, take ample assistance from the water; but the far greater number, whether taking occasional rests or not, achieve on the wing very wondrous distances in a very wondrously small number of hours. Yet all have more or less the-sagacity to wait for a favourable wind, and are powerfully helped by it; and most also fly in enormous flocks, and may be supposed to derive advantage, by sympathy and good offices, from their union. A single migrating flock of the passenger-pigeons of North America has been computed to include upwards of twenty-two hundred millions of individuals.

"It is often stated, as a matter of surprise," remarks Dr Fleming, "how migrating birds know the precise time of the year at which to execute their movements, or the direction in which to migrate.

- Who calls the council, states the certain day?

Who forms the phalanx, and who leads the way?'

But this is merely expressing surprise that a kind and watchful Providence should bestow on the fea- 
thered creation, and other migratory animals, powers and instincts suited to their wants, and calculated to supply them. How, we ask, does the curlew, when perched upon a neighbouring moor during the flowing of the tide, know to return at the first of the ebb, to pick up the accidental bounty of the waves? How are the sea-fowl, in hazy weather, guided to the sea-girt isles they inhabit, with the food to their young, which they have procured at the distance of many miles? "The inhabitants of St Kilda,' says Martin, 'take their measures from the flight of these fowls, when the heavens are not clear, as from a sure compass; experience showing that every tribe of fowls bend their course to their respective quarters, though out of sight of the isle. This appeared clearly in our gradual advances; and their motion, being compared, did exactly quadrate with our compass.' The proper answer to all such questions is- "Their God doth instruct them to discretion." "

Many kinds of animals, on the approach of winter; instead of getting warm clothing or removing to a warmer climate, feed themselves into fat condition, adopt measures to keep out the cold, and fall into long, profound, and almost unbreathing sleep till spring. Spiders take meshes of their webs about them, and lie up in some obscure corner as dormantly as if they were dead. House-flies and late-fledged butterflies curl themselves up in warm nooks as snugly and motionlessly as if they had again become pupæ. Snails retreat to crevices of rocks and apertures in walls, and there retire within their shell, and form an adhesive lid over its mouth, and fix 
this with air-tight closeness on the rock. Reptiles bore into mud, or penetrate holes or crevices, far enough to be away from cold, and there become torpid. And bats, dormice, the hamster, the hedgehog, the alpine marmot, the jumping mouse of Canada, and some other small mammals, select retreats in grottos, excavations, outhouses, thickets, or similar places, line them well with grasses, mosses, or herbage, and lie down in them almost as if lying down in graves,_-becoming so stiff and cold and lightly breathing that an observer, ignorant of their condition, would certainly believe them to be dead. They sleep so fast that a very great dcgree of violence will scarcely or not at all awake them; and they so essentially need their death-like sleep that, if repeatedly aroused by any extraordinary mcans before the arrival of spring, they die.

A remarkable instinct of many animals is their gregariousness. They live in flocks or communities, and travel or work together in companies or armies. Many insects, as was remarked in our former chapter, and especially ants and bees, as has been wonderingly remarked by all classes of men in all ages, display more social order than some of the best constructed, best governed, and most enlightened greatorganisations of men. Shoals of fishes also are simply vast orderly travelling societies. And migratory birds, before commencing a flight, marshal their numbers as regularly and skilfully as ever human warrior marshalled an army, and then proceed to their destination with a steadiness of array which no marching human army ever equalled. Cranes, for example, call on one another by certain cries several days before they depart, 
and gradually congregate at a place of rendezvous, and there make a great noise as if in consultation, and then arrange themselves in two lines converging to an angle. And their leader takcs station at the angle, and conducts them off; and afterwards gives them orders to form a circle in a tcmpest, to guard against approaching eagles, to descend and take food, or to behave in any other way suitable to emergencies; and when he becomes tired, he falls back into the line, and the bird ncxt him takes his place. And during their progress they utter keener cries in the night than in the day, and seem then to be passing words of command for their proper guidance in the dark.

Rookeries are a notable instance of birds living together in well-organised societies. But there are vastly grander instances of several kinds of aquatic birds living in immense colonies, more densely and harmoniously than the mixed multitudes of men in any great sea-port cities. And one of these, on an insulated rock in the Faroe Islands, visited by the traveller Graba, and situated in a most sequestered nook, may be sclected as a spccimen of many thousands in the wcstern seas. "This rock," says the Rev. Thomas Milner, "lies in a frightful chasm in the precipitous shores of the island, which rise to the height of a thousand feet, only accessible from the sea by a narrow passage. Here congregate a host of birds. Thousands of guillemots and auks swim in groups around the boat which conveys man to their domain, look curiously at him, and vanish beneath the water to rise in his immediate neighbourhood. The Black guillemot comes close to the very oars. The seal stretches his head above the waves, not comprehend- 
ing what has disturbed the repose of his asylum, while the rapacious skua pursues the puffin and gull. High in the air the birds seem like bees clustering about the rocks, whilst lower they fly past so close that they might be knocked down with a stick. But not less strange is the domicile of this colony. On some low rocks scarcely projecting above the water sit the glossy cormorants, turning their long necks on every side. Next are the skua gulls, regarded with an anxious eye by the kittiwakes above. Nest follows nest in crowded rows along the whole breadth of the rock; and nothing is visible but the heads of the mothers and the white rocks between. A little higher on the narrow shelves sit the guillemots and auks; arranged as on parade, with their white breasts to the sea, and so close that a hailstone could not pass between them. The puffins take the highest station, and, though scarcely visible, betray themselves by flying backwards and forwards. The noise of such a multitude of birds is confounding; and in vain a person asks a question of his nearest neighbour. The harsh tones of the kittiwake are heard above the whole, the intervals being filled with the monotonous note of the auk, and the softer voice of the guillemot. When Graba visited the place, he was tempted by the sight of a crested cormorant to fire a gun; but what became of it, he remarks, it was impossible to ascertain. The air was darkened by the birds roused from their repose. Thousands hastened out of the chasm with a frightful noise, and spread themselves in troops over the ocean. The puffins came wandering from their holes, and regarded the universal confusion with comic gestures. The kittiwakes remained composedly in their nests; whilst 
the cormorants tumbled headlong into the sea. Similar great congregations of the feathered race appear where the shores are rocky, high, and precipitous; but this is strikingly the case where

"The northern ocean in vast whirls

Boils round the naked melancholy isles

Of farthest Thule; and the Atlantic surge .

Pours in among the stormy Hebrides.

Who can recount what transmigrations there

Are annual made? what nations come and go?

And how the living clouds on clouds arise?

Infinite wings! till all the plume-dark air

And rude resounding shore are one wild cry."

The many kinds of quadrupeds who live in herds or flocks display the social instinct very strikingly, and in a great variety of ways. All the individuals of a herd know one another, and are mutually attached. They have perfect sympathy among themselves, but no sympathy whatever with the members of other herds, or with any isolated wanderer. They regard their feeding-ground as their peculiar property, - common to all their own number, but sacred from the touch of others; and they promptly unite to repel or punish any intrusion on it by beasts of their own species, as an impudent and intolerable injury. Any stray stranger who seeks to be admitted to their fellowship must hover long and cautiously at a distance from them, and make his approaches very slowly and submissively, before he has the least chance of success, and may after all get a very rough reception, or be trundled off, and compelled to flee. All the herd follow a leader who has proved himself to be the strongest or bravest or most sagacious of their number; and at 
every moment of emergency, or on every occasion for joint action or a common movement, they confide in him, and obey him as hastily as ever human army did a Cæsar or a Bonaparte. A herd of wild horses of South America, for example, follow their leader to war, and obey his signals of advance or onset or retreat with as warm a devotion and as prompt a will as if all lived in his life and thought in his thoughts; and, if he should fall in the fight, they disperse in wild panic, and flee all at random.

Some quadrupeds, such as the beavers of North America, live so very socially as to form conjoint habitations, and lay up conjoint stores of food. In summer, the beavers roam about in families, and feed at large in the forest; but in autumn, even while continuing to enjoy warmth and plenty, they concentrate into flocks, and begin to make preparation for the severity of the approaching winter. Old flocks may not need to do more than repair their former winter abodes; but new oncs go through a kind and an amount of work wonderfully similar to the founding and building of a commercial town. "In selecting a convenient spot, they seem always to secure a sufficient depth of water for keeping their store of wood soft, and for securing a ready egress under the surface when needed, while they require a current towards the spot to aid them, in the first instance, in the transport of their stores. The store is situate either on the margin of a lake or river; and in the latter case, where the stream is small, a dam is formed across by branches, stones, and mud, of sufficient strength to resist ordinary floods and ice. Into this wet dock they collect the trees which they have cut 
down, and which they bring up to their cabin as they are required. The cabin itself is an excavation in the bank, the floor of which is highest in the middle, to secure a dry sleeping-place. The principal opening is under the surface of the water, while a smaller one, next the land, admits the requisite supply of air. Their houses have seldom more than one apartment, and contain from ten to twenty inmates; and occasionally there may be seen twenty or thirty such houses forming a beaver village."

Men, too, are social beings; and, in some instances, they do not act much differently from wild horses and beavers. They are the highest kind of animals, and have correspondingly high animal instincts. The line between their instincts and their reasonings is often so hid by the blendings or co-operations of the two, as to be utterly imperceptible; but, in all cases where little or no social improvement goes on, it can beclearly seen. Instinct serves only definite purposes, and neither acquires increase of its own power nor communicates from individual to individual any fruits of experience. What it is in any race of animals now, or what it will be at the remotest futurity, that it has been all along since ever they were created. In infancy and in idiocy, men act on the sheer instincts of self-preservation; and in all social intercourse which aims only at the indulgence of their appetites, and involves no progression of the intellect, they act on the sheer instinct of animal gregariousness. Savage nations remain low and stationary in character; and grovelling groups of men in civilised lands, who never labour for one another's enlightenment-no matter how many or hearty or vigorous may be their social 
usages-act in essentially the same way as ants and bees and beavers and wild horses, and do very little more than display a higher degree of gregarious instinct corresponding to the higher nature of their animal conformation. And if they are ingenious enough to use narcotics and pamperings and luxuries, in order to heighten their physical enjoyments, they simply prostitute their reason to overdo and abuse the offices of instinct. Brutes are less brutal than such men,_- "whose end is destruction, whose god is their belly, and wliose glory is in their shame, who mind earthly things."

But men are more than animals. They have another nature, as different from their animal one as the viewless seraph is from the hideous reptile. This is not an adjunct of their organisation, still less a power or property of it, but a thing distinct from it, and inconceivably superior to it, and destined to exist in a condition closely akin to that of angels. It differs totally from instinct. It reasons, develops, and is capable of indefinite improvement. It feels interest in all things, and observes them all, and can acquire benefit from all. It works not only for the passing moment, but for futurity or for eternity. It regards things, not merely in their fitness to supply a man's physical necessities, but vastly more in their relations to one another, in their subserviences to the widest possible uses of mankind, in the place they occupy in the scheme of creation and system of the universe, and, above all, in the manifestation which they severally make of "the eternal power and godhead" of the Creator. And what it acquires in one individual or in any number of individuals, it can communicate to 
others, and can retain and expand in them; so that, in any community of men, just as truly as in any one man, it may improve and progress on and on without any assignable limit. Hence the intellectual sociality of mankind,-the superiority of thinking nations to thoughtless ones,-the varieties of civilisation,--the institutions of arts and commerce,- the advancement of literature and science,- - the glorious fellowship of enlightened intellect, comprising stars of all magnitudes, interfusing their light far above the influence of perishable things, and overspanning our mere animal nature as loftily and brilliantly as the starry heavens overspan the earth.

But the regenerated portion of men, "new creatures in Christ Jesus," far more transcend the merely intellectual than the merely intellectual transcend the brutal. They belong to the inner heavens, the central spheres of the universe; and have a social principle, not exactly similar to the social principle of cherubs and seraphs, but grander and more profound. They are one in law, and have begun to be one in moral nature, with the Lord of angels. $\mathrm{He}$ is their representative and their elder brother, their wisdom and their righteousness, their thinking head and their living heart. Their "life is hid with Christ in God." Their "fellowship is with the Father and with his Son Jesus Christ." "They are come unto Mount Zion, and unto the city of the living God, the heavenly Jerusalem, and to an innumerable company of angels, to the general assembly and church of the first-born, which are written in heaven, and to God the judge of all, and to the spirits of just men made perfest, and to Jesus the mediator of the new covenant, 
and to the blood of sprinkling, that speaketh better things than that of Abel." Such men, when they make due use of their privileges, are least alone when most alone. Every meditating one among them lives in the outskirts of "the city," and hears its hallelujahs, and receives many a message of love from its central glory. And even such an one as Bernard, a recluse of the dark ages, could feel himself close by its gates, and near the dear hour of admittance within it, to worship for ever the all-loving God face to face, and to study for ever the types of the wonders with which he has filled the universe. And he exclaimed-as every Christian may do, who is used to hear a response to the heavenly anthems in the rustling of every leaf, and a reflection of the crown of Immanuel in the glittering of every gem-

"Jerusalem, the glorious!

o paradise of joy!

Where tears are ever banish'd, And smiles have no alloy,

Beside thy living waters All plants are great and small;

The cedar of the forest, The hyssop of the wall:

With jaspers glow thy bulwarks, Thy streets with emeralds blaze;

The sardius and the topaz

Unite in thee their rays.

Thy ageless walls are bonded

With amethysts unpriced;

Thy saints build up its fabric, And the corner-stone is Christ. 


\section{IN D E X.}

ACtivias, 335.

Actinism, 76 .

Adamantine Spar, 246.

Adansonia, 294.

Adelsberg Cavern, 170-172.

Aerolites, 48.

Africa, 152-154, 162.

Air, 20-56.

Alimentary Canal, 384, 385.

Aloe-tree, 272, 273.

Alpine Mountains, 156-158.

Alps, 157-159, 165,

Altivaig Bay in Skye, 173.

Alumina, 245, 246.

Amazon River, 197.

America, 151-154.

American Aloes, 272.

American Prairics, 163, 164, 168, 169.

Amethyst, 246 .

Ammonites, 228, 229.

Andes, 157, 166, 190.

Animal Mragnetism, 81.

A nimalcules, 326-33s.

Animals, 326-378.

Ants, $346-349$.

Economy of, 379-411.

Aphides, 349-355.

Aqua Fortis, 104.

Ararat, 160.

Arctic Regions, 53, 54 .

Asia, 152-154, 161, 162.

Atmosphere, Adaptations of the, 55 , 56.

Constitution of the, 20 , 21.

Diffusion of the, 145149.

". $\quad$ Elasticity of the, 145.

i) Pressure of the, 21, 22, 141-149.
Attraction, 133-137.

Auks and Guillemots, 403, 404.

Auracaria, 279.

Aurora Borealis, 53, 54, 87-90.

Autumn, 54.

Avalanches, 177, 178.

Backstroke in Thunder-storms, 86.

Balkau Mountains, 165.

Ball Lightning, 84, 85 .

Bamboos, 267, 268.

Banyan-tree, 282, 283.

Baobab, 294.

Basaltic Rocks, 172-174.

Bats, 377, 402.

Beasts of Prey, 377.

Beavers, 407, 408.

Bee, $342,345$.

Beetles, 343, 344 .

Birds, 368-376.

"Cells and Songs of, 121, 122

" of Paradise, 374-376.

$"$ of Passage, 396-101.

Bitumen, 238.

Blackcap, 372, 373.

Blood, 382.

Boiling Springs, 190, 191.

Bombax, 293, 294.

Bonniton Linn, 199.

Bread-fruit-tree, 281,

Brighton, 206.

Brocken, The, 75, 76.

Burning Springs, 115, 116.

Butterfly, 342.

Cactus, 288, 289.

Camelias, 291, 292.

Capsicums, 287.

Carbon, 106.

Carbonic Acid, 107, 108.

Cascades, 198.

Caspian Sea, 165.

Cataracts, 198. 
Caucasus, 165, 166.

Caves and Caverns, 169-174.

Cedar of Lebanon, 279.

Cells of Animals, 327, 380, 381.

Cells of Plants, $305-309$.

Central Heavens, 16-19.

Chætodon, 362.

Chamouni, Vale of, 176.

Chcmical Action, 94-118.

Chlorine, 106

Affinity, 97-100.

Cholie-damp, 107.

Cliyle, 385.

Clreulation of the Blood, 381 .

Clay, 250-253.

Climate, 50-52.

Clouds, 28, 29.

Clyde, Falls of, 198-200.

Coal Fussils, 225, 226.

" Gas, 215.

, Strata, 224.

Coast Linc, Alterations of, 205-207.

" $"$ Projections of, 150-152.

Cocoa-nut Palm, 270.

Colours, 58, 59, 61-63.

" Chemical Change of, 113, 114.

Comets, 12, 15.

Cong, Whirlpool at, 193.

Conifers, 278, 280.

Continents and Islands, 150-174.

Continents, Contour of, 152, 153.

Corals, 332-334.

Corn-weevil, 342.

Corpse, Galvanizing of a, 91-93. " Light, 110.

Corra Linn, 199, 200.

Corundum, 246.

Cow-tree, 281, 282.

Crabs, 356.

Crancs, 402, 403.

Creation, Mosaic A ccount of, 212-216.

" Prospective Adaptations of, 233-237.

" Successive Stages of, 213$216,232-234$,

Crustaceans, 356.

Crystalline Rocks, 218, 219.

Cumulus Clond, 28.

Curl Cloud, 28.

Cuttlc-fish, 358-361.

Date-palm, 270.
Day-lily, 271, 272.

Days of Creation, 213-216.

Dead Sea, 165.

Development, Law of, 211.

Dcw, 25.

Diffusion of the Atmosphere, 145149.

Digestion, 384.

Dogs of St. Bernard, 390, 391.

Dolphlns, 377.

Domestication of Animals, 390, 391.

Dragons, 366.

Draining, Effects of, on Climates, 51, 52.

Drift Avalanches, 178.

Dry Fogs, 27.

Dunwich, 206.

Eagle, 370-372.

Earth, The, 1-4.

"Connection of the, with the Central Heavens, 17-19.

" Grcat Age of the, 212, 213.

Earthquakes, 181-187.

Earthworms, 339, 340.

Echo, 129-131.

Eclipses, 8, 9.

Economy of Animals, 379-409.

,$\quad$ of Plants, 300-325.

Egmont, Mount, 160.

Electricity, 78-93.

Electric Ecl, 90.

Electric Fishes, 364.

Electric Telegraph, 90.

Elevation of Land and Sea-bottom, 209.

Emery, 246.

Enchanted Coast, 73.

Endogens and Exogens, 278.

Entozoons, 336-338.

Erebus, Mount, 160.

Erosions by the Sea, 205-207.

Etna, 159.

Europe, 153, 154, 161.

Evaporation, 23, 24.

Exhalation, 52, 53.

Fair Head, 174.

Fall-cloud, 29.

Faroe Islands, 403-405.

Fata Morgana, 72.

Feathers. 368.

Felspar, 247.

Ferns, 266, 267. 
Fields of firc, 114, 115.

Fireballs, 47, 48.

Fislıes, 361-364.

Flxed Stars, 13-19.

Flat Fish, 362, 363.

Flat Landscapc, 164.

Fleecy Cloud, 29.

Floods, 203-205.

Flowerless Plants, 260-267.

Flowers, 296-299.

Flying-fish, 362.

Fogs, 26-28.

Force and Motion, 132-149.

Forth, Windings of the, 196.

Fossiliferous Rocks, 221-231.

Freezing of Water, 109, 110.

Freshwater Weeds, 264, 265.

Frictlon Machinc, Electric, 80.

Frog, 366.

Frogbit, 276.

Frost, 109, 142.

Fruits, 322.

Fullers' Earth, 247.

Funguses, 262-264.

Galvanic Electrlcity, 90.

Galvanizing of a Corpse, 91-93.

Ganges, 195.

Garnets, 247.

Genı, 246, 253.

Geyser Springs, 191.

Gianto Causeway, 174.

Glacicrs, 175-177.

Glands, 389.

Glens and Gorges, 166-16s.

Glow-worm, 118.

Glyptodon, 230.

Goldau, Valley of, 181.

Golden Eagle, 371, 372.

Grasses, 267, 278.

Gravity, 13อ-137.

Gregariousncss of Animals, 402-408.

Grottos, 169.

Guillemots and Auks, 403, 404.

Gulls, 404.

Gymnotus, 364 .

Hail, 35.

Halos of the Sun and Moon, 67.

Hand, 388.

Harmattan Wind, 39, 40.

Hartz Mountains, 75, 76.

Haze in the Atmosphere, 26.

Heat, 94-97.
Heliotrope, 253.

Hemp Plant, 280.

Herds of Quadrupeds, 405, 406.

Hermon, Mount, 157.

Himalayas, 166.

Hippopotamus, 377 .

Hoar-frost, 25, 26.

Hop Plant, 280.

House Flies, 143, 401.

Humidity of the Atmosphere, 24.

Hybernation of Animals, 401, 402.

Hydrogen, 104-106.

Ichthyolites, 223.

Ichtliyosaurus, 226, 227.

Ignis Fatuus, 116, 117.

Iguanodon, 228.

Images of 'lerrestrial Objects in the Air, 69-76.

Indus River, 204, 205.

Inflammable Gas, 105.

Insects, $340,356$.

Springs, 115.

Instinct, 390, 407.

Intestinal Worms, 336 .

Iron, 241-245.

Jack-o'-Lantern, 116, 117.

Jasper, 253.

Jelly Fishes, 335.

Jordon, Valley of the, 165.

Jorullo, Mount, 189.

Jupiter, 9, 10.

Kanzaroos, 376.

Kaolin, 248.

Kingston Caves, 170.

Kittiwakes, 404.

Lace-winged Flics, 3554, 255 .

Lady-birds, 354.

Lakes, 201, 202.

Land and Sea, 175-210.

Land and Water Hemispheres, 150 .

Land-slips, 179-181.

Lark, 373.

Larvæ of Insects, $341,342$.

Laughing Gas, 104.

Law of Devclopment, 211.

Laws of Chemical Combination, 100 , 101.

"Motion, 133-155.

Leares, 315-318.

Lebanon, 157.

Lichens, $26 \hat{i}$. 
Life, 257-259, 379.

Light, 57-78.

"Moral Analogics of, $7 \overline{7}, 78$.

Lightning, 82-87.

Lilies of the Field, 273, 274.

Lime, 254.

Limestone, 221.

Limpets, 143.

Liriodendron, 293.

Llanos, 163.

Lobster's. 356 .

Locusts, 343.

London Fogs, 26, 27.

Nachrauchania, 230.

Macquarie River, 203, 204.

Madrepores, 332.

Mrander, Windings of the, 196.

Magnetic Electricity, 90.

Magnolia, 292, 293.

Mammals, 376-378.

Man, as an Animal, 378.

$\because$ as a Social Being, 407, 408.

$"$ as an Intellectual Being, 408, 409.

, as a Fallen Moral Agent, 234237.

, as a Redeemcd Creaturc, 1619.

, as a Regenerated Creature, 409411.

Mandrakc, 287, 288.

Mangrove, 289.

Mars, 9.

Yrarshes, 51, 52.

Iatter, Peciprocations of Organic and Inorganic, 254-256.

Megalosaurus, 228.

Mcgathere, 230.

Nicreury, 9.

Mesmerism, 81, 90 .

Metals, 239-245.

Meteors, 47, 48, 87.

Mcteoric Slowers, 48-50.

Migration, 396-401.

Mineral Kingtom, Functions of the, 254-257.

Minerals, 238-254.

Mirage, 74,75 .

Mist, 26.

Mist-bows, 66.

Mocksuns and Mockmoons, 68.

Moles and Hedgehogs, 377.
Molluses, 356-361.

Monkeys, 378.

Monocotyledons, 278.

Mont Blanc, 158.

Mont Grenier, 181.

Moon, 4-7.

Moray Floods, 125, 126.

Mosaic Account of the Creation, 212216.

Moselle River, 194.

Motion, Laws of, 133-135.

Motions of Animals, 390 .

Motions of the Plunets, 136, 137.

Moulting, 394, 395.

Mountain-falls, 181.

Mountain-lcather, 249.

Mountain Sccnery, 157-159.

Mountains, Comparative Ages of, 155 , 156.

" Great Chains of, 153-161.

$" \quad$ Single, 160, 161.

Mount Erebus, 160.

Mulberry-tree, 280.

Muscular System, 389.

Music of Nature, 121-126.

Musical Mountains and Rocks, 127129.

Musical Sounds, 120, 121.

Mussels, 143.

Naphtha, 115.

Nature, Music of, 121-126.

Nautilus, 229.

Neap-tides, 138.

Nelumbium, 295.

Neptune, 10.

Nerbuddah Tree, 194.

Nervous System, 389.

Nettlc, 280-282.

New Red Sandstone, 226, 227.

Niagara, 194, 200, 201.

Nightingale, 373.

Nightshade, 266-268.

Nile River, 197.

" Floods of, 203.

Nitrogen, 103, 104.

Norfolk Island Pine, 279.

Nostocs, 265, 266.

Noxious Winds, 39-42.

Nutrition, 384, 385.

Nymphæa, 296.

Obsidian, 247.

Oceans, $205-210$. 
Old World and New World, 151-153.

Onyx, 253.

Opal, 253.

Opuntia, 289.

Orehids, 275, 276.

Organic and Inorganic Matter, Reciproeations of, 254-256.

Organization, 379,380 .

Orinoeo River, 196.

Ornithorlyyncus, 376.

Oxygen, 102, 103.

Oxy-hydrogen Blowpipe, 105, 106.

Oysters, 143.

Palms, 268-271.

Palmyra-tree, 270.

Pampas, 162.

Paradise, Birds of, 374-376.

Parasites, 338.

Peak Cavern, 170.

Pearl-stone, 249.

Periwinkles, 143.

Perturbations of the Planets, 15.

Peter Botte Mountain, 161.

Pliosphorescenee, 117, 118.

Phosphoretted Hydrogen, 116, 117.

Phosphorus, 112.

Pliotography, 76.

Pine-apple, 271, 272.

Piteher Plant, 283, 284.

Plains, 161, 164.

Planets, 9-13.

"Motions of the, $136,137$.

" Perturbations of the, 15.

Plants, 260-300.

" and Animals, Contrast and Resemblanee between, 300¿05.

"Economy of, 300-325.

, Flowerless, 260.

Plateaus, 161-164.

Plesiosaurus, 236.

Po River, 195, 196.

Polypes, 331-335.

Potato, 287.

Potstone, 248.

Prairies, 163, 164, 168, 162.

Prellension, 388.

Pressure of the Atmosphere, 141-149. " of Water, 140, 141.

Preternatural Showers, 31, 32.

Prickly Pear, 289.

Primioses, 285, 2 S6.
Prognostics of Weather, 391-393.

Projecting Fol'ce, 134.

Pterodactyle, 228.

Puffins, 404.

Pupa of Inseets, 342.

Rafflesia, 84.

Rainbow, 63-66.

Rains, 29-32.

Raised Sea-beaches, 208.

Ratlilin Island, 173, 174.

Reeiproeation of Lifeless and Liring

Matter, 254-256.

Red Sandstone, New, 226, 227.

$" \quad " \quad$ Old, 223.

Refiactions of Light, 59, 60 .

Regla, Basaltie Rocks and Caseade of, 174 .

Reptiles, 305-367, 402.

Respiration, 382-384.

Rivers, 194-201.

Rocks and Fossils, 211-237.

" Formation of, 217.

Rookcries, 403.

Roots, 309-315.

Royal Water-lily, 234, 295.

Ruminants, 376, 377.

Salt pet re, 238.

Samiel Wind, 41, 42.

Sand-drifts and Sand-whirls, 42.

Sapphire, 246.

Sardonyx, 253.

Sap of Plants, 315.

Saturn, 10.

Sea-beaehes, Raised, 208.

Sea-bow, 66.

Sea-jellies, 335.

Sea-nettles, 335.

Sea-weeds, 264, 265.

Seas and Oceans, 205-210.

Seasons, 53-55.

Sedimentary lioeks, 219-228.

Seeds, 321-324.

Sepia, 358.

Serpents, 365, 366 .

Sheet Lightning, 86, 87 .

Shell-fisl, 356-358.

Shells, 357-361.

Shooting-stars, 47, 48.

Shrimps, 356.

Silica, 253.

Silk Cotton-tree, 293, 294 .

Silkworm, 343, 345 . 
Silvas, $162,163$.

Simoom, 40, 41.

Siroeco, 40,

Skeleton, 388, 389.

Skin or Integument, 389.

Sliy-lark, 373, 374.

Snails, 401, 402.

Snow, 32, 35.

Snòw Avalanehes, $177,178$.

Soapstone, 248.

Soeial Prineiple in Man, 407, 408.

Solar System, 10.

Solway 'lide, 139, 140.

Sonorous Currents of Air, 127.

Sound, 119, 131.

Spectral Illusions, 69-72.

Speetrum, 58, 59.

Spider's, 401.

Sporules, 260, 261.

Spring, 55.

Springs, 192.

Spring-tides, 138.

Staeken-Cloud, 28.

Staffa, 172, 173.

Stars, Fixed, 3-19.

Staubbach, Fall of the, 197.

Steain Eleetrieity, 90.

Stomaelıs, 384, ‘̊s.

Stonebyres, 200.

Streams, 193.

Subsidenees and Upheavals of Land, 207-209.

Subterranean Convulsion, 183-186.

Subterranean Streams, 192, 193.

Suck-giving Animals, 376-378.

Suetion, 142, 143.

Sulphur, 112, 238, 244.

Summer, 53, 54.

Sun, 7-9.

Sunbeams, 60-62.

Sword-fish, 362.

Table Mountain, 160.

Talc, 248.

Ten-plant, 290, 291, 364.

Teeth, 385-388.

Temperatc Zone, 545 .

Tempests, 44-46.

Teneriffe, Peak of, 161.

Terek, Pass of, 165, 166.

Thawing, 110.

Thunder, 83, 84.
Tides, 137-140.

Tints of Sky and Landseape, 62, 63.

Tobaeeo, 287.

Topaz, 246.

Tornedo, 448.

Torpedo, 90, 364 .

Torrents, 202, 203.

Tortoise, $366,367$.

Toueh, Sense of, 389,390 .

Toxodon, 230.

Trade Winds, $38,39$.

Tropics, 29, 30, 54 .

Trosaehs, 167.

Tulips, 273-275.

Tulip-tree, 293.

Tunnels, Natural, 169, 170, 193, 196.

Turtle 366,367 .

Typhooll, 44.

Universe, Vastness of the, 12-16,

Upheavals and Subsidenees of Land, 207-209.

Uranus $10,11$.

Valisneria, 276, 277.

Valleys, 164-16s.

Vapour, 23, 24. 51.

Venus, 9.

Victoria Land, 159, 160.

Vietoria Regia, 294, 295.

Vision, System of, 76,339 .

Vis Inertia, 134.

Voleanoes, 187-190.

Wane-cloud, 29.

Wasps, 344, 345.

Water, 108-112.

" Pressure of, 140, 141.

Waterfalls, 198-201.

Water-lily, 296.

Water-lily, Royal, 294, 295.

Waterspouts, 43, 85 .

Weather Prognosties, 391-393.

Weiglit, 132-134.

Whales, 377.

Whirlpool at Cong, 192.

Whirlwinds, 43.

Will-o'-wisp, 116, 117.

Winds, 36-43.

Winter, 53-55.

Witehes' Butter, 266.

Worms, 339, 340.

Worms, Intestinal, 336.

Zoophytes, 330, 331. 


$-$ 
$g^{3} x^{3}-a^{3}(2)$

- 7 in

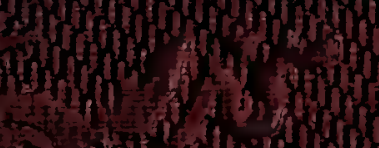

(1)

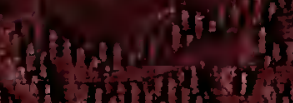

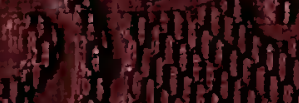

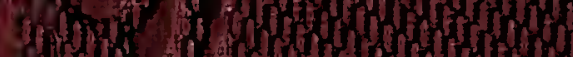

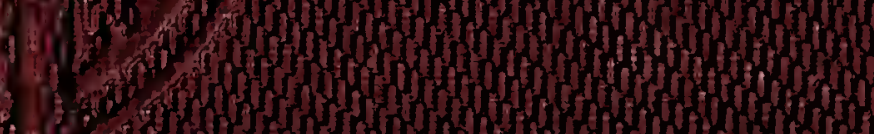

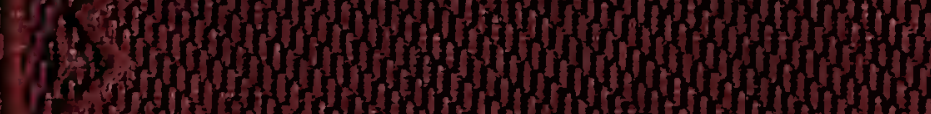

it)

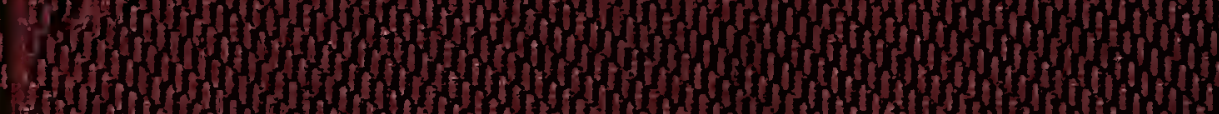

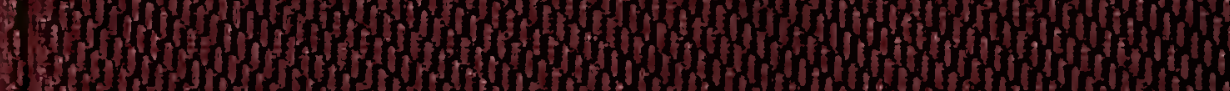

Hommonmmomm

Hormonty

thimhonmomm

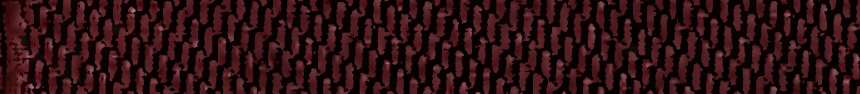

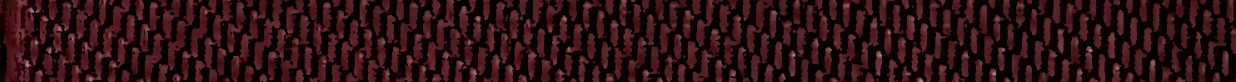

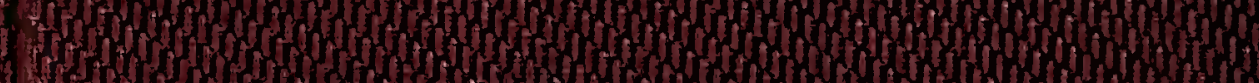

Inthommommommomm

sing

1 ingmongh

ghomphnm

Int

Thmoln

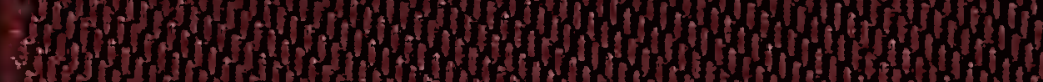

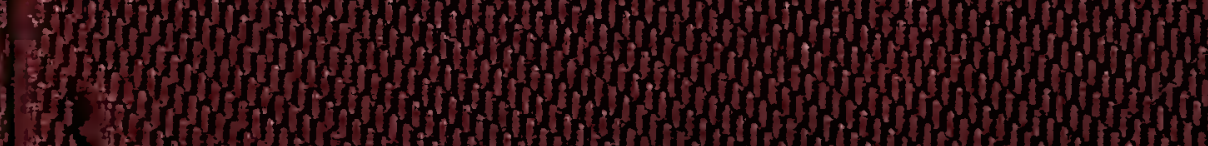

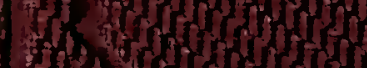

I. 1 mommommomm

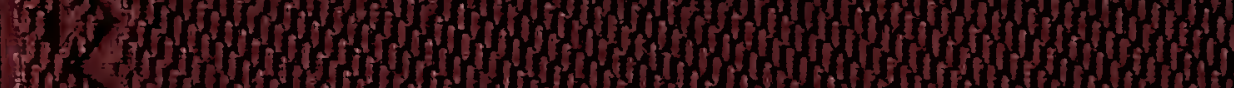

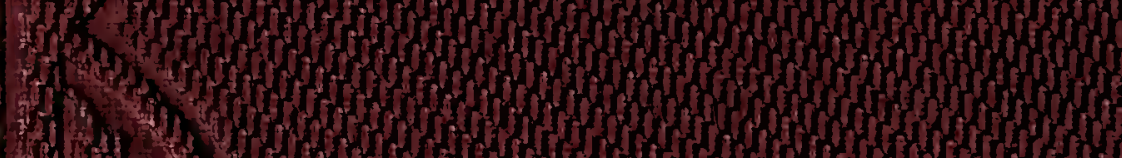

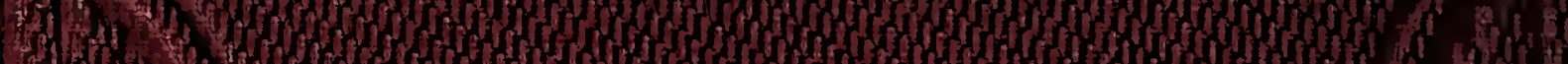

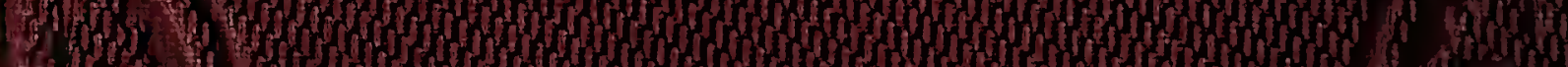

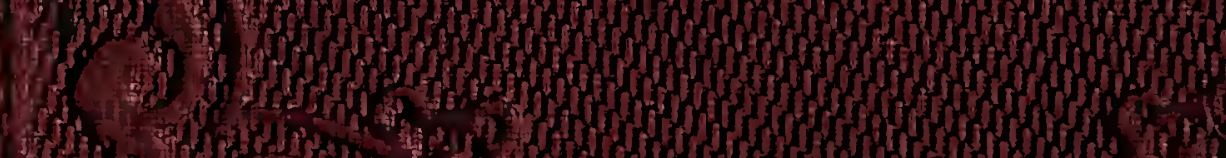

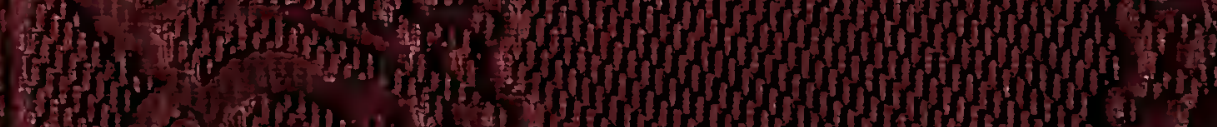

(1)

N 